\title{
Maternal essential fatty acid status
}

Citation for published version (APA):

Otto, S. J. (2000). Maternal essential fatty acid status: before, during and after pregnancy. [Doctoral Thesis, Maastricht University]. UM. https://doi.org/10.26481/dis.20001020so

Document status and date:

Published: 01/01/2000

DOI:

10.26481/dis.20001020so

Document Version:

Publisher's PDF, also known as Version of record

\section{Please check the document version of this publication:}

- A submitted manuscript is the version of the article upon submission and before peer-review. There can be important differences between the submitted version and the official published version of record.

People interested in the research are advised to contact the author for the final version of the publication, or visit the DOI to the publisher's website.

- The final author version and the galley proof are versions of the publication after peer review.

- The final published version features the final layout of the paper including the volume, issue and page numbers.

Link to publication

\footnotetext{
General rights rights.

- You may freely distribute the URL identifying the publication in the public portal. please follow below link for the End User Agreement:

www.umlib.nl/taverne-license

Take down policy

If you believe that this document breaches copyright please contact us at:

repository@maastrichtuniversity.nl

providing details and we will investigate your claim.
}

Copyright and moral rights for the publications made accessible in the public portal are retained by the authors and/or other copyright owners and it is a condition of accessing publications that users recognise and abide by the legal requirements associated with these

- Users may download and print one copy of any publication from the public portal for the purpose of private study or research.

- You may not further distribute the material or use it for any profit-making activity or commercial gain

If the publication is distributed under the terms of Article $25 \mathrm{fa}$ of the Dutch Copyright Act, indicated by the "Taverne" license above, 
MATERNAL ESSENTIAL FATTY ACID STATUS

before, during and after pregnancy 
() Suzie Otto. Maastricht 2000

ISBN 9090141251

Productie: Datawyse Boekproducties Maastricht 


\title{
MATERNAL ESSENTIAL FATTY ACID STATUS
}

\author{
before, during and after pregnancy
}

\author{
PROEFSCHRIFT
}

ter verkrijging van de graad van doctor aan de Universiteit Maastricht, op gezag van de Rector Magnificus, Prof. Dr. A.C. Nieuwenhuizen Kruseman, volgens het besluit van het College van Decanen in het openbaar te verdedigen op vrijdag 20 oktober 2000 om 14.00 uur

door

Suzie Judessa Otto

geboren te Curaçao 


\section{Promotores:}

Prof. dr. G. Hornstra

\section{Co-promotor:}

Dr. A.C. van Houwelingen

\section{Beoordelingscommissie:}

Prof. dr. P.A. van den Brandt (voorzitter)

Prof. dir. C.E. Blanco

Prof. dr. E.R. Boersma (Rijksuniversiteit Groningen)

Dr. P. Sanjurjo (Pais Vasco University)

Prof. dr. ir. W.H.M. Saris

Studies of this thesis were financially supported by Nutricia B.V, Zoetermeer, The Netherlands

Financial support by the Netherlands Heart Foundation and the Dr. Ir. Van de Laar Stichting for the publication of this thesis is gratefully acknowledged.

Additionally, the author wishes to express her gratitude to Friesland Coberco Dairy Foods, Friesland Nutrition Research and Numico Research B.V. for their financial support. 
Aan mijn ouders 



\section{CONTENTS}

Chapter 1 Introduction 9

Chapter 2 Effects of storage on venous and capillary blood samples: the influence of deferoxamine and butylated hydroxytoluene on the fatty acid alterations of red blood cell phospholipids

Chapter 3 Maternal and neonatal essential fatty acid status in phospholipids: an international comparative study

Chapter 4 Effects of pregnancy-induced hypertension on the essential fatty acid statuses of Ecuadorian and Dutch women

Chapter 5 Changes in the maternal essential fatty acid profile during early pregnancy, and its relation to diet

Chapter 6 Comparison of the peri- and postpartum polyunsaturated fatty acid profile of lactating and non-lactating mothers

Chapter 7 The effect of different supplements containing docosahexaenoic acid on plasma and erythrocyte fatty acids of healthy non-pregnant women

Chapter 8 The effect of supplementation with docosahexaenoic and arachidonic acid derived from single cell oils on plasma and erythrocyte fatty acids of pregnant women in the second trimester

Chapter 9 General discussion

Summary

Samenvatting

Dankwoord

Curriculum vitae

Publications 



\section{Chapter 1}

\section{Introduction}

Pregnancy is accompanied by hyperlipidemia, which is especially characterized by a marked rise in plasma triglycerides, while moderate increases occur in cholesterol and phospholipid concentrations (1-5). Desoye et al found by time series analysis that the concentration of triglycerides was about $220 \%$ higher at term compared to early pregnancy, whereas plasma cholesterol and phospholipids increased by about 65\% (1). These quantitative lipid changes go along with qualitative modifications in the lipoproteins (4-7). It has been suggested that this hyperlipidemia might be a physiological adaptation of the mother to pregnancy to meet her increased energy demand $(4,5,8)$. Moreover, this hyperlipidemia possibly increases the fetal access to cholesterol and essential fatty acids required for structural development $(4,5,8)$. However, not only the quantity of these essential fatty acids, but also their quality is of great significance. Particularly the presence and the availability of the long-chain polyunsaturated fatty acids docosahexaenoic acid $(22: 6 n-3)$ and arachidonic acid $(20: 4 n-6)^{1}$ are of vital importance, since they play important roles during fetal growth and development.

\section{Essential fatty acids: $n-6$ and $n-3$ families}

The beneficial effects the polyunsaturated fatty acids on human health are well documented by now (9-13). The essentiality of linoleic acid (18:2n-6) and $\alpha$-linolenic acid $(18: 3 n-3)$ has first been reported by Burr and Burr $(14,15)$ in their observations that hair loss, cessation of growth, scaly skin, renal disorders and failure of reproduction occurred in rats fed a fat-free diet. These symptoms were found to be corrected after addition of a fat extract containing $18: 2 n-6$ and $18: 3 n-3$ to the diet; both fatty acids were then denoted as "essential constituents of the diet" (14).

Besides saturated fatty acids, human tissues can synthesize the monounsaturated fatty acids of the n-9 and n-7 families de novo, since they dispose of the $\Delta 9$-desaturase enzyme. However, fatty acids of n-6 and n-3 families cannot be synthesized de novo in human body. Unlike plants, humans do not have $\Delta 12$ - and $\Delta 15$-desaturases, which enable the insertion of double bonds at the n- 6 and n-3 position, making possible the formation of the 'parent'

1 nomenclature used: first number denotes length of $\mathrm{C}$-chain, number following colon refers to the number of double bonds, number after $\mathrm{n}$ represents the number of $\mathrm{C}$-atom from the methyl end of the fatty acid molecule to the first double bond. 
essential fatty acids $18: 2 n-6$ and $18: 3 n-3$ respectively (16). Hence, n- 6 and $n-3$ fatty acids must be obtained either from the diet or by synthesis from the respective dietary precursors, $18: 2 n-6$ and $18: 3 n-3$. Therefore, the $n-6$ and $n-3$ fatty acids together with their precursors are considered essential fatty acids (EFAs). In the body, the longer-chain more polyunsaturated (long-chain polyenes: LCPs ${ }^{2}$ ) n-3 and n-6 fatty acids are synthesized through a series of alternating elongations and desaturations. In the elongation reaction two carbon atoms are added at the carboxyl end of the fatty acid chain, whereas in the desaturation reaction a double bond is inserted between the carboxyl group and the nearest double bond $(16,17)$. The conversion of $18: 2 n-6$ and $18: 3 n-3$ starts with $\Delta 6$-desaturation and usually ends with the " $\Delta 4$-desaturation" of adrenic acid (22:4n-6) and 22:5n-3, which results in the formation of docosapentacnoic acid (also named Osbond acid, 22:5n-6) and 22:6n-3, respectively, as presented in figure $1(18)$. The " $\Delta 4$-desaturation" step was shown to consist of elongation of $22: 4 n-6$ and $22: 5 n-3$, followed by $\Delta 6$-desaturation and one cycle of peroxisomal $\beta$-oxidation $(19,20)$.

Since both $18: 2 n-6$ and 18:3n-3 are substrates for the same enzymes, competition occurs between the two fatty acid families with the competitive capacities being 18:3n-3>18:2n-6 (see figure 1), since the enzymes have higher affinities for the n-3 fatty acids (21). No interconversion is possible between the fatty acid families (21).

The EFAs -18:2n-6, 18:3n-3 and their LCPs- are structural constituents of cell membrane phospholipids. Therefore, EFAs play important roles in the physical properties of cell membranes, like fluidity and flexibility, which influence the cell's integrity (11). The composition of the EFA in the cell membranes is also vital for the activities of membranebound receptors, enzymes, and ion-channels, which are all important for signal transduction $(11,22)$. Some EFAs also serve as a precursor for oxygenated substances called eicosanoids, which have various biological (regulatory) functions (23). This concerns the fatty acids 20:4n-6, dihomo- $\gamma$-linolenic acid (20:3n-6) and eicosapentaenoic acid (20:5n-3) that can be either cyclooxygenated or lipoxygenated into these eicosanoids, including prostacyclins, prostaglandins, thromboxanes, leukotrienes and hydroxy fatty acids (23). The importance of EFAs, particularly AA and DHA, is for their role in growth and development (24). They are abundantly present in the brain lipids $(25,26)$ and the retina $(27)$.

Whenever the diet is deficient in 'parent' EFAs or their LCPs, the cells respond by increasing the further conversion of oleic acid (18:1n-9), through the same desaturation and elongation enzyme system as the EFAs (Figure 1), consequently increasing the levels of Mead acid (20:3n-9). The latter is, therefore, a marker of the EFA status. In case the dietary supply of 22:6n-3 is insufficient, the conversion of 22:4n-6 into $22: 5 n-6$ increases, resulting in relatively high levels of $22: 5 n-6$ (the end product of the n- 6 fatty acids). Therefore, two

2 LCPs (long-chain polyenes) are defined as the $n-3$ and n- 6 fatty acids with a chain length of $\geq 20$-atoms and at least one more double bond than their parent essential fatty acid. 


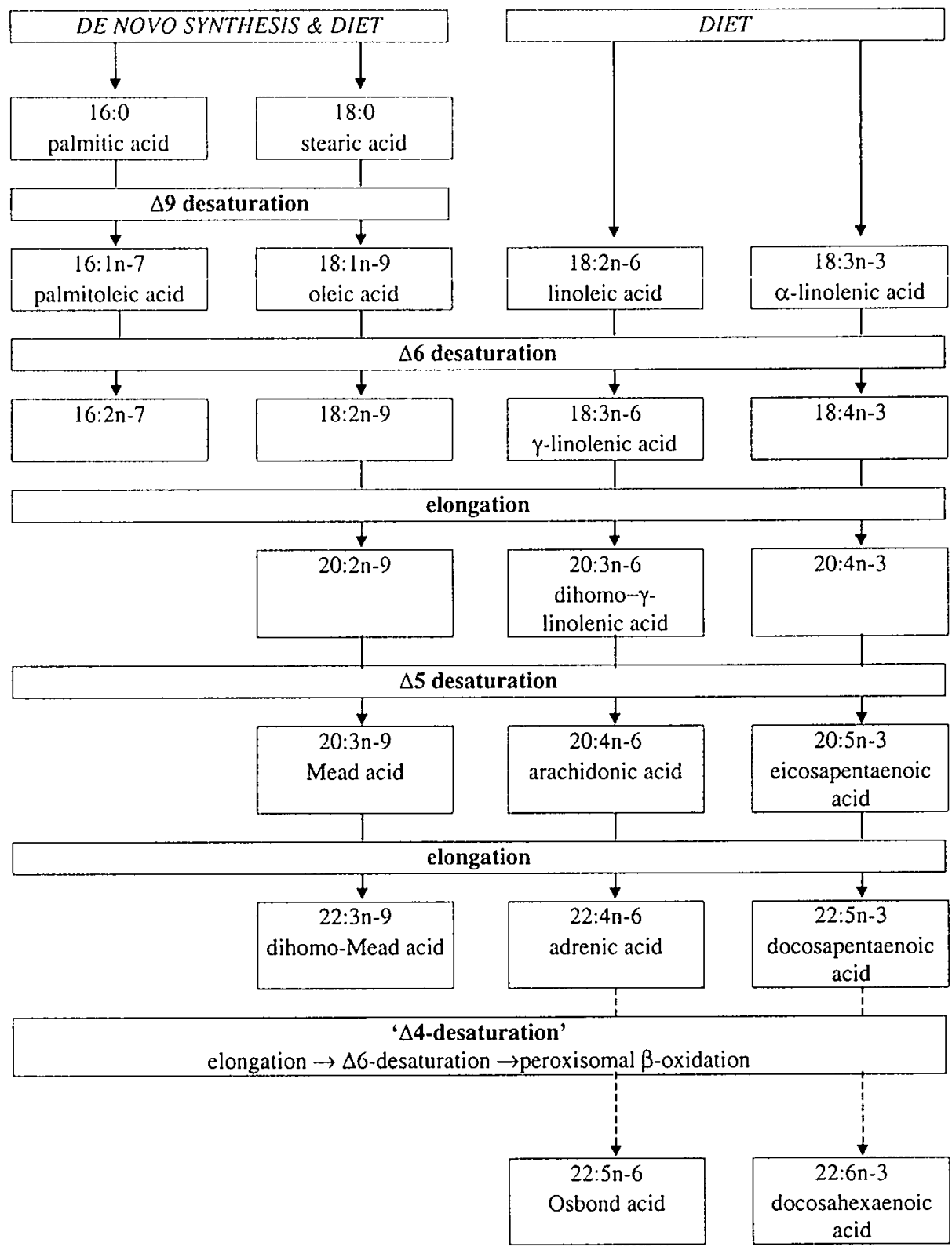

Figure 1. Schematic presentation of the major pathways of fatty acid biosynthesis. 
indexes were formulated to indicate the 22:6n-3 (docosahexaenoic acid, DHA) status: the DHA deficiency index, 22:5n-6/22:4n-6 (28), and the DHA sufficiency index, 22:6n-3/ $22: 5 n-6(29)$.

\section{Essential fatty acids and early development}

The interest into EFAs research has focused on the requirements for LCPS and their beneficial effects on normal growth and development. As stated earlier, high amounts of 22:6n-3 are present in the outer segment membranes of the retinal photoreceptors; it accounts for about $60 \%$ of the fatty acids in the phospholipids of these membranes (27). The brain is also highly rich in 22:6n-3 (and 20:4n-6), predominantly in the synaptic membranes. The accretion of 22:6n-3 into the brain begins during early fetal development and becomes higher during the last trimester of pregnancy, the period of rapid brain growth $(25,26)$.

From the moment of conception on and throughout pregnancy, the number of cells of the developing fetus is rapidly increasing. Therefore, it is understandable that the fetus needs EFAs for incorporation into the lipids of proliferating membranes, including those of brain tissue. The fetal supply of these fatty acids depends largely on placental transfer and any limitation may have functional consequences. Studies in rhesus monkeys exposed prenatally and postnatally to n-3 fatty acids deficiency have already demonstrated impaired neural and visual function (28). Therefore, the maternal EFA status in general, and the n-3 fatty acid status in particular, has to be adequate to ensure optimum conditions for maturation of central nervous system. Moreover, since it was found that the EFA status at birth of infants affected their postnatal status (30), an adequate maternal EFA status might positively influence the starting condition of these children.

There are few reports in which the maternal fatty acids were investigated during pregnancy. In 1980, Skryten et al published that the levels (\% wt/wt) of both 22:6n-3 and 20:4n-6 decreased during pregnancy in a Swedish population (31). Holman et al reported that the levels of the n-3 and n-6 LCPs decreased during pregnancy, which were determined at week 36 of pregnancy, during labor, and 6 weeks postpartum (32). In another study, Sanjurjo et al investigated the proportional changes of total plasma fatty acids during pregnancy (33), and observed that after an initial increase, the levels of 22:6n-3 decreased from the second trimester on until delivery. However, all these studies were carried out cross-sectionally.

The first longitudinal study was performed by Al and coworkers (34), in Dutch Caucasian women, to investigate the EFA composition of the maternal diet and the maternal EFA status, in relation to the neonatal EFAs and the outcome of pregnancy. Results of this longitudinal study showed that from the 10th week of normal, uncomplicated pregnancies there is a continuous decline of the overall maternal EFA status, expressed by the EFA index, [(sum of $n-3+n-6$ fatty acids)]/(sum of $n-9+n-7$ fatty acids)]. The same was observed for the 22:6n-3 status, as represented by the DHA sufficiency index (ratio $22: 6 n-3$ to $22: 5 n$ - 
6). Slight decreases were reported for the relative amounts of 20:4n-6 and 22:6n-3 as well $(34,35)$. The authors suggested that under the present dietary conditions the mother probably cannot meet the EFA requirements during pregnancy, since no changes were observed in the composition of the maternal diet and the mean daily intakes of saturated, monounsaturated and polyunsaturated fat $(34,36)$.

From the results of $\mathrm{Al}$ and coworkers (34), a need for EFA supplementation during pregnancy was proposed. Maternal supplementation would probably influence the EFA status of the infant, since strong correlations were found, at birth, between the maternal and neonatal n-6 and n-3 LCPs status. In two pilot studies this appeared indeed to be true. In one study, pregnant women were supplemented with $2.7 \mathrm{~g}$ n-3 LCPs/day obtained from fish oil, from week 30 of pregnancy until term. The supplementation resulted in significantly higher levels of n-3 LCPs and 22:6n-3 accompanied by lower levels of n-6 LCPs in these mothers and their neonates as compared to the control group (37). The opposite effect was observed in the other study, where pregnant women received daily a 18:2n-6 enriched diet (an additional intake of about $10 \mathrm{~g} /$ day) from the 20 th week of pregnancy until delivery (38). Since both fatty acid families play vital roles in fetal and neonatal growth and development, it is conceivable that for supplementation a combination of both families should be considered. However, a proper balance must first be found between the fatty acids families in order to avoid the concomitant decrease of one in case of high dietary intake of the other.

\section{Outline of the thesis}

The aim of the studies presented in this thesis was to further extend the knowledge of the EFA pattern before and during pregnancy, and in the postpartum period.

Usually, blood samples collected in clinical trials, from either a venous or capillary origin, have to be stored frozen before they can be analyzed. The storage condition of these samples has to be optimal to avoid oxidation of the fatty acids, especially the LCPs, which are very susceptible to oxidation. Erythrocyte samples were found to be very sensitive to oxidation. Therefore, it was investigated whether the observed LCP loss in erythrocyte samples could be prevented by storage of washed erythrocyte suspensions at $-50^{\circ} \mathrm{C}$ in the presence of either the iron-binding agent deferoxamine or the free radical scavenger butylated hydroxytoluene. The effect of storage of lipid extracts of red blood cell at $-50^{\circ} \mathrm{C}$ was also assessed. In Chapter 2 are the results of this study presented and discussed.

As mentioned before, Al and coworkers (35) showed that the overall maternal EFA status, expressed by the EFA index $[(n-3+n-6) /(n-7+n-9)]$, steadily declines during normal, uncomplicated pregnancies of Dutch pregnant women. The same was described for the 22:6n-3 status. Based on these findings, the question arose whether these results are specific for the Dutch population and the dietary habits in the Netherlands or whether it is a more general phenomenon. Therefore, direct comparisons of the EFA status during pregnancy were made between these women and women from four other countries to obtain 
information from a wider variation in dietary compositions and to further elucidate the course of the EFAs during pregnancy (Chapter 3).

Pregnancy-induced hypertension (PIH) is a condition that complicates about $10 \%$ of all pregnancies. In their longitudinal study, $\mathrm{Al}$ and colleagues (39) observed that in Dutch women this condition is associated with elevated levels of the LCPs of $18: 2 n-6$ and $18: 3 n-3$, in combination with reduced levels of these 'parent' EFAs. This suggests an enhanced EFA desaturation and elongation. To study whether this also occurs under completely different nutritional and geographical conditions, plasma fatty acids of primiparous Ecuadorian Mestizo women with normal and PIH pregnancies were assessed at delivery and compared with similar data of Dutch Caucasian women. In addition, neonatal values, determined in umbilical plasma and umbilical vessel walls, were compared (Chapter 4).

As stated above, the pattern of $22: 6 \mathrm{n}-3$ has been shown to change considerably from the 10 th week of pregnancy on (35). There is no information on the course of $22: 6 \mathrm{n}-3$ during the first weeks of pregnancy, particularly, at what time the changes from the non-pregnant state occurred. On the other hand, there is also hardly any data on the recovery of $22: 6 n-3$ postpartum, especially in women breast-feeding their infants. Since breast milk contains 22:6n-3, breast-feeding, in contrast to bottle-feeding, may further impose on the maternal 22:6n-3 status after delivery. Therefore, additional data were collected in very early pregnancy (Chapters 5) and in the postpartum period (Chapters 6) to achieve a complete view of the course of the EFAs before, during and after pregnancy. During these periods, the dietary EFA intakes were assessed as well. In the postpartum study, a comparison was made between lactating and non-lactating mothers also.

Since the maternal supplementation with one essential fatty acid family was associated with a concomitant reduction in the levels of the other $(37,38)$, a dose-finding study was performed to find a proper mixture of n-6 and n-3 LCPs as a possible supplement to the diet of pregnant women. This mixture was first tested in non-pregnant women, and thereafter, on a pilot base, in pregnant women. The results are presented in Chapters $\mathbf{7}$ and 8.

Finally, in Chapter 9 the conclusions of these studies and their implications will be discussed.

\section{REFERENCES}

1. Desoye G, Schweditsch MO, Pfeiffer KP, Zechner R. Kostner GM. Correlation of hormones with lipid and lipoprotein levels during normal pregnancy and postpartum. J Clin Endocrinol Metab 1987;64:70412.

2. Vikrot $O$. Individual plasma phospholipids with special reference to the changes in pregnancy. Acta Med Scand Suppl 1965;435:1-23.

3. Cramer K, Vikrot O. Plasma phospholipid levels and distribution in human maternal blood and in blood from the umbilical cord. Acta Med Scand 1966;179:1-4. 
4. Warth MR. Arky RA. Knopp RH. Lipid metabolism in pregnancy. II. Altered lipid composition in intermediage, very low, low and high-density lipoprotein fractions. J Clin Endocrinol Metab 1975:41:049-55.

5. Dejager S. Turpin G. [Hyperlipidemia in pregnancy]. Presse Med 1996;25:1839-45.

6. Alvarez JJ, Montelongo A. Iglesias A. Lasuncion MA. Herrera E. Longitudinal study on lipoprotein profile, high density lipoprotein subclass, and postheparin lipases during gestation in women. J Lipid Res 1996;37:299-308.

7. Sattar N. Greer IA, Louden J, Lindsay G, McConnell M. Shepherd J. Packard CJ. Lipoprotein subfraction changes in normal pregnancy: threshold effect of plasma triglyceride on appearance of small, dense low density lipoprotein. J Clin Endocrinol Metab 1997;82:2483-91.

8. Chiang AN. Yang ML, Hung JH, Chou P, Shyn SK, Ng HT. Alterations of serum lipid levels and their biological relevances during and after pregnancy. Life Sci 1995;56:2367-75.

9. Simopoulos AP. Omega-3 fatty acids in health and disease and in growth and development [see comments]. Am J Clin Nutr 1991:54:438-63.

10. Knapp HR. Fatty acids and hypertension. World Rev Nutr Diet 1994;76:9-14.

11. Bezard J, Blond JP, Bernard A. Clouet P. The metabolism and availability of essential fatty acids in animal and human tissues. Reprod Nutr Dev 1994;34:539-68.

12. Endres $S$, De Caterina R. Schmidt EB. Kristensen SD. n-3 polyunsaturated fatty acids: update 1995. Eur J Clin Invest 1995;25:629-38.

13. Holman RT. w3 and w6 Essential fatty acid status in human health and disease. In: Yehuda S, Mostofsky DI. eds. Handbook of essential fatty acid biology. Totowa: Humana Press, 1997:139-82.

14. Burr GO. Burr MM. A new deficiency disease produced by rigid exclusion of fat from the diet. $J$ Biol Chem 1929:25:629-638.

15. Burr GO. Burr MM. On the nature and role of fatty acids essential in nutrition. $J$ Biol Chem 1930;86:587-621.

16. Hornstra G. Dietary fats and arterial thrombosis. . Maastricht: Maastricht University, 1980:8-32.

17. Sprecher H. Biochemistry of essential fatty acids. Prog Lipid Res 1981;20:13-22.

18. Brenner RR. The desaturation step in the animal biosynthesis of polyunsaturated fatty acids. Lipids 1971;6:567-75.

19. Voss A. Reinhart M. Sankarappa S. Sprecher H. The metabolism of 7,10,13,16,19-docosapentaenoic acid to 4.7.10.13.16.19-docosahexaenoic acid in rat liver is independent of a 4 -desaturase. $\mathrm{J}$ Biol Chem 1991;260:19995-20000.

20. Sprecher H, Luthria DL, Mohammed BS. Baykousheva SP. Reevaluation of the pathways for the biosynthesis of polyunsaturated fatty acids. J Lipid Res 1995;36:2471-7.

21. Holman RT. Control of polyunsaturated acids in tissue lipids. J Am Coll Nutr 1986;5:183-211.

22. Crawford MA, Costeloe K, Ghebremeskel K. Phylactos A. Skirvin L. Stacey F. Are deficits of arachidonic and docosahexaenoic acids responsible for the neural and vascular complications of preterm babies? Am J Clin Nutr 1997;66: 1032S-104IS.

23. Gurr MI. Harwood JL. Lipid Biochemistry: an introduction. 4th ed. London: Chapman \& Hall, 1991:99118.

24. Innis SM. Essential fatty acids in growth and development. Prog Lipid Res 1991;30:39-103. 
25. Clandinin MT. Chappell JE, Leong S, Heim T, Swyer PR. Chance GW. Intrauterine fatty acid accretion rates in human brain: implications for fatty acid requirements. Early Hum Dev 1980;4:121-9.

26. Martinez M. Tissue levels of polyunsaturated fatty acids during early human development. J Pediatr 1992; 120:S 129-38.

27. Stinson AM, Wiegand RD, Anderson RE. Fatty acid and molecular species compositions of phospholipids and diacylglycerols from rat retinal membranes. Exp Eye Res 1991;52:213-8.

28. Neuringer M. Connor WE, Lin DS. Barstad L. Luck S. Biochemical and functional effects of prenatal and postnatal omega 3 fatty acid deficiency on retina and brain in rhesus monkeys. Proc Natl Acad Sci U S A 1986;83:4021-5.

29. Hoffman DR, Uatuy R. Essentiality of dietary omega 3 fatty acids for premature infants: plasma and red blood cell fatty acid composition. Lipids 1992:27:886-95.

30. Foreman-van Drongelen MM. Houwelingen ACv, Kester AD, Hasaart TH, Blanco CE, Hornstra G. Long-chain polyunsaturated fatty acids in preterm infants: status at birth and its influence on postnatal levels. J Pediatr 1995;126:011-8.

31. Skryten A, Johnson P, Gustafson A. Studies in normal pregnancy. III. Fatty acid composition of serum phosphoglycerides and cholesterol esters. Acta Obstet Gynecol Scand 1980;59:305-9.

32. Holman RT. Johnson SB. Ogburn PL. Deficiency of essential fatty acids and membrane fluidity during pregnancy and lactation. Proc Natl Acad Sci U S A 1991;88:4835-9.

33. Sanjurjo P. Matorras R. Ingunza N, Alonso M. Rodriguez Alarcon J. Perteagudo L. Cross-sectional study of percentual changes in total plasmatic fatty acids during pregnancy. Horm Metab Res 1993:25:590-2.

34. Al MDM. Essential fatty acids, pregnancy, and pregnancy outcome: relationship between mother and child. PhD Thesis. Human Biology. Maastricht: Maastricht University, 1994.

35. Al MD. Houwelingen ACv, Kester AD, Hasaart TH, de Jong AE, Hornstra G. Maternal essential fatty acid patterns during normal pregnancy and their relationship to the neonatal essential fatty acid status. $\mathrm{Br}$ J Nutr 1995;74:55-68.

36. Al MD, Badart Smook A, Houwelingen ACv, Hasaart TH, Hornstra G. Fat intake of women during normal pregnancy: relationship with maternal and neonatal essential fatty acid status. J Am Coll Nutr 1996;15:49-55.

37. Houwelingen ACv, Sørensen JD. Hornstra G, Simonis MM, Boris J, Olsen SF, Secher NJ. Essential fatty acid status in neonates after fish-oil supplementation during late pregnancy. $\mathrm{Br} J$ Nutr 1995;74:723-31.

38. Al MD. Houwelingen ACV. Badart Smook A. Hornstra G. Some aspects of neonatal essential fatty acid status are altered by linoleic acid supplementation of women during pregnancy. J Nutr 1995:125:282230.

39. Al MD, van Houwelingen AC, Badart Smook A, Hasaart TH, Roumen FJ, Hornstra G. The essential fatty acid status of mother and child in pregnancy-induced hypertension: a prospective longitudinal study. Am J Obstet Gynecol 1995:172:1605-14 


\section{Chapter 2}

\section{Effects of storage on venous and capillary blood samples: the influence of deferoxamine and butylated hydroxytoluene on the fatty acid alterations of erythrocyte phospholipid}

Suzie J. Otto, Magritha M.P.H. Foreman-van Drongelen, Adriana C. van Houwelingen, Gerard Hornstra

Based on European Journal of Clinical Chemistry and Clinical Biochemistry 1997;35:907913.

\section{ABSTRAC'T}

Fatty acid concentrations of plasma and erythrocyte phospholipids isolated from paired venous and capillary blood samples were compared and the effect of storage at $-20^{\circ} \mathrm{C}$ was evaluated as well. Plasma fatty acid profiles from venous and capillary blood were found to be comparable and not affected by up to four weeks of storage, while fatty acid profiles of venous and capillary erythrocytes were no longer comparable after four weeks. Substantial losses of long-chain polyenes (LCPs) were observed in capillary erythrocytes.

To investigate whether the observed LCPs loss could be prevented, capillary erythrocyte samples were stored for up to one year at $-50^{\circ} \mathrm{C}$ in presence of the iron-binding agent deferoxamine or the free radical scavenger butylated hydroxytoluene (BHT). Both compounds protected the LCPs. Similarly, storage of BHT-protected erythrocyte lipid extracts at $-50^{\circ} \mathrm{C}$ for up to one year was not associated with reduced levels of LCPs.

In conclusion, the lipid loss from capillary erythrocytes can be reduced for at least one year during storage at $-50^{\circ} \mathrm{C}$ with prior addition of either a metal chelating compound or a free radical scavenger, or by preparing lipid extracts of the samples within one week of blood collection. 


\section{IN'TRODUCTION}

To study the human essential fatty acid status, blood samples are usually collected through venipuncture. Studies in preterm infants. however, often rely' on 'diagnostic' blood samples, which can be of either venous or capillary origin. As a result, a longitudinally collected series of blood samples are likely to contain both venous and capillary blood. The fatly acid profiles of venous and capillary plasma and erythrocyte phospholipids should, therefore, be comparable.

A lew studies, in which the fatly acid compositions of venous and capillary plasma were compared, have yiclded ambiguous results $(1,2)$. Therefore, the initial aim of the present study was to compare phospholipid-associated fatty acid profiles of plasma and crythrocytes, collected through either venous or capillary puncture. In addition, the effects of storage at $-20^{\circ} \mathrm{C}$ for a period up to four weeks on both venous and capillary plasma and crythrocyte phospholipids were evaluated. The results showed alterations in the polyunsaturated fatty acids composition of capillary erythrocyte phospholipids, probably due to oxidation. To protect these fatty acids, an experiment was subsequently carried out, in which capillary erythrocyte samples were stored at $-50^{\circ} \mathrm{C}$ for up to one year in the presence of an antioxidant (butylated hydroxytoluene) or an iron chelator (deferoxamine). In addition, erythrocyte lipid extracts were prepared immediately upon sampling and also stored at $-50^{\circ} \mathrm{C}$ for a period up to 44 weeks. The fatty acid content of the phosphotipids was analyzed at several intervals during this period.

\section{SUBJECTS AND METHODS}

\section{Experimental design}

Comparison of venous and capillary plasma and eryhrocyte phospholipids

Blood samples were collected in eight healthy adults ( 3 males, 5 females, aged 26-30 years) from an antecubital vein in EDTA vacutainer tubes $(5 \mathrm{~mL})$ and from a finger-prick (approximately $2 \mathrm{~mL}$ ) in microtainer tubes containing EDTA. The plasma was separated from the erythrocytes by centrifugation $\left(10 \mathrm{~min}, 3000 \mathrm{rpm}, 4^{\circ} \mathrm{C}\right)$. Erythrocytes were washed twice ( $15 \mathrm{~min}, 1500 \mathrm{rpm}, 4^{\circ} \mathrm{C}$ ) with EDTA-containing saline ( $\mathrm{Na}_{2}$ EDTA.2 $\mathrm{H}_{2} \mathrm{O} 28.64 \mathrm{~g}$, $\mathrm{NaCl} 7 \mathrm{~g} . \mathrm{H}_{2} \mathrm{O} 1000 \mathrm{~mL}$ ). For the additional evaluation of a possible effect of storage on the fatty acids, aliquots of the plasma and erythrocyte samples of each participant were divided over polypropylene storage cups and stored at $-20^{\circ} \mathrm{C}$ for one and four weeks before lipid extraction. The cups were closed under a stream of nitrogen to prevent oxidation. The lipid extraction of one aliquot of each plasma and erythrocyte sample was performed on the same day of blood collection. To ensure uniformity of analytical conditions, the venous and capillary hlood samples of each subject were analyzed simultaneously. 


\section{Protection of fally acids}

Approximately $3.5 \mathrm{~mL}$ of capillary blood were collected from eleven healthy subjects (4 males, 7 females, aged 23-55 years) by finger-prick into EDTA-containing tubes. The plasma was separated from the erythrocytes by centrifugation. After washing the erythrocyte with EDTA-containing saline, the suspensions were collected in screw-capped lubes. To facilitate possible oxidation of the fatty acids, the erythrocytes were destructed by one cycle of freezing (30) $\mathrm{min}$ in liquid nitrogen) and thawing. Subsequently, aliquots of 50 $\mu \mathrm{L}$ of each erythrocyte sample were taken for immediate lipid extraction and for preparing six duplicate samples to which $2 \mu \mathrm{L}$ of a butylated hydroxytoluene, BHT $(500 \mu \mathrm{g} / \mathrm{mL})$ or a deferoxamine $(18.75 \mathrm{mg} / \mathrm{mL}$.) solution was added. The polypropylene storage cups were closed under a stream of nitrogen and stored at $-50^{\circ} \mathrm{C}$. To study the effect of these storage conditions on the fatty acid content of the crythrocyte samples, the seven sample sets of each subject were analyzed at the day of collection, and 2, 4, 8, 16, 32 and 52 weeks thereatter. From the remaining capillary erythrocyte sample $(600 \mu \mathrm{L})$ of each subject, lipid extracts were prepared on the day of blood collection. Each lipid extract was equally divided over 11 screw-capped vials, which were closed under a stream of nitrogen and stored at $-50^{\circ} \mathrm{C}$. The fatty acid content was analyzed every four weeks, up to 44 weeks. Informed consent was obtained from all participants.

\section{Fatty acid analyses}

After addition of an internal standard, 1,2-ct-dinonadecanoyl phosphatidylcholine (PC[19:0 $]_{2}$ ), total lipid extracts of plasma or erythrocyte suspensions were prepared according to the method of Bligh \& Dyer (3). Heptadecaenoic acid (17:1) was added to the samples to check for any carry-over of free fatty acids during the isolation of phospholipids. The phospholipid fractions were isolated by solid phase extraction from the total lipid extracts on aminopropyl bonded phase silica columns (4). The resulting phospholipids were saponified and the fatty acids converted to the corresponding methyl esters by reaction with $14 \%$ boron trifluoride in methanol at $100^{\circ} \mathrm{C}$ for one hour (5). To all organic solvents, BHT $(50 \mathrm{mg} / \mathrm{L})$ was added as an antioxidant. The fatty acid composition of the phospholipids was determined by capillary gas liquid chromatography' as described before (6), only modified by the use of a CP-Sil 88 column (Chrompack®, Middelburg, the Netherlands). Fatty acid amounts present in the phospholipid fraction were quantified based on the amount of 19:0 internal standard fatty acid methyl ester recovered. The results are expressed as $\mathrm{mg} / \mathrm{L}$ plasma or erythrocyte suspension and as $\% \mathrm{w} t / \mathrm{wt}$ of total fatty acids.

\section{Statistical analyses}

Comparison of venous and capillary plasma and erythrocyte phospholipid fatty acids

Fatty acid concentrations are presented as medians and interquartile ranges and compared for each of the three intervals between blood sampling and lipid extraction (zero days, one weck and four weeks). In addition, fatty acid concentrations in samples of which lipids were extracted one or four weeks after blood collection were compared with fatty acid 
concentrations in samples extracted on the day of blood sampling. The results were evaluated by the two-tailed Wilcoxon signed rank test.

Butylated hydrontoluene and deferoxamine in erythrocye suspensions

Possible changes over time in the fatty acid composition of erythrocyte samples stored in presence of BHT or deferoxamine were studied by calculating the slope (regression coelficient) of a given fatty acid for each participant. To enable the calculation of a linear regression coeflicient, the logarithms of the storing times $(2,4,8,16,32$ and 52 wecks) were used in the analysis. For each fatty acid, the average slope was compared to zero by the two-tailed Wilcoxon signed rank test.

Erythocyte lipid extracts

The data of the stored erythrocyte lipid extracts were analyzed by calculating the slopes by linear regression analysis and, thereafter, evaluated by the two-tailed Wilcoxon signed rank test.

Because of multiple comparisons. P-values $<(0.01$ were considered significantly different.

\section{RESUI,TS}

\section{Comparison of venous and capillary plasma and erythrocyte phospholipid fatty acids}

There was no difference between venous and capillary plasma phospholipids with respect to the absolute amounts $(\mathrm{mg} / \mathrm{L}$ ) of the fatty acids after one or four weeks of storage at $-20^{\circ} \mathrm{C}$ before lipid extraction (Figure 1). This also holds for the absolute amounts of the fatty acid of venous and capillary erythrocyte phospholipids extracted on the day of blood collection and one week thereafter (Figure 1). In venous erythrocyte, four weeks of storage hefore lipid extraction did not result in significantly different fatty acid levels, when compared with the samples extracted on the day of collection. In capillary erythrocyte phospholipids, however, substantial differences from the initial values were observed in the fatty acid profiles after four weeks of storage (Figure 1). The total amount of phospholipidassociated fatty acids decreased to about $55 \%$ of the initial values (Table 1). The largest decrease $(90.1 \%$ ) was observed in the absolute amounts of $n-6$ and $n-3$ fatty acids (Figure 1).

When expressed as proportion of the total falty acid amounts, it was obvious that the decrease concerned the $n-6$ long-chain polyenes (LCPS) in particular (Table 1). The levels of n-3 LCPS declined to about half the initial values. Values for the unsaturation index [number of double bonds $x \%$ fraction of the corresponding fatty acid] (7), were also decreased in capillary erythrocyte phospholipids after four weeks of storage, again reflecting the loss of unsaturated fatty acids.

\section{Butylated hydroxytoluene and deferoxamine}

The results of the erythrocyte samples stored in presence of BHT or deferoxamine are presented in Table 2. Analyses of the slopes showed a slight but significant decline in the 
levels of $18: 2 \mathrm{n}-6(\mathrm{p}<0.01)$ in the samples stored in presence of BHT (Table 2). The deferoxamine samples showed significant changes over time in the levels of $22: 4 n-6$ and $22: 5 n-6(p<0.005), 22: 5 n-3$ and $22: 6 n-3(p<0.01)$ and the levels of the sum of the monounsaturated fatty acids and the n-3 LCPs.
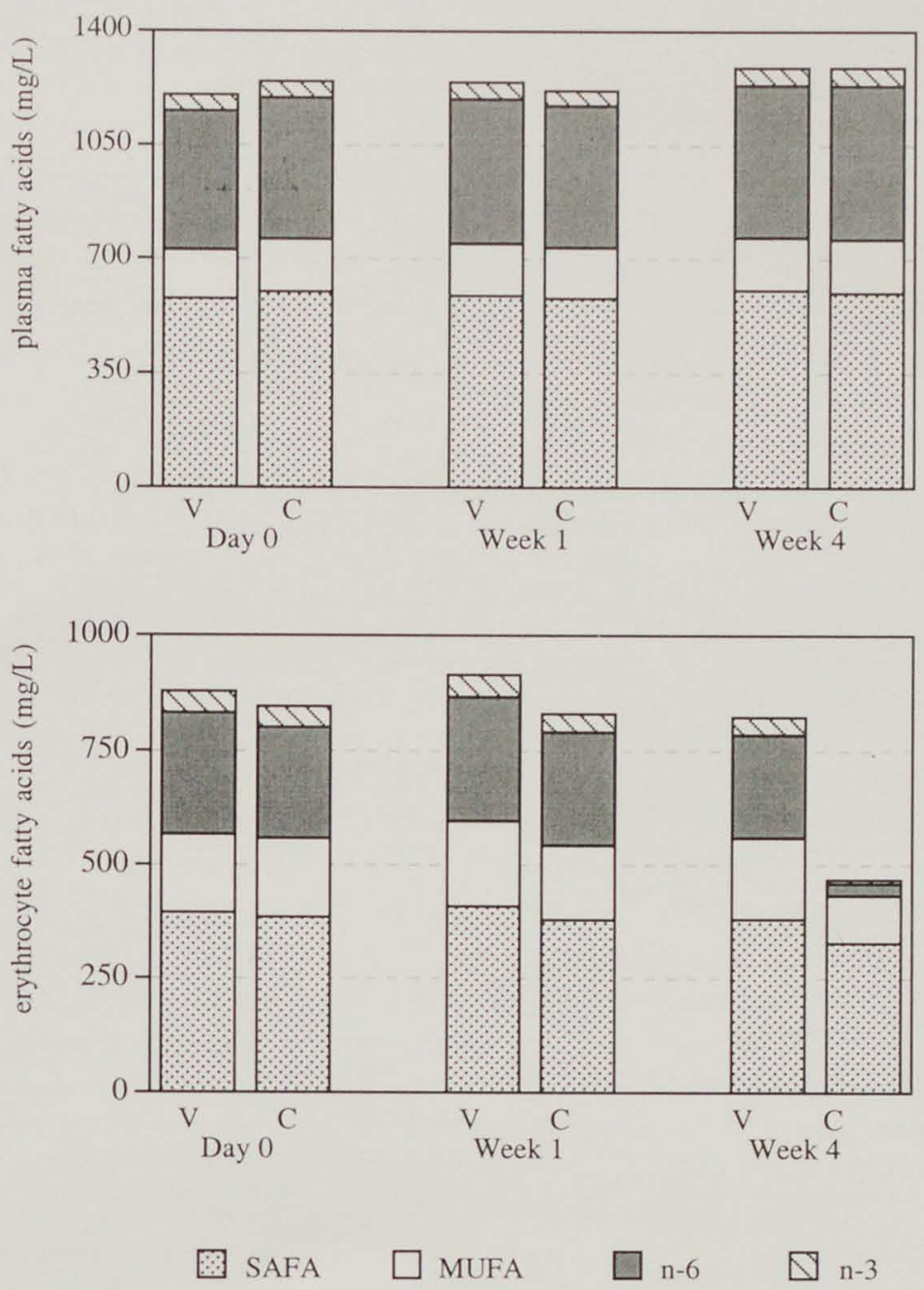

Figure 1. Absolute fatty acid composition (medians) of venous (V) and capillary (C) plasma and erythrocyte phospholipids, stored at $-20^{\circ} \mathrm{C}$ for 0 days, 1 week and 4 weeks before lipid extraction. For all venous and capillary samples $n=8$, except for the capillary erythrocyte samples of week $1, n=6$. SAFA: saturated fatty acids, MUFA: monounsaturated fatty acids, $n-6$ and n-3: sum of all n-6 and n-3 fatty acids, respectively. 
Table 1. Fatty acid composition of venous and capillary erythrocyle phospholipids, with lipid extraction done on the day of collection (Day 0) and 4 weeks thereafter /median (interquartile range)].

\begin{tabular}{|c|c|c|c|c|}
\hline \multirow[b]{2}{*}{$\begin{array}{l}\text { Fitly acids" } \\
\% \text { wt wt }\end{array}$} & \multicolumn{2}{|c|}{ Day 0} & \multicolumn{2}{|c|}{ Week 4} \\
\hline & $\begin{array}{c}\text { Venous } \\
n=8\end{array}$ & $\begin{array}{c}\text { Capillary } \\
n=8\end{array}$ & $\begin{array}{c}\text { Venous } \\
n=8\end{array}$ & $\begin{array}{c}\text { Capillary } \\
n=8\end{array}$ \\
\hline Total |mg/L | & $881.9(345.6)$ & $840.8(281.7)$ & $810.6(241.4)$ & $461.5(136.5)^{c}$ \\
\hline SAFA & $44.8(1.5)$ & $45.2(0.7)$ & $46.3(4.9)$ & $66.2(6.0)$ \\
\hline MUFA & $20.2(1.0)$ & $20.0(1.0)$ & $21.3(3.1)$ & $24.0(2.6)$ \\
\hline $18: 2 n-6$ & $13.2(2.0)$ & $13.3(3.0)$ & $13.0(4.1)$ & $4.43(1.29)^{\prime}$ \\
\hline $20: 3 n-6$ & $1.32(0.26)$ & $1.30(0.36)$ & $1.08(0.34)$ & $0.22(0.22)^{r}$ \\
\hline $20: 4 n-6$ & $10.5(1.8)$ & $10.1(1.5)$ & $9.48(1.88)$ & $0.48(1.60)^{\prime}$ \\
\hline $22: 4 n-6$ & $2.55(0.86)$ & $2.54(0.78)$ & $2.49(0.60)$ & $0.33(0.20)^{\prime}$ \\
\hline $22: 5 n-6$ & $0.30(0.12)$ & $0.29(0.10)$ & $0.30(0.10)$ & $0.03(0.07)^{\prime}$ \\
\hline n-6 LCPs & $14.5(2.4)$ & $14.1(2.3)$ & $13.4(2.0)$ & $1.24(1.58)^{\prime}$ \\
\hline $20: 5 n-3$ & $0.45(0.35)$ & $0.44(0.39)$ & $0.40(0.40)$ & $0.02(0.15)^{\prime}$ \\
\hline $22: 5 n-3$ & $1.50(0.33)$ & $1.44(0.31)$ & $1.57(0.52)$ & $0.52(0.20)^{\prime}$ \\
\hline $22: 6 n-3$ & $3.38(1.02)$ & $3.17(0.95)$ & $1.99 \quad(1.83)$ & $0.51(0.34)$ \\
\hline n-3 LCPs & $5.47(1.64)$ & $5.05(1.66)$ & $4.00(1.73)$ & $2.01(0.72)^{\prime}$ \\
\hline UI & $131.3(11.5)$ & $131.4(9.7)$ & $117.5(20.1)$ & $49.7(12.8)^{\prime}$ \\
\hline
\end{tabular}

"SAFA: sum of all saturated fatty acids; MUFA: sum of all monounsaturated fatty acids: LCPs: longchain polyenes ( 20 or more $(-$-itoms with 3 or more double bonds): UI: unsaturation index is defined as sum of [number of double bonds $x \%$ fraction of corresponding fatty acid].

"at week 4. all capillary phospholipid fatty acids tended to be significant different from the venous falty acids, $0.01<\mathrm{P}<0.05$.

"tendency for difference from day $0.0 .01<\mathrm{P}<0.05$.

\section{Erythrocyte lipid extracts}

Table 3 shows the levels of fatty acids in the phospholipids of the erythrocyte lipid extracts which were prepared on the same day of blood collection and stored up to 44 weeks. Significant increases $(\mathrm{P}<0.005)$ were observed for the levels of monounsaturated fatty acids and n-3 LCPs. The slope of the relative levels of $22: 5 n-3$ and $22: 6 n-3$ also showed a significant increase $(P<0.01)$ in time, whereas the percentages of $18: 2 n-6$ decreased significantly $(\mathrm{P}<0.005)$.

\section{DISCUSSION}

This study demonstrates that, after four weeks of storage at $-20^{\circ} \mathrm{C}$ before lipid extraction, fatty acid profiles of erythrocyte phospholipids isolated from venous and from capillary blood are no longer comparable. This is the result of substantial losses of fatty acids, 
particulary long-chain polyenes (LCPS), in capillary erythrocytes. These LCP losses appeared to he prevented by adding BHT or deferoxamine to erythrocyte samples before storage.

The fatly acid profiles of venous and capillary plasma phospholipids are unaffected by four wecks of storage and remain to be essentially similar. This enables an accurate evaluation of the fatly acid composition in longitudinal sample sets consisting of both venous and capillary plasma.

Loss of phospholipid-associated polyunsaturated fatty acids from erythrocytes as a consequence of storage at temperatures below $0{ }^{\circ} \mathrm{C}$ has been reported by others $(8-11)$. Autoxidation of LCP is the obvious major cause for the changes observed. In our study. the multiple fatty acid losses were mainly observed in the capillary erythrocyte samples. All capillary and none of the venous samples collected in our study showed signs of hatemolysis, indicating loss of erythrocyte membrane structural integrity. This crythrocyte damage may enhance the susceptibility for lipid peroxidation through the release of otherwise sequestered iron, present in hacmoglobin, which thus becomes available for the free radical reactions involved in autoxidation $(12,13)$. Indeed, in contrast to his observations in intact erythrocytes, Ways (9) reported that the phospholipid content of haemoglobin free erythrocyle ghosts was not affected by storage under the same conditions. Brown et al (11) also ascribed the loss of fatty acids observed in erythrocyte phospholipids after repeated freezing and thawing cycles $\left(a t-20^{\circ} \mathrm{C}\right)$ to lysing of the cells.

Attempts were considered to prevent the observed loss of erythrocyte fatty acids. An option was storage of erythrocytc suspensions at temperatures below $-20^{\circ} \mathrm{C}$, e.g. at $-50^{\circ} \mathrm{C}$ or even $-80^{\circ} \mathrm{C}$, but this will possibly delay and not prevent lipid loss. Another option was to remove haemoglobin from the crythrocyte lipids by cither preparing red cell ghosts (9) or extracting the lipid from the erythrocyte within one week after blood sampling. However, if one wishes all steps of the analyses to be simultaneously performed for a series of consecutive erythrocyte samples, storage of erythrocyte suspensions is unavoidable. In this case, autoxidation may be prevented by handling and storing the erythrocyte samples in the presence of a chelating agent, which can bind iron and thus prevents it from promoting lipid peroxidation. Knight et al $(14,15)$ reported that addition of deferoxamine, an iron-chelating agent, to stored whole blood was effective in reducing lipid peroxidation of the $R B C$. Dodge \& Phillips (8) observed no signs of autoxidation of erythrocyte phospholipids in lipid extracts if the antioxidants BHT or $\alpha$-tocopherol were present during storage. In our study, we assessed the ability of deferoxamine and BHT to protect against LCP loss from erythrocyte samples stored at a temperature of $-50^{\circ} \mathrm{C}$. Our findings showed no reduction of the phospholipid-associated LCPs, as observed earlier in the capillary erythrocyte samples after four-week storage. This was supported by the unsaturation index, which showed no changes over time in the samples (Tables 2 and 3). In contrast, n-3 LCP levels of the samples stored in presence of deferoxamine showed a significant increase of the slopes (Table 2), the reason for which is not known. This also holds for the observed increase in the n-3 fatty acids in the erythrocyte lipid extracts prepared on the day of blood collection. 


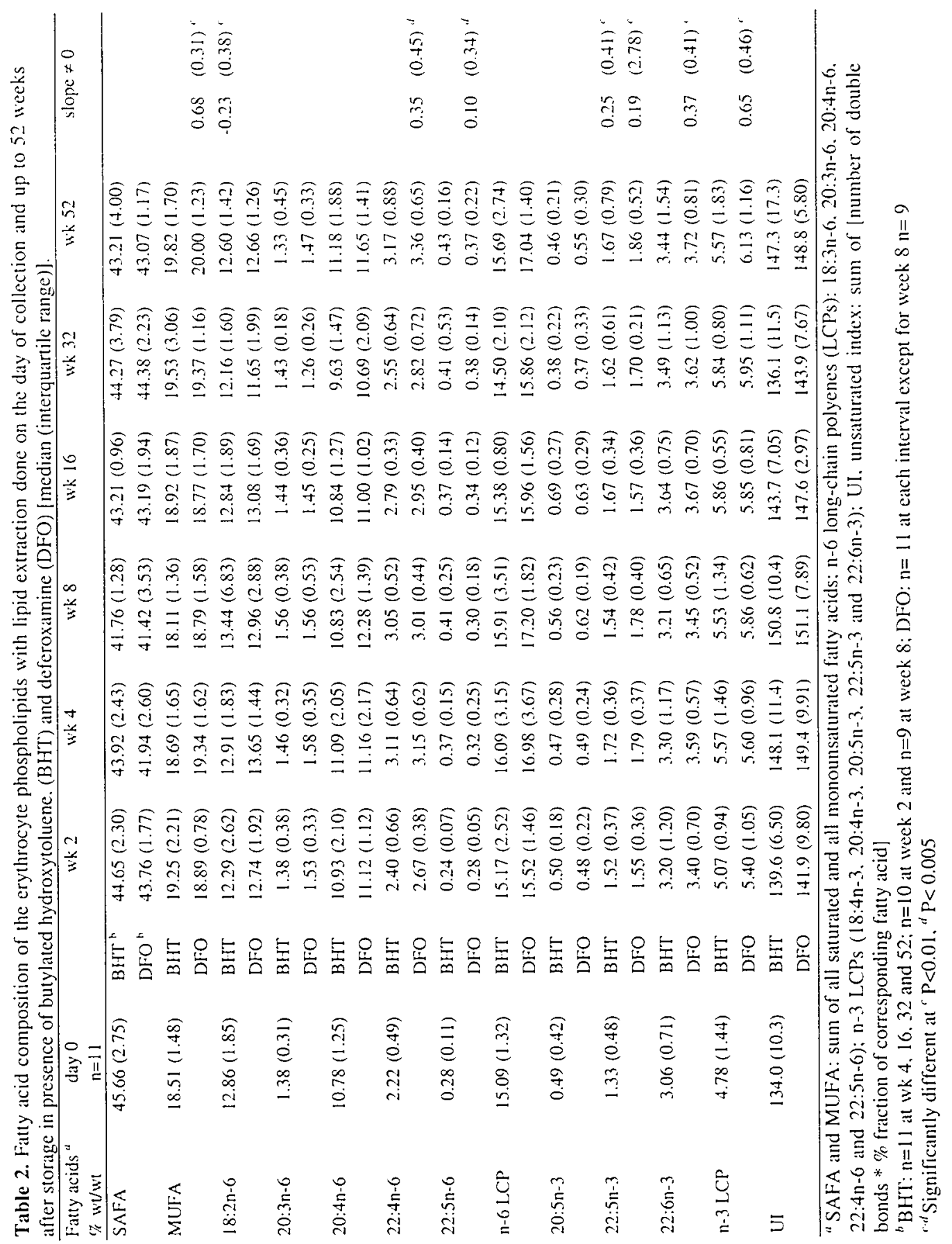


Table 3. Fatty acid composition of the erythrocyte phospholipid extracts analyzed after storage up to 44 weeks [median (interquartile range) |"

\begin{tabular}{|c|c|c|c|c|c|c|}
\hline $\begin{array}{l}\text { Fatty acids } \\
\text { \% wl/wt }\end{array}$ & $\begin{array}{l}\text { day } 0 \\
n=11\end{array}$ & $\begin{array}{l}w k 4 \\
n=11\end{array}$ & $\begin{array}{l}\text { wh } 8 \\
n=11\end{array}$ & $\begin{array}{l}w k 12 \\
n=11\end{array}$ & $\begin{array}{l}\text { wh } 16 \\
n=11\end{array}$ & $\begin{array}{l}\text { wk } 24 \\
n=11\end{array}$ \\
\hline SAFA & $45.7 \quad(2.8)$ & $44.7 \quad(2.8)$ & $46.2 \quad(0.7)$ & $44.1 \quad(3.5)$ & $44.6 \quad(1.5)$ & $46.3 \quad(0.7)$ \\
\hline MUFA & $18.5 \quad(1.5)$ & $18.1 \quad(1.3)$ & $19.1 \quad(0.9)$ & $18.6 \quad(1.8)$ & $18.7(1.4)$ & $18.9 \quad(1.2)$ \\
\hline $18: 2 n-6$ & $12.9 \quad(1.9)$ & $12.3 \quad(1.7)$ & $12.2(1.7)$ & $13.1 \quad(3.1)$ & $12.3(1.9)$ & $12.3 \quad(2.1)$ \\
\hline $20: 3 n-6$ & $1.38(0.31)$ & $1.32(0.39)$ & $1.43(0.25)$ & $1.43(0.28)$ & $1.47(0.27)$ & $1.28(0.24)$ \\
\hline $20: 4 n-6$ & $10.8 \quad(1.3)$ & $11.2 \quad(2.1)$ & $10.7(1.5)$ & $10.7 \quad(2.5)$ & $10.7 \quad(1.2)$ & $10.5 \quad(1.6)$ \\
\hline $22: 4 n-6$ & $2.22(0.49)$ & $2.87(0.54)$ & $2.46(0.25)$ & $2.50(0.53)$ & $2.70(0.49)$ & $2.66(0.50)$ \\
\hline $22: 5 n-6$ & $0.28(0.11)$ & $0.34(0.17)$ & $0.31(0.13)$ & $0.32(0.13)$ & $0.41 \quad(0.15)$ & $0.22(0.06)$ \\
\hline$n-0 L C P$ & $15.1 \quad(1.3)$ & $16.1 \quad(3.1)$ & $15.2 \quad(1.9)$ & $15.0 \quad(4.1)$ & $15.7 \quad(1.1)$ & $14.8 \quad(2.2)$ \\
\hline $20: 5 n-3$ & $0.49(0.42)$ & $0.46(0.22)$ & $0.56(0.23)$ & $0.34(0.23)$ & $0.51(0.24)$ & $0.45(0.23)$ \\
\hline $22: 5 n-3$ & $1.33(0.48)$ & $1.63(0.39)$ & $1.56(0.34)$ & $1.55(0.42)$ & $1.57(0.40)$ & $1.48(0.28)$ \\
\hline $22: 0 n-3$ & $3.06(0.71)$ & $3.61 \quad(0.89)$ & $3.20(0.73)$ & $3.30(1.00)$ & $3.16(0.79)$ & $3.00(0.35)$ \\
\hline$n-3$ LCP & $4.78(1.44)$ & $5.70(0.90)$ & $5.18(0.95)$ & $5.32(1.06)$ & $5.41(0.97)$ & $4.76(0.71)$ \\
\hline UI & $132.3(11.0)$ & $144.1(10.2)$ & $136.8 \quad(6.8)$ & $138.8 \quad(10.7)$ & $140.2 \quad(6.6)$ & $133.8 \quad(4.9)$ \\
\hline
\end{tabular}

Table 3 continued

\begin{tabular}{|c|c|c|c|c|c|c|}
\hline $\begin{array}{l}\text { Fatty acids }{ }^{b} \\
\% \text { wd } / \mathrm{wt}\end{array}$ & $\begin{array}{c}w k 28 \\
n=11\end{array}$ & $\begin{array}{c}w k 32 \\
\mathrm{n}=10\end{array}$ & $\begin{array}{c}\text { wk } 36 \\
n=10\end{array}$ & $\begin{array}{l}\text { wh } 40 \\
n=11\end{array}$ & $\begin{array}{c}w k 44 \\
n=11\end{array}$ & slope $\neq 0$ \\
\hline SAFA & $42.1 \quad(1.1)$ & $44.0 \quad(2.9)$ & $43.5 \quad(0.9)$ & $43.6 \quad(1.5)$ & $43.1 \quad(1.1)$ & \\
\hline MUFA & $19.0(1.5)$ & $19.7 \quad(1.3)$ & $22.6 \quad(0.9)$ & $20.4 \quad(1.1)$ & $21.0 \quad(2.7)$ & $0.07(0.03)^{d}$ \\
\hline $18: 2 n-6$ & $12.6(1.6)$ & $11.8 \quad(2.1)$ & $11.9(1.0)$ & $12.5 \quad(1.6)$ & $12.2(0.7)$ & $-0.02(0.02)^{d}$ \\
\hline $20: 3 n-6$ & $1.60(0.37)$ & $1.22(0.29)$ & $1.10(0.25)$ & $1.25(0.31)$ & $1.38(0.72)$ & \\
\hline $20: 4 n-6$ & 12.0 & $10.5 \quad(2.6)$ & $10.6(1.9)$ & $11.0 \quad(1.4)$ & 11.7 & \\
\hline $22: 4 n-6$ & $2.97(0.33)$ & $2.64(0.38)$ & $2.74(0.53)$ & $2.82(0.39)$ & $2.66(0.44)$ & \\
\hline $22: 5 n-6$ & $0.40(0.14)$ & $0.34(0.08)$ & $0.32(0.12)$ & $0.23(0.19)$ & $0.29(0.37)$ & \\
\hline n-6 LCCP & $17.0(2.58)$ & $15.4(2.63)$ & $14.9(2.11)$ & $15.6(1.26)$ & $16.2(3.02)$ & \\
\hline $20: 5 n-3$ & $0.53(0.34)$ & $0.43(0.25)$ & $0.43(0.28)$ & $0.59(0.41)$ & $0.57(0.29)$ & \\
\hline $22: 5 n-3$ & $1.63(0.29)$ & $1.40(0.59)$ & $1.54(0.42)$ & $1.66(0.47)$ & $1.92(0.58)$ & $0.01(0.01)^{c}$ \\
\hline $22: 6 n-3$ & $3.62(0.71)$ & $3.73(0.79)$ & $3.39(0.69)$ & $3.66(0.71)$ & $4.19(0.71)$ & $0.02(0.01)^{r}$ \\
\hline$n-3$ LCP & $5.81(1.42)$ & $5.46(1.00)$ & $5.09(1.02)$ & $5.96(1.41)$ & $6.70(0.92)$ & $0.03(0.02)^{r}$ \\
\hline UI & $151.7 \quad(7.6)$ & $139.0 \quad(6.3)$ & $138.0 \quad(2.2)$ & $141.5 \quad(8.7)$ & $152.0(8.8)$ & \\
\hline
\end{tabular}

"No data available for week 20 due to analytical reasons.

${ }^{b}$ SAFA: sum of all saturated fatty acids: MUFA: sum of all monounsaturated fatty acids; $n-6$ LCPs (longchain polyenes): $18: 3 n-6,20: 3 n-6,20: 4 n-6,22: 4 n-6$ and 22:5n-6); n-3 LCPS $(18: 4 n-3,20: 4 n-3,20: 5 n-3$. 22:5n-3 and 22:0n-3): UI, unsaturation index: sum of [number of double bonds * \% fraction of corresponding fatty acid]

"Significantly different at ${ }^{c} \mathrm{P}<0.01 .{ }^{a} \mathrm{P}<0.005$ 
The levels of 18:2n-6 of the samples stored in presence of BHT and the lipid extracts were, however, found to be decreased. This was striking because even the LCPs (containing 3 or more double bounds) showed no significant decrease in time.

In conclusion, the results of this study indicate that plasma phospholipid-associated fatty acid profiles of venous and of capillary blood are comparable and unaffected by storage at $-20^{\circ} \mathrm{C}$ for up to four weeks before lipid extraction. However, the fatty acid content of erythrocyte suspensions of capillary origin, stored for more than one week before lipid extraction, shows lipid losses, with the largest decreases observed in the highly unsaturated latty acids. Both BHT and deferoxamine combined with storage at $-50^{\circ} \mathrm{C}$ appeared to protect these LCPS against deterioration upon storage of erythrocytes.

\section{ACKNOWLEDGEMENTS}

The authors gratefully acknowledge the assistance of Marianne Simonis and Hasibe Aydeniz for their technical assistance and Arnold Kester for the statistical advises.

\section{REFERENCES}

1. Kupke IR, Zeugner S, Gottschalk A. Kather B. Differences in lipid and lipoprotein concentrations of capillary and venous blood samples. Clin Chim Acta 1979:97:279-83.

2. Thiclmann K, Ruhling K. Schatuer I. Heller R, Traut H. Suitability and recovery of capillary blood plasma for lipid determinations. Acta Biol Med Ger 1979;38:1115-21.

3. Bligh E. Dyer WJ. A rapid method for total lipid extraction and purification. Can J Biochem Physiol 1959:37:911-917.

4. Kaluzny MA. Duncan L.A. Merritt MV. Epps DE. Rapid separation of lipid classes in high yield and purily using bonded phase columns. J Lipid Res 1985;26:135-40.

5. Morrison WR. Smith LM. Preparation of fatty acid methyl esters and dimethylacetals from lipids with boron fluoride-methanol. J Lipid Res 1964:5:600-8.

6. Foreman-van Drongelen MM. Houwelingen ACv. Kester AD. de Jong AEP. Blanco CE. Hasaart THM. Hornstra G. Long-chain polyene status of preterm infants with regard to the fatty acid composition of their dict: comparison between absolute and relative fatty acid levels in plasma and erythrocyte phospholipids. Br J Nutr 1995;73:405-22.

7. Hoffman DR, Uauy R. Essentiality of dietary omega 3 fatty acids for premature infants: plasma and red blood cell fatty acid composition. Lipids 1992:27:886-95.

8. Dodge J'T, Phillips GB. Autoxidation as a cause of altered lipid distribution in extracts from human red cells. J Lipid Res 1900:7:387-95.

9. Ways PO. Degradation of glycerophosphatides during storage of saline-washed. saline-suspended red cells at -20 degrees C. J l.ipid Res 1967:8:518-21. 
10. Glatz JP. Soffers AE. Katan MB. Fatty acid composition of serum cholesteryl esters and erythrocyte membranes as indicators of linoleic acid intake in man. Am J Clin Nutr 1989;49:269-76.

11. Brown VI. Shaly JC. Morse-Fisher NI. Horrobin DF. Effect of repeated periods of freezing and thawing on fatty acid composition of red blood cells and plasma. Med Sci Res 1992;20:225-7.

12. (hiu D, Kuypers F. Lubin B. Lipid peroxidation in human red cells. Semin Hematol 1989;26:257-76.

13. Gutteridge JM. Iron and oxygen: a biologically damaging mixture. Acta Paediatr Scand Supp! 1989;361:78-85.

14. Knight JA. Voorhees RP. Martin L. The effect of metal chelators on lipid peroxidation in stored erythrocyles. Ann Clin I.ab Sci 1992:22:207-13.

15. Knight JA. Searles DA. Clayton FC. The effect of desferrioxamine on stored erythrocytes: lipid peroxidation. deformability. and morphology. Ann Clin Lab Sci 1996:26:283-90. 



\title{
Chapter 3
}

\section{Maternal and neonatal essential fatty acid status in phospholipids: an international comparative study}

Suzie J. Otto, Adriana C. van Houwelingen, Magda Antal, Auli Manninen, Keith Godfrey, Patricio López-Jaramillo, Gerard Hornstra

Based on European Journal of Clinical Nutrition 1997;51:232-242.

\begin{abstract}
To investigate whether the steady decline in the maternal essential fatty acids (EFAs) status during pregnancy observed in Dutch pregnant women is a local or general phenomenon, the EFA status of healthy women from the Netherlands, Hungary, Finland, England and Ecuador was measured during uncomplicated, singleton pregnancy. In addition, the EFA statuses of their neonates were determined at birth. Fatty acid profiles of phospholipids isolated from maternal plasma and from umbilical plasma and cord vessel walls were analyzed.

Considerable differences were observed between these centers in the maternal EFA levels and EFA indexes. However, the change in the absolute as well as relative amounts of the EFA followed a similar course in the five populations during pregnancy. The neonatal EFA profiles rellected the differences found in maternal plasma during pregnancy and shortly after delivery. Comparable correlations were found, particularly, between the neonatal and the maternal n-3 fatty acids in the participating groups.

The reduction in maternal EFA status during pregnancy seems to be a general phenomenon, largely independent of differences in dietary habits and ethnic origin. The lowest values of certain maternal EFAs in late pregnancy in a given country were significantly higher than the highest value in early pregnancy in other countries. Hence, the functional implications of the pregnancy-associated reduction in the maternal EFA status for the fetal and neonatal development is not obvious and needs to be further elucidated.
\end{abstract}




\section{INTRODUCTION}

Maternal nutrition is an important factor for growth of the fetus. In particular, low birth weight has been shown to be related to maternal malnutrition (1). In a study in mothers from low socio-cconomic class, the mothers whose babies were born with low birth weight $(<2500 \mathrm{~g})$ had significantly lower intakes of dictary energy, especially fat, implying a low intake of essential fatty acids (EFAs) (2). Crawford et al (3) found a strong relationship between birth weight and maternal EFA intake. EFAs play a crucial role during fetal growth and development, and are important components of all cell membranes, especially those in the brain and in the nervous and vascular systems (4-7). In addition, they are of major importance in the maturation of the retina and the visual process (7).

In a longitudinal study in Dutch pregnant women, a decline in the overall maternal EFA status was observed (8), which implies that the present dietary EFA intake of pregnant women may not be adequate. However, this may be specific for the dietary situation in the Netherlands and, in order to oblain information from a wider variation in dietary compositions, we extended this study to areas with different dietary habits. For this purpose, the essential fatty acid status in plasma phospholipids during pregnancy and shortly after delivery were compared in women from five countries. In addition, the EFA statuses of their neonates were compared as well, based on fatty acid profiles of umbilical plasma and vessel wall phospholipids.

\section{SUBJECTS, MATERIAL AND METHODS}

\section{Subjects and sample collection}

In each participating center, of which four in Europe (the Netherlands, Hungary, Finland and England) and one in South America (Ecuador), healthy women, pregnant of a singleton, were recruited. In case complications developed during pregnancy, the data of the participant concerned were excluded from analysis. The total study population finally involved 50 Dutch, 55 Hungarian, 52 Finnish, 56 English and 26 Ecuadorian mothers and their neonates. All participants were Caucasians, except for the Ecuadorians, who were Mestizos.

Maternat venous blood samples were collected in EDTA tubes before 18 weeks of gestation and at 22 and 32 weeks of pregnancy. Shortly after delivery, a maternal venous blood sample was collected, logether with a blood sample from the umbilical vein and about $15 \mathrm{~cm}$ of the umbilical cord. Plasma was separated from erythrocytes by centrifugation and each plasma sample was divided over plastic tubes, which were tightly closed under nitrogen. The cord vessels were rinsed with saline solution and the cords packed into plastic bags. The plasma samples and the cord vessels were stored frozen (max. $-40^{\circ} \mathrm{C}$ ) and transported in dry ice to Maastricht, the Netherlands, for analysis. 
The protocol of the study was approved by the local Ethics Committees and written consent was oblained from each participant.

\section{Fatty acid analyses}

The fatty acid composition of phospholipids isolated from maternal and umbilical plasma, and from umbilical venous and arterial vessel walls was determined as previously described (8). All analyses were performed in the same laboratory. Briefly, after addition of an internal standard, 1,2-(x-dinonadecanoyl phosphatidylcholine (PC- $[19: 0]_{2}$ ), plasma total lipid extracts were prepared by a modified Folch extraction method (8-10) and phospholipid fractions were isolated from the lipid extracts by using aminopropyl bonded phase silica columns (11). Heptadecenoic acid (17:1) was added to the samples to check for any carryover of free latty acids during the isolation of phospholipids. The phospholipid fractions were hydrolyzed and the fatly acids methylated with boron trifluoride in methanol ((12). The latty acid composition of the phospholipids were then determined by capillary gas chromatography using a non-polar CPSil 5 CB column (Chrompack, Middelburg, the Netherlands), with nitrogen as carrier gas.

Five-centimeter segments of the umbilical cords were used to isolate both umbilical arteries and the veins. The vessel walls were frozen in liquid nitrogen and pulverized. The pulverized samples were freezc-dried before lipid extraction according to the method of Bligh \& Dyer (13). Further analytical procedures were similar to the plasma lipid extracts. Results are expressed in absolute amounts (mg fatty acid per L plasma or $\mathrm{mg}$ fatty acid per $\mathrm{kg}$ dry tissue) or in relative levels (\% of total fatly acids, wt/wt).

Forty four fatly acids were identified, but only the following fatty acids and sums of fatty acids are reported: $20: 3 n-9,22: 3 n-9,18: 2 n-6,20: 3 n-6,20: 4 n-6,22: 4 n-6,22: 5 n-6$, $18: 3 n-3,20: 5 n-3,22: 5 n-3,22: 6 n-3$, sum of the $n-7$ and $n-9$ fatty acids $(n-7+n-9)$, the $n-6$ fatty acids (n-6), the $n-6$ long chain polyenes ( $n-6$ LCP), the $n-3$ fatty acids (n-3) and n-3 LCP, sum of the saturated fatty acids (SAFA), and the monounsaturated fatty acids (MUFA). LCP is defined as the sum of the elongation and desaturation products of $18: 2 n-6$ $(20: 3 n-6,20: 4 n-6,22: 4 n-6,22: 5 n-6)$ and $18: 3 n-3(20: 4 n-3,20: 5 n-3,22: 5 n-3,22: 6 n-3)$.

Three indexes were calculated to describe the EFA status. The EFA index defined by Hornstra et al (14) as the ratio between the sum of the $n-3+n-6$ and the sum of the $n-7+n-9$ fatty acids $[(n-3+n-6) /(n-7+n-9)]$, was calculated because an adequate supply of $n-3$ and $n-6$ falty acids limits the desaturation of the non-essential $n-7$ and $n-9$ monoenes to their respective LCPS. The docosahexaenoic acid (DHA, 22:6n-3) deficiency index, DHADI: $22: 5 n-6 / 22: 4 n-6(15,16)$, and the DHA sufficiency index, DHASI: 22:6n3/22:5n-6 (17) were used because a shortage of $22: 6 \mathrm{n}-3$ is accompanied by an increase in the conversion of 22:4n-6 to 22:5n-6, resulting in higher DHADI and lower DHASI values.

\section{Statistical analyses}

Data are presented as mean \pm SEM. Clinical characteristics (continuous variables) of the study populations were compared by ANOVA, post hoc tested with the Bonferroni 
procedure for multiple comparisons. The discrete clinical variables were compared with the Chi-square test.

Comparisons of the courses of the maternal EFAs during pregnancy in the various centers were made by calculating for each participant the slope of the relation between gestational age (delivery excluded) and the fatty acid levels, using linear regression analysis. Possible differences in the average slopes and in the fatty acid levels (early pregnancy and alter delivery) between the centers were tested with ANOVA, followed by the post hoc Bonferroni procedure.

Between-center differences in neonatal EFA status were studied by comparing the fatty acid compositions of phospholipids isolated from umbilical venous plasma and venous and arterial cord vessel walls by means of ANOVA, followed by the Bonferroni procedure.

Relations between the maternal and neonatal EFA status were investigated by the use of multiple regression analysis, in which corrections for gestational age as a confounding factor were made, since the EFA status at birth is related to gestational age at birth (8). Corrections for possible effects of the countries were made as well. The slopes of the regression equations were tested for differences between the countries by using the F-test with 4 degrees of freedom.

Because of the large number of comparisons made, P-values $<0.01$ were considered significant.

\section{RESULTS}

\section{Clinical characteristics}

In Table 1, the relevant clinical information on the study populations is summarized. The Ecuadorian and Hungarian mothers were significantly younger $(\mathrm{P}<0.0001)$ than the other mothers. Moreover, the Ecuadorian mothers were significantly shorter in comparison with the European mothers $(P<0.0001)$. Although the Hungarian mothers tended to have a lower prepregnancy weight and body mass index (BMI), this difference was not statistically significant (data were not available for Ecuador). The English mothers had the lowest diastolic blood pressure at entry $(\mathrm{P}<0.001)$ as compared with the Finnish and Hungarian women. Maximum diastolic blood pressure during pregnancy did not, however, differ between the five groups.

The gestational age at delivery was similar in each of the groups. The Ecuadorian neonates were, however, significantly shorter as compared with the Dutch $(\mathrm{P}<0.001)$ and the other neonates $(P<0.0001)$. They also had the lowest birth weights, whereas the Finnish newborns had the highest birthwcights $(P<0.001)$. The Hungarian newborns were significantly longer $(\mathrm{P}<0.0001)$ than the Dutch, English and Ecuadorian neonates and they had the lowest Ponderal index as well. Apgar scores five minutes after birth were significantly lower $(\mathrm{P}<0.0001)$ in the neonates from Ecuador, England and Finland as compared with the neonates from Hungary. The newborn infants from Ecuador $(P<0.001)$ 


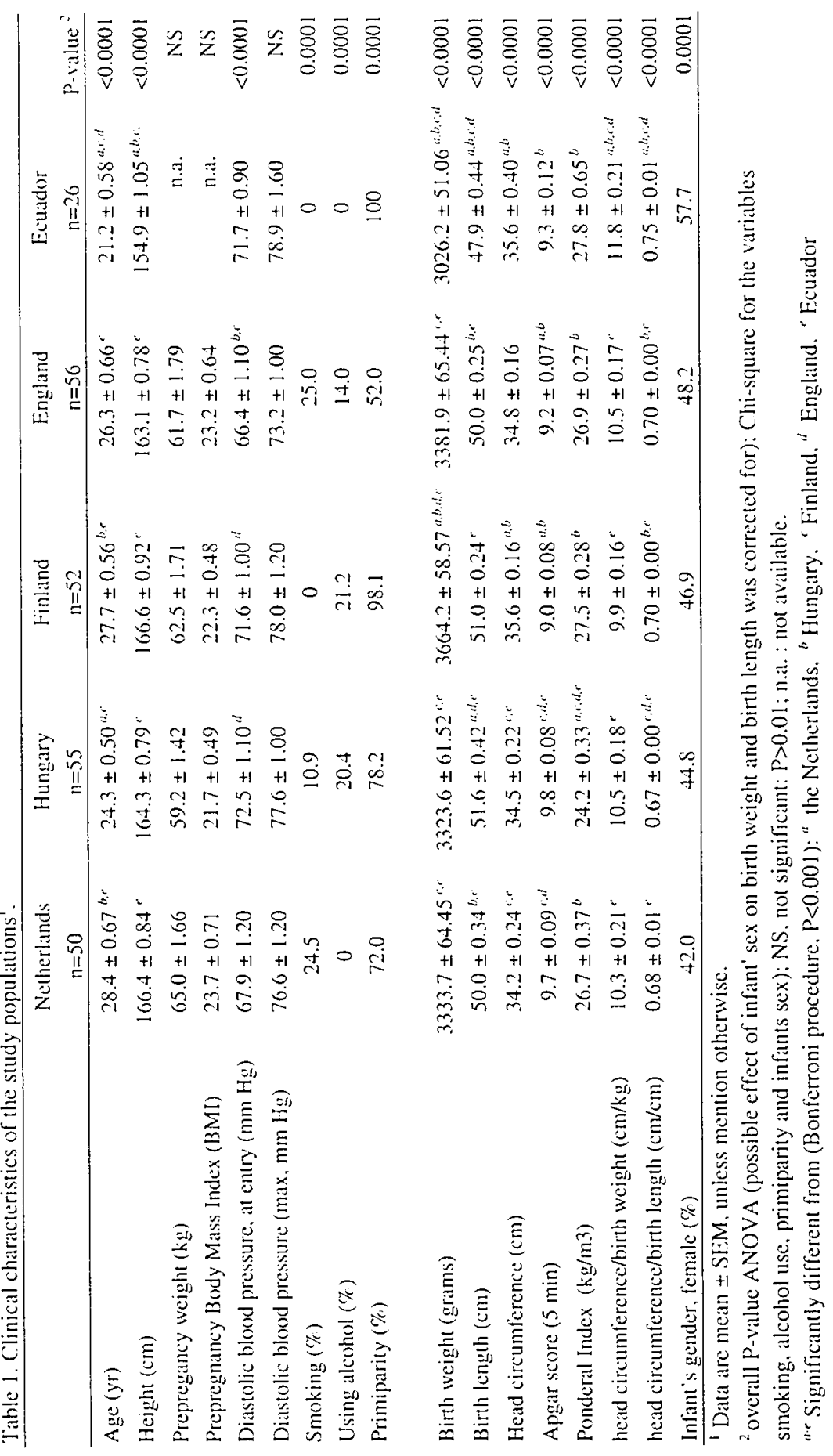


Table 2. Matcrnal plasma phospholipid fatly acid composition in carly pregnancy !

\begin{tabular}{|c|c|c|c|c|c|}
\hline $\begin{array}{l}\text { Fatty acids } \\
\mathrm{mg} / \mathrm{l} \text {. }\end{array}$ & $\begin{array}{c}\text { Netherlands } \\
n=50\end{array}$ & $\begin{array}{c}\text { Hungary } \\
n=54\end{array}$ & $\begin{array}{c}\text { Finland } \\
n=49\end{array}$ & $\begin{array}{c}\text { England } \\
n=56\end{array}$ & $\begin{array}{c}\text { Ecuador } \\
n=26\end{array}$ \\
\hline Total $^{3}$ & $1.382 \pm 40$ & $1478 \pm 29^{\circ}$ & $1382 \pm 37$ & $1522 \pm 29^{\circ}$ & $1317 \pm 50^{b . d}$ \\
\hline $18: 2 n-6^{4}$ & $290.1 \pm 9.2$ & $30.3 .1 \pm 7.0$ & $274.7 \pm 8.8^{d}$ & $319.4 \pm 7.8^{\circ}$ & $288.1 \pm 11.4$ \\
\hline $20: 3 n-6^{3}$ & $45.1 \pm 2.0$ & $48.6 \pm 1.8$ & $39.7 \pm 2.1^{d}$ & $51.7 \pm 1.5^{\circ}$ & $44.9 \pm 3.7$ \\
\hline $20: 4 n-6$ & $1.34 .4 \pm 5.2^{\prime \prime}$ & $170.2 \pm 5.0 a c d r$ & $117.9 \pm 3.5^{b}$ & $136.2 \pm 4.3^{b}$ & $113.4 \pm 6.3^{\circ}$ \\
\hline $22: 4 n-6$ & $5.09 \pm 0.20 \mathrm{~m}$ & $8.30 \pm 0.2^{a, c, d s c}$ & $3.75 \pm 0.15^{\text {w.thd.te }}$ & $5.17 \pm 0.16^{b c c}$ & $5.30 \pm 0.44^{b s}$ \\
\hline $22: 5 n-6$ & $4.62 \pm 0.31^{\prime \prime}$ & $11.0 \pm 0.5^{u c, d \sigma r}$ & $3.26 \pm 0.20^{b, t, r}$ & $5.44 \pm 0.31^{b c}$ & $6.10 \pm 0.62^{b . t}$ \\
\hline n-6 L_CPs & $189.2 \pm 7.0^{\prime \prime}$ & $238.2 \pm 6.5$ astue & $164.6 \pm 4.8^{b . t}$ & $198.6 \pm 5.2^{b, c}$ & $169.7 \pm 9.7^{b}$ \\
\hline $11-6$ & $489.3 \pm 14.2^{b}$ & $553.16 \pm 11.2$ wecr & $447.6 \pm 11.5^{b . d}$ & $528.4 \pm 10.7^{\circ}$ & $468.3 \pm 18.7^{b}$ \\
\hline $18: 3 n-3$ & $2.55 \pm 0.25^{b, r}$ & $0.93 \pm 0.08^{a . c d}$ & $3.57 \pm 0.28^{a, b, c}$ & $2.72 \pm 0.17^{b}$ & $1.90 \pm 0.18^{\circ}$ \\
\hline $20: 5 n-3$ & $7.49 \pm 0.54^{r}$ & $3.25 \pm 0.633^{c d t}$ & $15.9 \pm 1.8^{a, b, b c}$ & $8.39 \pm 0.41^{b . c}$ & $4.86+0.42^{\circ}$ \\
\hline $22: 5 n-3$ & $9.89 \pm 0.40^{b, c}$ & $7.48 \pm\left. 0.2\right|^{a c c d}$ & $11.9 \pm 0.47^{a, b, c}$ & $11.5 \pm 0.4^{b . e}$ & $8.90 \pm 0.61$ \\
\hline $22: 6 n-3$ & $58.7 \pm 2.8^{\circ}$ & $55.4 \pm 1.6^{a, d}$ & $74.5 \pm 3.2^{a, b}$ & $09.7 \pm 2.4^{\circ}$ & $62.9 \pm 3.5$ \\
\hline$n-3$ L.CPs & $78.0 \pm 3.5^{\circ}$ & $67.2 \pm 2.3^{c . t}$ & $104.9 \pm 5.1$ a.b.e & $91.8 \pm 3.0^{\circ}$ & $78.4 \pm 4.0^{\circ}$ \\
\hline$n-3$ & $81.0 \pm 3.6^{\circ}$ & $68.5 \pm 2.3^{i, t}$ & $109.1 \pm 5.1^{\text {a.t.e }}$ & $95.1 \pm 3.0^{b}$ & $80.8 \pm 4.0^{\circ}$ \\
\hline $20: 3 n-9$ & $1.94 \pm 0.11 d$ & $1.94 \pm 0.10^{d}$ & $2.24 \pm 0.11^{d}$ & $2.98 \pm 0.10^{a . b, c, c}$ & $1.75 \pm 0.14^{d}$ \\
\hline$n-7+n-9$ & $166.3 \pm 5.3^{d}$ & $183.4 \pm 4.5$ & $180.3 \pm 6.1$ & $197.2 \pm 4.3^{a, r}$ & $161.3 \pm 7.3^{d}$ \\
\hline SAFA & $619.7 \pm 17.9$ & $653.0 \pm 13.3$ & $619.0 \pm 16.5$ & $678.1 \pm 13.2^{\circ}$ & $578.5 \pm 22.8^{d}$ \\
\hline MUFA & $164.0 \pm 5.2 d$ & $181.0 \pm 4.4$ & $183.6 \pm 6.0$ & $193.7 \pm 4.3^{n, r}$ & $159.1 \pm 7.2^{d}$ \\
\hline EFA index & $3.46 \pm 0.05^{\circ}$ & $3.44 \pm 0.07$ & $3.03 \pm 0.05^{a . b e c}$ & $3.21 \pm 0.07$ & $3.45 \pm 0.09^{c}$ \\
\hline DHADI & $0.89 \pm 0.03^{b, r}$ & $1.31 \pm 0.03^{a, s, d}$ & $0.86 \pm 0.03^{b, d r}$ & $1.03 \pm 0.04^{b, r}$ & $1.14 \pm 0.06^{a x t}$ \\
\hline DHASI & $14.1 \pm 0.8^{b .}$ & $5.52 \pm 0.29^{u c c t}$ & $25.9 \pm 1.6^{u, b u t, r}$ & $15.6 \pm 1.5^{u, c}$ & $12.1 \pm 1.1^{\circ}$ \\
\hline
\end{tabular}

'Datia are mean \pm SEM; weeks of gestation in early pregnancy: Netherlands $11.7 \pm 0.33$; Hungary $13.5 \pm$ 0.19 ; Finland 10.2 \pm 0.35 ; Englind $14.1 \pm 0.22$ and Ecuador $11.8 \pm 0.61$ (comparisons made with gestational age adjusted at 14 weeks).

$2-1$ n-6 LCPS (long chain polyenes): 20:3n-6, 20:4n-6, 22:4n-6 and 22:5n-6; n-3 LCPs: 20:4n-3, 20:5n-3, 22:5n-3 and 22:0n-3: SAFA: sum of all saturated fatty acids; MUFA: sum of all monounsaturated fatty acids; EFA index: [sum n-3+n-6 fatty acids]/ [sum n-7+n-9 fatty acids]: DHADI, docosahexaenoic acid deficiency index. 22:5n-6/22:4n-6; DHASI: docosahexaenoic acid sufficiency index. 22:6n-3/22:5n-6. Fatty acids differed significantly between the countries (ANOVA) overall ${ }^{2} \mathrm{P}<0.0001,{ }^{3} \mathrm{P}<0.001,{ }^{4} \mathrm{P}<0.005$.

"w. Significantly different from (Bonferroni procedure, $P<0.001$ ): " the Netherlands. ${ }^{b}$ Hungary. "Finland,

"Englind, "Ecuidor.

and Finland $(P<0.0001)$ had significantly larger head circumferences than the Dutch and Hungarian newborns. The ratio of head circumference to birth weight as well as the head circumference to birth length ratio were significantly $(\mathrm{P}<0.0001)$ higher in the Ecuadorian neonates as compared to the others, whereas the latter ratio was significantly lower $(\mathrm{P}<0.0001)$ in the Hungarian neonates. 
Table 3. Matemal plasma phospholipid fatty acid composition shortly after delivery!

\begin{tabular}{|c|c|c|c|c|c|}
\hline $\begin{array}{l}\text { Falty acids } 2 \\
\text { mg/L }\end{array}$ & $\begin{array}{c}\text { Netherlands } \\
n=50\end{array}$ & $\begin{array}{c}\text { Hungary } \\
n=54\end{array}$ & $\begin{array}{c}\text { Finland } \\
n=49\end{array}$ & $\begin{array}{c}\text { England } \\
n=56\end{array}$ & $\begin{array}{c}\text { Ecuador } \\
\mathrm{n}=26\end{array}$ \\
\hline TO'MAL & $1759 \pm 50^{b r}$ & $2061 \pm 44^{0 ., d}$ & $2073 \pm 54^{u, d}$ & $1780 \pm 38^{b .}$ & $1860 \pm 56$ \\
\hline $18: 2 n-6^{4}$ & $363.7 \pm 10.9^{\prime \prime}$ & $418.7 \pm 12.3^{a . d}$ & $389.6 \pm 11.8$ & $356.1 \pm 9.7^{\circ}$ & $398.1 \pm 15.0$ \\
\hline $20: 3 n-6^{3}$ & $62.1 \pm 2.8^{\prime \prime}$ & $74.5 \pm 2.4^{a}$ & $70.3 \pm 2.7$ & $64.8 \pm 2.1$ & $74.7 \pm 3.9$ \\
\hline $20: 4 n-6$ & $152.5 \pm 6.3^{\circ}$ & $212.4 \pm 6.6^{a c k t r}$ & $153.1 \pm 4.9^{b}$ & $145.3 \pm 4.9^{b}$ & $138.1 \pm 7.0^{b}$ \\
\hline $22: 4 n-6$ & $6.57 \pm 0.28^{\circ}$ & $12.0 \pm 0.4^{a c c, d, r}$ & $5.78 \pm 0.26^{\circ}$ & $6.13 \pm 0.23^{\prime \prime}$ & $7.06 \pm 0.38^{\circ}$ \\
\hline $22: 5 n-6$ & $9.08 \pm 0.5^{\prime \prime}$ & $20.5 \pm 0.9^{a, c, d s r}$ & $8.59 \pm 0.53^{b}$ & $8.17 \pm 0.44^{b}$ & $10.4 \pm 0.8^{b}$ \\
\hline n-6 LCPs & $230.3 \pm 8.5^{\prime \prime}$ & $319.4 \pm 9.14 c c d r$ & $237.8 \pm 7.80^{\prime \prime}$ & $224.4 \pm 6.6^{\prime \prime}$ & $230.2 \pm 9.0^{b}$ \\
\hline$n-0$ & $60.5 .9 \pm 17.4^{6}$ & $753.8 \pm 17.5 \alpha, c, d, c$ & $639.9 \pm 17.6^{b}$ & $592.8 \pm 13.9^{b}$ & $642.7 \pm 19.2^{b}$ \\
\hline $18: 3 n-3$ & $3.60 \pm 0.34$ & $1.49 \pm 0.10^{u s c d r}$ & $0.43 \pm 0.34 a \cdot b, d t r$ & $3.79 \pm 0.19^{b s r}$ & $2.94 \pm 0.23^{\text {b.r }}$ \\
\hline $20: 5 n-3$ & $6.34 \pm 0.44^{\circ}$ & $2.61 \pm 0.17^{c .1}$ & $16.2+2.0^{a . b . t . r}$ & $8.74 \pm 0.44^{b, c}$ & $5.30 \pm 0.36^{r}$ \\
\hline $22: 5 n-3$ & $9.61 \pm 0.4^{\circ}$ & $8.30 \pm 0.26^{c t t}$ & $12.8 \pm 0.6^{m, b, d, d r}$ & $10.3 \pm 0.4^{b, c}$ & $9.42 \pm 0.49^{c}$ \\
\hline $22: 6 n-3$ & $68.0 \pm 2.8^{\circ}$ & $71.6 \pm 2.4^{\circ}$ & $108.9 \pm 4.7^{a, b, d . t r}$ & $74.6 \pm 2.3^{c}$ & $75.8 \pm 3.6^{\circ}$ \\
\hline n-3 LCPs & $86.4 \pm 3.5^{\circ}$ & $84.0 \pm 2.7^{\circ}$ & $142.5 \pm 6.9^{a d b \cdot b l c}$ & $96.5 \pm 2.9^{\circ}$ & $93.3 \pm 4.0^{r}$ \\
\hline$n-3$ & $90.3 \pm 3.6^{\circ}$ & $85.8 \pm 2.7^{\circ}$ & $149.6 \pm 7.0^{\text {a.b.d. }}$ & $100.8 \pm 3.0^{\circ}$ & $96.6 \pm 4.2^{c}$ \\
\hline $20: 3 n-9$ & $3.19 \pm 0.22$ c.d & $3.49 \pm 0.16^{\circ}$ & $4.81 \pm 0.29^{a . b}$ & $4.22 \pm 0.18$ & $3.62 \pm 0.22$ \\
\hline$n-7+n-9$ & $228.9 \pm 6.5 \%$ & $273.5 \pm 7.1^{a, c}$ & $316.2 \pm 9.5^{a, b, d c_{c}}$ & $262.7 \pm 6.3^{r}$ & $253.5 \pm 10.4^{\circ}$ \\
\hline SAFA & $807.3 \pm 23.5^{b, c}$ & $938.7 \pm 20.4^{a . d}$ & $938.3 \pm 24.6^{a, d}$ & $800.7 \pm 17.3^{b, c}$ & $831.9 \pm 25.3$ \\
\hline MUFA & $225.4 \pm 6.4^{b}$ & $269.5 \pm 7.0^{a, c}$ & $311.0 \pm 9.3^{a, b, b l d c}$ & $258.0 \pm 6.1^{\circ}$ & $249.5 \pm 10.3^{r}$ \\
\hline EFA index & $3.06 \pm 0.05^{c . d}$ & $3.11 \pm 0.06^{c, t}$ & $2.54 \pm 0.05^{u, b, r}$ & $2.66 \pm 0.05^{u, b . c}$ & $3.00 \pm 0.08^{c . d}$ \\
\hline DHADI & $1.38 \pm 0.04^{\prime \prime}$ & $1.69 \pm 0.05^{a, c . d t}$ & $1.5 \pm 0.04^{b}$ & $1.31 \pm 0.04^{b}$ & $1.47 \pm 0.06$ \\
\hline DHASI & $8.29 \pm 0.50^{b . c}$ & $3.83 \pm 0.21$ u.c.t & $15.5 \pm 1.5^{a, b, d, r}$ & $10.4 \pm 0.6^{b . c}$ & $8.11 \pm 0.60^{\circ}$ \\
\hline
\end{tabular}

See Table 2 for legend.

\section{Maternal fatty acid composition}

Early pregnancy

It appeared that the mean gestational age at which the blood samples were taken in early pregnancy differed between the five groups (10.2 to 14.1 weeks of gestation). Therefore, in the comparative analysis the gestational age in early pregnancy of each participant was adjusted at 14 weeks with multiple regression analysis. In early pregnancy, significant differences were observed between the centers for most of the fatty acids (Table 2). The absolute amounts of 20:4n-6, 22:4n-6, 22:5n-6 and the n-6 LCPs were significantly higher $(\mathrm{P}<0.0001)$ in the Hungarians as compared to the other women. No significant differences were found in the absolute amounts of n-6 fatty acids between the Dutch, English, and the Ecuadorian mothers. The concentrations of the n-3 fatty acids were highest in the Finnish samples and lowest in the Hungarian samples. Comparable amounts of these fatty acids were observed between the Dutch and Ecuadorian mothers, except for 18:3n-3 and 20:5n-3. 

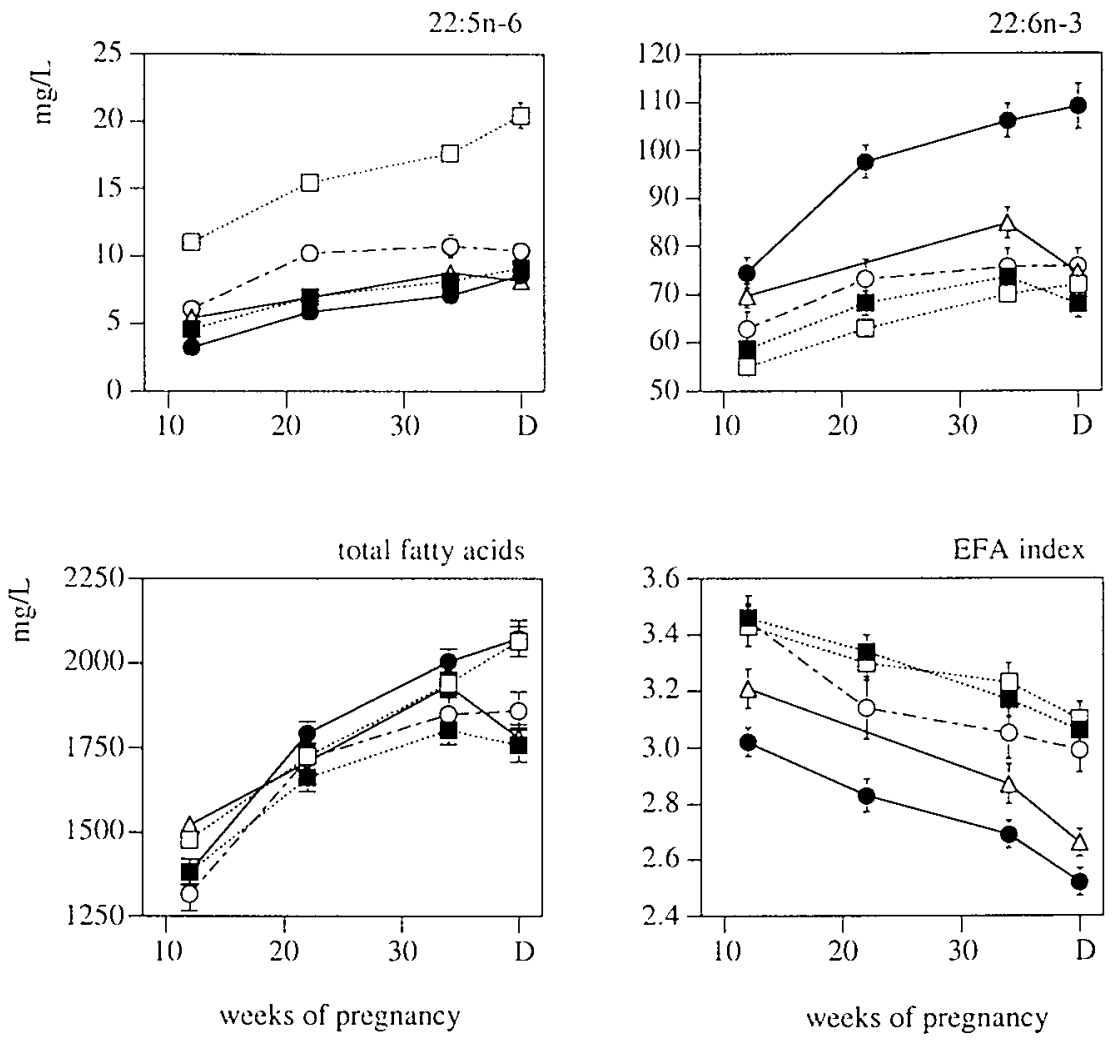

............... Netherlands ................ Hungary $\longrightarrow$ Finland

$\triangle \quad$ England $\quad-\cdot---$ Ecuador

Figure 1. Absolute amounts (mg/L) of $22: 5 n-6.22: 6 n-3$ and the total fatty acids, and the EFA index [sum n$3+n-6$ fatty acids $/ /$ s sum $n-7+n-9$ fatty acids $]$ in maternal plasma phospholipids during pregnancy and shortly after delivery. $D$, delivery.

The results for the relative fatty acid values $(\% \mathrm{wt} / \mathrm{wt})$ were largely comparable with that observed for the absolute amounts. Except for 18:2n-6 and 20:3n-6, the n-6 fatty acids levels were highest $(\mathrm{P}<0.0001)$ in the Hungarian mothers. No significant differences were observed between the centers for the percentages of $18: 2 n-6$. The relative levels of the $n-3$ fatty acids were highest $(\mathrm{P}<0.0001)$ in the Finnish mothers. 

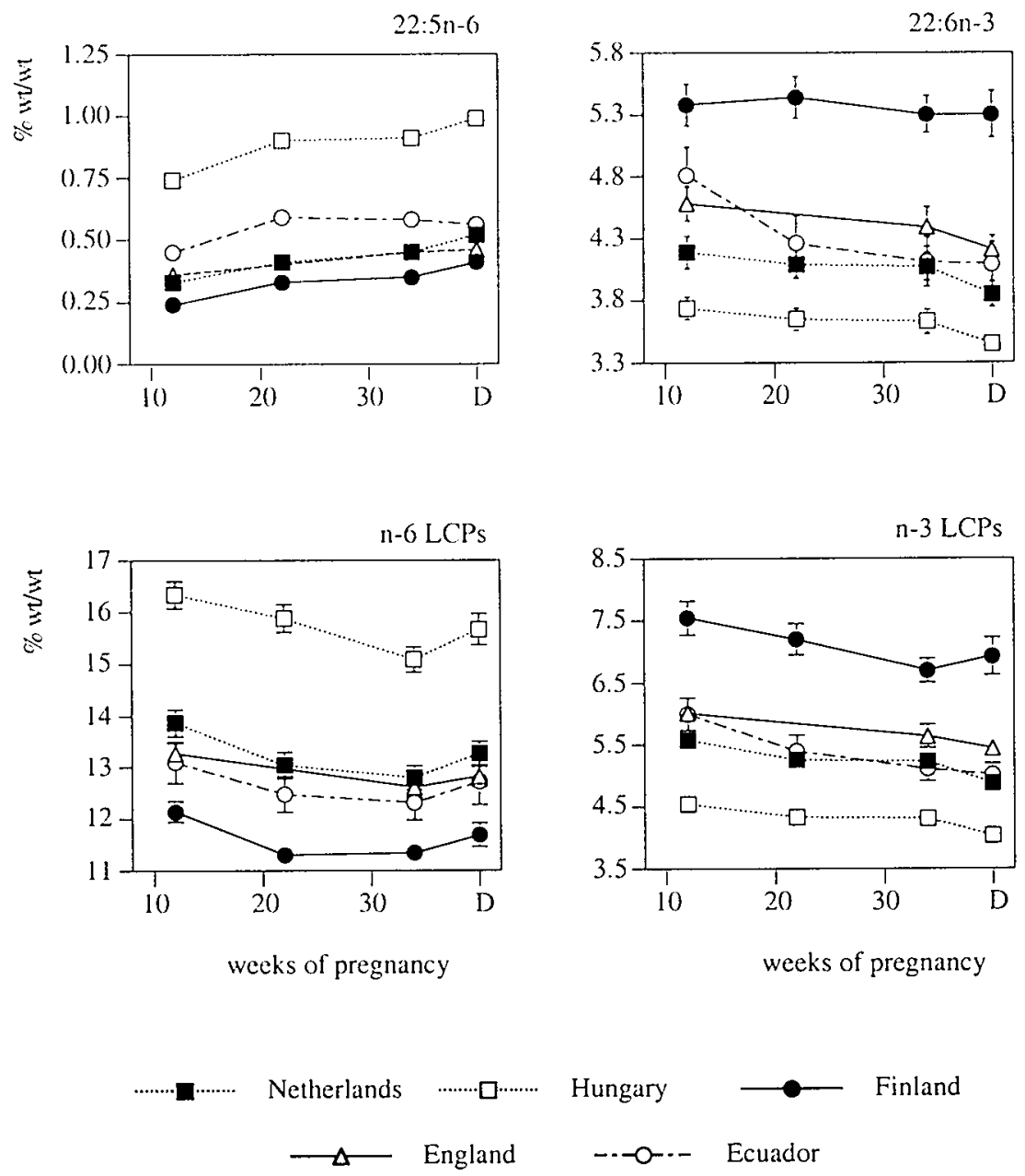

Figure 2. Percentages ( $\% w t / w t)$ of $22: 5 n-6,22: 6 n-3$, the $n-6$ long-chain polyenes (LCPs), the $n-3$ LCPs during pregnancy and shortly after delivery. $D$, delivery.

\section{During pregnancy}

In all centers the total fatty acid amounts in maternal venous plasma phospholipids increased during pregnancy at about the same rate and showed similar courses (Figure 1). The absolute amounts of all the fatty acids considered increased during pregnancy. The changes in the amounts of these fatty acids were quite similar for the women in the five countries; no significant differences were found between the slopes, except for $22: 5 n-6$ and 22:6n-3 (Figure 1), and 22:4n-6 (not shown). The rate at which 22:4n-6 and 22:5n-6 increased in the Hungarian group was significantly higher $(\mathrm{P}<0.0001)$ as compared to the 
Dutch, Finnish and English group, whereas the amounts of 22:6n-3 increased more rapidly in the Finnish mothers.

When expressed as percentages of total fatty acids (\% wt/wt), almost all the essential fatty acids slightly declined during pregnancy. However, the levels of 18:2n-6 and 22:4n-6 hardly changed. The differences between the centers observed for the percentages of $n-3$ and $n-6$ fatty acid in early gestation largely persisted throughout pregnancy (Figure 2). The patterns for the changes over time of these fatty acids were grossly comparable between the different populations, with the exception of n-6 LCP (Figure 2), which decreased at significantly $(\mathrm{P}<0.001)$ higher rates in the Hungarian mothers in comparison with the Finnish mothers.

The DHA deficiency index (DHADI: 22:5n-6/22:4n-6) increased in all centers during gestation (Figure 3). In early pregnancy, the level of this index was significantly higher $(\mathrm{P}<0.0001)$ in the Hungarian women and accompanied by the lowest DHA sufficiency index (DHASI: 22:6n-3/22:5n-6) as compared to the Dutch, Finnish and English women $(\mathrm{P}<0.0001)$. The Finnish DHASI levels were the highest (Figure 3), whereas the Hungarian DHASI hardly changed throughout pregnancy. The EFA index $[(n-3+n-6) /(n-7+n-9)]$ declined continuously in all countries (Figure 1).

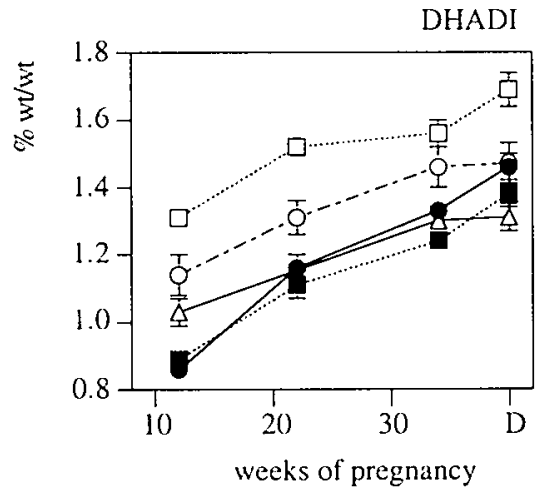

............. Netherlands $\quad \ldots \ldots \ldots . . \cdot \square \cdots \cdots . . . \quad$ Hungary
DHASI

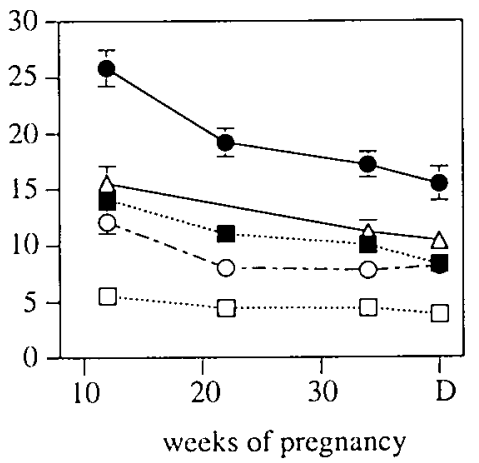

$\longrightarrow$ Finland

\section{$\triangle \quad$ England $\quad---\cdots-$ Ecuador}

Figure 3. The ratios 22:5n-6/22:4n-6 (DHADI, docosahexaenoic acid deficiency index) and 22:5n-6/22:6n-3 (DHASI, docosahexacnoic acid sufficiency index) in maternal plasma phospholipids during pregnancy and shortly after delivery. D. delivery. 
Afier delivery

The absolute amounts and the percentages of $20: 4 n-6,22: 4 n-6,22: 5 n-6$ and the $n-6$ LCPS in maternal plasma phospholipids of the Hungarian mothers were significantly higher $(\mathrm{P}<0.0001)$ as compared to the others after delivery (Table 3, Figure 2).

The differences observed between the groups in the percentages of the n-3 fatty acids did not change after delivery. These fatty acids were still highest in the Finnish mothers, whereas comparable levels were found in the Dutch, English and Ecuadorian mothers. The relatively low n-3 status of the Hungarian women was also observed after delivery (Table 3 , Figure 2).

\section{Neonatal fatty acid composition}

\section{Umbilical venous plasma}

Table 4 shows the fatty acid composition $(\mathrm{mg} / \mathrm{L})$ of the phospholipids isolated from umbilical venous plasma. The mean total fatty acid amounts were significantly higher in Hungarian $(P<0.0001)$ and the English $(P<0.001)$ neonates compared to the Finnish and Dutch neonates. The differences observed between the countries for the amounts of the n- 6 fatty acids generally reflected the differences found in maternal plasma shortly after delivery. Thus, almost all the fatty acids of the n- 6 family were higher in the Hungarian neonates as compared to the others. The amounts of the n-6 LCPs were lowest in the Finnish newborns, except for $20: 3 n-6$. These observations also applied to the percentages of the n- 6 fatty acids.

In contrast to the maternal plasma values, the absolute amounts of $n-3$ fatty acids in umbilical plasma phospholipids were highest in the English neonatal samples. Except for $20: 5 n-3$, the $n-3$ LCPs were significantly higher in the English samples $(P<0.001)$ as compared to the Dutch, Hungarian and Ecuadorian samples. On the other hand, the relative levels of the $n-3$ fatty acids were highest in the Finnish neonates as compared to the neonates from the four other countries. This latter observation is quite similar to the results of the relative levels of the maternal $n-3$ fatty acids after delivery.

\section{Umbilical veins}

The fatty acid composition ( $\mathrm{mg} / \mathrm{L}$ ) of the venous vessel wall phospholipids is shown in Table 5. Analysis of variance revealed that between the five groups significant differences existed for both the absolute amounts and the relative levels of almost individual fatty acids. The concentrations of the n- 6 LCPs were lower in the Dutch neonates, but expressed as percentages, the levels of $20: 4 n-6$ and 22:4n-6, were significantly higher $(P<0.001)$ in the Dutch neonates than the neonates from the Finland, England and Ecuador.

The concentrations of $n-3$ fatty acids in the vein were quite variable in the different countries. Except for 20:5n-3, these fatty acids were higher in the Finnish neonates as compared to the others. The percentages of the n-3 fatty acids were also highest in the Finnish infants. The absolute amounts and relative levels of 20:3n-9 were lowest in the Dutch neonates and highest in Finnish and Ecuadorian infants. In addition, the 
Table 4. Umbilical plasma phospholipid fatty acid composition '.

\begin{tabular}{|c|c|c|c|c|c|}
\hline $\begin{array}{l}\text { Fatty acids? } \\
\mathrm{mg} / \mathrm{L}\end{array}$ & $\begin{array}{c}\text { Netherlands } \\
n=50\end{array}$ & $\begin{array}{c}\text { Hungary } \\
n=50\end{array}$ & $\begin{array}{c}\text { Finland } \\
n=50\end{array}$ & $\begin{array}{c}\text { England } \\
n=43\end{array}$ & $\begin{array}{c}\text { Ecuador } \\
n=22\end{array}$ \\
\hline TOTAL & $571.1 \pm 15.5^{b . t}$ & $699.3 \pm 19.7^{a, r}$ & $601.7 \pm 15.0^{b, d}$ & $697.4 \pm 17.8^{a s r}$ & $627.1 \pm 32.3$ \\
\hline $18: 2 n-6^{4}$ & $41.7 \pm 1.3^{\circ}$ & $48.6 \pm 1.7$ & $42.2 \pm 1.6$ & $48.7 \pm 1.7$ & $52.3 \pm 4.2^{\prime \prime}$ \\
\hline $20: 3 n-6$ & $29.1 \pm 0.9^{d t r}$ & $33.8 \pm 1.5$ & $32.2 \pm 1.0^{d}$ & $38.5 \pm 1.4^{u, r}$ & $38.7 \pm 1.8^{\prime \prime}$ \\
\hline $20: 4 n-6$ & $97.5 \pm 3.2^{b, a t}$ & $128.0 \pm 3.7^{a, c t r}$ & $91.5 \pm 2.6^{b . d}$ & $116.1 \pm 3.3^{a, r}$ & $98.2 \pm 5.0^{b}$ \\
\hline $22: 4 n-6$ & $4.62 \pm 0.18^{i, d}$ & $6.98 \pm 0.27^{d c t d t r}$ & $3.75 \pm 0.11^{b . t}$ & $5.55 \pm 0.20^{a . b v c}$ & $4.77 \pm 0.20^{b}$ \\
\hline $22: 5 n-6$ & $4.74 \pm 0.27^{b}$ & $9.98 \pm 0.48^{a c c, d e r}$ & $4.20 \pm 0.24^{b . s t}$ & $0.18 \pm 0.39^{b . c}$ & $6.11 \pm 0.44^{\prime \prime}$ \\
\hline n- 6 LCPs & $136.0 \pm 4.14^{b . c t}$ & $178.8 \pm 5.1^{a, c, c e}$ & $131.7 \pm 3.5^{b . d}$ & $166.3 \pm 4.5$ & $147.7 \pm 6.1^{\circ}$ \\
\hline$n-6$ & $183.8 \pm 5.21^{b . t}$ & $235.2 \pm 6.7^{a . r}$ & $179.1 \pm 4.6^{b . d}$ & $222.6 \pm 6.0^{a . r}$ & $206.7 \pm 10.0$ \\
\hline $20: 5 n-3$ & $1.29 \pm 0.06$ & $0.55 \pm 0.04$ & $3.34 \pm 0.38$ & $1.71 \pm 0.11$ & $1.29 \pm 0.11$ \\
\hline $22: 5 n-3$ & $2.83 \pm 0.15$ & $2.23 \pm 0.13^{c, d}$ & $3.07 \pm 0.12^{b}$ & $3.54 \pm 0.20^{\prime}$ & $2.65 \pm 0.18$ \\
\hline $22: 6 n-3$ & $37.1 \pm 1.45^{d}$ & $36.6 \pm 1.51^{d}$ & $41.9 \pm 1.09$ & $46.1 \pm 1.6^{a b b r}$ & $35.1 \pm 1.6^{d}$ \\
\hline n-3 LCPS & $41.6 \pm 1.62^{d}$ & $39.9 \pm 1.66^{r d t}$ & $48.8 \pm 1.35^{\nu}$ & $52.0 \pm 1.8^{a b . c c}$ & $39.7 \pm 1.8^{d}$ \\
\hline$n-3$ & $41.8 \pm 1.63^{d}$ & $39.9 \pm 1.66^{c . d}$ & $49.0 \pm 1.35^{b}$ & $52.1 \pm 1.8^{a . b r}$ & $39.7 \pm 1.8$ \\
\hline $20: 3 n-9$ & $2.09 \pm 0.18^{c d}$ & $3.12 \pm 0.24$ & $3.83 \pm 0.29^{a}$ & $3.36 \pm 0.27^{a}$ & $3.26 \pm 0.44$ \\
\hline $22: 3 n-9$ & $0.13 \pm 0.03^{b . d}$ & $0.28 \pm 0.01^{\prime \prime}$ & $0.19 \pm 0.02$ & $0.29 \pm 0.02^{\prime \prime}$ & $0.20 \pm 0.02$ \\
\hline$n-7+n-9$ & $68.6 \pm 2.2^{b, c, t}$ & $88.3 \pm 2.8^{\prime \prime}$ & $84.0 \pm 2.9^{\prime \prime}$ & $91.7 \pm 2.9^{a}$ & $82.8 \pm 0.4$ \\
\hline SAFA & $273.3 \pm 7.3^{b . t}$ & $332.8 \pm 9.4^{u, c}$ & $286.4 \pm 7.2^{b . t}$ & $327.8 \pm 58.5^{u, r}$ & $288.9 \pm 14.9$ \\
\hline MUFA & $66.3 \pm 2.1^{b, c . d t}$ & $84.9 \pm 2.7^{\prime \prime}$ & $79.9 \pm 2.7^{\circ}$ & $87.9 \pm 2.8^{\circ}$ & $79.3 \pm 6.0$ \\
\hline EFA index & $3.34 \pm 0.07^{c}$ & $3.16 \pm 0.07^{\circ}$ & $2.80 \pm 0.06^{m . L}$ & $3.05 \pm 0.07$ & $3.11 \pm 0.12$ \\
\hline DHADI & $1.01 \pm 0.04^{b, r}$ & $1.43 \pm 0.04 d s, d t$ & $1.10 \pm 0.05^{b}$ & $1.10 \pm 0.05^{b}$ & $1.27 \pm 0.06^{a, b}$ \\
\hline DHASI & $9.06 \pm 0.56^{\prime \prime}$ & $3.94 \pm 0.21^{a \cdot c \cdot d t}$ & $11.7 \pm 0.8^{\text {b.d.e }}$ & $8.71 \pm 0.63^{b s c}$ & $0.17 \pm 0.41^{\circ}$ \\
\hline
\end{tabular}

See Table 2 for legend.

concentration of $22: 3 n-9$, the elongation product of $20: 3 n-9$, was highest in the Ecuadorian veins as compared to the others, but differed significantly $(\mathrm{P}<0.0001)$ from the Dutch samples only. The EFA index was highest in the Dutch infants, whereas the DHASI levels were highest $(\mathrm{P}<0.0001)$ in the Finnish infants.

\section{Umbilical arteries}

Analyses of the total fatty acids of the umbilical arterial vessel wall phospholipids showed significantly lower amounts in the Hungarian and the Dutch neonates as compared to the other infants $(P<0.0001$, Table 6$)$. Significant differences were also found between the countries for the absolute amounts of the EFA. Except for 22:5n-6, the percentages of the arterial $n-6$ fatty acid were higher in the Dutch neonates as compared to the others. It is apparent from the data of the arterial vessel walls, that, again, the Finnish newborns had the 
Table 5. Fatty acid composition of umbilical vein vessel wall phospholipids ${ }^{1}$.

\begin{tabular}{|c|c|c|c|c|c|}
\hline $\begin{array}{l}\text { Fatty acids } 2 \\
\text { mg/kg dry } \\
\text { weight }\end{array}$ & $\begin{array}{l}\text { Netherlinds } \\
n=50\end{array}$ & $\begin{array}{c}\text { Hungary } \\
n=47\end{array}$ & $\begin{array}{l}\text { Finland } \\
n=51\end{array}$ & $\begin{array}{l}\text { England } \\
\qquad n=56\end{array}$ & $\begin{array}{c}\text { Ecuador } \\
n=22\end{array}$ \\
\hline TOTAL. & $14717 \pm 463^{r d t r}$ & $16685 \pm 276^{\prime \prime}$ & $18378 \pm 453^{\prime \prime}$ & $20027 \pm 444^{k . b}$ & $19801 \pm 1626^{a}$ \\
\hline $18: 2 n-6$ & $267.2 \pm 10.8$ & $263.2 \pm 10.4$ & $283.3 \pm 11.4$ & $324.7 \pm 11.1^{\circ}$ & $334.3 \pm 33.6$ \\
\hline $20: 3 n-6$ & $273.0 \pm 11.7$ & $299.6 \pm 9.7^{\circ}$ & $348.4 \pm 12.6^{\prime \prime}$ & $350.0 \pm 12.5^{a}$ & $386.8 \pm 33.2^{a . b}$ \\
\hline $20: 4 n-6$ & $2645 \pm 80 d \cdot$ & $2957 \pm 59$ & $3055 \pm 84$ & $3268 \pm 89^{\prime \prime}$ & $3262 \pm 237^{a}$ \\
\hline $22: 411-6^{3}$ & $746.4 \pm 24.3^{d}$ & $837.1 \pm 20.0$ & $809.7 \pm 27.7$ & $923.1 \pm 30.8^{a}$ & $827.0 \pm 62.1$ \\
\hline $22: 5 n-6$ & $390.2 \pm 20.2^{b, d, e}$ & $547.5 \pm 16.8^{a, c}$ & $423.6 \pm 16.9^{\prime \prime c}$ & $505.4 \pm 17.3^{a}$ & $560.2 \pm 65.9^{a, r}$ \\
\hline n-6LCPs & $4055 \pm 122^{d t}$ & $4641 \pm 87$ & $4637 \pm 120$ & $5047 \pm 131^{\prime \prime}$ & $5036 \pm 384$ \\
\hline$n-6$ & $4496 \pm 133^{d r}$ & $5090 \pm 98$ & $5088 \pm 131$ & $5578 \pm 145^{\prime \prime}$ & $5580 \pm 431^{a}$ \\
\hline $20: 5 n-3$ & $1.42 \pm 0.26^{i, r}$ & $1.40 \pm 1.25^{c r}$ & $6.46 \pm 1.40^{\text {a.b.d }}$ & $0.66 \pm 0.41$ & $10.4 \pm 1.5^{a, b, d}$ \\
\hline $22: 5 n-3$ & $45.0 \pm 2.2^{b . r}$ & $26.9 \pm 1.7^{a, c, d}$ & $65.1 \pm 4.4^{a . b \cdot c}$ & $55.3 \pm 3.5^{b}$ & $43.8 \pm 3.6^{r}$ \\
\hline $22: 6 n-3$ & $759.6 \pm 28.7^{c, d}$ & $680.9 \pm 17.3^{c . t}$ & $1056 \pm 39^{a, b}$ & $966.8 \pm 33.6^{a . b}$ & $881.3 \pm 69.7$ \\
\hline n-3 LCPS & $810.1 \pm 29.9$ & $.712 .8 \pm 18.5$ cat & $1135 \pm 43^{a . b}$ & $1027 \pm 35^{a . b}$ & $943.1 \pm 72.5^{6}$ \\
\hline$n-3$ & $810.1 \pm 29.9^{r . t}$ & $714.8 \pm 18.5^{c d t}$ & $1136 \pm 43^{a . b}$ & $1027 \pm 35^{a, b}$ & $945.5 \pm 73.3^{\circ}$ \\
\hline $20: 3 n-9$ & $54.3 \pm 4.7^{c . e}$ & $75.5 \pm 8.7$ & $103.1 \pm 7.2^{\prime}$ & $85.6 \pm 6.0$ & $115.9 \pm 20.3^{a}$ \\
\hline $22: 3 n-9$ & $49.6 \pm 3.3^{\text {s.der }}$ & $66.8 \pm 5.6^{\prime \prime}$ & $84.4 \pm 5.4^{a}$ & $105.2 \pm 7.6^{a b b}$ & $89.8 \pm 13.9^{a}$ \\
\hline$n-7+n-9$ & $2364 \pm 83^{c t d r}$ & $2742 \pm 69^{d, r}$ & $3220 \pm 93^{\prime \prime}$ & $3473 \pm 90^{a, b}$ & $3423 \pm 335^{a . b}$ \\
\hline SAFA & $7044 \pm 230^{c . t}$ & $8062 \pm 135^{\prime \prime}$ & $8711 \pm 207^{a, a l}$ & $9813 \pm 206^{a, b, c, c}$ & $8388 \pm 669^{d}$ \\
\hline MUFA & $2226 \pm 76^{c, d r}$ & $2560 \pm 60^{d}$ & $2982 \pm 83^{\prime \prime}$ & $3215 \pm 83^{a, b}$ & $3134 \pm 299^{a}$ \\
\hline EFA index & $2.28 \pm 0.03^{r, d r}$ & $2.16 \pm 0.05^{d a t}$ & $1.95 \pm 0.03^{a b b}$ & $1.93 \pm 0.04^{a . b}$ & $1.98 \pm 0.05^{a}$ \\
\hline DHADI & $0.53 \pm 0.03^{b}$ & $0.67 \pm 0.03^{u s c}$ & $0.54 \pm 0.03^{b}$ & $0.57 \pm 0.02$ & $0.68 \pm 0.04$ \\
\hline DHASI & $2.10 \pm 0.10^{b x}$ & $1.32 \pm 0.07$ ws. & $2.69 \pm 0.14^{\text {a.b.de }}$ & $1.98 \pm 0.07^{b . r}$ & $1.69 \pm 0.08^{\circ}$ \\
\hline
\end{tabular}

See Table 2 for legend.

highest $\mathrm{n}-3$ status as compared to the others, particularly as compared to the Hungarian infants, who had the lowest values. The concentrations and percentages of 20:3n-9 were significantly higher $(\mathrm{P}<0.001)$ in the Ecuadorian arterial samples as compared to the Dutch samples, which contained the lowest levels of this fatty acid. In contrast to results for the absolute amounts, no significant differences were observed between the centers for the percentages of $22: 3 n-9$ in the arteries. The DHASI levels of the Finnish infants were also significantly higher in arterial vessel wall phospholipids.

\section{Relation between maternal and neonatal EFA status}

After correction of gestational age at birth and the effect the countries, highly significant and positive correlations $(\mathrm{P}<0.001)$ were found between the relative values of the $\mathrm{n}-6$ fatty acids $(\mathrm{r}=0.35-0.61)$ and $\mathrm{n}-3$ fatty acids $(\mathrm{r}=0.39-0.48)$ in maternal and umbilical plasma in the total population $(n=210)$. This was no longer observed for each country 
Table 6. Fatty acid composition of umbilical arteries vessel wall phospholipid '

\begin{tabular}{|c|c|c|c|c|c|}
\hline $\begin{array}{l}\text { Fatty acids }{ }^{2} \\
\mathrm{mg} / \mathrm{kg} \text { dry } \\
\text { weight }\end{array}$ & $\begin{array}{l}\text { Netherlands } \\
\quad n=50\end{array}$ & $\begin{array}{c}\text { Hungary } \\
n=54\end{array}$ & $\begin{array}{c}\text { Finland } \\
n=49\end{array}$ & $\begin{array}{l}\text { England } \\
n=56\end{array}$ & $\begin{array}{c}\text { Ecuador } \\
\qquad n=26\end{array}$ \\
\hline TOTAL & $13780 \pm 454^{r d t r}$ & $14077 \pm 260$ c.der & $18817 \pm 377^{a b b}$ & $17995 \pm 349^{a, b}$ & $17090 \pm 874^{a . b}$ \\
\hline $18: 2 n-6$ & $156.5 \pm 7.2$ & $126.4 \pm 5.8$ & $167.8 \pm 7.1^{b}$ & $167.2 \pm 6.5^{b}$ & $163.6 \pm 10.0$ \\
\hline $20: 3 n-6$ & $167.5 \pm 7.2^{\prime}$ & $154.6 \pm 6.3^{r, d t r}$ & $218.3 \pm 7.0^{a . b}$ & $195.9 \pm 7.4^{b}$ & $208.0 \pm 13.3^{b}$ \\
\hline $20: 4 n-6$ & $1879 \pm 67^{\circ}$ & $1798 \pm 56^{c d t}$ & $2260 \pm 71^{u, b}$ & $2205 \pm 81^{\circ}$ & $1896 \pm 107$ \\
\hline $22: 4 n-6^{5}$ & $413.9 \pm 18.7$ & $419.7 \pm 17.8$ & $465.8 \pm 14.4$ & $467.6 \pm 19.5$ & $387.4 \pm 21.3$ \\
\hline $22: 5 n-6^{6}$ & $407.6 \pm 19.0^{\prime \prime}$ & $465.0 \pm 13.1$ & $468.5 \pm 14.1$ & $496.5 \pm 16.8^{a}$ & $495.3 \pm 41.3$ \\
\hline$n-6$ LCPS & $2868 \pm 105^{c t}$ & $2837 \pm 86^{c d t}$ & $3412 \pm 96^{a b b}$ & $3365 \pm 114^{u, b}$ & $2986 \pm 171$ \\
\hline$n-6$ & $3088 \pm 113^{c t}$ & $3026 \pm 94 c . l$ & $3647 \pm 104^{a . b}$ & $3608 \pm 121^{a, b}$ & $3220 \pm 184$ \\
\hline $20: 5 n-3$ & $1.23 \pm 0.23$ & $0.73 \pm 0.26^{\circ . r}$ & $7.99 \pm 1.36^{u, b . t d}$ & $0.33 \pm 0.23^{c . r}$ & $8.71 \pm 1.25^{a b . b d}$ \\
\hline $22: 5 n-3$ & $24.6 \pm 2.2^{c}$ & $13.7 \pm 1.0^{c . d}$ & $45.7 \pm 3.0^{a, b . d e r}$ & $29.8 \pm 2.6^{b, c}$ & $22.7 \pm 1.8^{c}$ \\
\hline $22: 6 n-3$ & $727.2 \pm 31.1^{b, r, d t}$ & $566.6 \pm 17.1^{c s, c d t}$ & $1085 \pm 38^{a, b, t, r}$ & $875.4 \pm 35.1^{a . b . c}$ & $738.8 \pm 39.0^{\circ}$ \\
\hline$n-3$ LCPS & $761.7 \pm 32.4^{b s, d}$ & $594.8 \pm 17.5^{t r, c t d r}$ & $1158 \pm 41$ d.bsdrer & $918.8 \pm 36.6^{u a b . c}$ & $794.1 \pm 40.6^{b . r}$ \\
\hline$n-3$ & $774.8 \pm 32.2^{b, c, d}$ & $613.9 \pm 17.2^{a_{c}, r d t r}$ & $1185 \pm 41^{a, b, d, e r}$ & $940.8 \pm 36.3^{a . b . r}$ & $813.6 \pm 42.4^{b, r}$ \\
\hline $20: 3 n-9$ & $364.0 \pm 19.8^{c . t h r}$ & $417.4 \pm 21.4$ & $600.7 \pm 22.6^{a . b}$ & $499.6 \pm 25.6^{a}$ & $603.1 \pm 39.6^{a, b}$ \\
\hline $22: 3 n-9$ & $189.4 \pm 8.5^{c d r e}$ & $225.7 \pm 10.0 r . r$ & $290.6 \pm 10.6^{a . b}$ & $269.5 \pm 12.24$ & $294.1 \pm 20.9^{a . b}$ \\
\hline$n-7+n-9$ & $3243 \pm 119$ ade & $3555 \pm 107$ & $4773 \pm 114^{a, b}$ & $4408 \pm 113^{a b b}$ & $4540 \pm 254^{a . b}$ \\
\hline SAFA & $6669 \pm 220$ & $6772 \pm 135^{r, d t}$ & $8864 \pm 169^{a, b, e}$ & $8868 \pm 164^{\text {a.b.r }}$ & $7128 \pm 316^{r . d}$ \\
\hline MUFA & $2659 \pm 96^{t \cdot d, c^{c}}$ & $2875 \pm 79^{r a t r}$ & $3842 \pm 87^{a . b}$ & $3588 \pm 84^{a, b}$ & $3585 \pm 198^{a . b}$ \\
\hline EFA index & $1.23 \pm 0.04^{r}$ & $1.08 \pm 0.05$ & $1.03 \pm 0.03$ & $1.07 \pm 0.05$ & $0.91 \pm 0.04^{\prime \prime}$ \\
\hline DHADI & $1.03 \pm 0.04^{\circ}$ & $1.15 \pm 0.04$ & $1.03 \pm 0.04^{\circ}$ & $1.10 \pm 0.04$ & $1.31 \pm 0.09^{a r}$ \\
\hline DHASI & $1.86 \pm 0.07^{b . r}$ & $1.26 \pm 0.05^{\text {a.c.d }}$ & $2.58 \pm 0.19^{a, b . d, e}$ & $1.79 \pm 0.06^{b, r}$ & $1.56 \pm 0.06^{\circ}$ \\
\hline
\end{tabular}

${ }^{5} \mathrm{NS},{ }^{6} \mathrm{P}<0.01$ and see Table 2 for legend.

individually; in the Ecuadorian and the English group only the relative values of $20: 4 n-6$ in maternal and umbilical plasma correlated significantly $(r=0.72, P<0.001$ and $r=0.51$, $\mathrm{P}<0.005$, respectively).

No significant correlations were observed between maternal plasma and umbilical vessel wall relative values for any of the $n-6$ fatty acids, neither in the total population nor in each country individually. This was in striking contrast to the percentages of the $n-3$ fatty acids for which highly significant and positive correlations were found between maternal and neonatal values in the Dutch group $(r=0.40-0.53, P<0.01)$, the Hungarian group $(r=0.46-$ $0.60, \mathrm{P}<0.005)$ and the Finnish group $(r=0.51-0.67, \mathrm{P}<0.001)$. In the English group, only between maternal plasma and umbilical artery were significant correlations found for the percentages of $22: 6 n-3(r=0.38, P<0.01)$ and $n-3$ LCP $(r=0.37, P<0.01)$ groups. When the 
regression coefficients of the above equations were analyzed, it was found that the amount by which the neonatal n-3 fatty acids increased in response to an increase of the maternal plasma n-3 fatty acids was highest in the Hungarian population (in both umbilical plasma and vessel walls). Morcover, only the regression coefficients of n-3 LCPs (between maternal and umbilical plasma) differed significantly between the centers $(\mathrm{P}<0.01, \mathrm{~F}$-test).

\section{DISCUSSION}

In this study, the EFA status of Dutch, Hungarian, Finnish, English and Ecuadorian mothers during pregnancy and shortly after delivery was compared, together with the EFA status of their neonates. Significant differences were found in the maternal EFA status during pregnancy between the groups. In the Hungarian mothers, for instance, the highest absolute and relative amounts are found of the n- 6 fatty acids. This particularly applied to 20:4n-6, 22:4n-6, 22:5n-6 and n-6 LCPs (Tables 2 and 3). A possible explanation for the high $n-6$ LCPs levels in the plasma phospholipids of the Hungarian mothers may be a high metabolic conversion of the parent $n-6$ fatty acid, $18: 2 n-6$. The (n-6)-metabolic index $[(n-6$ LCPs+18:3n-6)/18:2n-6], which gives an impression of the overall desaturation and elongation of the 18:2n-6, appeared to be significantly higher in the Hungarian mothers $(0.81 \pm 0.03)$ in comparison with the others $(0.61 \pm 0.03-0.68 \pm 0.02)$.

The highest n- 6 status in the Hungarian mothers as compared to the other mothers is associated with the lowest n-3 status, both during pregnancy as well as after delivery. Since both EFA families compete for the same desaturation- and elongation enzymes (18) the high n- 6 LCP status of the Hungarian mothers may be secondary to their low n- 3 status. In addition, the amount of the parent n-3 fatty acid, 18:3n-3, was lowest in the Hungarian group (Tables 2 and 3 ). Since this fatty acid has to be derived from the diet, this finding might indicate a low intake of $18: 3 n-3$ by the Hungarians.

Interestingly, amongst the Finnish mothers the opposite is observed for the relation between n-6 and n-3 fatty acids: their n-3 status is the highest and their n- 6 status the lowest. This may be due to a rather high consumption of green vegetables (relatively rich in 18:3n-3) and fish (relatively rich in n-3 LCPs) by the Finnish mothers. The situation amongst the Finnish women is similar to that of pregnant Danish women after supplementation with fish oil: this treatment resulted in an increase of the $n-3$ fatty acid levels at the expense of the n- 6 fatty acids (19). The mean daily intake of fish reported for Finnish women, $34 \mathrm{~g}(20)$ is higher compared to that of the average Dutch pregnant women,

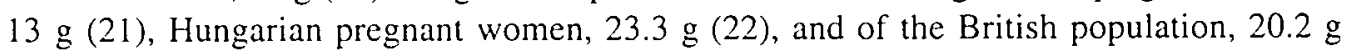
(23).

Plasma of Ecuadorian mothers contained the highest relative amounts of $18: 2 n-6$ and $20: 3 n-6$. However, the percentages of $20: 4 n-6$ were rather low and the ratio between $20: 4 n-$ 6 and its precursor $20: 3 n-6,20: 3 n-6 / 20: 4 n-6)$, particularly shortly after delivery, appeared significantly higher for the Ecuadorian $(0.56 \pm 0.04)$ as compared to the other mothers $(0.36$ 
$\pm 0.01-0.47 \pm 0.02$ ). This finding, also observed in the neonatal samples, might indicate a relatively low activity of the $\Delta 5$-desaturase, which may be related to the mixed Indian/Caucasian descent of the Ecuadorian participants. A low $\Delta 5$-desaturase activity has been suggested to exist amongst American Indians and amongst -genetically relatedGreenland Eskimos and Canadian Inuit $(14,24,25)$.

Results from pre-and postnatal analysis of fetal plasma phospholipids showed that 22:6n-3 levels increase during pregnancy $(26,27)$. Gestational age at birth, therefore, largely determines the neonate's 22:6n-3 status. In our study, all the neonates were born at term, suggesting that all these neonates had similar periods to obtain their necessary $22: 6 \mathrm{n}$ 3. Therefore, the significant differences observed between the neonates in the $22: 6 n-3$ levels cannot be due to their gestational age.

The differences between the groups as observed for the various maternal EFAs immediately after delivery, are only partly reflected in the neonates. Although the developing fetus depends on the mother for its EFA supply, this may indicate a certain degree of 'autonomy' of the fetus with respect to the establishment of its EFA status, independent from the maternal EFA status. This autonomy seems less pronounced for the n3 fatty acids: all relative and most absolute neonatal values are highest in the Finnish neonates and lowest in the Hungarian infants, as is the case for their mothers. Moreover, the strong positive relationship between maternal and neonatal n-3 values within each participating group supports a relatively low degree of autonomy of the fetus with respect to the establishment of its n-3 status which, therefore, seems strongly dependent on the maternal n-3 intake during pregnancy. The neonatal values for the $n-6$ fatty acids in umbilical vessel wall phospholipids were not significantly related to the maternal plasma values, whereas the relationships between maternal and umbilical plasma phospholipids were significant in few cases only. This suggests a relatively higher degree of autonomy of the developing fetus with respect to the establishment of its n- 6 status, which would imply that the fetal n-6 status is less strictly related to the maternal n- 6 intake than is the case for the $n-3$ fatty acids. This has been observed in an earlier study (8) and is possibly explained by the fact that the maternal diet usually contains much more n- 6 than $n-3$ fatty acids. Furthermore, the average increase in the percentages of the neonatal n-3 fatty acids that accompanies an increase in the maternal $n-3$ fatty acids was shown to be highest in the population with the lowest maternal $n-3$ status (Hungary). This indicates that in case of low maternal n-3 levels, every additional n-3 fatty acids in the maternal blood circulation preferentially goes to the fetus.

Although large differences were observed between the groups with respect to the various maternal EFAs and EFA status parameters during pregnancy and after delivery, most of these variables followed comparable courses during pregnancy in the five participating populations Figures 1-3). It seems, therefore, that the reduction in the maternal EFA status during pregnancy is a general phenomenon, and is largely independent of differences between the populations in dietary habits and ethnic origin. Moreover, since the lowest values for certain maternal EFAs or EFA status parameters during pregnancy and after 
delivery in a given group were often higher than the highest values in some other group(s) throughout pregnancy, the functional implications of the pregnancy-associated reduction in the maternal EFA status for fetal and neonatal development are not obvious and need further study.

\section{ACKNOWLEDGEMENT}

The authors wish to thank all the mothers and their neonates who participated in this study and are grateful to Andrea Regöly-Mérei, Arnold Kester (statistician), Vera Földes, Marianne Simonis and Hasibe Aydeniz (technicians) for their assistance. The cooperation of Hajnalka Varsány (obstetrician) and the other medical and nursing personell of the Departments of Obstetrics involved in this study are greatly appreciated.

Supported by a grant from Nutricia Research, Zoetermeer, the Netherlands.

\section{REFERENCES}

1. Gabr M. Malnutrition during pregnancy and lactation. World Rev Nutr Diet 1981:36:90-9.

2. Doyle W. Crawford MA. Laurance BM. Drury P. Dietary survey during pregnancy in a low socioeconomic group. Hum Nutr Appl Nutr 1982;36:95-106.

3. Crawford MA. Doyle W. Drury P, Lennon A. Costeloe K. Leighfield M. n-6 and n-3 fatty acids during early human development. J Intern Med Suppl 1989:225:159-69.

4. Clandinin MT, Chappell JE. Leong S. Heim T. Swyer PR, Chance GW. Intrauterine fatty acid accretion rates in human brain: implications for fatty acid requirements. Early Hum Dev 1980;4:121-9.

5. Imis SM. Essential fatty acids in growth and development. Prog Lipid Res 1991;30:39-103.

6. Martinez M. Tissue levels of polyunsaturated fatty acids during early human development. J Pediatr 1992; 120:S129-38.

7. Uauy R. Birch E. Birch D, Peirano P. Visual and brain function measurements in studies of n-3 fatty acid requirements of infants. J Pediatr 1992;120:S168-80.

8. Al MD. Houwelingen ACV. Kester AD. Hasaart TH, de Jong AE. Hornstra G. Maternal essential fatty acid patterns during normal pregnancy and their relationship to the neonatal essential fatty acid status. $\mathrm{Br}$ J Nutr 1995:74:55-68.

9. Folch J. Sloane Stanley GH. A simple method for the isolation and purification of total lipides from animal tissues. J Biol Chem 1957;226:497-509.

10. Hoving EB, Jansen G. Volmer M. Van Doormaal JJ, Muskiet FA. Profiling of plasma cholesterol ester and triglyceride fatty acids as their methyl esters by capillary gas chromatography, preceded by a rapid aminopropyl-silica column chromatographic separation of lipid classes. J Chromatogr 1988;434:395409. 
11. Kaluzny MA. Duncan LA. Merritu MV. Epps DE. Rapid separation of lipid classes in high yield and purity using bonded phase columns. J Lipid Res 1985:26:135-40.

12. Morrison WR. Smith LM. Preparation of fatty acid methyl esters and dimethylacetals from lipids with boron fluoride-methanol. J Lipid Res 1904:5:000-8.

13. Bligh E. Dyer WJ. A rapid method for total lipid extraction and purification. Can J Biochem Physiol 1959:37:911-7.

14. Hornstra G. Al MD, Gerrard JM. Simonis MM. Essential fatty acid status of neonates born to Inuit mothers: comparison with Caucasian neonates and effect of diet. Prostaglandins Leukot Essent Fatty Acids 1992;45:125-30.

15. Holman R'T. Control of polyunsaturated acids in tissue lipids. J Am Coll Nutr 1986:5:183-211.

16. Neuringer M. Connor WE. L.in DS, Barstad L. Luck S. Biochemical and functional effects of prenatal and postnatal omega 3 fatly acid deficiency on retina and brain in rhesus monkeys. Proc Natl Acad Sci U S A 1986;83:4021-5.

17. Hoffman DR. Uauy R. Essentiality of dietary omega 3 fatty acids for premature infants: plasma and red blood cell fatly acid composition. Lipids 1992;27:886-95.

18. Uauy R. Treen M. Hoffman DR. Essential fatty acid metabolism and requirements during development. Semin Perinatol 1989:13:118-30.

19. Houwelingen ACv. Sorensen JD. Hornstra G, Simonis MM. Boris J, Olsen SF. Secher NJ. Essential fatty acid status in neonates after fish-oil supplementation during late pregnancy. Br J Nutr 1995;74:723-31.

20. Kleemola P. Virtanen M. Pietinen P. The 1992 Dictary Survey of Finnish Adults. Publications of the National Health Institute, B2: Helsinki:1994.

21. Ministry of Welfare. Health and Cultural Affairs. Ministry of Agriculture, Nature Management and Fisheries. The Dutch National Food Consumption Survey 1992. the Hague, the Netherlands: Voorlichtingbureau voor de Voeding. 1993.

22. Antal M, Regoly Merei A. Varsanyi H, Biro L, Sagi K, Molnar DV, Zajkas G, Nagy K, Avar Z. Biro G. Nutritional survey of pregnant women in Hungary. Int J Vitam Nutr Res 1997:67:115-22.

23. Ministry of Agriculture. Fisheries and Food. National Food Survey 1992: Annual Report on the Household Food Consumption and Expenditure. London: HMSO. 1993.

24. Bates C. van Dam C. Horrobin DF. Morse N. Huang YS, Manku MS. Plasma essential fatty acids in pure and mixed race American Indians on and off a diet exceptionally rich in salmon. Prostaglandins Lecukot Med 1985:17:77-84.

25. Horrobin DF. Low prevalences of coronary heart disease (CHD). psoriasis, asthma and rheumatoid arthritis in Eskimos: are they caused by high dietary intake of eicosapentaenoic acid (EPA), a genetic variation of essential fatty acid (EFA) metabolism or a combination of both? Med Hypotheses 1987:22:421-8.

26. Friedman Z. Danon A. Lamberth EL. Jr. Mann WJ. Cord blood fatty acid composition in infants and in their mothers during the third trimester. J Pediatr 1978;92:461-6.

27. Houwelingen ACv, Foreman-van Drongelen MM. Nicolini U. Nicolaides KH, Al MD, Kester AD. Hornstra G. Essential fatty acid status of fetal plasma phospholipids: similar to postnatal values obtained at comparable gestational ages. Early Hum Dev 1996:46:141-52. 


\title{
Chapter 4
}

\section{Effects of pregnancy-induced hypertension on the essential fatty acid statuses of Ecuadorian and Dutch women}

Suzie J. Otto , Adriana C. van Houwelingen, Patricio López-Jaramillo, Gerard Hornstra

Based on American Journal of Obstetrics and Gynecology 1999;180:1185-1190.

\begin{abstract}
In Dutch Caucasian women, pregnancy-induced hypertension (PIH) was shown to be associated with elevated levels of the long-chain polyenes (LCPs) of $18: 2 n-6$ and $18: 3 n-3$ in combination with reduced levels of those 'parent' essential fatty acids. This observation suggested an enhanced desaturation and elongation of the latter. The present study was performed to investigate whether this phenomenon also occurs under completely different nutritional and geographical conditions.

Plasma fatty acids of primiparous Ecuadorian Mestizo women with normal and PIH pregnancies were assessed at delivery and compared with similar data from Dutch Caucasian women. Neonatal values, as determined in umbilical plasma and umbilical vessel walls, were also compared.

In contrast to the pattern seen in Caucasian mothers, PIH did not increase the LCP status of Mestizo mothers. Despite the absence of this compensatory mechanism, the LCP status was not compromised in Mestizo neonates born after PIH. The results suggest that additional mechanisms may be active in maintaining the LCP status of neonates born after $\mathrm{PIH}$.
\end{abstract}




\section{INTRODUCTION}

There has been considerable interest in the possible role of essential fatty acids (EFAs), particularly arachidonic acid (20:4n-6), in the pathophysiology of pregnancy-induced hypertension (PIH). Arachidonic acid is the precursor of prostaglandin $\mathrm{I}_{2}$ ( $\mathrm{PGI}_{2}$; prostacyclin) and thromboxane $A_{2}\left(\mathrm{TxA}_{2}\right)$, which are involved in the control of blood pressure.

A reduced $\mathrm{PGI}_{2}$ synthesis, increased $\mathrm{TxA}$, production or both have repeatedly been observed in PIH (1-4). Studies in Canadian Inuit showed a lower PIH incidence among women consuming a diet rich in $\mathrm{n}-3$ fatly acids than among women with a relatively low $\mathrm{n}$ 3 fatty acids intake (5). This may be explained by an effect of $n-3$ fatty acids on the functional balance of $\mathrm{PGI}_{2} / \mathrm{TxA}_{2}$, because the vasodilatory effect of $\mathrm{PGI}_{3}$ is comparable to that of $\mathrm{PGI}_{2}$, whereas the vasoconstrictive influence of $\mathrm{TxA}_{3}$ is considerably less than that of $\mathrm{TxA}_{2}$ (6). Indeed, dietary supplementation with fish oil has been shown to alter the cicosanoid metabolism by favoring the synthesis of $\mathrm{PGI}_{3}$ and $\mathrm{TxA}_{3}$ in pregnant women (6).

Several investigators (7-11) have also studied the fatty acid compositions of women with PIH. Ogburn et al (7) observed slightly elevated levels of $20: 4 \mathrm{n}-6$ in serum of preeclamptic women (PIH with proteinuria). On the other hand, Craig-Schmidt et al (8) found no differences between normotensive women and women with preeclampsia or PIH. Plasma levels of the parent EFAs, linoleic acid (18:2n-6) and $\alpha$-linolenic acid (18:3n-3) were found to be lower after preeclamptic pregnancies than after normal pregnancies (9). In previous studies among Caucasian women in the Netherlands, similar results were observed at delivery for the relative amounts of $18: 2 n-6$ and 18:3n-3 after PIH $(10,11)$. This was associated with significantly higher levels of the n-6 long chain polyenes (LCPs) and docosahexaenoic acids (22:6n-3) in plasma phospholipids of the mothers with PIH compared with those of normotensive mothers. Higher concentrations of LCPs combined with lower amounts of their respective parent EFAs suggest an enhanced EFA desaturation and elongation. This may be considered a compensatory mechanism to ensure an adequate fetal LCP supply, despite placental dysfunction. This mechanism proved to be successful, because the neonatal EFA status after PIH was comparable to that of neonates born after normal uncomplicated pregnancies. To investigate whether such a mechanism also operates successfully under completely different nutritional and geographical conditions, we performed a study in an Andean Mestizo population and compared the results with Dutch data.

The EFA statuses of a group of primiparous Ecuadorian women and of their neonates after PIH were compared with normotensive primiparous pregnancies. In addition, the data from the Ecuadorian group with PIH were compared with those of a Dutch PIH group. Finally, the difference in EFA status between PIH and normotensive pregnancies in the Ecuadorian population was compared with this difference in the Dutch population. 


\section{SUBJECTS, MATERIALS AND METHODS}

\section{Subjects and sample collection}

The study comprised healthy primiparous women with normotensive pregnancies and primiparous women with PIH from a high altitude city in Ecuador and from the Netherlands. PIH was defined as a blood pressure of $\geq 140 / 90 \mathrm{mmHg}$ observed from 20 weeks of gestation on $\geq 2$ occasions with $\geq 4$ hours in between, with or without proteinuria ( $\geq$ $30 \mathrm{mg} / 100 \mathrm{~mL}$ ) (12).

The EFA statuses of the healthy normotensive primiparous women from the Netherlands and Ecuador have previously been described in an international comparative study (13). The Dutch women took part in a prospective longitudinal study concerning PIH and EFA status of mother and child, as described elsewhere (11), that included primiparous and multiparous women. In the present study only the data of the primiparous women are analyzed. The Ecuadorian mothers, both those with PIH and the normotensive mothers, attended the Hospital Gineco-Obstétrico Isidro Ayora in Quito, whereas the Dutch mothers, both normotensive and PIH groups, were recruited from three hospitals in the area of Southern Limburg, the Nerherlands, where they were receiving prenatal care. Except for their PIH, none of the women had any medical disorder (cardiovascular, renal or endocrinologic disease) during pregnancy. All mothers had singleton pregnancies. Three $(11.5 \%)$ of the Ecuadorian mothers with PIH delivered prematurely (224-239 days' gestation), compared with $6(17.6 \%)$ in the Dutch group with PIH (224-254 days' gestation).

The study design and the methods applied have been fully described previously $(11,13$, 14). Briefly, maternal venous blood samples were collected shortly after delivery together with a blood sample from the umbilical vein. A piece of the umbilical cord (about $15 \mathrm{~cm}$ ) was also collected for analysis of the arterial and venous vessel walls. Plasma was separated from the erythrocytes by centrifugation and divided over polypropylene storage cups that were tightly closed under nitrogen. The cord samples were rinsed with saline solution and packed into plastic bags which, together with the plasma samples, were stored frozen. The Ecuadorian samples were transported in dry ice to Maastricht, the Netherlands, for analysis.

The protocol of the study was approved by the local Ethics Committees and written consent was obtained from each participant.

\section{Fatty acid analyses}

The fatty acid compositions of phospholipids isolated from maternal and umbilical plasma, and from umbilical venous and arterial vessel walls were determined, as described by Al et al (14). All the analyses were done in the same laboratory.

Added 1,2- $\alpha$-dinonadecanoyl phosphatidylcholine (PC-[19:0 $]_{2}$ ) was used as an internal standard and heptadecenoic acid (17:1) served to check any carry-over of free fatty acids during the phospholipid separation procedure. Plasma total lipid extracts were prepared by a modified Folch extraction method $(15,16)$. The method of Bligh \& Dyer $(17)$ was used for umbilical vessel walls. Aminopropyl-bonded phase columns were applied to separate the 
Table 1. Clinical characteristics of the study populations!

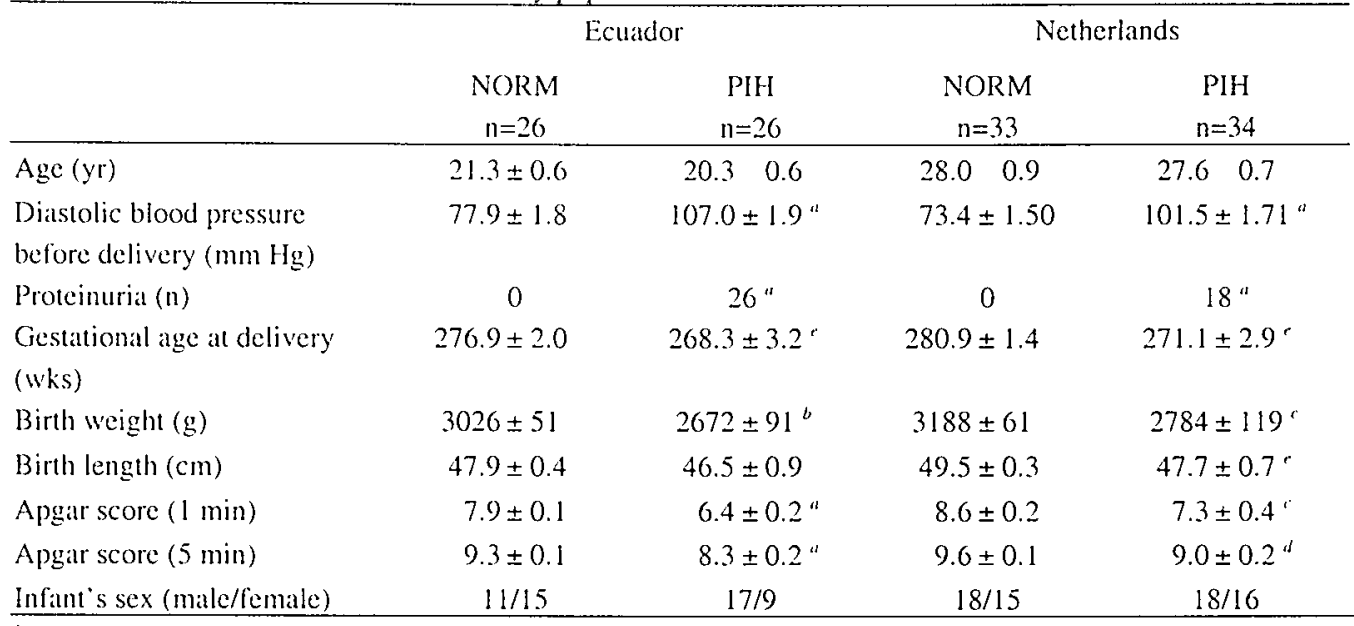

Data are mean \pm SEM. unless mention otherwise. Maternal variables: unpaired t-test; neonatal variables (birth outcome): multiple regression; proteinuria and sex variabale: $\chi 2$. PIH: pregnancy-induced hypertension: NORM: normotensive pregnancy. Variables concerning the birth outcome were all corrected for the possible effect of infant's sex.

at) PIH versus NORM (within same country) significantly different at: " $\mathrm{P}<0.0001$, $^{b} \mathrm{P}<0.001$, ${ }^{c} \mathrm{P}<0.005$, " $P<0.01$, ' $P<0.05$

phospholipids from the other lipid fractions (18). The phospholipids were hydrolyzed and the fatty acids methylated by reaction with boron trifluoride in methanol (19). The composition of the fatty acids was then determined by capillary gas chromatography using a non-polar CPSil 5 CB column (Chrompack, Middelburg, the Netherlands), with nitrogen as carrier gas.

Fatty acids were quantified by the amount of the internal standard and are expressed in absolute amounts ( $\mathrm{mg} / \mathrm{L}$ plasma or $\mathrm{mg} / \mathrm{g}$ dry tissue) or in relative levels (\% of total fatty acids, wt/wi). For the sake of clarity only a selected set of fatty acids and fatty acid indexes are reported.

\section{Statistical analyses}

Data are presented as mean \pm SEM. Differences in the clinical characteristics (continuous variables) within each country were compared by the unpaired t-test. Variables concerning birth outcome were all corrected for the possible effect of the infant's sex. The discrete variables proteinuria and infant's sex were analyzed using the Chi-square test.

Comparisons of the maternal EFA status at delivery between the normotensive mothers and the mothers with PIH were made by means of multiple regression analysis, with 
Table 2. Maternal plasma phospholipid fatty acid composition after delivery!

\begin{tabular}{|c|c|c|c|c|}
\hline \multirow[b]{2}{*}{$\begin{array}{l}\text { Fatty acids }{ }^{\prime} \\
\% \text { wht }\end{array}$} & \multicolumn{2}{|c|}{ Ecuador } & \multicolumn{2}{|c|}{ Netherlands } \\
\hline & $\begin{array}{c}\text { NORM } \\
n=26\end{array}$ & $\begin{array}{l}\mathrm{PIH} \\
\mathrm{n}=26\end{array}$ & $\begin{array}{c}\text { NORM } \\
n=33\end{array}$ & $\begin{array}{c}\mathrm{PIH} \\
\mathrm{n}=34\end{array}$ \\
\hline Total $|\mathrm{mg} / \mathrm{L}|$ & $1856 \pm 50$ & $2011 \pm 60$ & $1751 \pm 58$ & $1833 \pm 73$ \\
\hline $18: 2 n-6$ & $21.4 \pm 0.4$ & $21.7 \pm 0.4$ & $20.7 \pm 0.4$ & $18.7 \pm 0.4^{b .3}$ \\
\hline $20: 3 n-6$ & $3.99 \pm 0.13$ & $4.03 \pm 0.15$ & $3.49 \pm 0.10$ & $3.84 \pm 0.15$ \\
\hline $20: 4 n-6$ & $7.55 \pm 0.40$ & $0.81 \pm 0.23$ & $8.59 \pm 0.30$ & $8.87 \pm 0.26^{4}$ \\
\hline $22: 5 n-6$ & $0.56 \pm 0.04$ & $0.57 \pm 0.04$ & $0.49 \pm 0.03$ & $0.64 \pm 0.03^{\prime \prime}$ \\
\hline n-6 LCPs & $12.5 \pm 0.4$ & $11.8 \pm 0.3$ & $12.9 \pm 0.3$ & $13.8 \pm 0.3^{5}$ \\
\hline $18: 3 n-3$ & $0.16 \pm 0.01$ & $0.12 \pm 0.01$ & $0.23 \pm 0.02$ & $0.22 \pm 0.02^{2}$ \\
\hline $20: 5 n-3$ & $0.29 \pm 0.02$ & $0.23 \pm 0.02$ & $0.38 \pm 0.03$ & $0.32 \pm 0.02$ \\
\hline $22: 611-3$ & $4.11 \pm 0.18$ & $4.23 \pm 0.17$ & $3.86 \pm 0.12$ & $4.42 \pm 0.14^{d}$ \\
\hline$n-3$ LCPS & $5.05 \pm 0.18$ & $5.05 \pm 0.20$ & $4.92 \pm 0.15$ & $5.47 \pm 0.15^{d}$ \\
\hline SAFA & $45.6 \pm 0.2$ & $45.5 \pm 0.2$ & $46.1 \pm 0.2$ & $45.5 \pm 0.2$ \\
\hline MUFA & $13.4 \pm 0.30$ & $14.0 \pm 0.4$ & $12.9 \pm 0.2$ & $13.7 \pm 0.3$ \\
\hline (n-6)-metabolic index & $0.59 \pm 0.03$ & $0.55 \pm 0.02$ & $0.64 \pm 0.02$ & $0.75 \pm 0.03^{r .4}$ \\
\hline
\end{tabular}

\footnotetext{
'Data are mean \pm SEM. PH: pregnancy-induced hypertension; NORM: normotensive pregnancy; $n-$ 6 LCPS (long chain polyenes; 20:3n-6. 20:4n-6. 22:4n-6 and 22:5n-6); n-3 LCPs: (20:4n-3, 20:5n-3, 22:5n-3 and 22:6n-3); SAFA: sum of all saturated fatty acids; MUFA: sum of all monounsatusrated fatty acids; (n-6)-metabolic index: n-6 LCPs/18:2n-6.

"، $\mathrm{PIH}$ versus NORM (within country) significantly different: " $\mathrm{P}<0.001$, " $\mathrm{P}<0.005$, $\mathrm{P}<0.01$.

"P $\mathrm{P}<0.05$.

${ }^{2.5}$ Two PIH groups significantly different among countries: ${ }^{2} \mathrm{P}<0.0001,{ }^{3} \mathrm{P}<0.005,{ }^{4} \mathrm{P}<0.01$, ${ }^{5} \mathrm{P}<0.05$.
}

corrections for maternal age and gestational length as confounding factors. The same analysis was used to compare the Ecuadorian and the Dutch group with PIH.

The fatty acid compositions of phospholipids isolated from umbilical venous plasma and venous and arterial cord vessel walls were studied in a similar way, with addition of the variable infant's sex' to the regression model. P-values $<0.05$ were considered significant.

\section{RESULTS}

\section{Characteristics of the study populations}

Table 1 shows the characteristics of the Ecuadorian and the Dutch populations. There were no significant differences with respect to maternal age between the normotensive mothers and the mothers with PIH in the two populations. The Ecuadorian mothers were, however, younger than the Dutch mothers $(\mathrm{P}<0.0001)$. In both countries, the diastolic blood 
Table 3. Umbilical plasma phospholipid fatty acid composition.

\begin{tabular}{|c|c|c|c|c|}
\hline \multirow[b]{2}{*}{$\begin{array}{l}\text { Falty acids } \\
\% \text { w } 1 \text { wt }\end{array}$} & \multicolumn{2}{|c|}{ Ecuador } & \multicolumn{2}{|c|}{ Netherlands } \\
\hline & $\begin{array}{c}\text { NORM } \\
n=22\end{array}$ & $\begin{array}{c}\mathrm{PIH} \\
\mathrm{n}=26\end{array}$ & $\begin{array}{c}\text { NORM } \\
n=33 \\
\end{array}$ & $\begin{array}{c}\mathrm{PIH} \\
n=29\end{array}$ \\
\hline Total $[\mathrm{mg} / \mathrm{L}$. & $620.0 \pm 32.2$ & $596.9 \pm 21.9$ & $560.6 \pm 19.6$ & $596.3 \pm 21.8$ \\
\hline $18: 2 n-6$ & $8.21 \pm 0.26$ & $9.03 \pm 0.41$ & $7.53 \pm 0.22$ & $7.64 \pm 0.25$ \\
\hline $20: 3 n-6$ & $6.27 \pm 0.24$ & $6.37 \pm 0.21$ & $5.25 \pm 0.18$ & $4.67 \pm 0.15^{d}$ \\
\hline $20: 4 n-6$ & $15.8 \pm 0.5$ & $14.6 \pm 0.3$ & $16.9 \pm 0.3$ & $16.7 \pm 0.2^{5}$ \\
\hline $22: 5 n-6$ & $0.99 \pm 0.05$ & $0.90 \pm 0.06$ & $0.74 \pm 0.04$ & $0.75 \pm 0.05$ \\
\hline n-6LCPS & $23.8 \pm 0.4$ & $22.6 \pm 0.3$ & $23.6 \pm 0.3$ & $22.9 \pm 0.2$ \\
\hline $18: 3 n-3$ & not detected & not detected & not detected & not detected \\
\hline $20: 5 n-3$ & $0.21 \pm 0.01$ & $0.23 \pm 0.01$ & $0.24 \pm 0.02$ & $0.23 \pm 0.02$ \\
\hline $22: 6 n-3$ & $5.71 \pm 0.22$ & $5.71 \pm 0.31$ & $6.55 \pm 0.22$ & $6.72 \pm 0.27^{d}$ \\
\hline n-3 LCPs & $6.45 \pm 0.24$ & $6.48 \pm 0.34$ & $7.37 \pm 0.24$ & $7.59 \pm 0.31$ d \\
\hline SAFA & $47.1 \pm 0.2$ & $47.3 \pm 0.2$ & $48.1 \pm 0.2$ & $47.3 \pm 0.3$ \\
\hline MUFA & $12.5 \pm 0.4$ & $13.0 \pm 0.4$ & $11.4 \pm 0.2$ & $12.3 \pm 0.5$ \\
\hline (n-6)-metabolic index & $2.98 \pm 0.13$ & $2.64 \pm 0.13$ & $3.23 \pm 0.11$ & $3.08 \pm 0.10$ \\
\hline
\end{tabular}

See Table 2 for legends.

pressure of the PIH group was significantly $(\mathrm{P}<0.0001)$ higher than that of the normotensive pregnancy group.

In both the Netherlands and Ecuador, neonates born after PIH had significantly lower gestational ages than did infants born after uncomplicated pregnancies. Moreover, in both countries the birth weights and Apgar scores of the neonates born to mothers with PIH were significantly lower than those of the infants born in the normotensive groups. The average birth length of the infants born after PIH was also lower than that of the normotensive pregnancy group, but this difference was significant for the Dutch neonates only.

\section{Maternal fatty acids}

The fatty acid compositions of the plasma phospholipids are given in Table 2 . In the Ecuadorian women, significant differences between both groups were observed for the percentages of $18: 3 n-3(P<0.01)$ only. This fatty acid was lower in the PIH group compared with the normotensive pregnancy group.

In contrast, PIH in the Dutch mothers was characterized by lower levels of $18: 2 n-6$ $(P<0.005)$ combined with higher amounts of $22: 5 n-6(P<0.001), 22: 6 n-3(P<0.05)$ and $n-3$ LCPs $(P<0.05)$ than seen with normotensive pregnancy. Only in the Dutch mothers was the n-6 metabolic index, reflecting the conversion of 18:2n-6 into its LCPs, significantly higher $(\mathrm{P}<0.01)$ in the PIH group than in the normotensive pregnancy group. Comparison of the Ecuadorian and the Dutch PIH groups showed significantly higher percentages of 18:2n-6 $(\mathrm{P}<0.005)$ in the Ecuadorian PIH group. The levels of $20: 4 n-6(P<0.01), n-6$ LCPS 
Table 4. Venous and anterial vessel wall phospholipid fatty acid composition '.

\begin{tabular}{|c|c|c|c|c|c|}
\hline \multirow[b]{2}{*}{$\begin{array}{l}\text { Fatty acids" } \\
\% \text { wt/wt }\end{array}$} & & \multicolumn{2}{|c|}{ Ecuador } & \multicolumn{2}{|c|}{ Netherlands } \\
\hline & & $\begin{array}{c}\text { NORM } \\
n=22\end{array}$ & $\begin{array}{c}P I H \\
n=26\end{array}$ & $\begin{array}{c}\text { NORM } \\
n=33\end{array}$ & $\begin{array}{c}\mathrm{PIH} \\
\mathrm{n}=29\end{array}$ \\
\hline \multirow[t]{2}{*}{ Total /mg/g dry weight | } & venous & $17.9 \pm 1.5$ & $19.1 \pm 0.9$ & $13.8 \pm 0.5$ & $15.9 \pm 0.4^{d}$ \\
\hline & arteria! & $15.2 \pm 0.8$ & $17.7 \pm 0.7$ & $12.6 \pm 0.4$ & $14.8 \pm 0.6^{4 / 4}$ \\
\hline \multirow[t]{2}{*}{$18: 2 n-6$} & venous & $1.85 \pm 0.07$ & $2.24 \pm 0.11$ & $2.00 \pm 0.08$ & $2.04 \pm 0.08$ \\
\hline & arterial & $1.08 \pm 0.05$ & $1.17 \pm 0.09$ & $1.24 \pm 0.05$ & $1.30 \pm 0.05$ \\
\hline \multirow[t]{2}{*}{$20: 3 n-6$} & venous & $2.17 \pm 0.08$ & $2.19 \pm 0.07$ & $1.98 \pm 0.07$ & $1.77 \pm 0.08$ \\
\hline & arterial & $1.36 \pm 0.05$ & $1.29 \pm 0.05$ & $1.35 \pm 0.04$ & $1.21 \pm 0.05$ \\
\hline \multirow[t]{2}{*}{$20: 4 n-6$} & venous & $18.5 \pm 0.2$ & $18.1 \pm 0.4$ & $19.2 \pm 0.2$ & $18.4 \pm 0.3$ \\
\hline & arterial & $12.4 \pm 0.3$ & $12.3 \pm 0.4$ & $14.6 \pm 0.3$ & $13.8 \pm 0.5$ \\
\hline \multirow[t]{2}{*}{$22: 5 n-6$} & venous & $3.06 \pm 0.12$ & $3.00 \pm 0.13$ & $2.63 \pm 0.12$ & $2.71 \pm 0.13$ \\
\hline & arterial & $3.19 \pm 0.13$ & $3.25 \pm 0.13$ & $2.99 \pm 0.09$ & $3.27 \pm 0.11$ \\
\hline \multirow[t]{2}{*}{$n-6$ LCPS } & venous & $28.4 \pm 0.3$ & $27.2 \pm 0.6$ & $29.2 \pm 0.3$ & $28.1 \pm 0.4$ \\
\hline & arterial & $19.6 \pm 0.5$ & $19.1 \pm 0.6$ & $22.3 \pm 0.4$ & $21.2 \pm 0.6$ \\
\hline \multirow[t]{2}{*}{$22: 6 n-3$} & venous & $4.98 \pm 0.11$ & $5.07 \pm 0.17$ & $5.43 \pm 0.12$ & $5.64 \pm 0.18$ \\
\hline & arterial & $4.86 \pm 0.15$ & $4.97 \pm 0.21$ & $5.65 \pm 0.15$ & $5.78 \pm 0.19$ \\
\hline \multirow[t]{2}{*}{ SAFA } & venous & $45.8 \pm 0.2$ & $45.6 \pm 0.4$ & $46.6 \pm 0.2$ & $47.4 \pm 0.4^{d .3}$ \\
\hline & arterial & $45.3 \pm 0.2$ & $45.3 \pm 0.7$ & $47.1 \pm 0.3$ & $47.5 \pm 0.5$ \\
\hline \multirow[t]{2}{*}{ MUFA } & venous & $16.9 \pm 0.3$ & $17.6 \pm 0.4$ & $15.0 \pm 0.2$ & $15.2 \pm 0.4^{6}$ \\
\hline & arterial & $23.0 \pm 0.5$ & $23.4 \pm 0.6$ & $19.3 \pm 0.4$ & $19.5 \pm 0.6^{2}$ \\
\hline
\end{tabular}

See Table 2 for legends, and ${ }^{6} \mathrm{P}<0.001$

$(\mathrm{P}<0.05)$, and $18: 3 n-3(\mathrm{P}<0.0001)$ were significantly lower in the Ecuadorian $\mathrm{PIH}$ group than in the Dutch PIH group.

\section{Neonatal fatty acids}

The fatty acids of the phospholipids isolated from umbilical plasma and umbilical cord veins and arteries are presented in Tables 3 and 4, respectively. All comparisons between the infants born to normotensive mothers and those born to mothers with PIH were made with adjustments for the variables gestational age, maternal age and infant's sex.

\section{Umbilical plasma.}

In the Ecuadorian population no significant differences were observed between the two groups. Among the Dutch neonates, significantly higher levels of 22:6n-3 and n-3 LCP $(\mathrm{P}<0.05)$ were found in the samples of the infants born after PIH than in samples from the 
normotensive pregnancy group. Comparison of the samples of the infants born after PIH showed that the Ecuadorian neonates had significantly lower levels of $20: 4 n-6(\mathrm{P}<0.05$ than did the Dutch neonates.

\section{Umbilical veins.}

No significant differences were found for the total fatty acid amounts and percentages of SAFA between the two Ecuadorian groups, whereas significantly higher values were found for the Dutch PIH as compared to the control group ( $\mathrm{P}<0.05$; Table 4). In addition, the levels of SAFA of venous vessel wall phospholipids in the Ecuadorian PIH group were found to be significantly lower than those in the corresponding Dutch group $(\mathrm{P}<0.01)$. With respect to the MUFA, the Ecuadorian PIH group had significantly lower levels compared with those of the Dutch PIH group $(\mathrm{P}<0.001)$.

\section{Umbilical arteries.}

Among the Dutch infants, the total fatty acid amounts were significantly higher in the PIH as compared to the control group $(\mathrm{P}<0.05)$, whereas no significant differences were observed among the Ecuadorian groups (Table IV). The total fatty acid amounts and the percentages of MUFA were significantly higher in the Ecuadorian PIH group infants than in the Dutch PIH group infants $(P<0.005)$.

\section{DISCUSSION}

In pregnancy-induced hypertension (PIH), the placental perfusion can be compromised, which possibly results in an insufficient transfer of oxygen and nutrients, including essential fatty acids (EFAs), from mother to fetus. Previously, Al et al (11) showed that, at birth, the EFA status of infants born to mothers with PIH was comparable or even higher than that of the infants born to normotensive mothers. Because in mothers with PIH lower linoleic acid $(18: 2 n-6)$ levels were associated with higher levels of the $n-6$ long-chain polyenes (LCPs) than seen in normotensive mothers, an enhanced desaturation and elongation of 18:2n-6 into its LCPs was suggested as a possible compensatory mechanism in PIH to ensure an adequate supply of LCPs through the placenta to the fetus.

In the present study, however, no such differences were found between Ecuadorian mothers with and without PIH. This indicates that these women did not have increased desaturation and elongation of 18:2n-6, as was suggested for the Dutch population. This suggestion is supported by the effect of PIH on the levels of Mead acid (20:3n-9), a desaturation and elongation product of oleic acid (18:1n-9). Dutch women with PIH had significantly higher levels of $20: 3 \mathrm{n}-9$ than did normotensive mothers $(0.43 \pm 0.03$ vs. $0.18 \pm$ $0.02)$, whereas for Ecuadorian mothers with PIH this was not the case $(0.19 \pm 0.01$ vs. 0.14 \pm 0.01 ). 
Unlike Dutch women, Ecuadorian mothers do not respond to PIH with an increased fatty acid desaturation and clongation. This difference in fatty acid pattern may result from a difference in PIH severity between the two populations; in all the Ecuadorian mothers PIH was accompanied by proteinuria, whereas only $53 \%$ of the Dutch PIH mothers had proteinuria. However, additional comparison of the EFA status of the Dutch mothers with PIH and proteinuria with that of the Ecuadorian mothers with PIH did not significantly alter the results found. Moreover, within the Dutch PIH group no significant differences were observed between mothers with and without proteinuria. In the light of these results, it appears that the difference between the Ecuadorian and the Dutch women cannot be attributed to differences in severity of PIH.

In contrast to common practice in Dutch hospitals, the Ecuadorian mothers were treated with barbiturates during labor. Although an effect of this treatment on enzyme activities involved in fatty acid desaturation and elongation cannot be excluded, the short treatment period is unlikely to allow an effect on the fatty acid composition of maternal plasma phospholipids, which by definition, determines the EFA and LCP status.

A more likely explanation for the difference between the Dutch and the Ecuadorian populations may be a reduced $\Delta 5$-desaturase activity, such as has previously been observed in healthy Mestizo women (13). In the present study, we again observed that the plasma ratio between 20:4n-6 and its precursor 20:3n-6 (20:4n-6/20:3n-6), which can be considered a reflection of the $\Delta 5$-desaturase activity, was significantly $(\mathrm{P}<0.001)$ lower in both Ecuadorian groups ( $1.77 \pm 0.11$ and $1.94 \pm 0.11$ for $\mathrm{PIH}$ and controls, respectively) than in both Dutch groups $(2.44 \pm 0.13$ and $2.57 \pm 0.15)$.

PIH is associated with multiple placental infarcts, which reduce the exchange surface between mother and fetus. The fact that the EFA status was not reduced in Dutch neonates born after PIH (it was even slightly higher than after uncomplicated pregnancy) was taken as evidence for a successful compensatory mechanism to guarantee an adequate fetal LCP supply (11). The increase in desaturation and elongation of dietary EFAs to LCPs was suggested as this mechanism. However, the EFA status of the Ecuadorian neonates born after PIH was also not different from that of neonates born after uncomplicated pregnancies (Tables 3 and 4). Because their mothers did not show such an enhanced fatty acid desaturation and elongation, other compensatory mechanisms must also exist. Evidence has also been presented that pregnancy is associated with LCP mobilization from maternal stores for fetal use and/or a shift in LCPs utilization from energy substrate to structural component (14). Our current results indicate that these processes can be more active in PIH also, especially under conditions in which fatty acid desaturation and elongation cannot be stimulated.

In summary, the enhanced LCPs status at delivery observed before in Caucasian (Dutch) women with PIH was not seen in Mestizo (Ecuadorian) women. This is most likely due to a genetically determined lower $\Delta 5$-desaturase activity in Mestizos than in Caucasians. Although PIH is generally associated with a reduced maternal-fetal nutrient transfer, it compromises the EFA status of neither Caucasian nor Mestizo neonates. The enhanced 
maternal EFA to LCP conversion that most likely occurs in Caucasian but not in Mestizo mothers with PIH therefore cannot be the only mechanism to maintain the neonatal EFA status during PIH.

\section{ACKNOWLEDGMENT}

We thank Arnold Kester, Marianne Simonis, Hasibe Aydeniz, and Andres Calle for their assistance.

\section{REFERENCES}

1. Ylikorkala O. Makila UM. Prostacyclin and thromboxane in gynecology and obstetrics. Am J Obstet Gynecol 1985:152:318-29.

2. Walsh SW. Preeclampsia: an imbalance in placental prostacyclin and thromboxane production. Am J Obstet Gynecol 1985; 152:335-40.

3. Fitzgerald DJ, Rocki W, Murray R, Mayo G. FitzGerald GA. Thromboxane A2 synthesis in pregnancyindiced hypertension. I_ancet 1990;335:751-4.

4. Felix C, Lopez A, Delgado F, Amores E, Narvaez M, Lopez-Jaramillo P. Vascular prostacyclin production in Andean women with pregnancy-induced hypertension. Braz J Med Biol Res 1991;24:5962.

5. Popeski D, Ebbeling LR, Brown PB. Hornstra G, Gerrard JM. Blood pressure during pregnancy in Canadian Inuit: community differences related to diet. Cmaj 1991;145:445-54.

6. Sorensen JD. Olsen SF, Pedersen AK, Boris J. Secher NJ. FitzGerald GA. Effects of fish oil supplementation in the third trimester of pregnancy on prostacyclin and thromboxane production. Am $\mathrm{J}$ Obstet Gynecol 1993;168:915-22.

7. Ogburn PL. Jr, Williams PP, Johnson SB, Holman RT. Serum arachidonic acid levels in normal and preeclamptic pregnancies. Am J Obstet Gynecol 1984;148:5-9.

8. Craig-Schmidt MC, Carlson SE, Crocker L, Sibai BM. Plasma total phospholipid arachidonic acid and eicosapentaenoic acid in normal and hypertensive pregnancy. World Rev Nutr Diet 1994;76:126-9.

9. Wang YP, Kay HH, Killam AP. Decreased levels of polyunsaturated fatty acids in preeclampsia. Am J Obstet Gynecol 1991:164:812-8.

10. Van der Schouw YT, Al MD. Hornstra G. Bulstra-Ramakers MT, Huisjes HJ. Fatty acid composition of serum lipids of mothers and their babies after normal and hypertensive pregnancies. Prostaglandins Leukot Essent Fatty Acids 1991:44:247-52.

11. Al MD. Houwelingen ACv, Badart Smook A. Hasaart TH, Roumen FJ, Hornstra G. The essential fatty acid status of mother and child in pregnancy-induced hypertension: a prospective longitudinal study. Am J Obstet Gynecol 1995;172:1605-14.

12. Davey DA. MacGillivray I. The classification and definition of the hypertensive disorders of pregnancy. Am J Obstet Gynecol 1988;158:892-8. 
13. Otto SJ, Houwelingen ACv, Antal M, Manninen A. Godfrey K, Lopez-Jaramillo P, Hornstra G. Maternal and neonatal essential fatty acid status in phospholipids: an international comparative study. Eur J Clin Nutr 1997:51:232-42.

14. Al MD, Houwelingen ACv. Kester AD. Hasaart TH. de Jong AE. Hornstra G. Maternal essential fatty acid patterns during normal pregnancy and their relationship to the neonatal essential fatty acid status. $\mathrm{Br}$ J Nutr 1995:74:55-68.

15. Folch J, Sloane Stanley GH. A simple method for the isolation and purification of total lipides from animal tissues. J Biol Chem 1957;226:497-509.

16. Hoving EB, Jansen G, Volmer M. Van Doormalal JJ, Muskiet FA. Profiling of plasma cholesterol ester and triglyceride fatty acids as their methyl esters by capillary gas chromatography, preceded by a rapid aminopropyl-silica column chromatographic separation of lipid classes. J Chromatogr 1988;434:395409.

17. Bligh E. Dyer WJ. A rapid method for total lipid extraction and purification. Can J Biochem Physiol 1959:37:911-7.

18. Kaluzny MA. Duncan LA. Merritt MV. Epps DE. Rapid separation of lipid classes in high yield and purity using bonded phase columns. J Lipid Res 1985;26:135-40.

19. Morrison WR. Smith LM. Preparation of fatty acid methyl esters and dimethylacetals from lipids with boron fluoride-methanol. J Lipid Res 1964;5:600-8. 



\title{
Chapter 5
}

\section{Changes in the maternal essential fatty acid profile during early pregnancy and its relation to diet}

Suzie J. Otto, Adriana C. van Houwelingen, Anita Badart-Smook, Gerard Hornstra

Based on American Journal of Clinical Nutrition, accepted.

\begin{abstract}
Although the pattern of the essential fatty acids (EFA) changes considerably from week 10 of pregnancy to term, there is currently no information available on changes in EFA levels in early stages of pregnancy. The main objectives of present study were to assess the EFA status, particularly $22: 6 \mathrm{n}-3$, in women during the first 10 weeks of pregnancy and to investigate the relation of EFA status to the dietary EFA intake during this period.

Healthy women $(n=24)$ planning to become pregnant were recruited. Fatty acid composition of plasma and erythrocyte phospholipids was determined before and at weeks $4,6,8$ and 10 of pregnancy. Food intake was assessed at entry into the study and at week 10 of pregnancy using food frequency questionnaires.

A small but not statistically significant increase in dietary intake of 22:6n-3 was found. The plasma phospholipid content of $22: 6 \mathrm{n}-3(\% \mathrm{wt} / \mathrm{wt})$ increased continuously during the first 10 weeks of pregnancy. At week 10 of pregnancy, the percentages of plasma 16:0, 20:3n-6 and 20:4n-6 had increased significantly, whereas the levels of the C18-24 saturated fatty acids, $18: 2 n-6$, and the ratio $n-6 / n-3$ had dropped significantly. The erythrocyte phospholipid composition showed similar changes as observed in plasma.

The results demonstrate that maternal plasma and erythrocyte phospholipid 22:6n-3 levels start to increase in very carly pregnancy, which cannot be explained by changes in the dictary intake alone. This rise most probably represents early maternal adaptations to meet the requirement of highly proliferating and differentiating tissues at this stage of development.
\end{abstract}




\section{INTRODUCTION}

The $n-6$ and $n-3$ long-chain polyenes (LCPs) are important structural components of cell membrane phospholipids, and during the different stages of pregnancy an adequate LCP supply is required to sustain proper fetal growth and development. In recent years, extensive research has been performed on these LCPS in early human development, with emphasis on docosahexaenoic acid (22:6n-3), which is the predominant fatty acid in the central nervous system $(1,2)$ and retina (3). The functional significance of $22: 6 n-3$ as structural constituent of the phospholipids in nervous and retinal tissues is illustrated by the (irreversible) impairment of neural and visual function in animals exposed to a n-3 fatty acids deficient diets throughout the prenatal and the postnatal period (4).

Longitudinal data of fatty acid levels in pregnant women indicate that the amounts $(\mathrm{mg} / \mathrm{L})$ of saturated, monounsaturated and polyunsaturated fatty acids in the maternal plasma phospholipids increase from week 10 of pregnancy until delivery (5). However, a continuous decline was observed in the overall 'functional' essential fatty acids (EFAs) status, reflected by the ratio between the essential n-3+n-6 and the non-essential n-7+n-9 unsaturated fatty acids. Bccause no information is available during the first 10 weeks of gestation, it is not clear when the fatty acids levels start to change. This period of early pregnancy is important considering the findings by Wynn et al $(6,7)$ that the nutritional status of women is important not only during pregnancy, but around the time of conception as well. Surprisingly, little is known about the maternal dietary fat intake, the EFA consumption in particular, around conception and during early pregnancy. Therefore, we decided to study the EFA status in plasma and erythrocyte phospholipids in women before conception and during the first 10 weeks of pregnancy, and to assess their dietary EFA intake in this period.

\section{SUBJECTS AND METHODS}

\section{Subjects and study design}

Women planning to become pregnant in the near future were recruited through advertisements in the local papers. Only healthy women, not suffering from any metabolic, cardiovascular, neurological, or renal disorders, were included. From all eligible respondents, 67 women agreed to participate in the study. Before the initial blood sample collection, 6 women appeared to be pregnant already and 11 decided not to participate after all. Of those who started the study, 20 dropped out for different reasons, such as lack of motivation or miscarriage before reaching week 10 of pregnancy. Another 6 women failed to conceive within the study period. Finally, 24 subjects completed the study. The research protocol was approved by the Medical Ethics Committee of the University Hospital Maastricht. A signed informed consent was obtained from each participant. 
Table 1. Characteristics of the subjects '.

\begin{tabular}{lc} 
Number of subjects $(\mathrm{n})$ & 24 \\
Age $(\mathrm{yr})$ & $30.7 \pm 0.6$ \\
Height $(\mathrm{m})$ & $1.70 \pm 0.01$ \\
Length of last menstrual cycle (days) & $30.1 \pm 0.9$ \\
Primiparous/multiparous $(\mathrm{n})$ & $10 / 14$ \\
Prepregnancy & \\
$\quad$ Weight $(\mathrm{kg})$ & $67.1 \pm 2.8$ \\
$\quad$ BMI $\left(\mathrm{kg} / \mathrm{m}^{2}\right)$ & $23.1 \pm 0.91$ \\
Al week JO of $\mathrm{pregnancy}$ & \\
$\quad$ Weight $(\mathrm{kg})$ & $68.7 \pm 2.8^{2}$ \\
$\quad$ BMI $\left(\mathrm{kg} / \mathrm{m}^{2}\right)$ & $23.8 \pm 0.94^{2}$ \\
\hline
\end{tabular}

'Data are mean \pm SEM, unless stated as $n$.

' Significantly different from prepregnancy value. $\mathrm{P}<0.01$

Every month, on the first or second day of the menstrual cycle, a venous blood sample was collected into EDTA-containing tubes. When the menstruation did not occur at the expected time, the women were instructed to have a blood sample taken as well. When pregnancy was confirmed (often already at week 4-5 of pregnancy), further samples were collected at weeks 6, 8 and 10 of pregnancy. Pregnancy duration was calculated from the first day of the last menstrual cycle. After blood collection, plasma was separated from the erythrocytes by centrifugation. The erythrocytes were washed twice with an EDTAcontaining saline solution. The plasma and erythrocyte samples were divided over two storage cups, closed tightly under nitrogen, and stored at $-80^{\circ} \mathrm{C}$ until fatty acid analysis. BHT was added to all erythrocyte samples before storage. These procedures have been described in detail before (8).

\section{Fatty acid analyses}

The fatty acid composition of plasma and erythrocyte phospholipids was analyzed in the blood samples as described previously (8). The fatty acids were determined by capillary gas chromatography using a polar capillary column (50 m x $0.25 \mathrm{~mm}$ CPSil 88; Chrompack, Middelburg, the Netherlands), with helium as carrier gas. The amount of each fatty acid was quantified by the amount recovered of the internal standard (1,2- $\alpha$-dinonadecanoyl phosphatidylcholine; PC-[19:0] $]_{2}$ ) added to each sample. The fatty acids are expressed as $\mathrm{mg} / \mathrm{L}$ plasma or erythrocyte suspension, and as percentage of total fatty acids by weight (\% $\mathrm{w} / \mathrm{wt}$ ). The sum of the saturated, monounsaturated and the polyunsaturated fatty acids as well as the sum of the n-6 LCPs $(20: 3 n-6,20: 4 n-6,22: 4 n-6,22: 5 n-6)$ and the n-3 LCPs (20:5n-3, 22:5n-3, 22:6n-3) and the ratio between $n-6$ and $n-3$ are also presented. In addition, the EFA index [sum n-3+n-6 fatty acids]/[sum n-7+n-9 fatty acids], which reflects the overall EFA status, was calculated. 


\section{Assessment of the dietary fatty acid intake}

The subjects' food intike in the period before pregnancy and during the first 10 weeks of gestation was assessed using a food frequency questionnaire (FFQ). This questionnaire was previously used and validated in the longitudinal study of Al et al (9). The FFQ was sent the first time at entry and the second time at week 10 of pregnancy. The food consumption data were encoded according to the system of the Dutch Nutrient Databank (NEVO) and converted into the dietary intake data by using the extended computerized version of the Dutch Food Table 1996 I (10). The total fat and total saturated, mono- and polyunsaturated fatty acid and linoleic acid (18:2n-6) were calculated. In addition, the Dutch Year Table 96.II provides data on palmitic acid (16:0), stcaric acid (18:0), oleic acid (18:1n-9), $\gamma$ linolenic acid (18:3n-6), arachidonic acid (20:4n-6), $\alpha$-linolenic acid (18:3n-3), eicosapentaenoic acid (20:5n-3), 22:5n-3 and docosahexaenoic acid (22:6n-3), the intakes of which were assessed as well.

\section{Statistical analyses}

Data are presented as mean \pm SEM. In eight subjects, fatty acid data of one sampling point were missing, because an occasional blood sample was not collected on the intended sampling time. The paired t-test was used to examine whether the fatty acid values measured at weeks $4,6,8$ and week 10 changed significantly from baseline (prepregnant values).

Differences between the dictary intake data of the two assessment periods were performed using the Wilcoxon signed rank test. The relationship between maternal dietary fatty acid intake (\% wt/wt of total fat intake) and maternal plasma and erythrocyte phospholipid fatty acid levels (\% w/ wt of total fatty acids) were evaluated by the Spearman rank correlation test. In addition, the relationship between the change in maternal dietary fatty acid intake and the change in maternal plasma and erythrocytes fatty acid levels were evaluated as well. Non-parametric tests were used because the data were not normally distributed.

Because of multiple testing, $P<0.01$ was considered significant. All statistical analyses were performed by using StatView version 5.0 for Macintosh PPC (SAS Institute Inc., Cary, North Carolina).

\section{RESULTS}

\section{Subject's characteristics}

The characteristics of the study population are given in Table 1. There was a significant weight gain of $1.6 \pm 0.5 \mathrm{~kg}$ during the first 10 weeks of pregnancy. Of the 14 women who reported the consumption of aicoholic beverages before conception, only three continued to do so in the first 10 weeks of pregnancy. The only subject who reported to smoke did not quit this habit during the study period. 

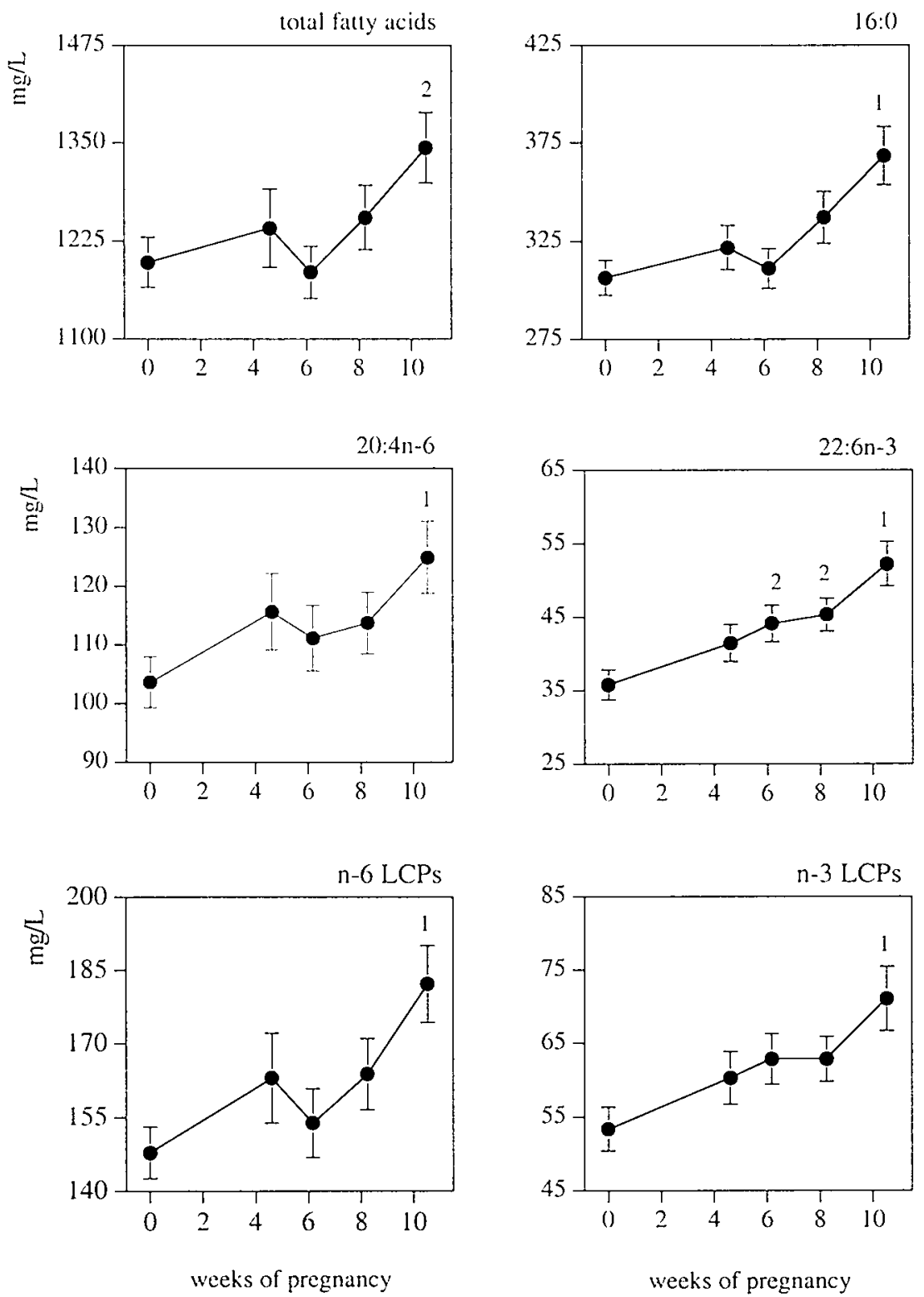

Figure 1. Changes in plasma phospholipid concentrations (mg/L) of total fatty acids, 16:0, 20:4n-6, 22:6n-3. and $n-6$ and $n-3$ long-chain polyenes (LCPs) in the first weeks of pregnancy. Values are given as mean \pm SEM. for baseline (prepregnant, $n=23)$, week $4.6(n=21)$, week $0.2(n=21)$, week $8.2(n=24)$ and week 10.5 $(n=23)$.

1.2 Significantly different from prepregnant value: $\mathrm{P}<0.0001$, and ${ }^{2} \mathrm{P}<0.01$ (paired t-test). 


\section{Fatty acids}

Comparison of the baseline fatty acid values with those obtained at the first blood sampling in the pregnant state did not reveal significant differences in either plasma or erythrocyte phospholipids. A tendency for a statistically significant increase was, however, observed for plasma 22:6n-3 ( $P=0.013$ for the absolute amounts, and $P=0.026$ for the percentages). Changes for other fatty acids and fatty acid combinations were not significant.

From prepregnancy through week 10 of pregnancy, significant increases were observed in the amounts ( $\mathrm{mg} / \mathrm{L}$ ) of plasma phospholipid total fatty acids and for most of the individual fatty acids. In Figure 1, the results are presented for total fatty acids, 16:0, 20:4n6, n-6 LCPs, 22:6n-3 and n-3 LCPs.

In the erythrocyte phospholipids the total fatty acid amounts and most individual fatty acids measured did not change significantly during the first 10 weeks of pregnancy. However, the amounts of $18: 0$ and $18: 2 n-6$ declined significantly during this period (from $86.69 \pm 9.71$ to $78.23 \pm 11.50 \mathrm{mg} / \mathrm{L}$, and $119.77 \pm 15.75$ to $106.19 \pm 15.79$, respectively) The 22:6n-3 levels of erythrocyte phospholipids rose from $30.78 \pm 6.68 \mathrm{mg} / \mathrm{L}$, prepregnant, to $35.60 \pm 9.66 \mathrm{mg} / \mathrm{L}$, but the $P$-value just failed to reach the required level for significance (week 10: $\mathrm{P}=0.011$ ).

The percentages of the fatty acids in plasma and erythrocyte phospholipids are shown in Table 2 and 3, respectively. While the percentages of the plasma phospholipid total saturated fatty acids did not change in time, the percentages of the individual saturated fatty acids did. A significant decrease was observed in the percentages of plasma 18:0, 20:0, 22:0 and 24:0 at week 10 of pregnancy, whereas the percentages of 16:0 increased significantly. In the erythrocyte phospholipids, the percentages of 18:0 decreased significantly at week 10 of gestation; no significant changes were observed for the total nor for the other individual saturated fatty acids.

A small but statistically significant increase was observed for the percentages of $18: \ln -7$ in plasma and erythrocyte phospholipids; for the erythrocytes, a significant increase was also observed in the percentages of $24: \ln -9$. No changes were found in the other nonessential n-9 unsaturated fatty acids, neither in plasma nor in erythrocyte phospholipids.

With respect to the n-6 fatty acids, at week 10 of pregnancy the percentages of most individual n-6 fatty acids were significantly increased, whereas 18:2n-6 was decreased. Comparable results were observed for the erythrocyte phospholipids.

In the n-3 series, plasma and erythrocyte percentages of $22: 6 n-3$, total n-3 and n-3 LCPs increased continuously throughout the first weeks of pregnancy. The percentages of plasma $22: 5 n-3$ tended to decline during this period, but at week 10 this fatty acid was not yet significantly different from baseline.

The ratio between total $n-6$ and total $n-3$ fatty acids in both plasma and erythrocytes had dropped significantly at week 6 of pregnancy already (Tables 2 and 3). The EFA index, [sum $n-3+n-6$ fatty acids]/[sum $n-7+n-9$ fatty acids], remained unchanged similar to the total polyunsaturated fatty acids. 
Table 2. Plasma phospholipid fatty acid composition in early pregnancy'.

\begin{tabular}{|c|c|c|c|c|c|}
\hline \multirow{3}{*}{$\begin{array}{l}\text { Fatty acids } \\
\% \text { wt/wt }\end{array}$} & \multirow[b]{2}{*}{ prepregnant } & \multicolumn{4}{|c|}{ weeks of pregnancy } \\
\hline & & $\begin{array}{c}4.6 \pm 0.1 \\
(32.2 \text { days })\end{array}$ & $\begin{array}{c}6.2 \pm 0.1 \\
(43.2 \text { days })\end{array}$ & $\begin{array}{c}8.2 \pm 0.1 \\
(57.6 \text { days })\end{array}$ & $\begin{array}{c}10.5 \pm 0.1 \\
(73.7 \text { days })\end{array}$ \\
\hline & $n=2.3$ & $n=21$ & $n=21$ & $n=24$ & \\
\hline $16: 0$ & $25.6 \pm 0.2$ & $26.1 \pm 0.4$ & $26.2 \pm 0.3 \quad 2$ & $26.8 \pm 0.3^{3}$ & $27.3 \pm 0.4$ \\
\hline 18:0 & $13.2 \pm 0.2$ & $12.8 \pm 0.2$ & $12.7 \pm 0.2$ & $12.5 \pm 0.2$ & $11.7 \pm 0.2^{3}$ \\
\hline $20: 0$ & $0.59 \pm 0.02$ & $0.58 \pm 0.03$ & $0.56 \pm 0.02$ & $0.54 \pm 0.02$ & $0.52 \pm 0.02$ \\
\hline 22:0 & $2.02 \pm 0.09$ & $1.95 \pm 0.10$ & $1.72 \pm 0.06^{2}$ & $1.73 \pm 0.07^{3}$ & $1.68 \pm 0.07^{3}$ \\
\hline $24: 0$ & $1.60 \pm 0.08$ & $1.53 \pm 0.07$ & $1.35 \pm 0.05^{3}$ & $1.31 \pm 0.04^{3}$ & $1.28 \pm 0.05^{3}$ \\
\hline SAFA & $44.6 \pm 0.4$ & $44.6 \pm 0.7$ & $44.1 \pm 0.4$ & $44.6 \pm 0.4$ & $44.1 \pm 0.5$ \\
\hline $18: \ln -7$ & $1.18 \pm 0.04$ & $1.18 \pm 0.04$ & $1.27 \pm 0.04^{2}$ & $1.22 \pm 0.04$ & $1.29 \pm 0.04^{3}$ \\
\hline $18: \ln -9$ & $7.88 \pm 0.23$ & $7.60 \pm 0.21$ & $7.52 \pm 0.24$ & $7.71 \pm 0.26$ & $7.86 \pm 0.21$ \\
\hline $20: \ln -9$ & $0.13 \pm 0.01$ & $0.12 \pm 0.01$ & $0.14 \pm 0.01$ & $0.14 \pm 0.02$ & $0.17 \pm 0.03$ \\
\hline $24: \ln -9$ & $2.24 \pm 0.08$ & $2.23 \pm 0.13$ & $2.35 \pm 0.09$ & $2.19 \pm 0.10$ & $2.22 \pm 0.09$ \\
\hline $20: 3 n-9$ & $0.11 \pm 0.02$ & $0.14 \pm 0.04$ & $0.09 \pm 0.02$ & $0.10 \pm 0.02$ & $0.13 \pm 0.03$ \\
\hline $18: 2 n-6$ & $22.3 \pm 0.4$ & $21.7 \pm 0.7$ & $21.9 \pm 0.5$ & $21.6 \pm 0.5$ & $20.5 \pm 0.5$ \\
\hline $20: 3 n-6$ & $3.12 \pm 0.12$ & $3.19 \pm 0.14$ & $3.01 \pm 0.11$ & $3.36 \pm 0.16$ & $3.53 \pm 0.17^{2}$ \\
\hline $20: 4 n-6$ & $8.68 \pm 0.30$ & $9.27 \pm 0.26$ & $9.35 \pm 0.32^{2}$ & $9.04 \pm 0.26$ & $9.34 \pm 0.35^{2}$ \\
\hline $22: 4 n-6$ & $0.36 \pm 0.02$ & $0.37 \pm 0.02$ & $0.34 \pm 0.02$ & $0.36 \pm 0.02$ & $0.39 \pm 0.02$ \\
\hline $22: 5 n-6$ & $0.19 \pm 0.02$ & $0.22 \pm 0.02$ & $0.22 \pm 0.02$ & $0.22 \pm 0.02$ & $0.29 \pm 0.03^{3}$ \\
\hline n-6 LCPs & $12.4 \pm 0.3$ & $13.1 \pm 0.4$ & $12.9 \pm 0.3$ & $13.0 \pm 0.3$ & $13.6 \pm 0.3^{3}$ \\
\hline$n-6$ & $35.5 \pm 0.5$ & $35.6 \pm 0.6$ & $35.5 \pm 0.5$ & $35.3 \pm 0.6$ & $34.9 \pm 0.6$ \\
\hline $18: 3 n-3$ & $0.16 \pm 0.01$ & $0.16 \pm 0.02$ & $0.16 \pm 0.01$ & $0.17 \pm 0.01$ & $0.23 \pm 0.03$ \\
\hline $20: 5 n-3$ & $0.63 \pm 0.07$ & $0.61 \pm 0.06$ & $0.72 \pm 0.14$ & $0.60 \pm 0.07$ & $0.62 \pm 0.11$ \\
\hline $22: 5 n-3$ & $0.84 \pm 0.03$ & $0.89 \pm 0.03$ & $0.88 \pm 0.04$ & $0.80 \pm 0.03$ & $0.80 \pm 0.03$ \\
\hline $22: 6 n-3$ & $2.98 \pm 0.14$ & $3.36 \pm 0.19$ & $3.73 \pm 0.19^{3}$ & $3.63 \pm 0.17^{3}$ & $3.93 \pm 0.22^{3}$ \\
\hline$n-3$ LCPs & $4.45 \pm 0.21$ & $4.86 \pm 0.23$ & $5.32 \pm 0.29^{2}$ & $5.03 \pm 0.22^{3}$ & $5.35 \pm 0.33^{3}$ \\
\hline$n-3$ & $4.75 \pm 0.21$ & $5.15 \pm 0.23$ & $5.60 \pm 0.28^{2}$ & $5.33 \pm 0.23^{3}$ & $5.71 \pm 0.32^{3}$ \\
\hline PUFA & $40.4 \pm 0.5$ & $41.0 \pm 0.6$ & $41.3 \pm 0.6$ & $40.8 \pm 0.6$ & $40.8 \pm 0.6$ \\
\hline MUFA & $11.9 \pm 0.3$ & $11.6 \pm 0.3$ & $11.8 \pm 0.3$ & $11.7 \pm 0.3$ & $12.1 \pm 0.3$ \\
\hline$n-6 / n-3$ & $7.78 \pm 0.35$ & $7.20 \pm 0.36$ & $6.68 \pm 0.36^{2}$ & $6.89 \pm 0.30^{2}$ & $6.44 \pm 0.29^{3}$ \\
\hline $22: 6 n-3 / 22: 5 n-6$ & $19.8 \pm 2.8$ & $19.2 \pm 3.3$ & $20.1 \pm 2.7$ & $19.7 \pm 2.5$ & $18.3 \pm 3.0$ \\
\hline $22: 5 n-6 / 22: 4 n-6$ & $0.56 \pm 0.06$ & $0.63 \pm 0.06$ & $0.66 \pm 0.05$ & $0.61 \pm 0.03$ & $0.71 \pm 0.05^{3}$ \\
\hline EFA index & $3.36 \pm 0.11$ & $3.48 \pm 0.09$ & $3.50 \pm 0.12$ & $3.48 \pm 0.13$ & $3.35 \pm 0.10$ \\
\hline Total mg/L & $1198 \pm 32$ & $1242 \pm 50$ & $1186 \pm 33$ & $1255 \pm 41$ & $1344 \pm 45$ \\
\hline
\end{tabular}

${ }^{1}$ Data are mean \pm SEM: SAFA: sum of saturated fatty acids; MUFA: monounsaturated fatty acids; $n-6$ LCPs. long-chain polyenes: 20:3n-6. 20:4n-6, 22:4n-6, 22:5n-6; n-3 LCPs: 20:5n-3, 22:5n-3, 22:6n-3; PUFA: polyunsaturated fatty acids: EFA index: [sum $n-3+n-6$ fatty acids] [ sum $n-7+n-9$ fatty acids].

${ }^{2.3}$ Comparison with prepregnant baseline values (paired t-test): ${ }^{2} 0.01<\mathrm{P}<0.005 .{ }^{3} 0.001<\mathrm{P}<0.0001$. 
Table 3. Erythrocyte phospholipid fatty acid composition in carly pregnancy'.

\begin{tabular}{|c|c|c|c|c|c|}
\hline \multirow[b]{2}{*}{$\begin{array}{l}\text { Fatly acids } \\
\% \mathrm{w} 1 / \mathrm{wt}\end{array}$} & \multirow[b]{2}{*}{ prepregnant } & \multicolumn{4}{|c|}{ weeks of pregnancy } \\
\hline & & $\begin{array}{c}4.6 \pm 0.1 \\
(32.2 \text { ditys }) \\
n=21\end{array}$ & $\begin{array}{c}6.2 \pm 0.1 \\
(43.2 \text { diays }) \\
n=21\end{array}$ & $\begin{array}{c}8.2 \pm 0.1 \\
\text { (57.6 days) } \\
n=24\end{array}$ & $\begin{array}{c}10.5 \pm 0.1 \\
(73.7 \text { days }) \\
n=23\end{array}$ \\
\hline 16:0 & $22.0 \pm 0.1$ & $22.0 \pm 0.1$ & $22.2 \pm 0.2$ & $22.2 \pm 0.2$ & $22.5 \pm 0.2$ \\
\hline 18:0 & $8.26 \pm 0.10$ & $8.13 \pm 0.11$ & $7.98 \pm 0.12^{2}$ & $7.79 \pm 0.13^{3}$ & $7.60 \pm 0.12$ \\
\hline $20: 0$ & $0.48 \pm 0.01$ & $0.48 \pm 0.01$ & $0.48 \pm 0.01$ & $0.47 \pm 0.01$ & $0.47 \pm 0.01$ \\
\hline $22: 0$ & $2.43 \pm 0.07$ & $2.28 \pm 0.13$ & $2.41 \pm 0.07$ & $2.36 \pm 0.07$ & $2.34 \pm 0.06$ \\
\hline $24: 0$ & $5.94 \pm 0.13$ & $5.85 \pm 0.17$ & $5.87 \pm 0.13$ & $5.94 \pm 0.15$ & $5.92 \pm 0.11$ \\
\hline SAFA & $40.3 \pm 0.2$ & $39.8 \pm 0.2$ & $40.1 \pm 0.2$ & $39.9 \pm 0.3$ & $40.0 \pm 0.2$ \\
\hline $18: \ln -7$ & $0.94 \pm 0.02$ & $0.93 \pm 0.02$ & $0.99 \pm 0.02^{3}$ & $0.97 \pm 0.03^{2}$ & $0.98 \pm 0.03^{3}$ \\
\hline $18: \ln -9$ & $11.0 \pm 0.2$ & $11.1 \pm 0.2$ & $11.0 \pm 0.2$ & $10.9 \pm 0.2$ & $10.8 \pm 0.2$ \\
\hline $20: \ln -9$ & $0.21 \pm 0.01$ & $0.22 \pm 0.01$ & $0.23 \pm 0.01$ & $0.22 \pm 0.01$ & $0.22 \pm 0.01$ \\
\hline $24: \ln -9$ & $5.31 \pm 0.10$ & $5.24 \pm 0.10$ & $5.39 \pm 0.13$ & $5.49 \pm 0.13$ & $5.55 \pm 0.12^{3}$ \\
\hline $20: 3 n-9$ & $0.03 \pm 0.01$ & $0.08 \pm 0.04$ & $0.04 \pm 0.01$ & $0.03 \pm 0.01$ & $0.03 \pm 0.00$ \\
\hline $18: 2 n-6$ & $11.4 \pm 0.2$ & $11.2 \pm 0.2$ & $10.8 \pm 0.2$ & $10.8 \pm 0.2$ & $10.3 \pm 0.2$ \\
\hline $20: 3 n-6$ & $1.42 \pm 0.06$ & $1.35 \pm 0.09$ & $1.42 \pm 0.05$ & $1.46 \pm 0.07$ & $1.54 \pm 0.07^{2}$ \\
\hline $20: 4 n-6$ & $10.4 \pm 0.2$ & $10.6 \pm 0.1$ & $10.5 \pm 0.2$ & $10.5 \pm 0.2$ & $10.6 \pm 0.2$ \\
\hline $22: 4 n-6$ & $2.77 \pm 0.08$ & $2.78 \pm 0.08$ & $2.79 \pm 0.08$ & $2.78 \pm 0.07$ & $2.88 \pm 0.08^{2}$ \\
\hline $22: 5 n-6$ & $0.29 \pm 0.02$ & $0.27 \pm 0.02$ & $0.28 \pm 0.02$ & $0.27 \pm 0.02$ & $0.30 \pm 0.02$ \\
\hline n-6 LCPs & $14.8 \pm 0.2$ & $15.0 \pm 0.2$ & $15.0 \pm 0.2$ & $15.0 \pm 0.2$ & $15.3 \pm 0.2$ \\
\hline$n-6$ & $27.4 \pm 0.3$ & $27.3 \pm 0.3$ & $27.0 \pm 0.3$ & $26.9 \pm 0.3$ & $26.9 \pm 0.3$ \\
\hline $18: 3 n-3$ & $0.11 \pm 0.01$ & $0.11 \pm 0.01$ & $0.10 \pm 0.01^{2}$ & $0.11 \pm 0.01$ & $0.13 \pm 0.01$ \\
\hline $20: 5 n-3$ & $0.48 \pm 0.04$ & $0.49 \pm 0.04$ & $0.50 \pm 0.05$ & $0.47 \pm 0.04$ & $0.46 \pm 0.06$ \\
\hline $22: 5 n-3$ & $1.96 \pm 0.06$ & $2.01 \pm 0.05$ & $2.02 \pm 0.06^{2}$ & $1.99 \pm 0.05$ & $1.97 \pm 0.05$ \\
\hline $22: 6 n-3$ & $2.94 \pm 0.12$ & $3.01 \pm 0.13$ & $3.14 \pm 0.14^{2}$ & $3.18 \pm 0.15^{3}$ & $3.43 \pm 0.15^{3}$ \\
\hline$n-3$ LCPs & $5.38 \pm 0.17$ & $5.51 \pm 0.17$ & $5.65 \pm 0.20$ & $5.64 \pm 0.20^{2}$ & $5.86 \pm 0.21^{3}$ \\
\hline$n-3$ & $5.54 \pm 0.17$ & $5.67 \pm 0.18$ & $5.80 \pm 0.20$ & $5.80 \pm 0.20^{2}$ & $6.04 \pm 0.20^{3}$ \\
\hline PUFA & $33.0 \pm 0.3$ & $33.1 \pm 0.2$ & $32.9 \pm 0.3$ & $32.8 \pm 0.3$ & $33.0 \pm 0.3$ \\
\hline MUFA & $17.9 \pm 0.2$ & $17.9 \pm 0.2$ & $18.0 \pm 0.2$ & $17.9 \pm 0.2$ & $17.9 \pm 0.2$ \\
\hline$n-6 / n-3$ & $5.1 \pm 0.3$ & $4.9 \pm 0.3$ & $4.8 \pm 0.3 \quad 2$ & $4.8 \pm 0.3$ & $4.6 \pm 0.1$ \\
\hline $22: 6 n-3 / 22: 5 n-6$ & $12.5 \pm 1.3$ & $12.6 \pm 1.4$ & $12.9 \pm 1.6$ & $13.9 \pm 1.7$ & $13.5 \pm 1.7$ \\
\hline $22: 5 n-6 / 22: 4 n-6$ & $0.10 \pm 0.01$ & $0.10 \pm 0.01$ & $0.10 \pm 0.01$ & $0.10 \pm 0.01$ & $0.10 \pm 0.01$ \\
\hline EFA index & $1.84 \pm 0.03$ & $1.84 \pm 0.03$ & $1.82 \pm 0.03$ & $1.82 \pm 0.04$ & $1.83 \pm 0.04$ \\
\hline Total mg/L & $1053 \pm 27$ & $1080 \pm 29$ & $1104 \pm 25$ & $1078 \pm 36$ & $1035 \pm 34$ \\
\hline
\end{tabular}

See Table 2 for legend. 
Table 4. Fatty acid intake (g/day) before pregnancy and at week 10 of pregnancy?

\begin{tabular}{|c|c|c|}
\hline & $\begin{array}{c}\text { Prepregnant } \\
n=19\end{array}$ & $\begin{array}{c}\text { week } 10 \\
n=20\end{array}$ \\
\hline Total fatt & $88.2 \pm 6.1$ & $86.9 \pm 4.0$ \\
\hline $16: 0$ & $15.6 \pm 1.3$ & $15.4 \pm 0.9$ \\
\hline $18: 0$ & $7.70 \pm 0.66$ & $7.3 \pm 0.4$ \\
\hline total sitturated fatty acids & $35.0 \pm 3.2$ & $34.1 \pm 1.7$ \\
\hline $18: \ln -9$ & $20.4 \pm 1.5$ & $20.9 \pm 1.2$ \\
\hline tolal monounsaturated fatty acids & $31.1 \pm 2.1$ & $30.9 \pm 1.6$ \\
\hline $18: 2 n-6$ & $13.2 \pm 0.9$ & $13.2 \pm 0.9$ \\
\hline $18: 3 n-6$ & $0.02 \pm 0.00$ & $0.01 \pm 0.00$ \\
\hline $20: 4 n-6$ & $0.03 \pm 0.01$ & $0.02 \pm 0.00$ \\
\hline total n-6 fatty acid & $1.3 .2 \pm 0.9$ & $13.2 \pm 0.9$ \\
\hline $18: 3 n-3$ & $1.09 \pm 0.12$ & $1.02 \pm 0.09$ \\
\hline $20: 5 n-3$ & $0.05 \pm 0.02$ & $0.08 \pm 0.03$ \\
\hline $22: 5 n-3$ & $0.01 \pm 0.00$ & $0.02 \pm 0.01$ \\
\hline $22: 6 n-3$ & $0.09 \pm 0.03$ & $0.14 \pm 0.05$ \\
\hline total $n-3$ fatty acids & $1.27 \pm 0.13$ & $1.29 \pm 0.12$ \\
\hline$n-6 / n-3$ & $11.3 \pm 0.8$ & $12.0 \pm 1.6$ \\
\hline total polyunsaturated fatty acids & $15.9 \pm 1.1$ & $15.7 \pm 0.9$ \\
\hline
\end{tabular}

${ }^{1}$ Datat are mean \pm SEM. There were no significant differences between the two assessment periods.

\section{Dietary fatty acid intakes and the relation with plasma and erythrocyte fatty acid compositions}

Dietary intakes were assessed twice using food frequency questionnaires (FFQs). In the first period, before pregnancy, intake data of five subjects were excluded from analysis and in the second period, at week 10 of pregnancy, intake data of four subjects were discarded because the FFQs were incomplete or were not returned. In Table 4, the data are presented of the remaining FFQs from which the dietary fatty acid intake was estimated. Paired t-test analysis was possible with data from the 15 subjects, of which both FFQs were analyzed. No significant differences between the two periods were found.

Before pregnancy, significant positive correlations were found between the dietary 22:6n-3 intake and the percentages of 22:6n-3 in plasma ( $P=0.009, r=0.64)$ and erythrocyte phoshpolipids $(\mathrm{P}=0.007, \mathrm{r}=0.65$ ). These correlations had disappeared at week 10 of pregnancy. For the other fatty acids presented in Table 4 , a statistically significant correlation was found only between dietary and plasma phospholipid 18:2n-6 at week 10 of pregnancy $(\mathrm{P}=0.004, \mathrm{r}=0.67)$. 
Analysis of the relationship between the change in maternal dietary fatty acid intake and the changes in maternal plasma and erythrocyte phospholipid fatty acid levels showed no statistical significant outcomes.

\section{DISCUSSION}

The present study shows the maternal essential fatty acids (EFAs) status in the first 10 week of pregnancy in a group of healthy women and changes in their dietary intake of EFAs in this period.

Al et al reported before that fat content and composition of the maternal diet remained unaltered during pregnancy, assessed at approximately week 13, and at weeks 22 and 32 of pregnancy (9). Using the same food frequency questionnaires, no major significant changes in dietary fatty acid intake were observed between the prepregnant period and week 10 of pregnancy. The total fat intake as well as the intake of saturated and polyunsaturated fatty acids during both periods was comparable to that reported before in Dutch pregnant women $(9,11)$. The results showed a low intake of $20: 4 n-6$ compared to data reported recently for British pregnant women (12): $26 \mathrm{mg} / \mathrm{day}$ and $21 \mathrm{mg} / \mathrm{day}$ compared to $198 \mathrm{mg} / \mathrm{day}$, respectively. This is probably due to the fact that, except for poultry and fish, the Dutch Nutrient Year Table did not contain information on the amounts of 20:4n-6 in meat. The meat consumption in the present study was slightly higher compared to data for pregnant women from the Dutch National Food Survey. Mean daily intakes of $110.8 \mathrm{~g}$ prepregnant and $136.0 \mathrm{~g}$ at week 10 of pregnancy were recorded compared to $104 \mathrm{~g}$ in the National Survey. The dictary 22:6n-3 intake in our group was also small, but higher than that reported for vegetarian pregnant women (12) and for Spanish women ingesting less than two fish meals/month (13). Similar to meat, the consumption of fish was slightly higher than that reported in the above mentioned Dutch Survey (14.84 and $16.33 \mathrm{~g} / \mathrm{d}$ compared to $11 \mathrm{~g} / \mathrm{d})$.

Pregnancy is generally associated with a marked hyperlipidemia, involving all lipid classes (14-19). These elevated lipid concentrations were suggested to improve fetal access to EFAs $(20,21)$. The concentration of plasma phospholipids was reported to increase over $65 \%$ from the first trimester through term $(14,16,22)$. An increase in phospholipidassociated fatty acids during pregnancy has also been reported $(5,23)$. Results of the present study revealed that plasma total fatty acid content starts to increase already within the first 10 weeks of pregnancy.

For its supply of $22: 6 n-3$, the fetus depends largely on the placental transfer (24). Previously, Al et al (5) reported a continuous increase in the amounts (mg/L) of 22:6n-3 in the maternal plasma from week 10 through term of approximately $52 \%$. In the present study we observed that at week 10 of pregnancy (mean $73.7 \mathrm{~d}$ ), the absolute and relative amounts of 22:6n-3 had already significantly increased. This observation might reflect maternal adjustment(s) at this stage of development to meet requirements for $22: 6 \mathrm{n}-3$ incorporation in 
the embryonic tissues. It should be recalled that the neural tube from which the central nervous system will be formed, starts to develop in these early days after conception (25).

At the first measurement during pregnancy, the amounts (mg/L) of 22:6n-3 had already increased by $14.26 \%$ from prepregnancy. Although the power of the study was too limited for this small change to become fully significant, the $\mathrm{P}$-value attained $(\mathrm{P}=0.013)$ indicates a true increase in the amounts of 22:6n-3 during this early phase of pregnancy already. This is supported by the significant, positive linear regression between the change in 22:6n-3 amounts and gestational age $(r=0.36, P=0.0006)$.

The mean estimated dietary 22:6n-3 intake in the present study over both periods was $117 \mathrm{mg} /$ day (range from 3 to $1,061 \mathrm{mg}$ ). Daily supplementation of non-pregnant women with either $285 \mathrm{mg}$ of 22:6n-3 alone as a microalgal oil (DHASCO) or with $266 \mathrm{mg}$ of 22:6n-3 as tuna fish oil, on top of their habitual diet for a 4-week period, increased plasma phospholipids $22: 6 \mathrm{n}-3$ by approximately $+34 \%$ and $+31 \%$, respectively (26). In the present study, the absolute amounts of plasma $22: 6 \mathrm{n}-3$ increased from $35.8 \pm 9.9 \mathrm{mg} / \mathrm{L}$ prepregnant to $52.3 \pm 14.5 \mathrm{mg} / \mathrm{L}$ at week 10 of pregnancy (Figure 1), representing an increase of approximately $46 \%$ from the non-pregnant state. This demonstrates that the effect of early pregnancy on the 22:6n-3 content of plasma phospholipids is considerably stronger than that of an increased consumption of about $270 \mathrm{mg} 22: 6 \mathrm{n}-3$ per day. Since a small but statistically not significant increase in the dietary $22: 6 \mathrm{n}-3$ intake was observed $(90 \mathrm{mg} / \mathrm{d}$ prepregnant compared with $142 \mathrm{mg} / \mathrm{d}$ at week 10 of pregnancy), the increased 22:6n-3 content of plasma phospholipids is unlikely of dietary origin only. Moreover, there was no correlation between the change in dietary 22:6n-3 intake and the change of this fatty acid in neither maternal plasma or erythrocyte phospholipids. As plasma phospholipids mainly originate from hepatic synthesis, the increase in 22:6n-3 levels during pregnancy might reflect a pregnancy-associated adjustment of the hepatic synthesis of $22: 6 \mathrm{n}-3$, with an enhanced or selective incorporation of this fatty acid in the phospholipids.

No changes were observed in the erythrocyte phospholipids total fatty acids amounts (Table 3). Nevertheless, clear compositional shifts were observed among the fatty acids, which largely reflected the changes found in plasma. As in plasma, there was a marked decrease in the percentages of 18:2n-6 accompanied by a significant increase in the percentages of the n- 6 LCPs, which suggests an enhanced elongation and desaturation of 18:2n-6 during early pregnancy.

In conclusion, this study demonstrates that the amounts of $22: 6 n-3$ in maternal plasma and erythrocyte phospholipids start to rise in very early pregnancy, which cannot be explained by changes in the dictary intake only. This rise likely reflects enhanced synthesis of 22:6n-3 from its precursor fatty acids, however, mobilization from maternal stores, reduced oxidation or both cannot be excluded. 


\section{ACKNOWLEDGEMENT}

We thank Hasibe Aydeniz and Marianne Simonis for their analytical work and assistance, Arnold Kester for his advice on the statistical analyses, and all women who parlicipated in this study.

\section{REFERENCES}

1. Clandinin MT, Chappell JE. Leong S. Heim T'. Swyer PR. Chance GW. Intrauterine fatty acid accretion rates in human brain: implications for fatty acid requirements. Early Hum Dev 1980:4:121-9.

2. Martinez M. Tïsue levels of polyunsaturated fatty acids during early human development. J Pediatr 1992;120:S129-38.

3. Stinson AM, Wiegand RD, Anderson RE. Fatty acid and molecular species compositions of phospholipids and diacylglycerols from rat retinal membranes. Exp Eye Res 1991;52:213-8.

4. Neuringer M. Connor WE, Lin DS, Barstad L, Luck S. Biochemical and functional effects of prenatal and postnatal omega 3 fatty acid deficiency on retina and brain in rhesus monkeys. Proc Natl Acad Sci U S A 1986:83:4021-5.

5. Al MD. Houwelingen ACV. Kester AD. Hasaart TH, de Jong AE. Hornstra G. Maternal essential fatly acid patterns during normal pregnancy and their relationship to the neonatal essential fatty acid status. $\mathrm{Br}$ J Nutr 1995;74:55-68.

6. Wynn M, Wynn A. Nutrition around conception and the prevention of low birthweight. Nutr Health 1988:6:37-52

7. Wynn AH. Crawford MA. Doyle W, Wynn SW. Nutrition of women in anticipation of pregnancy. Nutr Health 1991;7:69-88.

8. Otto SJ, Foreman-v. Drongelen MM. Houwelingen ACv, Hornstra G. Effects of storage on venous and capillary blood samples: the influence of deferoxamine and butylated hydroxytoluene on the fatty acid alterations in red blood cell phospholipids. Eur J Clin Chem Clin Biochem 1997;35:907-13.

9. Al MD, Badart Smook A. Houwelingen ACv, Hasaart TH. Hornstra G. Fat intake of women during normal pregnancy: relationship with maternal and neonatal essential fatty acid status. J Am Coll Nutr 1996; 15:49-55.

10. Netherlands Bureau of Nutrition Education. Dutch Food Composition Table 1996. the Hague: NEVO Foundation, 1996.

11. Voedingscentrum. The Dutch National Food Consumption Survey 1997-1998. the Hague, the Netherlands: Voorlichtingbureau voor de Voeding, 1998.

12. Lakin V. Haggarty P. Abramovich DR, et al. Dietary intake and tissue concentration of fatty acids in omnivore. vegetarian and diabetic pregnancy. Prostagland Leuk Essent Fatty 1998;59:209-220.

13. Sanjurjo P. Matorras R. Perteagudo L. Influence of fatty fish intake during pregnancy in the polyunsaturated fatty acids of erythrocyte phospholipids in the mother at labor and newborn infant. Acta Obstet Gynecol Scand 1995:74:594-8. 
14. Punnonen R. The relationship between serum oestradiol levels and serum triglyceride. cholesterol and phospholipid levels in normal human pregnancy. Br J Obstet Gynaecol 1977;84:838-45.

15. Darmady JM. Postle AD. Lipid metabolism in pregnancy. Br J Obstet Gynaecol 1982;89:211-5.

16. Desoye G. Schweditsch MO. Pfeiffer KP. Zechner R, Kostner GM. Correlation of hormones with lipid and lipoprotein levels during normal pregnancy and postpartum. J Clin Endocrinol Metab 1987;64:70412.

17. Jimenez DM, Pocovi M. Ramon-Cajal J, Romero MA. Martinez H. Grande F. Longitudinal study of plasma lipids and lipoprotein cholesterol in normal pregnancy and puerperium. Gynecol Obstet Invest 1988:25:158-64.

18. Alvarez JJ, Montelongo A. Iglesias A. Lasuncion MA. Herrera E. Longitudinal study on lipoprotein profile, high density lipoprotein subclass, and postheparin lipases during gestation in women. J Lipid Res 1996:37:299-308.

19. Sattar N. Greer IA. Louden J, et al. Lipoprotein subfraction changes in normal pregnancy: threshold effect of plasma triglyceride on appearance of small. dense low density lipoprotein. J Clin Endocrinol Metab 1997:82:2483-91.

20. Warth MR. Arky RA, Knopp RH. Lipid metabolism in pregnancy. II. Altered lipid composition in intermediage, very low, low and high-density lipoprotein fractions. J Clin Endocrinol Metab 1975;41:649-55.

21. Hachey DL. Benefits and risks of modifying maternal fat intake in pregnancy and lactation. Am J Clin Nutr 1994:59:454S-463S; discussion 463S-464S.

22. Vikrot $O$. Individual plasma phospholipids with special reference to the changes in pregnancy. Acta Med Scind Suppl 1965:435:1-23.

23. Otto SJ. Houwelingen ACv. Antal M, et al. Maternal and neonatal essential fatty acid status in phospholipids: an international comparative study. Eur J Clin Nutr 1997;51:232-42.

24. Innis SM. Essential fatty acids in growth and development. Prog Lipid Res 1991;30:39-103.

25. Clandinin MT. Brain development and assessing the supply of polyunsaturated fatty acid. Lipids 1999:34:131-7.

20. Otto SJ. Houwelingen ACV. Homstra G. The effect of different supplements containing docosahexaenoic acid on plasmal and erythrocyte fatty acids of healthy non-pregnant women. Nutr Res 2000;20:917-27. 


\title{
Chapter 6
}

\section{Comparison of the peri- and postpartum phospholipid polyunsaturated fatty acid profiles of lactating and non-lactating women}

Suzie J. Otto, Adriana C. van Houwelingen, Anita Badart-Smook, Gerard Hornstra

Submitted for publication

\begin{abstract}
Pregnancy is associated with increased absolute amounts of docosahexaenoic acid $(22: 6 n-3)$ in plasma phospholipids. Expressed as proportion of total fatty acids, 22:6n-3 declines slightly in late pregnancy. Hardly any information is available on the normalization of 22:6n-3 postpartum, which may be different between lactating and non-lactating mothers.

The aim was to investigate the postpartum course of the maternal plasma and erythrocyte long-chain polyenes (LCPs), particularly 22:6n-3, in relation to lactation and the dietary LCP intake.

Study population comprised healthy women, 36-37 week pregnant, intended to breastleed or bottle-feed their infant. Blood samples were collected at entry, after parturition on days 2 and 5, and at 1, 2, 4, 8, 16, 32 and 64 weeks postpartum. Fatty acid profiles were analyzed in plasma and erythrocyte phospholipids. Dietary intakes were assessed at weeks 4 and 32 postpartum, using a validated food frequency questionnaire.

After delivery, the percentages of plasma 18:2n-6, 20:4n-6, 20:5n-3 and 22:5n-3 increased over time, whereas those of 22:5n-6 decreased, but the patterns of change did not differ between the two groups. The percentages of 22:6n-3 declined significantly in the two groups, but more pronounced in the lactating mothers; this change was enhanced when lactation period was extended. The erythrocyte phospholipid fatty acids showed comparable shifts as observed in plasma. Despite the apparent higher dietary intake of essential fatty acids in the lactating group at week 4 , these were not statistically different from the nonlactating group

In contrast to the n-6 LCPs, the normalization of the postpartum course of maternal plasma and erythrocyte phospholipid n-3 LCPs differs between lactating and non-lactating women.
\end{abstract}




\section{INTRODUCTION}

Pregnancy is generally associated with hyperlipidemia (1), which is thought to facilitate the maternal supply of lipids and (essential) fatty acids for energy and structural use by the growing fetus $(2,3)$. The concentrations of the plasma phospholipid-associated fatty acids rise as well, with a relatively strong increase for docosahexaenoic acid, 22:6n-3 (4, 5), the most prominent n-3 fatty acid present and an important component of the developing central nervous system. Between the 10 th and 40 th week of gestation, the 22:6n-3 content of matemal plasma phospholipid was shown to increase by $\approx 52 \%$, from 47.1 to $71.7 \mathrm{mg} / \mathrm{L}$, whereas the increase of the other $n-3$ fatty acids combined was only $19.2 \%$, from 21.3 to $25.4 \mathrm{mg} / \mathrm{L}(6)$.

The postpartum course of $22: 6 n-3$ has not been described in detail before. Approximately 6 months after delivery, the maternal plasma phospholipid 22:6n-3 content has been shown to have decreased to values which were well below those seen in early pregnancy (4), and comparable to values of non-pregnant women (Chapter 5). However, no information is available on the course of this normalization. This course may be different between lactating and non-lactating mothers, because, after delivery, breastfeeding women continue to supply their own 22:6n-3, and other long-chain polyunsaturated fatty acids (long-chain polyenes: LCPS), to their infants. Therefore, it was decided to compare the postpartum course of the LCPs between lactating and non-lactating women. In addition, the dietary fatty acid intake was examined.

\section{SUBJECTS AND METHODS}

\section{Subjects}

Healthy pregnant women, between week 36 and 37 of pregnancy, were recruited through midwives in the area of Southern Limburg, the Netherlands. Only women meeting the following criteria were included: absence of any metabolic, cardiovascular (including hypertension), neurological, or renal disorder, not using any medication except multivitamins and iron supplementation, singleton pregnancy, term delivery, and no blood transfusion in the perinatal period. In total, 68 women were enrolled. However, 11 women were not followed up: six subjects did not deliver at term, two subjects received blood transfusion immediately after delivery, and three others stopped their participation after 4 wceks postpartum due to hospitalization of the baby, fainting during blood collection, or for personal reasons. Of the remaining 57 women, 22 exclusively bottle-fed their child and 35 started breast-feeding their infant. The study was approved by the Medical Ethics Committee of the University Hospital Maastricht, and written informed consent was obtained from each participant. 
Table 1. Clinical characteristics of the study population '.

\begin{tabular}{|c|c|c|}
\hline & $\begin{array}{l}\text { Lactating } \\
\qquad n=3.5\end{array}$ & $\begin{array}{c}\text { Non-Lactating } \\
\mathrm{n}=22\end{array}$ \\
\hline Age $(y r)$ & $31.9 \pm 0.4$ & $29.1 \pm 0.7^{2}$ \\
\hline Height $(\mathrm{m})$ & $1.69 \pm 0.01$ & $1.68 \pm 0.0 \mathrm{I}$ \\
\hline \multicolumn{3}{|l|}{ Weigh (kg) } \\
\hline before pregniancy & $64.8 \pm 1.5$ & $69.0 \pm 2.7$ \\
\hline gain during pregnancy & $12.0 \pm 0.8$ & $13.3 \pm 1.2$ \\
\hline at wh 64 posipartum & $60.2 \pm 1.7$ & $69.0 \pm 2.9$ \\
\hline Duration of breast-feeding (wh) & $20.4 \pm 2.3$ & \\
\hline Parity, 1/2/3 (n) & $16 / 12 / 7$ & $11 / 10 / 1$ \\
\hline \multicolumn{3}{|l|}{ Gestational age (wk) } \\
\hline at entry & $36.5 \pm 0.1$ & $36.2 \pm 0.1$ \\
\hline at delivery & $40.2 \pm 0.2$ & $40.4 \pm 0.3$ \\
\hline \multicolumn{3}{|l|}{ Birth outcomes } \\
\hline weight (g) & $3543 \pm 83$ & $3594 \pm 119$ \\
\hline length $(\mathrm{cm})$ & $50.9 \pm 0.4$ & $51.2 \pm 0.4$ \\
\hline head circumference $(\mathrm{cm})$ & $34.8 \pm 0.3^{3}$ & $34.9 \pm 0.4^{3}$ \\
\hline
\end{tabular}

'Data are mean \pm SEM

${ }^{2} \mathrm{P}=0.0004$. unpaired t-test

${ }^{3}$ head circumference: $n=29$ in the lactating group, $n=17$ in the non-lactating.

\section{Blood sample and dietary data collection}

Venous blood samples were collected into EDTA containing tubes at entry, and after parturition on the second day and the fifth day, and at 1, 2, 4, 8, 16, 32 and 64 weeks postpartum. After blood collection, plasma was separated from the erythrocytes by centrifugation. Aliquots of the plasma samples were divided over 2 storage cups and closed tightly under nitrogen. These samples were stored at $-80^{\circ} \mathrm{C}$ until fatty acid analysis. Erythrocytes underwent the same procedure, but were first washed twice with EDTA containing saline. BHT was added to all erythrocyte samples before storage (7).

The dietary fatty acid intake was assessed, using a validated food frequency questionnaire, specifically designed to collect data on fat consumption (8). The subjects completed the questionnaire at 4 and 32 weeks postpartum. The food consumption data were encoded according to the system of the Dutch Nutrient Databank (NEVO), and converted into energy and nutrients using the computerized version of the Dutch Year Food Table 1996 II (9). This table enabled the calculation of the intake of total fat and total saturated, mono- and polyunsaturated fatty acids, linoleic acid (18:2n-6), $\alpha$-linolenic acid (18:3n-3), total n-6 fatty acid, eicosapentaenoic acid (20:5n-3), docosahexaenoic acid (22:6n-3) and total $n-3$ fatty acid. 


\section{Fatty acids analyses}

The fatty acids of phospholipids isolated from maternal plasma and erythrocytes were analyzed as previously described (10). The composition of these fatty acids was determined by capillary gas chromatography using a $50 \mathrm{~m} \mathrm{BP1} \mathrm{non-polar} \mathrm{column,} 0.22 \times 0.10 \mu \mathrm{m}$, and a $50 \mathrm{~m} \mathrm{BPx70}$ polar column, $0.22 \times 0.25 \mu \mathrm{m}$ (SGE, Bester BV, Amstelveen, the Netherlands; (11). The amoun of each fatty acid was calculated on basis of the recovered fatty acid amount of the internal standard (1,2- $\alpha$-dinonadecanoyl phosphatidylcholine; PC[19:0 $]_{2}$ ). The results were expressed as $\mathrm{mg} / \mathrm{L}$ plasma or erythrocyte suspension, and as percentages of the total fatly acids (\% w/wt). The following fatty acids are reported: 18:2n$6,20: 4 n-6,22: 5 n-6,18: 3 n-3,20: 5 n-3,22: 5 n-3$, and 22:6n-3.

\section{Statistical analyses}

The data are presented as mean \pm SEM. Comparison of the clinical characteristics (continuous variables) between the two groups was performed by the unpaired t-test, whereas the Chi-square test was used for the variable parity. Repeated-measures ANOVA was used to examine the effects of lactation on the fatty acid composition of plasma and erythrocytc phospholipids. The ANOVA model included a grouping factor (lactating and non-lactating mothers), a time factor (fatty acid data from day 2 through week 64 postpartum), an interaction term between time and group (time $x$ group) and the covariate parity. Parity has been shown to correlate inversely with the 22:6n-3 content of plasma phospholipids (12). If interaction term was significant, changes in the fatty acid composition over time within each group were further studied by the repeated measures ANOVA and between groups comparisons were made with one-way ANOVA. To correct for baseline (week 36 of pregnancy), the fatty acid data included in the ANOVA models were the postpartum data at each sampling point minus the pregnant baseline value ( $\Delta$-fatty acid). The lactating group consisted of all women who had breastfed their infants after delivery; when a woman stopped breastfeeding she remained in this group. Further comparison between non-lactating and lactating mothers were made including 4 subgroups of lactating women, divided according to length of lactation: $\leq 9$ weeks, $n=5 ; 10-15$ weeks, $n=10 ; 16-21$ weeks, $n=9$, and $32-50$ weeks, $n=11$.

Dietary intakes at weeks 4 and 32 were examined within the groups by the Wilcoxon signed rank test and between the groups by the Mann-Whitney $U$ test. The relation between dietary fatty acid intake (\% of total fat) and plasma and erythrocyte fatty acid composition (\% of total fatty acids) was evaluated by the Spearman rank correlation test. Non-parametric tests were used because the data were not normally distributed.

Because of multiple testing, P-values less than 0.01 were considered significant. All statistical analyses were performed using StatView version 5.0 for Macintosh PPC (SAS Institute Inc., Cary, North Carolina). 
Table 2. Postpartum changes in plasma phospholipid total fatty acid amounts (mg/L) of the lactating and the non-lactating mothers ${ }^{1,2}$.

\begin{tabular}{|c|c|c|c|}
\hline Sampling time & & $\begin{array}{l}\text { l.actating } \\
n=35\end{array}$ & $\begin{array}{c}\text { Non-lactating } \\
n=22\end{array}$ \\
\hline \multirow{10}{*}{$\begin{array}{l}\text { wk } 36 \text { of pregnancy } \\
\text { postpartum }\end{array}$} & & $1702 \pm 44$ & $1894 \pm 90$ \\
\hline & diay 2 & $1616 \pm 59$ & $1698 \pm 72$ \\
\hline & day 5 & $1617 \pm 50$ & $1716 \pm 54$ \\
\hline & week 1 & $1549 \pm 48$ & $1568 \pm 49$ \\
\hline & week 2 & $1473 \pm 48$ & $1548 \pm 44$ \\
\hline & week 4 & $1417 \pm 31$ & $1438 \pm 45$ \\
\hline & week 8 & $1340 \pm 35$ & $1351 \pm 41$ \\
\hline & week 16 & $1293 \pm 47$ & $1330 \pm 37$ \\
\hline & weck 32 & $1216 \pm 41$ & $1347 \pm 39$ \\
\hline & week 64 & $1278 \pm 43$ & $1452 \pm 50$ \\
\hline
\end{tabular}

\footnotetext{
'Data are mean \pm SEM

${ }^{2}$ Based on repeated measures ANOVA: lime factor, $P<0.0001$, group factor and time $x$ group by interaction were not significant.
}

\section{RESULTS}

\section{Clinical characteristics}

The characteristics of the two groups are presented in Table 1. Except for age, the groups were not significantly different. The non-lactating mothers were younger $(29.1 \pm 0.7$ yr.) than the lactating ones $(31.9 \pm 0.4 \mathrm{yr}$.). All mothers had uncomplicated pregnancies and delivered full term singleton newborns (gestational ages $40.2 \pm 0.2$ weeks in the lactating group and $40.4 \pm 0.3$ weeks in the non-lactating group). There were no significant differences in the mean birth weights, birth lengths and head circumferences between the two groups.

\section{Fatty acid changes in the non-lactating and in the total group of lactating women}

No significant differences were observed between the lactating and the non-lactating mothers for plasma and erythrocyte fatty acid compositions at entry.

After delivery, total fatty acids in the plasma phospholipids (Table 2) decreased significantly over time in the lactating and non-lactating groups. Comparable results were observed for the n-6 fatty acids (Figure 1). Results were less consistent for the plasma n-3 fatty acids. Although 22:6n-3 (Figure 1) and total n-3 fatty acids (not given) showed significant downward courses postpartum in both groups, a decline in 18:3n-3 was statistically not significant (Figure 1). The amounts of 20:5n-3 (Figure 1) and 22:5n-3 (not shown) increased significant after delivery. However, neither for the $n-3$ nor for the $n-6$ 

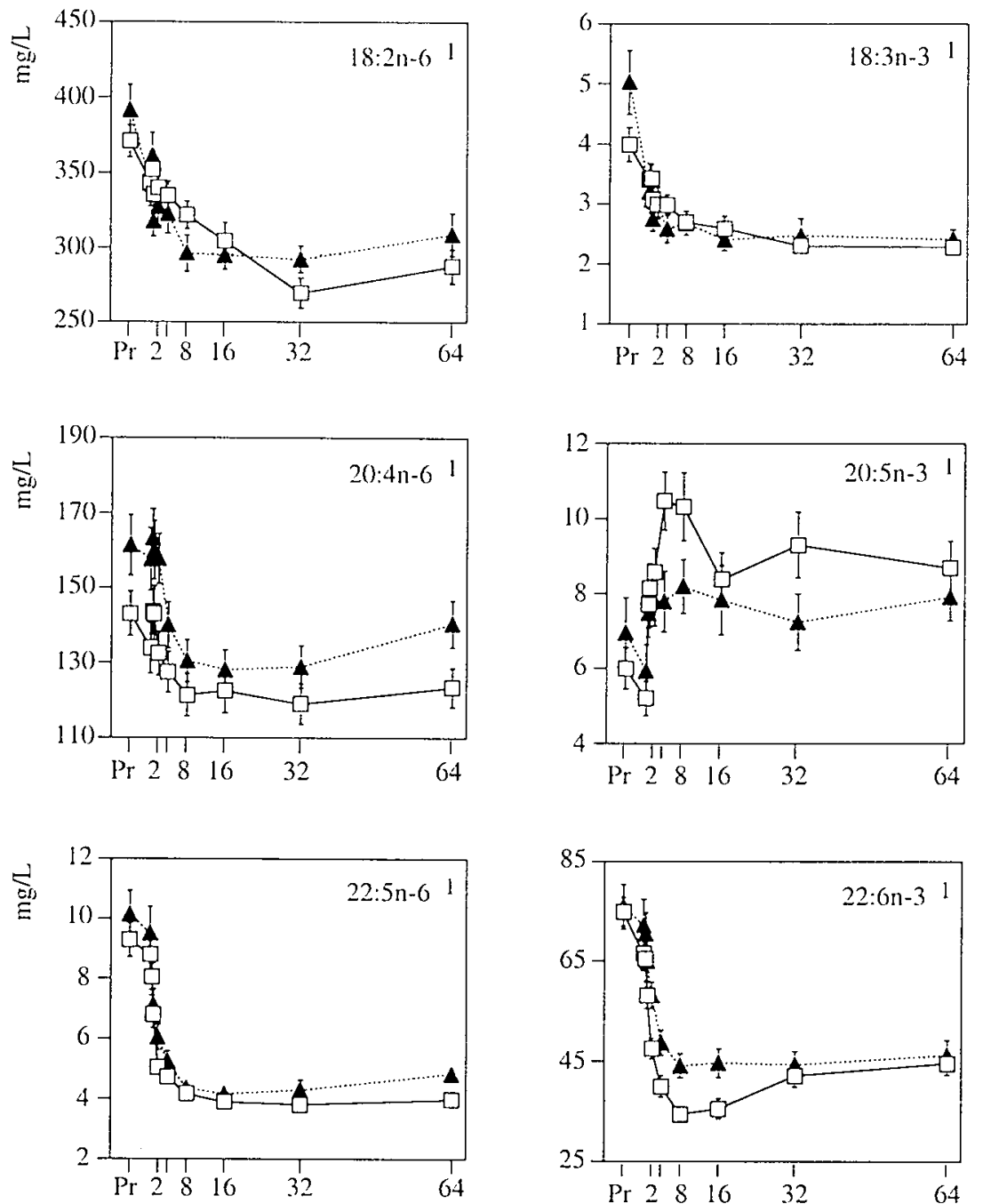

weeks postpartum

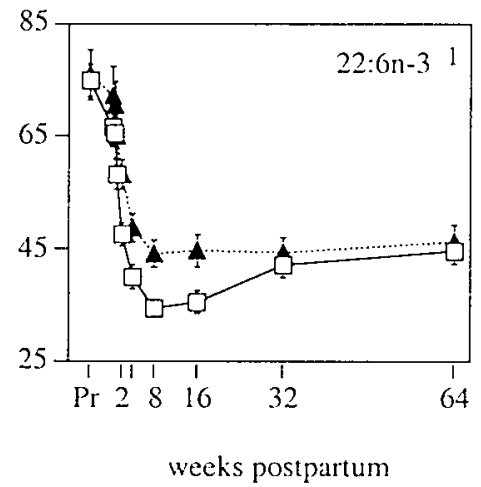

Figure 1. Postpartum changes in plasma phospholipid amounts (mg/L) of $n-6$ and $n-3$ fatty acids of the lactating. $-\square-$. and non-lactating mothers, …........ Data are mean \pm SEM. Straight dotted line represents mean value of 80 healthy non-pregnant women: $\operatorname{Pr}=$ week 36 of pregnancy.

' Significant effect of time, $\mathrm{P}<0.0001$ (repeated measures ANOVA). 

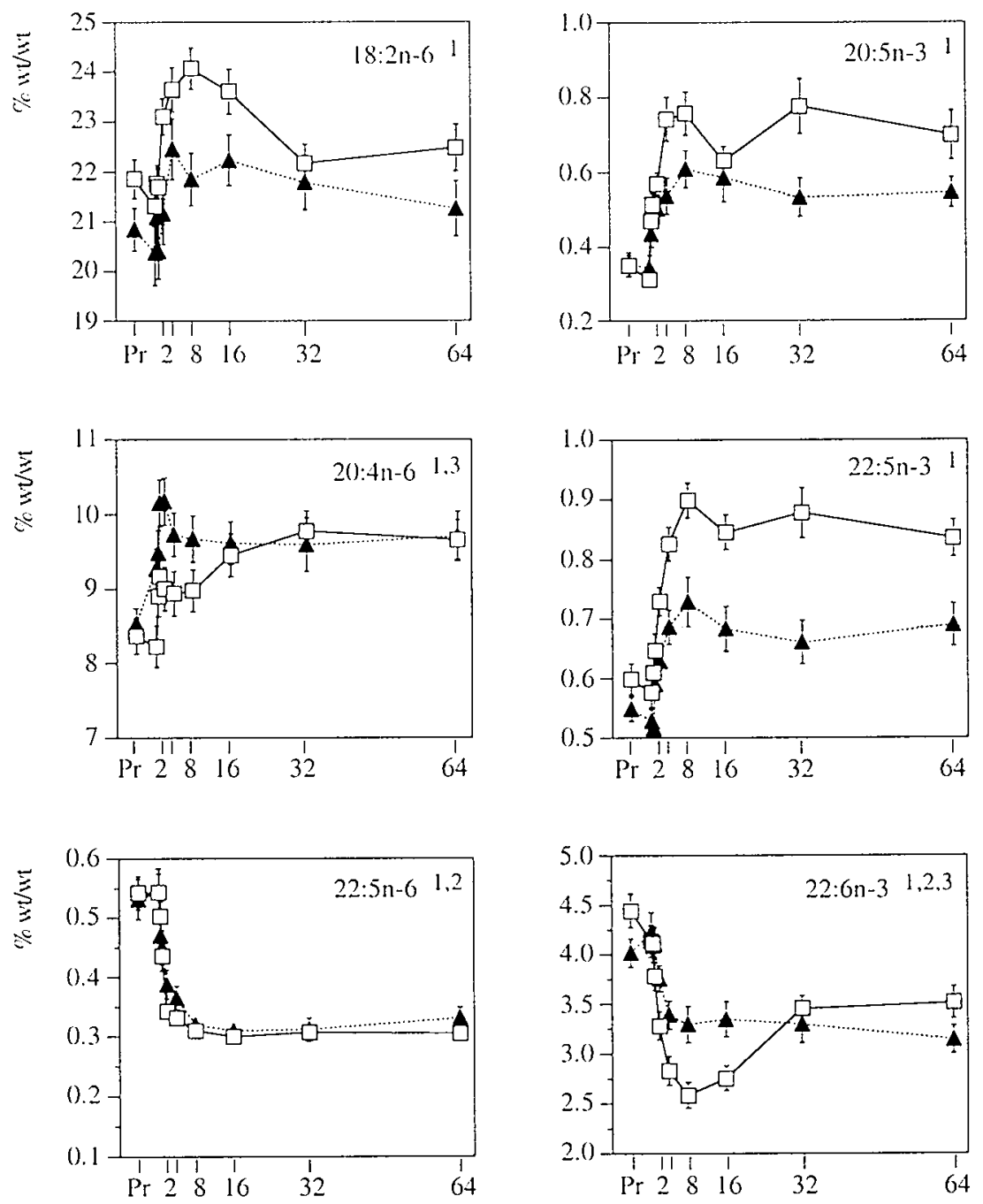

weeks postpartum

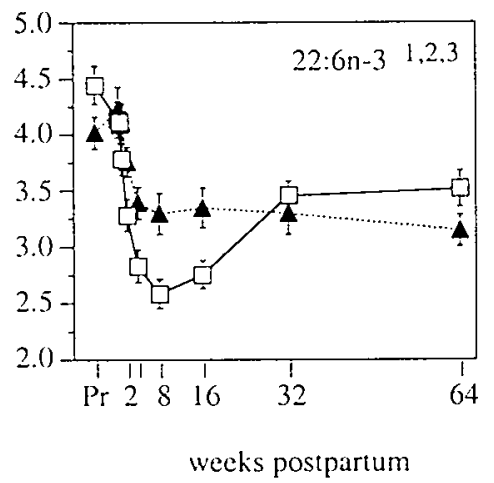

Figure 2. Postpartum changes in plasma phospholipid n-6 and n-3 fatty acid levels (\% wt/wt) of the lactating. $-\square-$. and non-lactating mothers. …....... Data are mean \pm SEM. Straight dotted line represents mean value of 80 healthy non-pregnant women: $\operatorname{Pr}=$ week 36 of pregnancy.

${ }^{1.2}$ Significant effect of ${ }^{1}$ time. $P<0.0001$, and ${ }^{2}$ group. $P=0.0014$ (repeated measures ANOVA).

'Significant time $x$ group interaction, $P<0.0001$ (repeated measures ANOVA). 

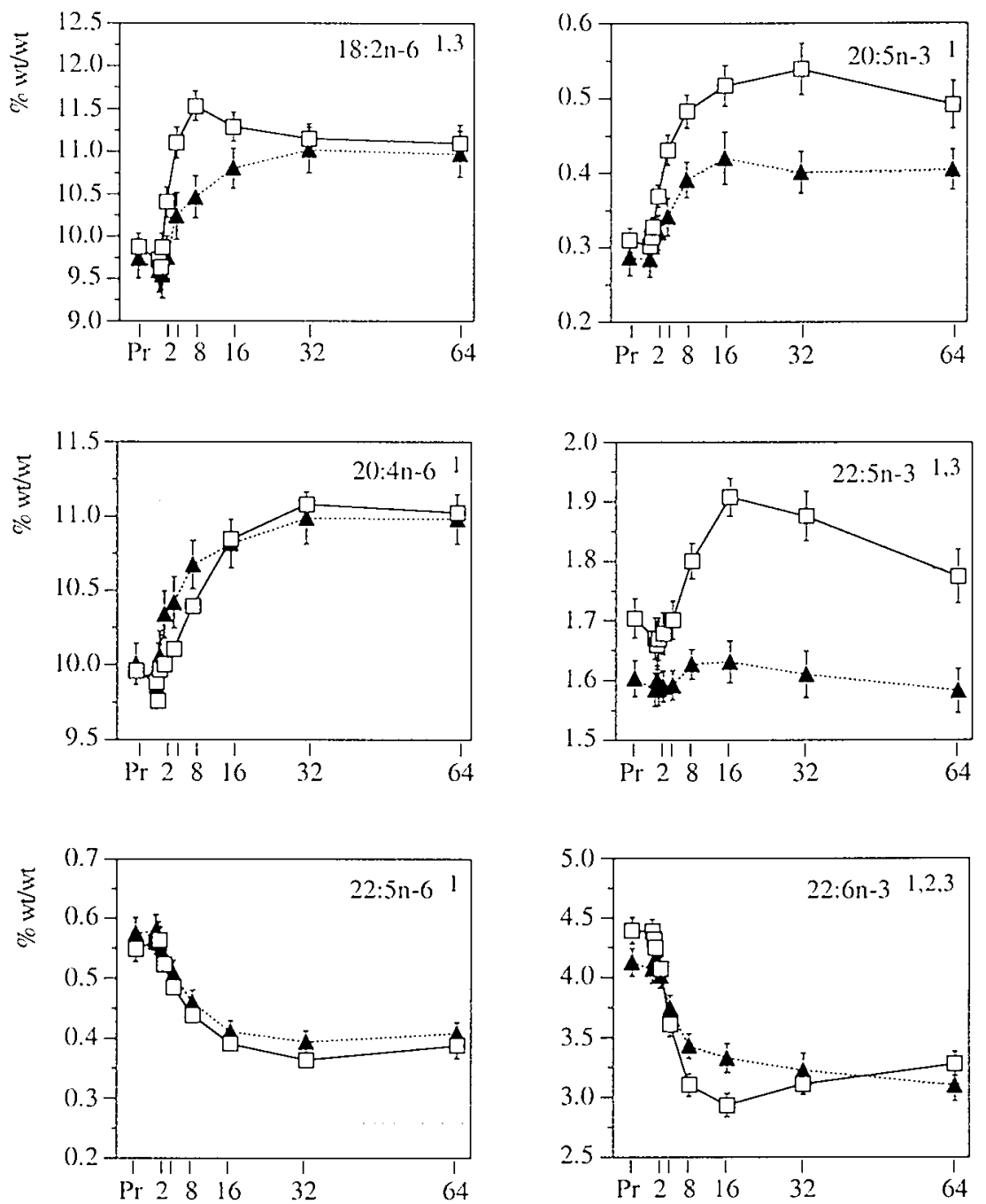

weeks postpartum

weeks postpartum

Figure 3. Postpartum changes in erythrocyte phospholipid n-6 and $n-3$ fatty acid levels (\% wt/wt) of the

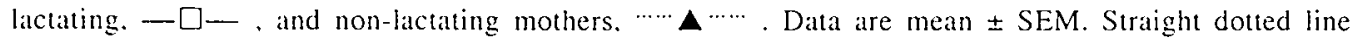
represents mean value of 80 healthy non-pregnant women: $\mathrm{Pr}=$ week 36 of pregnancy.

1.2 Significant effect of ${ }^{1}$ time, $P<0.0001$, and ${ }^{2}$ group, $P=0.0007$ (repeated measures ANOVA).

${ }^{3}$ Significant time $x$ group interaction, $P<0.001$ (repeated measures ANOVA). 
LCPs were the observed patterns of change significantly different between lactating and non-lactating mothers (no significant interaction terms).

When expressed as percentages of total phospholipid-associated plasma fatty acids (Figure 2), the courses of $18: 2 n-6$ and $20: 4 n-6$ were quite different from those seen for the absolute amounts. These fatty acids showed significant increases over time and the pattern of change (time $x$ group factor) of 20:4n-6 was significantly different between lactating and non-lactating mothers. Further analysis showed no significant differences between the two groups at any time point.
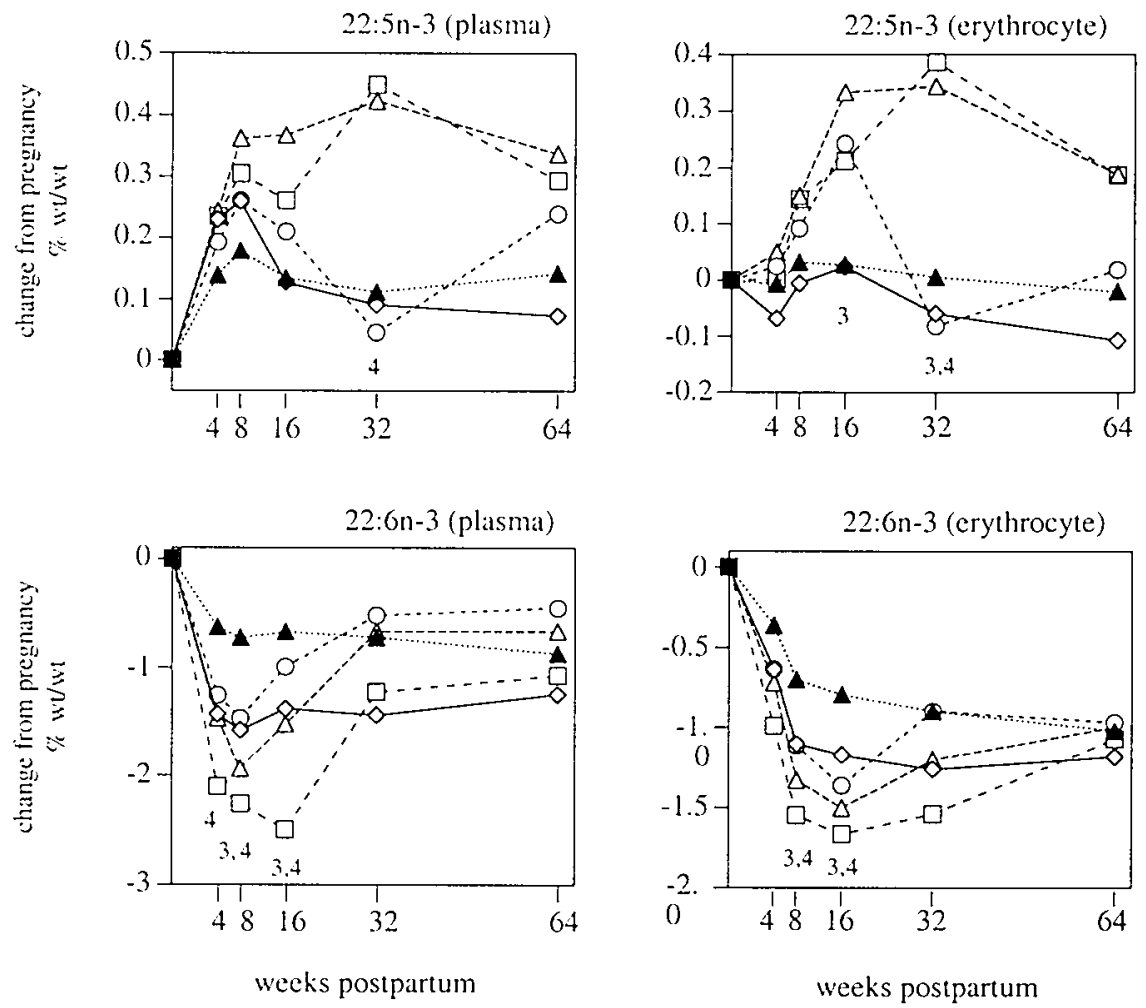

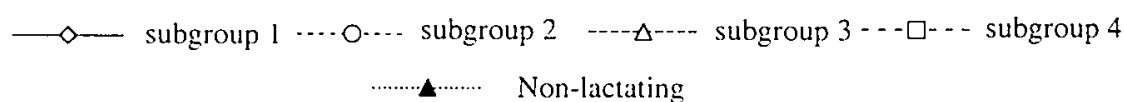

Figure 4. Changes from week 36 of pregnancy in plasma and erythrocyte phospholipid 22:5n-3 and 22:6n-3 (\% w $/ w t$ ) in relation to duration of breastfeeding: subgroup $1, n=5$ ( $\leq 9$ weeks). subgroup $2, n=10(10-15$ weeks), subgroup 3, $n=9(16-21$ weeks) and subgroup $4 . n=11$ ( $\geq 31$ weeks). For the sake of clarity the mean values between day 2 and week 2 postpartum and the SEM are not depicted; Pr= week 36 of pregnancy.

Time $x$ group interaction. $P<0.0001$ (repeated measures ANOVA).

i.4 Subgroups 3 and 4 differed significantly from the non-lactating group at the respective time points. $\mathrm{P}<0.0025$ (Bonferroni correction). 
No significant changes with time occurred in the percentages of $18: 3 n-3$ after delivery (data not shown), whereas the pereentages of $20: 5 n-3$ and $22: 5 n-3$ showed significant increalsed levels (Figure 2). For the percentages of plasma 22:6n-3 (Figure 2), the effects of time and group as well as the time by group interaction reached statistical significance. The percentages of 22:6n-3 decreased significantly over time in both groups and were between week 1 and week 16 significantly lower in lactating group than in the non-lactating group $(\mathrm{P}<0.001)$.

In general, the postpartum changes in the percentages of the fatty acids of erythrocyte phospholipids (Figure 3) were not different from those seen in plasma. However, the increasing patterns of $18: 2 n-6$ and $22: 5 n-3$ were now significantly different between lactating and non-lactating mothers. The postpartum downward course of 22:6n-3 resembled those seen in plasma and were, again, significantly different between the groups.

\section{Fatty acid changes in relation to duration of breast-feeding}

As mentioned carlier, during the observational period of 64 weeks there was a wide variation in the duration of lactation. Therefore, the effect of duration of lactation was studied by evaluating the pattern of change of the fatty acids between the non-lactating group and subgroups of women who breastfed their infants up to 9 weeks (subgroup 1), 10 15 weeks (subgroup 2), 16-21 weeks (subgroup 3), or 32-50 weeks (subgroup 4). No significant outcomes were found for the interaction terms of the n-6 fatty acids, neither in plasma nor in erythrocyte phospholipids (data not shown). In contrast, the patterns by which the plasma and erythrocyte phospholipid 22:5n-3 and 22:6n-3 changed over time were significantly different between the groups (Figure 4). Further comparisons between the nonlactating group with the 4 subgroups of lactating women showed significantly higher levels of plasma and crythrocyte phospholipid 22:5n-3 in the subgroups 3 and 4 at weeks 16 and 32 (Figure 4). Plasma and erythrocyte phospholipid 22:6n-3 were significantly lower in the subgroups 3 and 4 than in the non-lactating group at week 2 to 16 (Figure 4 ).

\section{Assessment of the dietary fatty acid intakes}

The mean daily intakes of total fat and the fatty acids are shown in Table 3. Although the dietary intakes of total fat and fatty acids in the lactating group seemed to be lower at week 32 than at week 4 , the differences were statistically not significant $(0.01<\mathrm{P}<0.05$, Wilcoxon signed rank test). At weeks 4 and 32 after delivery, the intakes of total saturated fatty acids were higher for the lactating as compared to the non-lactating group.

Significant correlations between maternal fatty acid intake and the respective fatty acid contents in plasma and erythrocyte phospholipids were observed only when the total group was considered ( $n=57$, both lactating and non-lactating mothers). These significant positive correlations were found only for total $n-6$ fatty acids at week $4(r=0.39, P=0.008$, plasma, and $r=0.41, P=0.004$, erythrocytes), and for $22: 6 n-3$ at week 32 ( $r=0.44, P=0.003$, plasma, and $\mathrm{r}=0.41, P=0.004$, erythrocytes). 
Table 3. The dictary intake of fatty acids (g/day) of the lactating and non-lactating mothers'.

\begin{tabular}{|c|c|c|c|c|}
\hline & \multicolumn{2}{|c|}{ Lactating } & \multicolumn{2}{|c|}{ Non-Lactating } \\
\hline & $\begin{array}{c}\text { week } 4 \\
n=33\end{array}$ & $\begin{array}{c}\text { week } 32 \\
n=28\end{array}$ & $\begin{array}{c}\text { week } 4 \\
n=17\end{array}$ & $\begin{array}{c}\text { week } 32 \\
n=19\end{array}$ \\
\hline Total fat ${ }^{2}$ & $101.9 \pm 5.6$ & $87.4 \pm 5.9$ & $79.2 \pm 4.6$ & $73.4 \pm 6.50$ \\
\hline total saturated fatty acids ${ }^{2}$ & $41.4 \pm 2.4$ & $35.5 \pm 2.3$ & $30.4 \pm 2.3^{3}$ & $26.5 \pm 2.69^{3}$ \\
\hline total monounsaturated fatty acids ${ }^{2}$ & $36.0 \pm 2.1$ & $30.9 \pm 2.2$ & $28.7 \pm 1.5$ & $27.3 \pm 2.36$ \\
\hline total polyunsaturated fatty acids 2 & $17.5 \pm 1.1$ & $15.0 \pm 1.3$ & $14.0 \pm 1.0$ & $14.4 \pm 1.31$ \\
\hline $18: 2 n-6$ & $14.9 \pm 1.0$ & $12.6 \pm 1.1$ & $12.4 \pm 1.0$ & $12.4 \pm 1.23$ \\
\hline tolal n-G fatty acids & $14.9 \pm 1.0$ & $12.7 \pm 1.1$ & $12.4 \pm 1.0$ & $12.5 \pm 1.24$ \\
\hline $18: 3 n-3$ & $1.23 \pm 0.09$ & $0.96 \pm 0.09$ & $0.93 \pm 0.08$ & $0.85 \pm 0.09$ \\
\hline $20: 5 n-3|\mathrm{mg}|$ & $47.3 \pm 11.1$ & $45.0 \pm 9.3$ & $28.8 \pm 8.3$ & $33.7 \pm 13.4$ \\
\hline 22:6n-3 lmgl & $90.6 \pm 18.1$ & $80.7 \pm 13.3$ & $51.8 \pm 11.5$ & $55.3 \pm 14.5$ \\
\hline lolal n-3 latty acids & $1.40 \pm 0.1$ & $1.1 \pm 0.10$ & $1.03 \pm 0.08$ & $0.90 \pm 0.10$ \\
\hline
\end{tabular}

'Data are mean \pm SEM.

${ }^{2}$ Dutch National Food Consumption Survey 1997-1998: total fat $=85 \mathrm{~g} / \mathrm{d}$, siturated fatty acids $=33 \mathrm{~g} / \mathrm{d}$. monounsaturated fatty acids $=30 \mathrm{~g} / \mathrm{d}$ and polyunsaturated fatty acids $=15 \mathrm{~g} / \mathrm{d}$.

${ }^{3}$ Significantly different from the lactating group (Mamn-Whitney U test, $P<0.01$ ).

\section{DISCUSSION}

The present study showed that the elevated amounts ( $\mathrm{mg} / \mathrm{L}$ ) of plasma phospholipid total fatty acids during pregnancy, declined in both lactating and non-lactating women after parturition. In addition, no significant differences were observed in their courses between the two groups (Table 2), which also applied to the individual n-3 and n-6 fatty acids (Figure 1). These results imply that the postpartum normalization of the quantitative plasma phospholipid fatty acid amounts occurs in the same manner in all women, regardless of the practice of breastfeeding or bottle-feeding.

However, when the relative fatty acid composition was considered ( $\% \mathrm{wt} / \mathrm{wt})$, significant differences were observed between non-lactating and lactating group, which involved the $\mathrm{n}$ 3 rather than the n-6 LCPs (Figures 2 and 3). The postpartum changes in the percentages of all n-6 LCPs (in Figures 2-3 shown for 20:4n-6 and 22:5n-6) were not significantly different between lactating and non-lactating mothers.

Compared to the levels measured at week 36 of pregnancy, the 22:6n-3 levels in maternal plasma, and erythrocyte phospholipids, decreased significantly after parturition in both lactating and non-lactating mothers, probably representing the postpartum normalization process of the plasma 22:6n-3 content. However, this decline was enhanced 
in the lactating group. As a result, the mothers still breastfeeding their infants at week 8 reached levels $(2.44 \pm 0.12 \%)$ significantly lower than the mean reference value $(2.95 \pm$ $0.08 \%)$ of non-pregnant women $(\mathrm{n}=80)$ of similar parity, whose last pregnancy was at least one year before blood collection ( $V$ an den Ham, submitted). These findings most likely reflect the utilization of DHA for breast milk. Breast milk DHA levels has been demonstrated to correlate positively with the content in maternal plasma phospholipid (13, 14), which is largely dependent on the dietary intake.

The mean estimated dietary intake of 22:6n-3 in the lactating group was not significantly different between the two assessment periods $(91 \mathrm{mg} / \mathrm{d}$ in early lactation and $81 \mathrm{mg} / \mathrm{d}$ at 32 weeks postpartum). Based on average Dutch figures for breast milk production (15) and composition (71.7 mg 22:6n-3 per L, $\mathrm{n}=65$, unpublished data), the daily 22:6n-3 transfer from a breastfeeding mother to her infant is approximately $50-53 \mathrm{mg}$. Comparable amounts of 22:6n-3 were estimated in the diet of the non-lactating women $(52$ and $55 \mathrm{mg} / \mathrm{d}$ at week 4 and 32 weeks postpartum, respectively). These data suggest that 22:6n-3 intake of the lactating women was probably sufficient to meet the demand for breastfeeding, but not to meet the mothers' own requirements and additionally maintain their plasma phospholipid 22:6n-3 at levels observed in the non-lactating women.

Recently, Makrides and Gibson (16) reported on postpartum changes in maternal plasma 22:6n-3. Just as our results, a decrease in maternal plasma 22:6n-3 content was observed in both lactating and non-lactating women after parturition, which they suggested to be probably related to a hormonal effect or increased utilization of maternal reserves, independent of lactation. It is conceivable that either or both 'processes' occur in women after parturition, but our longitudinal comparison between lactating and non-lactating mothers strongly suggest that the reductions in $22: 6 \mathrm{n}-3$ are at least in part related to lactation. Firstly, our data, as presented in Figure 4, show that the reductions in maternal 22:6n-3 became stronger the longer the duration of breastfeeding. Furthermore, it was demonstrated that at week 16 postpartum plasma and erythrocyte phospholipid 22:6n-3 levels of women still breastfeeding were significantly lower than those in the non-lactating group (Figure 4).

Unlike 22:6n-3, plasma phospholipid levels of the other n-3 LCPs rose after parturition. This effect was particularly evident in these women whose levels of 22:6n-3 showed the strongest reductions (Figure 4), suggesting that 22:6n-3 is selectively transferred to breast milk compared to the other n-3 LCPs. The postpartum courses as observed for $22: 6 n-3$ and the other n-3 LCPs showed opposite patterns than those observed for these fatty acids during pregnancy (6). Maternal plasma phospholipid 22:5n-3 decreased during pregnancy, whereas a decline was observed in 22:6n-3 after an initial increase until the second trimester (6). These observations suggest an enhanced synthesis of 22:6n-3 from the conversion of $22: 5 n-3$ to $22: 6 n-3$, which is no longer supported when pregnancy is terminated by delivery. 
Therefore, beside a selective transfer of $22: 6 n-3$ to breast milk, possibly the formation of DHA is altered, resulting in both a reduction in 22:6n-3 and an increase in 22:5n-3.

The mean daily intake of saturated fatty acids in the lactating women was significantly higher than that in the non-lactating women. Although the estimated dietary intake of the essential fatty acids in the lactating group at week 4 seemed higher than these recorded at week 32 and in the non-lactating group, these differences were statistically not significant (Table 4). Notwithstanding, compared with figures from the Dutch National Food Consumption Survey (17), for women in the same age category $(n=1472)$, the intake of total lat, saturated, monounsaturated and polyunsaturated fatty acids in the lactating women at week 4 appeared to be higher. This observation suggests that the practice of exclusive breastfecding might have an influence on the habitual maternal nutrition.

In summary, normalization of the postpartum course of maternal plasma and erythrocyte phospholipid n-6 LCPs did not differ between lactating and non-lactating women, in contrast to the n-3 LCPs. Plasma and erythrocyte phospholipid levels of 22:6n-3 decreased by approximately $20 \%$ in non-lactating women, whereas in the lactating women a further reduction was observed, augmented by duration of lactation. These markedly reduced 22:6n-3 levels had returned to non-lactating levels at week 32 postpartum. Further studies are required to elucidate the underlying mechanism involved in these postpartum changes of 22:6n-3.

\section{ACKNOWLEDGMENT}

We thank Hasibe Aydeniz for her technical assistance and Arnold Kester for his advice on the statistical analyses. We gratefully acknowledge the cooperation of Mrs. A. Heuts, Mrs. C. Smeets and Mrs. A. Merkx (midwives) and the participants.

\section{REFERENCES}

1. Dejager S. Turpin G. [Hyperlipidemia in pregnancy]. Presse Med 1996;25:1839-45.

2. Hachey DL. Benefits and risks of modifying maternal fat intake in pregnancy and lactation. Am J Clin Nutr 1994:59:454S-463S; discussion 463S-464S.

3. Warth MR. Arky RA, Knopp RH. Lipid metabolism in pregnancy. II. Altered lipid composition in intermediage, very low, low and high-density lipoprotein fractions. J Clin Endocrinol Metab 1975:41:649-55

4. Al MD, Houwelingen ACV, Kester AD, Hasalart TH, de Jong AE, Hornstra G. Maternal essential fatty acid patterns during normal pregnancy and their relationship to the neonatal essential fatty acid status. $\mathrm{Br}$ J Nutr 1995:74:55-68. 
5. Otto SJ, Houwelingen ACV. Antal M. Manninen A. Godfrey K. Lopez Jaramillo P. Hornstra G. Maternal and neonatal essential fatty acid status in phospholipids: an international comparative study. Eur J Clin Nutr 1997:51:232-42.

6. Al MDM. Essential fatty acids, pregnancy, and pregnancy outcome: relationship between mother and child. PhD Thesis. Human Biology. Maastricht: Matastricht University, 1994.

7. Otto SJ, Foreman-v. Drongelen MM. Houwelingen ACV. Hornstra G. Effects of storage on venous and capillary blood samples: the influence of deferoxamine and butylated hydroxytoluene on the fatty acid alterations in red blood cell phospholipids. Eur J Clin Chem Clin Biochem 1997:35:907-13.

8. A] MD. Badart Smook A. Houwelingen ACv. Hasaart TH. Hornstra G. Fat intake of women during normal pregnancy: relationship with maternal and neonatal essential fatty acid status. J Am Coll Nutr $1996: 15: 49-55$.

9. Netherlands Bureau of Nutrition Education. Dutch Food Composition Table 1990. the Hague: NEVO Foundation, 1990.

10. Foreman-v. Drongelen MM. Houwelingen ACv. Kester AD. de Jong AE, Blanco CE. Hasaart TH, Hornstra (s. Long-chain polyene status of preterm infants with regard to the fatty acid composition of their diet: comparison between absolute and relative fatty acid levels in plasma and erythrocyte phospholipids. Br J Nutr 1995:73:405-22.

11. Bakker EC, van Houwelingen AC, Hornstra G. Early nutrition. essential fatty acid status and visual acuity of term infants at 7 months of age. Eur J Clin Nutr 1999;53:872-879.

12. A] MDM. Houwelingen ACv. Hornstra G. Relation between birth order and the maternal neonatal docosahexaenoic acid status. Eur J Clin Nutr 1997;51:548-53.

13. Makrides M. Neumann MA. Gibson RA. Effect of maternal docosahexaenoic acid (DHA) supplementation on breast milk composition. Eur J Clin Nutr 1996:50:352-7.

14. Jensen CL. Maude M. Anderson RE. Heird WC. Effect of docosahexaenoic acid supplementation of lactating women on the fatty acid composition of breast milk lipids and maternal and infant plasma phospholipids. Am J Clin Nutr 2000;71:292S-9S.

15. van Ratij JM, Schonk CM, Vermat-Miedema SH, Peek ME, Hautvast JG. Energy cost of lactation, and energy balances of well-nourished Dutch lactating women: reappraisal of the extra energy requirements of lactation. Am J Clin Nutr 1991;53:612-9.

16. Makrides M. Gibson RA. Long-chain polyunsaturated fatly acid requirements during pregnancy and lactation. Am J Clin Nutr 2000:71:307-11.

17. Voedingscentrum. The Dutch National Food Consumption Survey 1997-1998. the Hague, the Netherlands: Voorlichtingbureau voor de Voeding, 1998. 


\title{
Chapter 7
}

\section{The effect of different supplements containing docosahexaenoic acid on plasma and erythrocyte fatty acids of healthy non-pregnant women.}

Suzie J. Otto, Adriana C van Houwelingen, Gerard Hornstra

Based on Nutrition Research 2000: 20: 917-927.

\begin{abstract}
To find an appropriate dictary supplement for pregnant women that would enhance their docosahexaenoic acid (22:6n-3) status, without decreasing the $n-6$ long-chain polyenes (LCPS) status, both in plasma and in erythrocyte phospholipids, a dose-finding study was performed in healthy non-pregnant women. Six groups of non-pregnant women received daily over a 4 -week period one of the following supplements: tuna fish oil $(0.266 \mathrm{~g} / \mathrm{d}$ or $0.532 \mathrm{~g} / \mathrm{d} 22: 6 \mathrm{n}-3)$, single cell-derived oils containing either $22: 6 \mathrm{n}-3$ alone $(0.285 \mathrm{~g} / \mathrm{d}$ or $0.570 \mathrm{~g} / \mathrm{d}$ ) or $22: 6 \mathrm{n}-3$ and arachidonic acid $(20: 4 \mathrm{n}-6 ; 0.570 \mathrm{~g} / \mathrm{d} 22: 6 \mathrm{n}-3$ and $0.259 \mathrm{~g} / \mathrm{d} 20: 4 \mathrm{n}-$ 6). A control group received a placebo containing microcrystalline cellulose. Fatty acids were analyzed in plasma, and erythrocyte phospholipids of the blood samples collected weekly.

After 4 weeks of supplementation, the levels of 22:6n-3 and n-6 LCPs of the control group were unchanged. In the other groups, the levels of 22:6n-3 were significantly and dose-dependently increased as compared to those in the control group. Significant reductions were found in the levels of $n-6$ LCPS, except in the group that received the mixture of 22:6n-3 and 20:4n-6 enriched single cell oils. So, only this latter mixture was eflective in increasing the levels of $22: 6 n-3$ and preventing an $n-3$ induced reduction in n-6 LCPs. Whether this supplement effect will be the same in pregnant women needs further investigation.
\end{abstract}




\section{INTRODUCTION}

It is well known that essential fatty acids (EFAs) and their longer-chain polyunsaturated derivatives, the long-chain polyenes (LCPS), serve important structural and regulatory functions during fetal and neonatal development. The most essential LCPs in this period are arachidonic acid (AA, 20:4n-6) and docosahexacnoic acid (DHA, 22:6n-3), which are found in high concentrations in the brain. Their accretions occur mainly during the third trimester of pregnancy, when the brain has its growth spurt, and in early childhood $(1,2)$. Consequently, the supply of these fatty acids to the fetus should be adequate and during pregnancy this is largely dependent on their levels in the maternal circulation and their transfer across the placenta.

Based on cross-sectional and longitudinal studies, several authors reported that the levels of the maternal 22:6n-3 decline during pregnancy (3-6), suggesting that mothers possibly cannot meet the requirements associated with their pregnancy. Moreover, the maternal levels of 22:6n-3 seemed to decline with the number of pregnancies (7). Since the maternal and the neonatal 22:6n-3 statuses are positively correlated, a low 22:6n-3 status of the mother can possibly lower that of the fetus $(6,8)$. The maternal 22:6n-3 status depends mainly on the dietary intake of this fatty acid, since conversion of $\alpha$-linolenic acid (18:3n-3) into 22:6n-3 seems to be low in humans. Therefore, in order to meet fetal requirements, it could be beneficial if the mothers increase their 22:6n-3 intake during pregnancy. Preliminary investigations showed that administration of $2.7 \mathrm{~g} \mathrm{n}-3$ fatty acids (from fish oil) during pregnancy not only increases the $\mathrm{n}-3 \mathrm{LCP}$ status of the neonates, but decreases the neonatal n-6 LCP status as well (9). These effects on the n-6 LCPs may not be desirable in pregnant women, since 20:4n-6 also plays an important role in fetal development and parturition. If it is felt that pregnant women need a $22: 6 \mathrm{n}$-3-containing supplement, than a supplement is required to enhance the 22:6n-3 status, without decreasing the n- 6 LCP status. To find such a supplement, we conducted a series of dose-finding studies in non-pregnant women, using the phospholipid fatty acid composition of their plasma and erythrocytes as markers of the systemic EFA and LCP status.

\section{SUBJECTS AND METHODS}

\section{Subjects}

The subjects included were healthy, non-pregnant women, aged 20 to 45 years who did not use any medication. After the study procedures were fully explained, each subject gave written consent to participate in the study, which was approved by the Medical Ethics Committee of the University Hospital Maastricht. The subjects were, thereafter, assigned to one of the six groups. The relevant clinical characteristics are presented in Table 1. 
Table 1. Clinical characteristics of the women'.

\begin{tabular}{lllllll}
\hline & \multicolumn{1}{c}{ low-FO } & high-FO & low-DHA & high-DHA & DHA+AA & Placebo \\
& \multicolumn{1}{c}{$\mathrm{n}=15$} & \multicolumn{1}{c}{$\mathrm{n}=15$} & \multicolumn{1}{c}{$\mathrm{n}=14$} & \multicolumn{1}{c}{$\mathrm{n}=12$} & \multicolumn{1}{c}{$\mathrm{n}=15$} & $\mathrm{n}=15$ \\
\hline Age $(\mathrm{yr})$ & $25.7 \pm 1.5$ & $24.5 \pm 0.9$ & $24.3 \pm 1.5$ & $24.7 \pm 1.8$ & $22.0 \pm 0.7$ & $23.7 \pm 0.9$ \\
Weight $(\mathrm{kg})$ & $60.6 \pm 2.4$ & $62.5 \pm 1.5$ & $60.6 \pm 2.3$ & $62.3 \pm 2.1$ & $62.4 \pm 2.1$ & $62.1 \pm 1.7$ \\
Height $(\mathrm{m})$ & $1.09 \pm 0.02$ & $1.71 \pm 0.02$ & $1.69 \pm 0.02$ & $1.69 \pm 0.02$ & $1.71 \pm 0.02$ & $1.08 \pm 0.01$ \\
BMI $\left(\mathrm{kg} / \mathrm{m}^{2}\right)$ & $21.1 \pm 0.5$ & $21.5 \pm 0.4$ & $21.1 \pm 0.6$ & $21.8 \pm 0.5$ & $21.4 \pm 0.6$ & $22.0 \pm 0.0$ \\
\hline
\end{tabular}

'Data are mean, with SEM in parentheses. No significant differences between the groups; FO: fish oil; DHA. docosahexaenoic acid (22:0n-3) and AA: arachidonic acid (20:4n-6).

\section{Supplements and design}

During the supplementation period of 4 weeks, each group received either encapsulated tuna fish oil, algae-derived 22:6n-3 containing oil (DHASCO), fungal-derived oil containing 20:4n-6 (ARASCO), or a placebo. The fatty acid compositions of the oils, determined after lipid extraction and gas-chromatographic analysis, are given in Table 2.

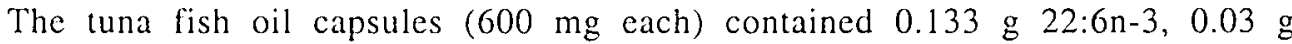
eicosapentaenoic acid (20:5n-3) and 0.01 g 20:4n-6 (Swiss Caps, Kirchberg, Switserland). Two groups received daily either two or four tuna fish oil capsules, the low-fish oil group (low-FO) and the high-fish oil group (high-FO), respectively. DHASCO was supplied in $500 \mathrm{mg}$ ( $0.19 \mathrm{~g}$ DHA/capsule) or $250 \mathrm{mg}$ capsules ( $0.10 \mathrm{~g} 22: 6 \mathrm{n}-3 /$ capsule). ARASCO was

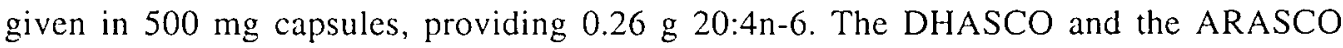
capsules were provided by Martek Biosciences, Columbia MD, USA. One group was supplemented daily with three $250 \mathrm{mg}$ DHASCO capsules (the low-DHA group), another with three $500 \mathrm{mg}$ DHASCO capsules (the high-DHA group) and one group received three 500 mg DHASCO capsules plus one ARASCO capsule (the DHA+AA group). The control group received daily three of the placebo capsules, containing $250 \mathrm{mg}$ microcrystalline cellulose. The final daily supplemented amounts of $22: 6 \mathrm{n}-3$ were: $0.27 \mathrm{~g}$ in the low-FO group, $0.53 \mathrm{~g}$ in the high-FO group, $0.29 \mathrm{~g}$ in the low-DHA group, and $0.57 \mathrm{~g}$ in the high-DHA and the DHA+AA groups. The latter group also received a daily amount of 0.26 g 20:4n-6.

The subjects were allowed to maintain their usual diets during the entire course of the study. Blood samples were collected into EDTA-containing tubes at each visit of the subjects to the department, at entry and weeks 1,2,3 and 4. The LCP status of the volunteers was evaluated by analysis of the phospholipid fatty acid composition in plasma and erythrocytes.

\section{Fatty acid analyses}

Plasma was separated from the erythrocytes by centrifugation, and the erythrocytes were washed twice with EDTA-containing saline before being properly stored (10) The fatty acid composition of phospholipids isolated from plasma and erythrocytes was 
Table 2. Fatty acid composition of the tuna fish oil and the DHASCO and ARASCO capsules

\begin{tabular}{lccc}
\hline $\begin{array}{l}\text { Fitty acids } \\
\text { \% wh/wt }\end{array}$ & Tuna Fish Oil & DHASCO & ARASCO \\
\hline Saturated & 36.2 & 44.1 & 23.0 \\
Monounsaturated & 19.9 & 14.9 & 8.8 \\
18:2n-6 & 1.7 & 0.9 & 6.3 \\
$20: 4 n-6$ & 1.8 & - & 51.7 \\
total n-6 & 3.9 & 0.9 & 65.1 \\
$20: 5 n-3$ & 5.1 & - & - \\
$22: 6 n-3$ & 22.2 & 37.9 & - \\
total n-3 & 29.6 & - & - \\
Unidentified & 9.9 & 1.5 & 2.6 \\
\hline
\end{tabular}

Each tuna fish oil capsule contiined $8 \mathrm{mg}$ vitamin E, whereas the DHASCO and ARASCO oils contained 0.025 weight \% vitamin $E$ and an equal amount of vitamin $C$.

determined, as previously described $(6,11)$. Briefly, after adding an internal standard (1,2$\alpha$-dinonadecanoyl phosphatidylcholine; (PC- $[19: 0]_{2}$ ) total lipid extracts of plasma and erythrocytes were prepared by a modified Folch extraction method $(12,13)$. The phospholipid fractions were isolated from the lipid extracts by using aminopropyl-bonded phase columns (14). The phospholipid fractions were hydrolyzed and the fatty acids methylated with boron trifluoride in methanol (15). The fatty acids methylesters were quantified on the basis of the recovery of the internal standard by capillary gas liquid chromatography, using a polar and a non-polar column (BPx70 and BP1, respectively, SGE, Bester BV, Amstelveen, the Netherlands), with helium as carrier gas. The fatty acids were expressed as $\mathrm{mg} / \mathrm{L}$ plasma or erythrocyte suspension, or as percentages of the total fatty acids $(\% \mathrm{wt} / \mathrm{wt})$. The following fatty acids and sums of fatty acids are reported: linoleic acid (18:2n-6), 20:4n-6, 22:5n-6, sum of the n-6 LCPs, 20:5n-3, 22:5n-3, 22:6n-3, sum of the n-3 LCPs. LCP is defined as the elongation and desaturation products of 18:2n-6 (20:3n-6, 20:4n-6, 22:4n-6 and 22:5n-6) and $\alpha$-linolenic acid, 18:3n-3 (20:4n-3, 20:5n-3, 22:5n-3 and 22:6n-3) that contain $\geq 20 \mathrm{C}$-atoms and $\geq 3$ double bound.

\section{Statistical analysis}

Data are presented as mean \pm SEM. Clinical variables were compared by analysis of variance (ANOVA). The effect of supplementation on the fatty acid levels was evaluated by comparing the supplemented groups with the control group using multiple regression analyses with the pretreatment fatty acid levels as covariate. Dummy variables were applied coding for the different treatment groups with the control group as reference. P-values less than 0.05 were considered significant. The analyses were done using StatView release 4.5 (Abacus Concepts, Inc., Berkeley, California). 
Table 3. Plasma phospholpid fatty acids at baseline, and changes after 4 weeks of supplementation with different n-3 preparations or placebo!

\begin{tabular}{|c|c|c|c|c|c|c|c|}
\hline $\begin{array}{l}\text { Falty acids } \\
\% w / w t\end{array}$ & & $\begin{array}{c}\text { low-FO } \\
\mathrm{n}=1.5\end{array}$ & $\begin{array}{c}\text { high-FO } \\
n=15\end{array}$ & $\begin{array}{c}\text { low-DHA } \\
n=14\end{array}$ & $\begin{array}{c}\text { high-DHA } \\
n=12\end{array}$ & $\begin{array}{c}D H A+A A \\
n=15\end{array}$ & $\begin{array}{c}\text { Placebo } \\
n=15\end{array}$ \\
\hline \multirow[t]{2}{*}{$18: 2 n-6$} & start & $23.0 \pm 1.0$ & $21.6 \pm 0.7$ & $23.1 \pm 0.7$ & $23.2 \pm 0.8$ & $21.3 \pm 0.8$ & $22.7 \pm 0.6$ \\
\hline & $w k 4$ & $22.7 \pm 0.8$ & $21.0 \pm 0.7$ & $23.0 \pm 0.7$ & $22.0 \pm 0.9$ & $19.5 \pm 0.79^{\circ}$ & $22.6 \pm 0.7$ \\
\hline \multirow[t]{2}{*}{$20: 4 n-6$} & start & $8.78 \pm 0.50$ & $10.1 \pm 0.36$ & $8.59 \pm 0.23$ & $9.10 \pm 0.45$ & $9.50 \pm 0.48$ & $8.90 \pm 0.31$ \\
\hline & $w k 4$ & $8.65 \pm 0.39$ & $8.90 \pm 0.31$ & $7.98 \pm 0.23$ & $8.34 \pm 0.55$ & $10.9 \pm 0.5$ & $8.96 \pm 0.34$ \\
\hline \multirow[t]{2}{*}{$22: 5 n-6$} & start & $0.22 \pm 0.03$ & $0.29 \pm 0.03$ & $0.33 \pm 0.03$ & $0.24 \pm 0.04$ & $0.28 \pm 0.02$ & $0.35 \pm 0.03$ \\
\hline & wk 4 & $0.19 \pm 0.02$ & $0.20 \pm 0.02$ & $0.26 \pm 0.03^{\prime \prime}$ & $0.10 \pm 0.01$ & $0.13 \pm 0.01$ & $0.34 \pm 0.03$ \\
\hline \multirow[t]{2}{*}{ n-6 LCPS ${ }^{2}$} & start & $12.3 \pm 0.7$ & $14.4 \pm 0.5$ & $12.5 \pm 0.3$ & $13.3 \pm 0.6$ & $13.8 \pm 0.5$ & $13.0 \pm 0.4$ \\
\hline & $w k 4$ & $11.8 \pm 0.5$ & $12.4 \pm 0.3$ & $11.6 \pm 0.3$ & $11.7 \pm 0.7$ & $14.2 \pm 0.6$ & $12.8 \pm 0.4$ \\
\hline \multirow[t]{2}{*}{$20: 5 n-3$} & start & $0.42 \pm 0.07$ & $0.41 \pm 0.03$ & $0.51 \pm 0.07$ & $0.50 \pm 0.09$ & $0.54 \pm 0.08$ & $0.45 \pm 0.05$ \\
\hline & wh 4 & $0.84 \pm 0.17$ & $0.79 \pm 0.04$ & $0.56 \pm 0.09$ & $0.73 \pm 0.19$ & $0.69 \pm 0.12$ & $0.49 \pm 0.04$ \\
\hline \multirow[t]{2}{*}{$22: 5 n-3$} & start & $0.52 \pm 0.03$ & $0.54 \pm 0.03$ & $0.58 \pm 0.04$ & $0.64 \pm 0.06$ & $0.62 \pm 0.05$ & $0.64 \pm 0.04$ \\
\hline & $w k 4$ & $0.60 \pm 0.06$ & $0.50 \pm 0.02$ & $0.48 \pm 0.03$ & $0.45 \pm 0.03^{b}$ & $0.47 \pm 0.03$ & $0.65 \pm 0.04$ \\
\hline \multirow[t]{2}{*}{$22: 6 n-3$} & start & $3.09 \pm 0.22$ & $3.25 \pm 0.16$ & $3.07 \pm 0.17$ & $2.98 \pm 0.20$ & $3.13 \pm 0.13$ & $3.20 \pm 0.17$ \\
\hline & $w k 4$ & $4.31 \pm 0.25^{\prime \prime}$ & $5.03 \pm 0.24$ & $4.16 \pm 0.19^{b}$ & $5.16 \pm 0.17^{a}$ & $5.35 \pm 0.20^{a}$ & $3.27 \pm 0.18$ \\
\hline \multirow[t]{2}{*}{$n-3$ LCPs ${ }^{2}$} & start & $4.17 \pm 0.30$ & $4.35 \pm 0.17$ & $4.32 \pm 0.22$ & $4.25 \pm 0.28$ & $4.44 \pm 0.20$ & $4.45 \pm 0.22$ \\
\hline & $w k 4$ & $5.88 \pm 0.43^{\circ}$ & $6.47 \pm 0.29$ & $5.35 \pm 0.25$ & $6.49 \pm 0.31$ & $6.65 \pm 0.30^{a}$ & $4.56 \pm 0.22$ \\
\hline
\end{tabular}

Data are mean \pm SEM; Fish oil (FO): low-FO $(0.27 \mathrm{~g}$ DHA/0.06 g EPA/0.02 g AA), high-FO $(0.53 \mathrm{~g}$ DHA/0.12 g EPA/0.04 g AA); Single Cells Oils: low-DHA (0.29 g DHA), high-DHA (0.57 g DHA). DHA+AA $(0.57 \mathrm{~g}$ DHA plus $0.26 \mathrm{~g}$ AA): Placebo: microcrystalline cellulose.

2 n-6 LCPs. long-chain polyenes: sum of 20:3n-6, 20:4n-6. 22:4n-6 and 22:5n-6;n-3 LCPs: sum of 20:4n-3. $20: 5 n-3,22: 5 n-3$ and $22: 6 n-3$.

ad Significantly different from control group: " $\mathrm{P}<0.0001,{ }^{b} \mathrm{P}<0.001$, $\mathrm{P}<0.01$, ${ }^{d} \mathrm{P}<0.05$ (multiple regression with correction for baseline value).

\section{RESULTS}

\section{Acceptability}

The six groups were comparable with respect to age, height, weight, and BMI (Table 1). No significant differences were found between the groups. No serious adverse reactions occurred in any of the groups. Occasionally, the subjects complained of eructation and a fishy taste after ingestion of the 22:6n-3 containing capsules, particularly in the groups receiving $0.57 \mathrm{~g}$ of $22: 6 \mathrm{n}-3$ from the algal-source. Two subjects complained of some other gastrointestinal side effects, which caused them to drop out before completion of the study (nausea, cramps and diarrhea, one subject, and bloating and flatulence, the other one; both in the high-DHA group). Another volunteer (low-DHA group) withdrew, because she moved to another city. Data of one subject in the high-DHA group were not included in the 
Table 4. Erythrocyte phospholpid fatty acids at baseline. and changes after 4 weeks of supplementation with different n-3 preparations or placebo 1 .

\begin{tabular}{|c|c|c|c|c|c|c|c|}
\hline $\begin{array}{l}\text { Fatty acids } \\
\% \mathrm{wt} / \mathrm{wt}\end{array}$ & & $\begin{array}{c}\text { low-FO } \\
n=1.5\end{array}$ & $\begin{array}{c}\text { high-FO } \\
n=15\end{array}$ & $\begin{array}{c}\text { low-DHA } \\
n=14\end{array}$ & $\begin{array}{c}\text { high-DHA } \\
n=12\end{array}$ & $\begin{array}{c}\mathrm{DHA}+\mathrm{AA} \\
\mathrm{n}=15\end{array}$ & $\begin{array}{c}\text { Placebo } \\
n=15\end{array}$ \\
\hline \multirow[t]{2}{*}{$18: 2 n-6$} & stant & $12.1 \pm 0.4$ & $11.1 \pm 0.3$ & $11.7 \pm 0.3$ & $12.2 \pm 0.3$ & $11.2 \pm 0.4$ & $11.7 \pm 0$ \\
\hline & $w k 4$ & $11.5 \pm 0.4$ & $10.6 \pm 0.3$ & $11.8 \pm 0.3$ & $11.5 \pm 0.4$ & $10.4 \pm 0.3$ & $11.6 \pm 0.3$ \\
\hline \multirow[t]{2}{*}{$20: 4 n-6$} & start & $10.9 \pm 0.28$ & $11.5 \pm 0.2$ & $10.5 \pm 0.1$ & $10.9 \pm 0.3$ & $11.3 \pm 0.3$ & $10.7 \pm 0.2$ \\
\hline & wk 4 & $10.5 \pm 0.2$ & $10.9 \pm 0.2$ & $10.2 \pm 0.1$ & $10.6 \pm 0.4$ & $11.6 \pm 0.2$ & $10.7 \pm 0.2$ \\
\hline \multirow[t]{2}{*}{$22: 5 n-6$} & start & $0.32 \pm 0.03$ & $0.38 \pm 0.03$ & $0.45 \pm 0.04$ & $0.32 \pm 0.03$ & $0.39 \pm 0.02$ & $0.44 \pm 0.03$ \\
\hline & wk 4 & $0.31 \pm 0.03$ & $0.34 \pm 0.02^{\prime \prime}$ & $0.43 \pm 0.04$ & $0.29 \pm 0.03$ & $0.30 \pm 0.02$ & $0.45 \pm 0.03$ \\
\hline \multirow[t]{2}{*}{ n-6 LCPs ${ }^{2}$} & stam & $15.6 \pm 0.4$ & $16.6 \pm 0.4$ & $15.6 \pm 0.2$ & $15.8 \pm 0.3$ & $16.4 \pm 0.3$ & $15.5 \pm 0.3$ \\
\hline & wh 4 & $15.0 \pm 0.3$ & $15.4 \pm 0.3$ & $15.0 \pm 0.2$ & $15.3 \pm 0.4$ & $16.2 \pm 0.3$ & 0.3 \\
\hline \multirow[t]{2}{*}{$20: 5 n-3$} & start & $0.37 \pm 0.08$ & $0.34 \pm 0.02$ & $0.36 \pm 0.03$ & $0.43 \pm 0.06$ & $0.42 \pm 0.05$ & $0.41 \pm 0.03$ \\
\hline & $w k 4$ & $0.48 \pm 0.07$ & $0.54 \pm 0.04$ & $0.40 \pm 0.04$ & $0.44 \pm 0.05$ & $0.43 \pm 0.04$ & $0.40 \pm 0.03$ \\
\hline \multirow[t]{2}{*}{$22: 5 n-3$} & start & $1.60 \pm 0.08$ & $1.53 \pm 0.04$ & $1.43 \pm 0.07$ & $1.67 \pm 0.06$ & $1.52 \pm 0.07$ & $1.56 \pm 0.04$ \\
\hline & $w k 4$ & $1.60 \pm 0.06$ & $1.46 \pm 0.03$ & $1.35 \pm 0.05^{\circ}$ & $1.40 \pm 0.07^{\prime \prime}$ & $1.32 \pm 0.06^{\prime \prime}$ & $1.55 \pm 0.05$ \\
\hline \multirow[t]{2}{*}{$22: 6 n-3$} & start & $3.36 \pm 0.16$ & $3.44 \pm 0.12$ & $3.32 \pm 0.12$ & $3.10 \pm 0.18$ & $3.20 \pm 0.15$ & $3.32 \pm 0.14$ \\
\hline & wh 4 & $3.97 \pm 0.15$ & $4.28 \pm 0.11$ & $3.80 \pm 0.12^{a}$ & $4.08 \pm 0.18^{a}$ & $4.28 \pm 0.10^{\circ}$ & $3.36 \pm 0.13$ \\
\hline \multirow[t]{2}{*}{$n-3 \operatorname{LCPS}^{2}$} & stant & $5.43 \pm 0.26$ & $5.40 \pm 0.14$ & $5.17 \pm 0.18$ & $5.25 \pm 0.21$ & $5.21 \pm 0.20$ & $5.35 \pm 0.18$ \\
\hline & wk 4 & $6.16 \pm 0.23^{\prime \prime}$ & $6.39 \pm 0.15^{\prime \prime}$ & $5.67 \pm 0.16^{a}$ & $5.99 \pm 0.16^{\circ}$ & $6.10 \pm 0.16^{a}$ & $5.38 \pm 0.18$ \\
\hline
\end{tabular}

See Table 3 for legend.

analyses after completion of the study, because of poor compliance. Eighty-six subjects completed the study.

\section{Fatty acid composition}

Since there was little difference noted in the total amounts of fatty acids in plasma and erythrocyte phospholipids between the supplemented groups and the control group, only the changes in the percentages of the fatty acids are shown in Tables 3 and 4, respectively. The time-related changes in the levels of 22:6n-3 and n-6 LCPs in plasma and erythrocytes of the six groups are presented in Figure 1.

After 4 weeks of supplementation, the plasma and erythrocyte levels of 22:6n-3 and n-3 LCPs had increased in all 22:6n-3-supplemented groups. These increases were all significantly different from those in the control group. The levels of 20:5n-3 remained unchanged, except for the two groups that received fish oil. In these two groups, plasma and erythrocyte levels of 20:5n-3 increased significantly in comparison with the control group.

As is also shown in Figure 1, after 4 weeks of intervention plasma levels of n-6 LCPs in most groups had decreased in comparison to the control group. There were two exceptions: in the DHA+AA group a small but significant increase was noted, whereas no difference in change was observed between the low-FO and the control group. Comparable results were 
observed for the erythrocyte phospholipids with again two exceptions: in the DHA+AA group no significant change occurred as compared to the control group, whereas the slight decrease in the low-FO group was significantly different from the change in the control group.
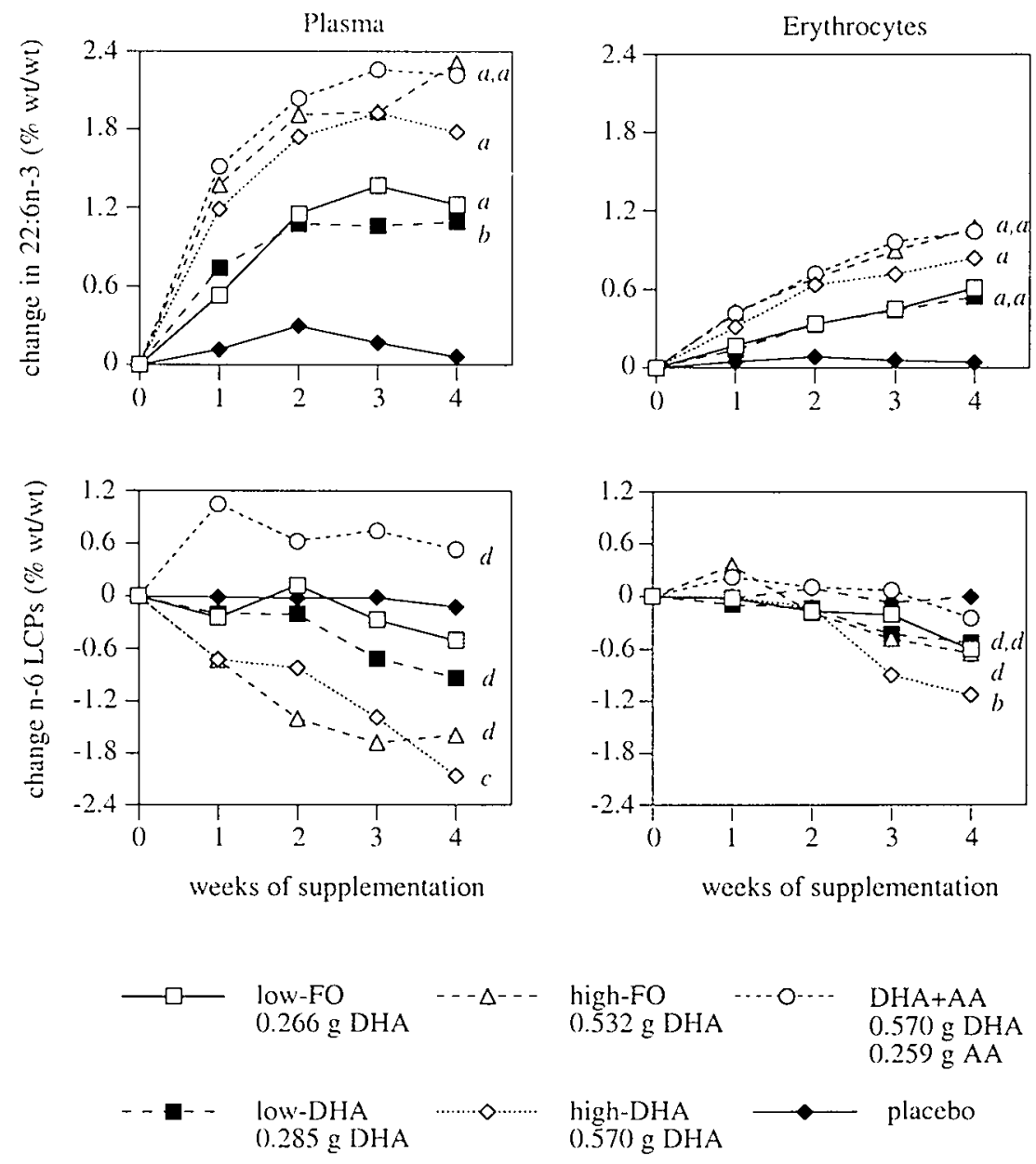

$0.259 \mathrm{~g} \mathrm{AA}$

high-DHA
0.570 g DHA

Figure 1. Time-related changes in the 22:6n-3 and the n-6 long-chain polyenes (LCPs) content of plasma and erythrocyte phospholipids after supplementation with different $n-3$ preparations or placebo.

a.d Significantly different from the control group at week 4: "P<0.0001. " $\mathrm{P}<0.001$, $\mathrm{P}<0.01$, , $\mathrm{P}<0.05$. 


\section{DISCUSSION}

The present study was conducted to find a supplement for pregnant women containing LCPs that would increase the levels ( $\% \mathrm{wt} / \mathrm{wt}$ ) of $22: 6 \mathrm{n}-3$ without reducing the levels of total n-6 LCPs in the phospholipids of both plasma and erythrocytes. As a first step, the study was performed in healthy non-pregnant women. Although the results obtained in nonpregnant women do not necessarily predict those in pregnant women, we adopted this procedure primarily to assess the acceptability and efficacy of the supplements containing either tuna fish oil or single cell oils. All five supplements tested proved to significantly increase the 22:6n-3 contents of both plasma and erythrocyte phospholipids compared to the placebo. The 22:6n-3 levels were dose-dependently increased. As shown in Figure 1, the levels of $22: 6 \mathrm{n}-3$ in plasma phospholipids appeared to reach a plateau between the second and the third week of supplementation. This failed to occur in erythrocyte phospholipids, suggesting a relatively slow 22:6n-3 turnover, regardless of its dose or source.

Two studies have so far been published in which pregnant women were supplemented with $22: 6 n-3$ in order to increase maternal and neonatal $22: 6 n-3$ status. In one study,

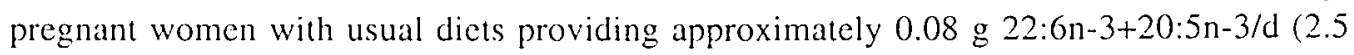
$\mathrm{g} /$ month), received daily an additional $2.6 \mathrm{~g} 22: 6 \mathrm{n}-3+20: 5 \mathrm{n}-3$, from fish oil and canned sardines (16). In the other study, the pregnant women were supplemented with $2.2 \mathrm{~g} 22: 6 \mathrm{n}$ $3+20: 5 n-3 / d$, from fish oil (9). Only the latter study reported on the effect of the supplement on the amounts of $n-6$ LCPs, which were shown to decline. A reducing effect of the $n-3$ LCP intake on the n-6 LCP status can also be deduced from the results of an observational study in Spanish pregnant women with high or low habitual fish consumption, equivalent to $0.65 \mathrm{~g} 22: 6 \mathrm{n}-3+0.32 \mathrm{~g} 20: 5 \mathrm{n}-3$ and $0.05 \mathrm{~g} 22: 6 \mathrm{n}-3$ plus $0.03 \mathrm{~g} \mathrm{20:5n-3}$ per day, respectively (17). As mentioned earlier, in the present study the highest dosages provided daily $0.53 \mathrm{~g}$ $22: 6 n-3$ plus 0.12 g 20:5n-3 or $0.57 \mathrm{~g} \mathrm{22:6n-3}$ alone. These are amounts that can be achieved in those subjects that, instead of fish oil, choose to increase their consumption of fatty fish, to at least $100 \mathrm{~g} /$ day (18). However, neither fish oil supplements (low- and highFO) nor the dosages of 22:6n-3 alone (low- and high-DHA) were able to maintain the total n-6 LCP levels in plasma and erythrocytes phospholipids, although these levels remained well within range observed for 186 not supplemented healthy women (plasma: 7.43$17.88 \%$, erythrocytes: $12.95-22.62 \%$ : unpublished data). However, for most groups these n6 LCP levels had not yet reached a steady-state after 4 weeks of supplementation. The same was observed for the change in erythrocyte 22:6n-3 levels. Recently, Katan and co-workers had shown that the steady-state for n-3 LCPs in erythrocyte phospholipids was reached after 180 days of supplementation, with $0.16 \mathrm{~g}-0.49 \mathrm{~g} 22: 6 \mathrm{n}-3$ plus $0.810 \mathrm{~g}-2.43 \mathrm{~g} 20: 5 \mathrm{n}-3$ (19).

The most appropriate supplement meeting our aim, was the mixture of $0.570 \mathrm{~g} 22: 6 \mathrm{n}-3$

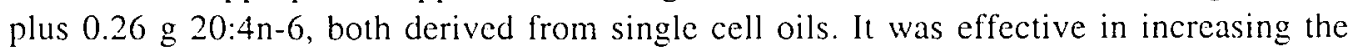
DHA levels without a reduction in the n-6 LCP status, both in plasma and in erythrocyte phospholipids. However, the levels of n-6 LCPs may further decrease, if the administration is prolonged (Figure 3). A mixture of the algal-derived 22:6n-3 and fungal-derived 20:4n-6, 
from the same manufacturer, has extensively been studied before in different dosages by Innis and Hansen (20). However, the 22:6n-3 to 20:4n-6 ratio used in that study ( $\approx 1: 1.25$ ) was markedly different from that investigated in our study $(\approx 2.2: 1)$. Innis and Hansen observed no significant adverse effects, apart from eructation which was also the major complaint in our study in those subjects receiving the single cell oils supplements.

In summary, administration of 22:6n-3 alone, even in a low dose, reduced the levels of the total n-6 LCPs. This study has shown that daily supplementation of $0.57 \mathrm{~g} 22: 6 \mathrm{n}-3 \mathrm{in}$ combination with $0.26 \mathrm{~g} 20: 4 \mathrm{n}-6$ increases the levels of $22: 6 \mathrm{n}-3$ without a concomitant decline in the levels of $n-6$ LCPs, particularly 20:4n-6, in both plasma and erythrocyte phospholipids. Whether the effect of this mixture of $22: 6 n-3$ and $20: 4 n-6$ will also be achieved in pregnant women, needs to be proven.

\section{ACKNOWLEDGEMENT}

We thank Martek Biosciences Corporation for the donation of the DHASCO and ARASCO capsules, and acknowledge the financial support by Numico BV, the Netherlands.

\section{REFERENCES}

1. Clandinin MT. Chappell JE, Leong S. Heim T. Swyer PR. Chance GW. Extrauterine fatty acid accretion in infant brain: implications for fatty acid requirements. Early Hum Dev 1980:4:131-8.

2. Clandinin MT, Chappell JE, Leong S. Heim T, Swyer PR. Chance GW. Intrauterine fatty acid accretion rates in human brain: implications for fatty acid requirements. Early Hum Dev 1980:4:121-9.

3. Skryten A. Johnson P. Gustafson A. Studies in normal pregnancy. III. Fatty acid composition of serum phosphoglycerides and cholesterol esters. Acta Obstet Gynecol Scand 1980:59:305-9.

4. Holman RT. Johnson SB, Ogburn PL. Deficiency of essential fatty acids and membrane fluidity during pregnancy and lactation. Proc Natl Acad Sci US A 1991;88:4835-9.

5. Sanjurjo P. Matorras R. Ingunza N. Alonso M. Rodriguez Alarcon J. Perteagudo L. Cross-sectional study of percentual changes in total plasmatic fatty acids during pregnancy. Horm Metab Res 1993:25:590-2.

6. Al MD. Houwelingen ACV. Kester AD. Hasaart TH. de Jong AE. Hornstra G. Maternal essential fatty acid patterns during normal pregnancy and their relationship to the neonatal essential fatty acid status. $\mathrm{Br}$ J Nutr 1995:74:55-68.

7. Al MDM. Houwelingen ACv, Hornstra G. Relition between birth order and the maternal neonatal docosahexaenoic acid status. Eur J Clin Nutr 1997:51:548-53.

8. Otto SJ. Houwelingen ACv. Antal M. Manninen A. Godfrey K. López-Jaramillo P. Hornstra G. Maternal and neonatal essential fatty acid status in phospholipids: an international comparative study. Eur J Clin Nutr 1997:51:232-42. 
9. Houwelingen ACV, Sorensen JD. Hornstra G. Simonis MM, Boris J, Olsen SF, Secher NJ. Essential fatty acid status in neonates after fish-oil supplementation during late pregnancy. Br J Nutr 1995;74:723-31.

10. Otto SJ, Foreman-van Drongelen MM, Houwelingen ACv. Hornstra G. Effects of storage on venous and capillary blood samples: the influence of deferoxamine and butylated hydroxytoluene on the fatty acid alterations in red blood cell phospholipids. Eur J Clin Chem Clin Biochem 1997;35:907-13.

11. Foreman-van Drongelen MM. Houwelingen ACV. Kester AD. de Jong AEP. Blanco CE. Hasaart THM. Hornstra $G$. Long-chain polyene status of preterm infants with regard to the fatly acid composition of their diet: comparison between absolute and relative fatty acid levels in plasma and erythrocyte phospholipids. Br J Nutr 1995:73:405-22.

12. Folch J. Sloane Stanley GH. A simple method for the isolation and purification of total lipides from animal tissues. J Biol Chem 1957:226:497-509.

13. Hoving EB, Jansen G, Volmer M. Van Doormal JJ. Muskiet FA. Profiling of plasma cholesterol ester and triglyceride fatty acids as their methyl esters by capillary gas chromatography. preceded by a rapid aminopropyl-silicil column chromatographic separation of lipid classes. J Chromatogr 1988:434:395409.

14. Kaluzny MA. Duncan LA. Merritt MV, Epps DE. Rapid separation of lipid classes in high yield and purity using bonded phase columns. J Lipid Res 1985:26:135-40.

15. Morrison WR. Smith LM. Preparation of fatty acid methyl esters and dimethylacetals from lipids with boron huoride-methanol. J Lipid Res 1964:5:600-8.

16. Connor WE, Lowensohn R. Hatcher L. Increased docosahexaenoic acid levels in human newborn infants by administration of sardines and fish oil during pregnancy. Lipids 1996:31:S183-7.

17. Sanjurjo P. Matoras R, Perteagudo L. Influence of fatty fish intake during pregnancy in the polyunsaturated fatty acids of erythrocyte phospholipids in the mother at labor and newborn infant. Acta Obstet Gynccol Scind 1995:74:594-8.

18. Houwelingen ACv. Kester AD. Kromhout D. Hornstra G. Comparison between habitual intake of polyunsaturated fatty acids and their concentrations in serum lipids fractions. Eur $J$ Clin Nutr 1989:43:11-20.

19. Katan MB. Deslypere JP. van Birgelen AP. Penders M. Zegwaard M. Kinetics of the incorporation of dietary fatty acids into serum cholesteryl esters. erythrocyte membranes, and adipose tissue: an 18 month controlled study. J Lipid Res 1997;38:2012-22.

20. Innis SM, Hansen JW. Plasma fatty acid responses, metabolic effects, and safety of microalgal and fungal oils rich in arachidonic and docosahexaenoic acids in healthy adults. Am $J$ Clin Nutr 1996:64:159-67. 


\section{Chapter 8}

\section{The effect of supplementation with docosahexaenoic and arachidonic acid derived from single cell oils on plasma and erythrocyte fatty acids of pregnant women in the second trimester}

Suzie J. Otto, Adriana C. van Houwelingen and Gerard Hornstra

Submitted for publication

\section{ABSTRACT}

This study was performed to investigate whether supplementation of docosahexaenoic (DHA, 22:6n-3) and arachidonic acid (AA, 20:4n-6) to pregnant women would enhance their $22: 6 n-3$ status and prevent the well-known n-3 induced reduction in the total n-6 longchain polyenes (LCPs) status both in plasma and in erythrocyte phospholipids.

Twenty-four healthy pregnant women, aged 20-38 yr in early second trimester, were recruited by the Department of Obstetrics and Gynecology (University Hospital Maastricht) and by midwives practices in the area of Maastricht. The volunteers were randomly assigned to either the control group $(n=12)$ or the intervention group $(n=12)$. The $n-3$ and $n$ 6 fatty acids status was investigated over a 4 -week period, in which blood samples were collected weekly. The control group received no supplements and the intervention group received encapsulated algae-derived $22: 6 \mathrm{n}-3$ oil and fungal-derived $20: 4 \mathrm{n}-6$ oil, providing

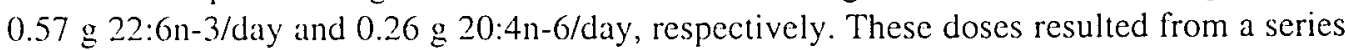
of pilot studies in non-pregnant women. All participants were allowed to maintain their usual dietary habits.

22:6n-3 and n-6 LCPs levels in plasma and erythrocyte phospholipids of the control group were unchanged during the 4 weeks. In the intervention group, the levels of 22:6n-3 in plasma and erythrocytes increased significantly compared to those in the control group. No significant reductions were found in the levels of 20:4n-6 and the total n-6 LCPs in both plasma and erythrocyte phospholipids.

The supplement proved to be effective in increasing the levels of 22:6n-3 in both plasma and erythrocyte phospholipids without a concomitant decline of the n-6 LCP status of the pregnant women in second trimester. 


\section{INTRODUCTION}

The long-chain polyenes (LCPS) docosahexaenoic acid (DHA, 22:6n-3) and arachidonic acid (AA, 20:4n-6) have important functions during fetal and neonatal development (1), particularly attributed to their incorporation into membrane phospholipids. 20:4n-6 was reported to have a positive effect on fetal growh $(2,3)$, whereas $22: 6 n-3$ is of great significince for an appropriate development of fetal brain, retina and other nervous tissues (4). In animals, prenatal and postnatal exposure to n-3 fatty acids deficiency resulted in impaired neural and visual function (5). Premature infants, born in the period of increased lipid accretion in the rapidly growing brain, were also considered of being at risk of these mentioned impairments, due to inadequate 22:6n-3 accumulation $(6,7)$.

The levels $(\%, w / w t)$ of maternal $20: 4 n-6$ and 22:6n-3 have been investigated during pregnancy by several authors in serum phosphatidylcholine (8), plasma phospholipids ( 9 $11)$ and in total plasma lipids (12). Despite of the differences in compartments studied, all authors demonstrated a reduction in the levels of the n-6 and the n-3 LCPs during pregnancy, including 20:4n-6 and 22:6n-3. The decrease in 22:6n-3 was found to occur after an initial increase until weck 18 of pregnancy (10). Since the maternal and the neonatal 22:6n-3 statuses are positively correlated, a low 22:6n-3 status of the mother is related to lower fetal 22:6n-3 statuses $(10,11)$. The maternal $22: 6 n-3$ status depends mainly on the dictary intake of this fatty acid, since conversion of $\alpha$-linolenic acid (18:3n-3) into 22:0n-3 scems to be slow in humans. Therefore, in order to ensure fetal requirements, it could be beneficial if mothers increase their 22:6n-3 intake during pregnancy. Increasing the dietary n-3 LCP intake of pregnant women by $2.7 \mathrm{~g}$ from fish oil (equivalent to about $920 \mathrm{mg}$ 22:6n-3/d) was shown to be accompanied by reductions in the n-6 LCPs, not only in maternal plasma but in that of the neonates as well (13).

Recently, a dose-finding study was performed in non-pregnant women to assess the acceptability, tolerance, and efficacy of different supplements with the aim to increase plasma and erythrocyte levels of 22:6n-3 without reducing the n-6 LCP content (14). This study has shown that daily supplementation of $22: 6 n-3$ in combination with 20:4n-6 increases the levels of 22:6n-3 without a concomitant decline in the levels of n-6 LCPs, particularly 20:4n-6, in both plasma and erythrocyte phospholipids. Because the results obtained do not necessarily predict those that could be achieved in pregnant women, in the present pilot study, the effect of the supplement containing 22:6n-3 and 20:4n-6, derived from single cell oils, was investigated in pregnant women.

\section{SUBJECTS AND METHODS}

\section{Subjects and intervention}

Twenty-four healthy women, aged 20-38 yr., in the second trimester of their pregnancy and pregnant of a singleton infant, were recruited through the Department of Obstetrics and 
Gynecology (University Hospital Maastricht) and midwife practices in the area of Maastricht. As demonstrated by $\mathrm{Al}$ et al (10), pregnancy is associated with an increase in the relative amount of $22: 6 \mathrm{n}-3$ (\% w/ wt) in plasma phospholipids which reaches a maximum around the 18 th weck of pregnancy. To avoid any interference of this physiological response with the effect of supplementation, women were recruited at approximately 16-20 weeks of pregnancy.

The volunteers were randomly assigned to two groups, each comprising 12 subjects. One group of pregnant women received daily supplements containing 22:6n-3 and 20:4n-6, derived from single cell oils. The other group, the pregnant control group, received no supplements in order to mimic the real life situation. The appointments with the participants of the control group were made so that they would not cross with those of the intervention group. A written informed consent was obtained from each participant before enrolment. The study protocol was approved by the Medical Ethics Committee of the University Hospital Maastricht.

The supplement consisted of encapsulated algae-derived (DHASCO) and fungal-derived (ARASCO) oils containing 22:6n-3 and 20:4n-6 as main fatty acid, respectively (both from Martek Biosciences Corporation, Columbia MD, USA). Each DHASCO and ARASCO oil capsule contained 0.025 weight \% vitamin $\mathrm{E}$ and an equal amount of vitamin $\mathrm{C}$. The fatty acid composition of these oils are given in Table 1. During a 4-week period, the supplemented group received six DHASCO capsules and one ARASCO capsule per day,

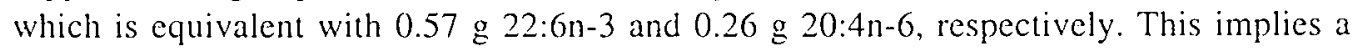
20:4n-6/22:6n-3 ratio of $1: 2.2$. The volunteers were instructed to take the prepacked capsules before each meal, and they were requested to maintain their usual dietary habits during the entire course of the study. Dietary intake was not assessed; only fish and seafood consumptions were recorded at the end of the study period. The subjects returned to the laboratory weekly for blood sample collection and to obtain the supplements for the following wcek.

\section{Blood sample collection and fatty acid analyses}

Venous blood samples were collected into EDTA containing tubes at entry, and after 1, 2, 3 and 4 wecks. After blood collection, plasma was separated from the erythrocytes by centrifugation. Aliquots of the plasma samples were divided over two storage cups, closed tightly under nitrogen, and stored at $-80^{\circ} \mathrm{C}$ until fatty acid analysis. Erythrocytes underwent the same procedure, but were first washed twice with EDTA containing saline. BHT was added to all erythrocyte samples before storage (15). The fatty acid composition of plasma and erythrocyte phospholipids was analyzed by capillary gas chromatography (16), using a 
Table 1. Fally acid composition of DHASCO and ARASCO.

\begin{tabular}{lcc}
\hline $\begin{array}{l}\text { Fatty acids } \\
(\% \text { w/wt })\end{array}$ & $\begin{array}{c}\text { DHASCO } \\
(250 \mathrm{mg} \text { capsule })\end{array}$ & $\begin{array}{c}\text { ARASCO } \\
(500 \mathrm{mg} \text { capsule })\end{array}$ \\
\hline Saturated & +4.1 & 23.0 \\
Monounsaturated & 14.9 & 8.8 \\
18:2n-6 & 0.9 & 6.3 \\
$20: 4 n-6$ & - & 51.7 \\
total n-6 & 0.9 & 65.1 \\
$20: 5 n-3$ & - & - \\
$22: 0 n-3$ & 37.9 & - \\
total n-3 & - & - \\
Unidentified & 1.5 & 2.6 \\
\hline
\end{tabular}

The DHASCO and ARASCO oils contained 0.025 weight \% vitamin $\mathrm{E}$ and an equal amount of vitamin C.

$50 \mathrm{~m}$ BPI non-polar column, $0.22 \times 0.10 \mu \mathrm{m}$, and a $50 \mathrm{~m}$ BPx70 polar column, $0.22 \times 0.25$ $\mu \mathrm{m}$ (SGE, Bester BV, Amstelveen, the Netherlands; (17). The amount of each fatty acid was calculated on basis of the recovered amount of the internal standard $(1,2-\alpha-$ dinonadecanoyl phosphatidylcholine; (PC- $[19: 0]_{2}$ ). The results are expressed as $\mathrm{mg} / \mathrm{L}$ plasma or erythrocyte suspension, and as percentages of the total fatty acid amount (\% $w(w 1)$. The following fatty acids are reported: $18: 2 n-6,20: 3 n-6,20: 4 n-6,22: 4 n-6,22: 5 n-6$, $18: 3 n-3,20: 5 n-3,22: 5 n-3,22: 6 n-3$, the sum of the n-6 LCPs $(20: 3 n-6,20: 4 n-6,22: 4 n-6$ and $22: 5 n-6)$ and the sum of $n-3$ LCPS (20:4n-3, 20:5n-3, 22:5n-3 and 22:6n-3).

\section{Statistical analyses}

All data are expressed as mean \pm SEM. Clinical variables were compared between the two groups by the unpaired t-test. The fatty acid levels within each group were first evaluated in time by the analysis of variance (ANOVA) for repeated measures. The supplemented group was compared with the control group at each sampling time by multiple regression analysis, with corrections for gestational age, and parity. For the comparisons at weeks 1-4 the pretreatment fatty acid levels were also included in the regression model.

Because of multiple comparisons, P-values less than 0.01 were considered significant. The analyses were done using STATVIEW release 4.5 (Abacus Concepts, Inc., Berkeley, California).

\section{RESULTS}

All volunteers enrolled completed the study. Their characteristics are presented in Table 2. The two groups of women were well comparable with respect to age, height, weight and body mass index of the volunteers. Although the control group did not receive any supplements, the gastrointestinal complaints (nausea, vomiting and eructation) reported 
Table 2. Characteristics of the study population'

\begin{tabular}{lcc}
\hline & $\begin{array}{c}\text { Supplemented group } \\
\mathrm{n}=12\end{array}$ & $\begin{array}{c}\text { Control group } \\
\mathrm{n}=12\end{array}$ \\
\hline Age $(\mathrm{y})$ & $30.3 \pm 1.5$ & $28.3 \pm 1.4$ \\
Height $(\mathrm{m})$ & $1.68 \pm 0.02$ & $1.66 \pm 0.02$ \\
Weight $(\mathrm{kg})$ & $65.4 \pm 2.8$ & $60.0 \pm 3.3$ \\
BMI $\left(\mathrm{kg} / \mathrm{m}^{2}\right)$ & $23.4 \pm 1.0$ & $23.8 \pm 1.1$ \\
Duration of pregnancy $(\mathrm{wk})$ & $18.0 \pm 0.5$ & $17.2 \pm 0.4$ \\
Primigravida $(\mathrm{n})$ & 8 & 5 \\
\hline
\end{tabular}

${ }^{1}$ Data are mean \pm SEM; no significant differences between groups.

were similar to those in the intervention group. One subject in the intervention group and four in the control group reported having nausea, sometimes accompanicd by vomiting, whereas two subjects in the intervention group and three in the control group complained of eructation. Only three subjects from either group consumed fish once a week during the study period.

Since there were hardly differences noted for the total amounts of fatty acids in plasma and erythrocyte phospholipids among the supplemented group and the control group, only the percentages (\% wt $/ \mathrm{wt}$ ) of fatty acids in the plasma and erythrocyte phospholipids are shown in Tables 3 and 4, respectively.

No significant differences were found between the two groups at entry. In the control group, the fatty acid composition of plasma and erythrocyte phospholipids showed no significant changes during the experiment. Supplementation temporarily increased the 20:4n-6 levels in plasma, but not in erythrocyte phospholipids. In contrast, both plasma and erythrocyte phospholipid levels of 22:5n-6 became significantly lower in the supplemented group as compared with the control group. After 4 weeks of supplementation, no significant differences were found between the control and the supplemented group regarding the total n-6 LCP levels, both in plasma and in erythrocyte phospholipids (Tables 3 and 4). Apart from one incidental occasion, differences between groups for changes over time were also not significant (Figure 1A \& B).

Compared with the control group, plasma phospholipid levels of 22:6n-3 in the supplemented group had increased already at week 1 and continued to be increased until the end of the intervention (Figure $1 \mathrm{C}$ and Table 3). Changes in the other n-3 fatty acids did hardly occur. The total n-3 LCP levels also showed significant increases during the intervention period, but they were no longer significantly different from the control group at week $4(\mathrm{P}=0.055)$. Comparable results were found in the erythrocyte phospholipids (Table 4 and Figure $1 \mathrm{D})$.

The ratio 22:5n-6/22:4n-6, DHA deficiency index (DHADI), became significantly lower in the plasma as well as the erythrocyte phospholipids of the supplemented as compared to 
Table 3. Plasma phospholipid fatty acids in the control group (C) and the supplemented group (S).

\begin{tabular}{|c|c|c|c|c|c|c|c|c|}
\hline $\begin{array}{l}\text { Fatty acids } \\
\% \times 1 / N 1\end{array}$ & & $w k 0$ & whl & wk 2 & & wk 3 & wk 4 & \\
\hline \multirow[t]{2}{*}{$18: 2 n-6$} & $C^{\prime}$ & $21.0 \pm 0.7$ & $20.7 \pm 0.4$ & $21.4 \pm 0.5$ & & $20.0 \pm 0.5$ & $20.1 \pm 0.6$ & \\
\hline & $S$ & $20.7 \pm 0.6$ & $20.8 \pm 0.7$ & $19.9 \pm 0.7$ & c & $19.6 \pm 0.7$ & $20.3 \pm 0.8$ & \\
\hline \multirow[t]{2}{*}{$20: 3 n-6$} & $C$ & $3.48 \pm 0.28$ & $3.67 \pm 0.23$ & $3.33 \pm 0.22$ & & $3.49 \pm 0.26$ & $3.58 \pm 0.27$ & \\
\hline & $S$ & $3.53 \pm 0.21$ & $3.22 \pm 0.17$ & $3.05 \pm 0.19$ & & $2.89 \pm 0.18$ & $3.03 \pm 0.20$ & b \\
\hline \multirow[t]{2}{*}{$20: 411-6$} & $C^{\prime}$ & $9.37 \pm 0.40$ & $8.87 \pm 0.30$ & $8.87 \pm 0.27$ & & $9.24 \pm 0.30$ & $8.78 \pm 0.29$ & \\
\hline & $S$ & $8.11 \pm 0.35$ & $9.01 \pm 0.41$ & $9.33 \pm 0.41$ & 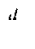 & $9.19 \pm 0.36$ & $8.74 \pm 0.35$ & " \\
\hline \multirow[t]{2}{*}{$22: 411-6$} & $C^{\prime}$ & $0.38 \pm 0.02$ & $0.39 \pm 0.02$ & $0.35 \pm 0.02$ & & $0.37 \pm 0.02$ & $0.38 \pm 0.02$ & \\
\hline & $\mathrm{S}$ & $0.38 \pm 0.03$ & $0.36 \pm 0.03$ & $0.33 \pm 0.02$ & & $0.33 \pm 0.02$ & $0.34 \pm 0.02$ & t \\
\hline \multirow[t]{2}{*}{$22: 5 n-6$} & $\mathrm{C}$ & $0.45 \pm 0.03$ & $0.48 \pm 0.03$ & $0.45 \pm 0.03$ & & $0.45 \pm 0.03$ & $0.46 \pm 0.03$ & \\
\hline & $\mathrm{S}$ & $0.45 \pm 0.03$ & $0.41 \pm 0.04$ & $0.35 \pm 0.03$ & 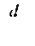 & $0.32 \pm 0.03$ & $0.31 \pm 0.03$ & $b . d$ \\
\hline \multirow[t]{2}{*}{ n-6 LCCPs } & $\mathrm{C}$ & $13.7 \pm 0.44$ & $13.4 \pm 0.4$ & $13.0 \pm 0.4$ & & $13.6 \pm 0.4$ & $13.2 \pm 0.4$ & \\
\hline & $\mathrm{S}$ & $12.5 \pm 0.44$ & $13.0 \pm 0.5$ & $13.1 \pm 0.5$ & r & $12.7 \pm 0.5$ & $12.4 \pm 0.5$ & \\
\hline \multirow[t]{2}{*}{$18: 3 n-3$} & $C$ & $0.17 \pm 0.01$ & $0.18 \pm 0.01$ & $0.18 \pm 0.02$ & & $0.19 \pm 0.02$ & $0.18 \pm 0.02$ & \\
\hline & $\mathrm{S}$ & $0.23 \pm 0.03$ & $0.24 \pm 0.03$ & $0.16 \pm 0.01$ & & $0.23 \pm 0.03$ & $0.22 \pm 0.02$ & \\
\hline \multirow[t]{2}{*}{$20: 5 n-3$} & $\mathrm{C}$ & $0.35 \pm 0.03$ & $0.42 \pm 0.07$ & $0.40 \pm 0.05$ & & $0.50 \pm 0.08$ & $0.54 \pm 0.16$ & \\
\hline & $\mathrm{S}$ & $0.54 \pm 0.10$ & $0.40 \pm 0.04$ & $0.41 \pm 0.05$ & & $0.68 \pm 0.15$ & $0.47 \pm 0.07$ & \\
\hline \multirow[t]{2}{*}{$22: 5 n: 3$} & $\mathrm{C}$ & $0.62 \pm 0.03$ & $0.59 \pm 0.02$ & $0.60 \pm 0.03$ & & $0.61 \pm 0.02$ & $0.64 \pm 0.05$ & \\
\hline & $\mathrm{S}$ & $0.69 \pm 0.03$ & $0.55 \pm 0.02$ & $0.50 \pm 0.03$ & r & $0.53 \pm 0.04$ & $0.56 \pm 0.06$ & $b$ \\
\hline \multirow[t]{2}{*}{$22: 6 n-3$} & C & $4.36 \pm 0.23$ & $4.16 \pm 0.18$ & $4.29 \pm 0.16$ & & $4.58 \pm 0.22$ & $4.60 \pm 0.31$ & \\
\hline & $\mathrm{S}$ & $4.19 \pm 0.30$ & $5.14 \pm 0.27 d$ & $5.76 \pm 0.25$ & $"$ & $5.92 \pm 0.29 d$ & $5.97 \pm 0.34$ & b.t \\
\hline \multirow[t]{2}{*}{ n-3 LCPs } & C & $5.41 \pm 0.25$ & $5.29 \pm 0.22$ & $5.40 \pm 0.19$ & & $5.83 \pm 0.26$ & $5.92 \pm 0.52$ & \\
\hline & $\mathrm{S}$ & $5.62 \pm 0.41$ & $6.23 \pm 0.32$ & $6.79 \pm 0.28$ & $"$ & $7.27 \pm 0.42^{r}$ & $7.15 \pm 0.45$ & $b$ \\
\hline \multirow[t]{2}{*}{ DHASI } & $\mathrm{C}$ & $10.3 \pm 1.1$ & $8.80 \pm 0.65$ & $9.92 \pm 0.75$ & & $10.6 \pm 0.8$ & $11.1 \pm 1.7$ & \\
\hline & $S$ & $10.0 \pm 1.5$ & $14.3 \pm 2.1$ & $18.1 \pm 2.0$ & $"$ & $20.9 \pm 2.4$ & $21.5 \pm 2.1$ & $b . d$ \\
\hline \multirow[t]{2}{*}{ DHADI } & $\mathrm{C}$ & $1.19 \pm 0.06$ & $1.27 \pm 0.06$ & $1.28 \pm 0.06$ & & $1.21 \pm 0.05$ & $1.22 \pm 0.04$ & \\
\hline & $\mathrm{S}$ & $1.19 \pm 0.03$ & $1.05 \pm 0.04^{d}$ & $1.05 \pm 0.04$ & $"$ & $0.97 \pm 0.05^{\circ}$ & $0.90 \pm 0.04$ & b.d \\
\hline
\end{tabular}

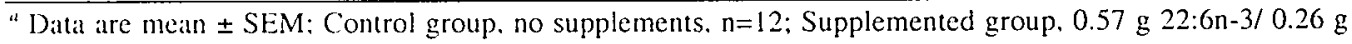
20:4n-6, n=12. n-6 LCPS (long-chain polyenes) $=20: 3 n-6,20: 4 n-6,22: 4 n-6$ and 22:5n-6;n-3 LCPs= 20:4n3, 20:5n-3, 22:5n-3 and 22:6n-3; DHASI. DHA sufficiency index: 22:6n-3/22:5n-6; DHADI, DHA deficiency index: 22:5n-4/22:6n-4.

"Significance level of the repeated measure ANOVA (within each group), $\mathrm{P}<0.003$.

${ }^{a}$ Significantly different from the control group (multiple regression analysis with correction for gestational age. parity and baseline): " $\mathrm{P}<0.01$ and " $\mathrm{P}<0.001$.

the control group, whereas the DHA sufficiency index (DHASI), the ratio 22:6n-3/22:5n-6, became significantly increased. 
Table 4. Erythrocyte phospholipid fatly acids in the control group (C) and the supplemented group (S).

\begin{tabular}{|c|c|c|c|c|c|c|c|}
\hline $\begin{array}{l}\text { Fanty acids } \\
\% \text { wUw }\end{array}$ & $" a$ & wk 0 & wkl & wk 2 & wh 3 & wh 4 & \\
\hline \multirow[t]{2}{*}{$18: 2 n-6$} & C & $10.4 \pm 0.3$ & $10.4 \pm 0.2$ & $10.4 \pm 0.5$ & $10.0 \pm 0.2$ & $10.1 \pm 0.3$ & \\
\hline & $s$ & $10.7 \pm 0.3$ & $10.5 \pm 0.4$ & $10.3 \pm 0.4$ & $10.1 \pm 0.3$ & $10.1 \pm 0.3$ & " \\
\hline \multirow[t]{2}{*}{$20: 3 n-6$} & $C$ & $1.65 \pm 0.12$ & $1.71 \pm 0.13$ & $1.03 \pm 0.11$ & $1.61 \pm 0.12$ & $1.62 \pm 0.12$ & \\
\hline & S & $1.57 \pm 0.08$ & $1.50 \pm 0.09$ & $1.49 \pm 0.08$ & $1.42 \pm 0.08$ & $1.43 \pm 0.08$ & $b$ \\
\hline \multirow[t]{2}{*}{$20: 4 n-6$} & C & $10.2 \pm 0.2$ & $10.2 \pm 0.2$ & $10.2 \pm 0.2$ & $10.2 \pm 0.2$ & $10.0 \pm 0.2$ & \\
\hline & $S$ & $9.88 \pm 0.19$ & $10.0 \pm 0.2$ & $10.1 \pm 0.2$ & $10.0 \pm 0.2$ & $9.89 \pm 0.18$ & \\
\hline \multirow[t]{2}{*}{$22: 4 n-6$} & $\mathrm{C}$ & $2.65 \pm 0.09$ & $2.71 \pm 0.08$ & $2.68 \pm 0.07$ & $2.69 \pm 0.07$ & $2.65 \pm 0.06$ & \\
\hline & $s$ & $2.63 \pm 0.11$ & $2.06 \pm 0.11$ & $2.60 \pm 0.13$ & $2.58 \pm 0.12$ & $2.54 \pm 0.11$ & $b$ \\
\hline \multirow[t]{2}{*}{$22: 5 n-6$} & $\mathrm{C}$ & $0.43 \pm 0.03$ & $0.46 \pm 0.0 .3$ & $0.45 \pm 0.02$ & $0.47 \pm 0.02$ & $0.46 \pm 0.02$ & \\
\hline & $S$ & $0.42 \pm 0.03$ & $0.42 \pm 0.02$ & $0.41 \pm 0.03$ & $0.40 \pm 0.03$ & $0.38 \pm 0.03$ & $b, d$ \\
\hline \multirow[t]{2}{*}{ n-6 LCCPs } & C & $15.0 \pm 0.3$ & $15.0 \pm 0.2$ & $15.0 \pm 0.2$ & $14.9 \pm 0.2$ & $14.8 \pm 0.2$ & \\
\hline & $S$ & $14.5 \pm 0.3$ & $14.7 \pm 0.3$ & $14.7 \pm 0.4$ & $14.4 \pm 0.3$ & $14.2 \pm 0.3$ & " \\
\hline \multirow[t]{2}{*}{$18: 3 n-3$} & C & $0.11 \pm 0.01$ & $0.10 \pm 0.01$ & $0.11 \pm 0.01$ & $0.09 \pm 0.02$ & $0.10 \pm 0.01$ & \\
\hline & $\mathrm{S}$ & $0.21 \pm 0.06$ & $0.14 \pm 0.03$ & $0.13 \pm 0.03$ & $0.20 \pm 0.05$ & $0.13 \pm 0.02$ & \\
\hline \multirow[t]{2}{*}{$20: 5 n-3$} & $\mathrm{C}$ & $0.35 \pm 0.03$ & $0.34 \pm 0.03$ & $0.33 \pm 0.03$ & $0.36 \pm 0.04$ & $0.38 \pm 0.08$ & \\
\hline & $S$ & $0.42 \pm 0.05$ & $0.38 \pm 0.04$ & $0.37 \pm 0.03$ & $0.42 \pm 0.06$ & $0.38 \pm 0.05$ & \\
\hline \multirow[t]{2}{*}{$22: 5 n: 3$} & C & $1.49 \pm 0.05$ & $1.46 \pm 0.05$ & $1.46 \pm 0.05$ & $1.46 \pm 0.05$ & $1.46 \pm 0.06$ & \\
\hline & $\mathrm{S}$ & $1.57 \pm 0.10$ & $1.57 \pm 0.09$ & $1.48 \pm 0.07$ & $1.40 \pm 0.06$ & $1.41 \pm 0.11$ & \\
\hline \multirow[t]{2}{*}{$22: 6 n-3$} & C & $3.76 \pm 0.13$ & $3.78 \pm 0.13$ & $3.84 \pm 0.11$ & $3.89 \pm 0.10$ & $3.96 \pm 0.14$ & \\
\hline & $s$ & $3.83 \pm 0.18$ & $4.13 \pm 0.17$ & $4.42 \pm 0.18$ & $4.63 \pm 0.18$ & $4.82 \pm 0.19$ & b.d \\
\hline \multirow[t]{2}{*}{$n-3$ LCPs } & C & $5.68 \pm 0.18$ & $5.66 \pm 0.17$ & $5.71 \pm 0.14$ & $5.77 \pm 0.16$ & $5.85 \pm 0.25$ & \\
\hline & S & $5.93 \pm 0.23$ & $6.15 \pm 0.22$ & $6.31 \pm 0.20$ & $6.54 \pm 0.23$ & $6.71 \pm 0.25$ & $b$ \\
\hline \multirow[t]{2}{*}{ DHASI } & C & $9.01 \pm 0.70$ & $8.59 \pm 0.79$ & $8.68 \pm 0.54$ & $8.55 \pm 0.48$ & $8.86 \pm 0.68$ & \\
\hline & S & $9.63 \pm 0.97$ & $10.4 \pm 1.0 \quad d$ & $11.5 \pm 1.1 d$ & $12.5 \pm 1.3$ & $14.0 \pm 1.6$ & $b, d$ \\
\hline \multirow[t]{2}{*}{ DHADI } & $\mathrm{C}$ & $0.16 \pm 0.01$ & $0.17 \pm 0.01$ & $0.17 \pm 0.01$ & $0.17 \pm 0.01$ & $0.17 \pm 0.01$ & \\
\hline & $S$ & $0.16 \pm 0.01$ & $0.16 \pm 0.01$ & $0.15 \pm 0.01$ & $0.15 \pm 0.01$ & $0.15 \pm 0.01$ & 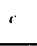 \\
\hline
\end{tabular}

See Table 3 for legend.

\section{DISCUSSION}

Recently, much attention has been given to maternal 22:6n-3 status during pregnancy, in view of the development of the brain and retina of the fetus. Hence, there is a growing interest in increasing maternal 22:6n-3 intake throughout gestation, in order to increase the neonate's starting conditions. The latter was proven to be feasible in two studies, in which pregnant women in their last trimester were daily supplemented with $2.7 \mathrm{~g} \mathrm{n}-3$ fatty acids from fish oil (13) or $2.6 \mathrm{~g}$ of $\mathrm{n}-3$ fatty acids from both fish oil and sardines (18). The authors of the first study reported that this supplementation had opposite effects on the levels of the 

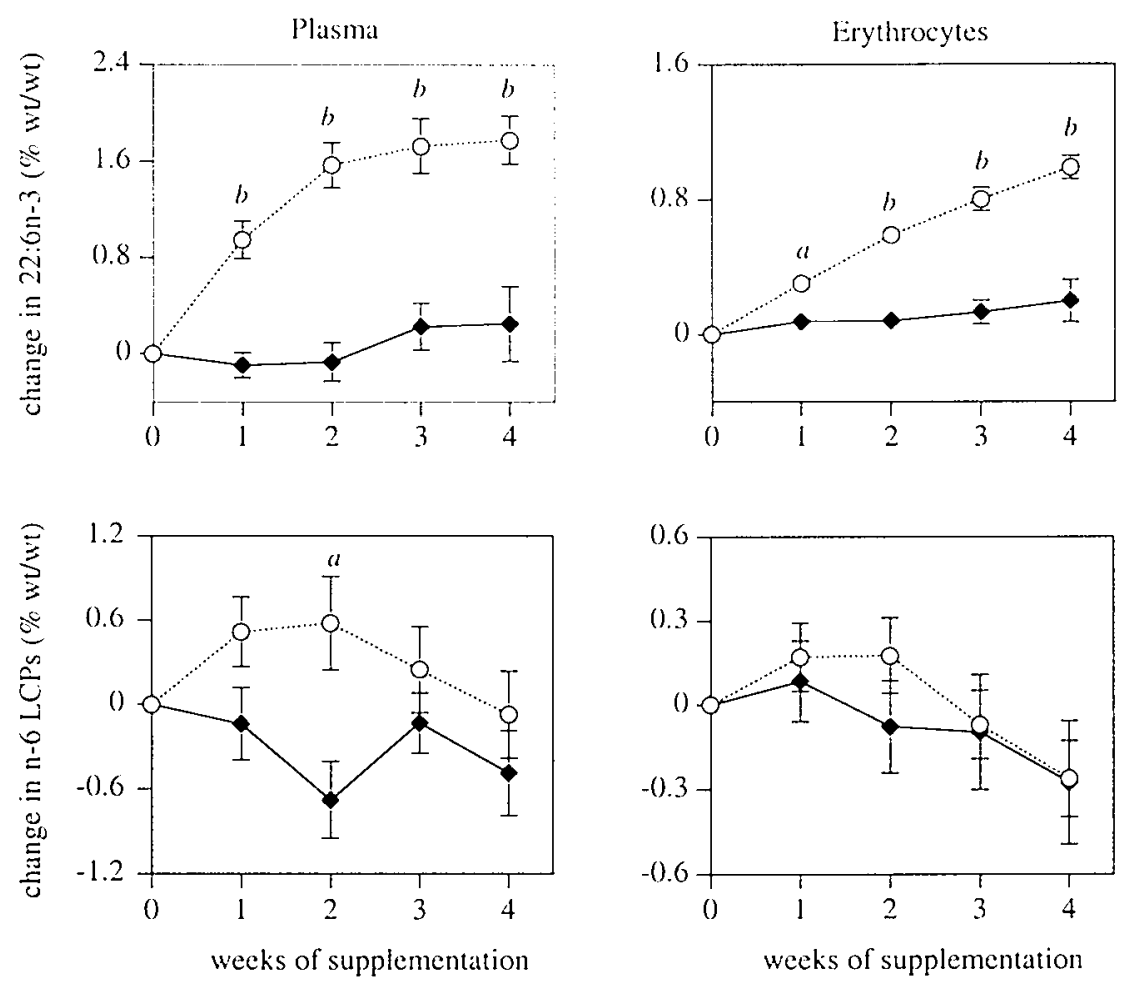

$0.57 \mathrm{~g} \mathrm{DHA} / 0.26 \mathrm{~g} \mathrm{AA}$

$\longrightarrow$ control (not supplemented)

Figure 1. Time-related changes in the 22:6n-3 and the n-6 long-chain polyenes (LCPs) content of plasma and erythrocyte phospholipids after supplementation.

"u,b Significantly different from the control group at week $4:$ " $\mathrm{P}<0.01,{ }^{6} \mathrm{P}<0.0001$.

n-6 LCPs (13). Also in pregnant women with habitual consumption of diets rich in n-3 fatty acids were reduced levels of plasma n-6 LCPs observed $(11,19,20)$. We have chosen to administer a supplement containing both 22:6n-3 and 20:4n-6, derived from single cell oils, to pregnant women. Such a supplement had already been proven to increase the levels (\% $\mathrm{wt} / \mathrm{wt}$ ) of 22:6n-3 without decreasing the levels of total n-6 LCPs in non-pregnant women

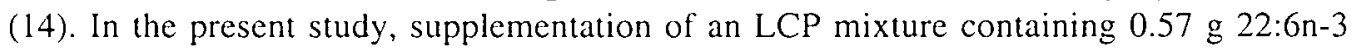

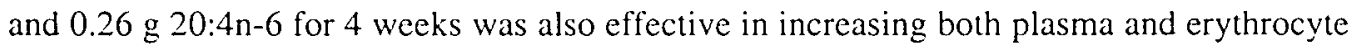
phospholipid levels of 22:6n-3 as compared to a non-supplemented control group (Tables 3 
and 4). The effect of the $22: 6 \mathrm{n}-3$ supplementation was also reflected by the ratios $22: 6 \mathrm{n}$ $3 / 22: 5 n-6$ and $22: 5 n-6 / 22: 4 n-6$, which are considered parameters of the functional $22: 6 n-3$ status, because a shortage of $22: 6 \mathrm{n}-3$ is usually accompanied by an increase conversion of $22: 4 n-6$ to $22: 5 n-6$. The $22: 6 n-3 / 22: 5 n-6$ ratio increased significantly during the supplementation period, indicating an improvement of the functional 22:6n-3 status. The latter is supported by the decreased $22: 5 n-6 / 22: 4 n-6$ ratio, which likely explains the decrease observed in the levels of $22: 5 n-6$ as well.

Compared to the control group, the supplement containing the mixture of 22:6n-3 and 20:4n-6 did not significantly reduce the total n-6 LCP levels both in plasma and in crythrocytc phospholipids (Tables 2 and 3 ). In the above-mentioned study by Houwelingen et al (13) a $\approx 17 \%$ decrease was observed in the total $n-6$ LCP levels of maternal plasma phospholipid after supplementation with fish oil. In our study the levels of total n-6 LCPs were maintained after supplementation, however, it is apparent from Figure 1 that after the second week of supplementation the course of the n-6 LCPs in plasma and erythrocyte phospholipid showed a downward movement. This decline probably represents the physiological effect of pregnancy on n-6 LCPs, since it was also observed in the control group.

Increasing the dietary 20:4n-6 intake might increase eicosanoid production (21). In our study, the dietary intake was not assessed, so the 20:4n-6 consumption of the pregnant women is not known. It is reported that a typical Western diet provides approximately 0.17 $0.22 \mathrm{~g} 20: 4 \mathrm{n}-6 / \mathrm{d}(22)$. Mean estimated intakes of $0.11-0.20 \mathrm{~g} / \mathrm{d}$ have been reported for healthy pregnant women $(23,24)$. If these amounts are extrapolated to our pregnant subjects, the total $20: 4 n-6$ intake of the supplemented group is approximately $0.36-0.46$ $\mathrm{g} /$ day. In non-pregnant subjects, the concomitant administration of $0.50 \mathrm{~g} 20: 4 \mathrm{n}-6$ and 0.50 g 22:6n-3 daily was shown to have no effect on the formation of thromboxane and prostacyclin, as measured by their metabolites in the urine (25). Similarly, Innis and Hansen (26) found no differences in the urinary excretion of these prostanoid metabolites after supplementation of $0.8-3.6 \mathrm{~g} 20: 4 \mathrm{n}-6$ in addition to $0.6-2.9 \mathrm{~g} 22: 6 \mathrm{n}-3$ (ratio $20: 4 \mathrm{n}-6 / 22: 6 \mathrm{n}-3$ $\approx 1.25: 1)$. Taken into account that in our study a lower dose of $20: 4 \mathrm{n}-6(0.26 \mathrm{~g})$ was administered together with $22: 6 n-3$ (ratio $20: 4 n-6 / 22: 6 n-3 \approx 1: 2.2$ ), any effect of this $20: 4 n$ 6 intake on eicosanoid production is probably negligible.

The results of the present study demonstrate that the daily supplementation of $0.57 \mathrm{~g}$ 22:6n-3 and 0.26 g 20:4n-6 derived from single cell oils increases the 22:6n-3 statuses of pregnant women. A concomitant decline of the n-6 LCP content of plasma and erythrocyte phospholipids did not occur. Whether this current effect will be maintained throughout pregnancy until term, needs to be confirmed in a longer-term study. In addition, the effect of the maternal supplementation on the LCP status of the newborn should be studied as well. 


\section{ACKNOWLEDGEMENT}

We thank Martek Biosciences Corporation for the donation of the capsules, and acknowledge the financial support by Numico BV, the Netherlands.

\section{REFERENCES}

1. Innis SM. Essential fatty acids in growth and development. Prog Lipid Res 1991:30:39-103.

2. Koletzko B. Braun M. Arachidonic acid and early human growth: is there a relation? Ann Nutr Metab $1991: 35: 128-31$.

3. Leaf AA. Leighfield MJ. Costeloe KL. Crawford MA. Long chain polyunsaturated fatty acids and fetal growth. Early Hum Dev 1992;30:183-91.

4. Martinez M. 'Tissue levels of polyunsaturated fatty acids during early human development. J Pediatr 1992;120:S129-38.

5. Neuringer M. Connor WE. Lin DS, Barstad L. Luck S. Biochemical and functional effects of prenatal and postnatal omega 3 fatty acid deficiency on retina and brain in rhesus monkeys. Proc Natl Acad Sci US A 1986;83:4021-5.

6. Hoffman DR, Uauy R. Essentiality of dietary omega 3 fatty acids for premature infants: plasma and red blood cell fatty acid composition. Lipids 1992;27:886-95.

7. Uauy Dagach R. Mena P. Nutritional role of omega-3 fatty acids during the perinatal period. Clin Perinatol 1995;22:157-75.

8. Skryten A, Johnson P. Gustafson A. Studies in normal pregnancy. III. Fatty acid composition of serum phosphoglycerides and cholesterol esters. Acta Obstet Gynecol Scand 1980;59:305-9.

9. Holman RT, Johnson SB. Ogburn PL. Deficiency of essential fatty acids and membrane fluidity during pregnancy and lactation. Proc Natl Acad Sci U S A 1991;88:4835-9.

10. Al MD, Houwelingen ACv. Kester AD. Hasaart TH, de Jong AE, Hornstra G. Maternal essential fatty acid patterns during normal pregnancy and their relationship to the neonatal essential fatty acid status. Br J Nutr 1995:74:55-68.

11. Otto SJ. Houwelingen ACV, Antal M. Manninen A. Godfrey K. Lopez Jaramillo P. Hornstra G. Maternal and neonatal essential fatty acid status in phospholipids: an international comparative study. Eur J Clin Nutr 1997:51:232-42.

12. Sanjurjo P. Matorras R. Ingunza N. Alonso M, Rodriguez Alarcon J, Perteagudo L. Cross-sectional study of percentual changes in total plasmatic fatty acids during pregnancy. Horm Metab Res 1993:25:590-2.

13. Houwelingen ACr. Sorensen JD. Hornstra G, Simonis MM. Boris J, Olsen SF, Secher NJ. Essential fatty acid status in neonates after fish-oil supplementation during late pregnancy. $\mathrm{Br} \mathrm{J}$ Nutr 1995; 74:723-31.

14. Otto SJ. Houwelingen ACV. Hornstra G. The effect of different supplements containing docosahexacnoic acid on plasma and erythrocyte fatty acids of healthy non-pregnant women. Nutr Res 2000:20:917-27. 
15. Otto SJ. Foreman-v. Drongelen MM. Houwelingen ACv. Hornstra G. Effects of storage on venous and capillary blood samples: the influence of deferoxamine and butylated hydroxytoluene on the fatly acid alterations in red blood cell phospholipids. Eur J Clin Chem Clin Biochem 1997:35:907-13.

16. Foreman-v. Drongelen MM. Houwelingen ACv. Kester AD, de Jong AE, Blanco CE. Hasaart TH, Hornstra G. Long-chain polyene status of preterm infants with regard to the fatty acid composition of their diet: comparison between absolute and relative fatly acid levels in plasma and erythrocyte phospholipids. Br J Nutr 1995:73:405-22.

17. Bakker EC, van Houwelingen AC. Hornstra G. Early nutrition. essential fatty acid status and visual acuity of term infants at 7 months of age. Eur J Clin Nutr 1999;53:872-879.

18. Connor WE. Lowensohn R. Hatcher L. Increased docosahexaenoic acid levels in human newborn infants by administration of sardines and fish oil during pregnancy. Lipids 1996:31 Suppl:S183-7.

19. Sanjurjo P. Matorras R. Ingunza N. Rodriguez Alarcon J. Perteagudo L. Blue fish intake and percentual levels of polyunsaturated plasmatic fatty acids at labor in the mother and the newborn infant. J Perinat Med 1994;22:337-44.

20. Sanjurjo P. Matorras R. Perteagudo L. Influence of fatty fish intake during pregnancy in the polyunsaturated fatty acids of erythrocyte phospholipids in the mother at labor and newborn infant. Acta Obstet Gynecol Scand 1995;74:594-8.

21. Whelan J. Antagonistic effects of dietary arachidonic acid and n-3 polyunsaturated fatty acids. J Nutr 1996;126:1086S-9!S.

22. Li B. Birdwell C, Whelan J. Antithetic relationship of dietary arachidonic acid and eicosapentaenoic acid on eicosanoid production in vivo. J Lipid Res 1994;35:1869-77.

23. Lakin V, Haggarty P. Abramovich DR. Ashton J. Moffat CF. McNeill G. Danielian PJ. Grubb D. Dietary intake and tissue concentration of fatty acids in omnivore, vegetarian and diabetic pregnancy. Prostagland Leuk Essent Fatty 1998;59:209-220.

24. Wijendran V. Bendel RB. Couch SC, Philipson EH. Thomsen K. Zhang X. Lammi-Keefe CJ. Maternal plasma phospholipid polyunsaturated fatty acids in pregnancy with and without gestational diabetes mellitus: relations with maternal factors [see comments]. Am J Clin Nutr 1999;70:53-61.

25. Sinclair AJ. Mann NJ. Short-term diets rich in arachidonic acid influence plasma phospholipid polyunsaturated fatty acid levels and prostacyclin and thromboxane production in humans. J Nutr $1996 ; 126: 1110 \mathrm{~S}-4 \mathrm{~S}$.

26. Innis SM. Hansen JW. Plasma fatty acid responses, metabolic effects, and safety of microalgal and fungal oils rich in arachidonic and docosahexaenoic acids in healthy adults. Am $J$ Clin Nutr 1996;64:159-67. 



\section{Chapter 9}

\section{General Discussion}

The levels of maternal plasma phospholipid fatty acids during pregnancy have extensively been investigated by $\mathrm{Al}$ et al (1). Results of their longitudinal study have shown that the total amounts of plasma phospholipid essential fatty acids (EFAs) increased during pregnancy. From week 10 until term the amounts of EFAs increased by about $40 \%$, but the non-essential n-9 and n-7 unsaturated fatty acids, increased considerably more. The ratio between essential and non-essential unsaturated fatty acids, the EFA index, declines throughout pregnancy, indicating that the EFA status of these women diminishes during pregnancy (1). After an initial increase until week 18 of pregnancy, the relative amounts of plasma phospholipid 22:6n-3 slightly decreased from the second trimester until term. Changes in the ratio $22: 6 n-3 / 22: 5 n-6$, the DHA sufficiency index, implied an increased demand for $22: 6 \mathrm{n}-3$ alrcady from week 10 of pregnancy $(2,3)$. These results suggest that mothers probably cannot meet the increasing EFA requirements during pregnancy, as a result of which pregnancy is associated with a reduction of the EFA status and of the functional 22:6n-3 status in particular (1).

During the past years we further studied the course of maternal EFAs, particularly 22:6n-3, in the periconceptional period, during pregnancy and in the postpartum period, in relation to possible differences among countries, lactation, habitual dietary intakes, and long-chain polyenes (LCPs) supplementation.

\section{Maternal EFA status: uncomplicated pregnancies and pregnancy-induced hypertension}

As stated before, the maternal EFA status declines steadily during pregnancy of Dutch Caucasian women (1). This might suggest that the present dietary EFA intake of pregnant women is not adequate and may need to be increased to ensure proper supply of EFAs to the developing fetus. To obtain information from a wider variation in dietary compositions, the study performed in Dutch women was extended to areas with dietary habits different to the Netherlands. The levels ( $\% \mathrm{wt} / \mathrm{wt}$ ) of EFAs in maternal plasma phospholipids were compared between women from Hungary, Finland, England, Ecuador and the Netherlands during the course of uncomplicated pregnancies. The result indicated that the formerly observed decrease in the EFA status in Dutch pregnant women is a general pregnancyassociated phenomenon (Chapter 3). 
The differences in the plasma EFA levels between the countries most likely reflect the differences in the usual dietary intake within each country. This suggests that the observed decline in plasma EFA status is independent of the habitual dietary intake, which would question a need of increasing maternal EFA intake during pregnancy. This holds for the n-6 fatty acids in particular (usually present in high amounts in the diet), since the neonatal $n-6$ LCP status appeared rather independent from the levels of the n-6 LCPs in maternal plasma phospholipids. For the n-3 LCPs, however, the neonatal levels were highest in the country with the highest maternal plasma n-3 LCP levels and lowest in the country with lowest maternal plasma n-3 LCP levels. Moreover, significant positive relationships were found between maternal and neonatal plasma n-3 LCPs within most countries. Therefore, increasing maternal dietary EFA intake during pregnancy would particularly concern the n3 LCPs, 22:6n-3 in particular.

The differences in the levels of plasma phospholipid 22:6n-3 among the mothers were also reflected in the phospholipids of the umbilical vessel walls. Since the 22:6n-3 content of umbilical vessel walls is regarded as a longer-term reflection of the (biochemical) 22:6n3 status of the fetus achieved during pregnancy $(4,5)$, it is important to evaluate whether such 'habitual' differences and variations in 22:6n-3 between the countries would result in differences in functional parameters.

As mentioned above, the changes in maternal plasma EFA levels during uncomplicated pregnancy in Dutch women were shown to occur in other populations as well, regardless of ethnicity. However, such similarities were found not to hold under all conditions. Previously, a compensatory mechanism has been described in Dutch women with pregnancy-induced hypertension $(\mathrm{PIH})(6)$. It was suggested that the conversion of the parent EFA (18:2n-6 and 18:3n-3) into their respective LCPs is enhanced in women with $\mathrm{PIH}$, possibly to ensure proper supply to the fetus despite probable compromised placental perfusion (6). This putative mechanism appeared to be absent in Ecuadorian Mestizo women with PIH; the EFA profiles of the normotensive mothers and the mothers with PIH were quite comparable. Differences in treatment and severity of PIH could not explain the observed difference between the Dutch Caucasian and the Ecuadorian Mestizo mothers. The most likely explanation remains the low activity of the $\Delta 5$-desaturase in the Mestizo group, as reported in Chapter 3 . The findings of this comparative study indicate that in pregnancies complicated by hypertension a phenomenon observed in one population cannot be generalized to women with the same condition in ethnic different populations.

Although the presumed compensatory mechanism was not present in the Ecuadorian mothers, the EFA status of their infants did not differ from that of the infants born to normotensive mothers. Recently, Velzing-Aarts et al (7) have shown that neonates born after PIH had low proportions of the $n-6$ and $n-3$ fatty acids compared to the control group, in an Afro-Caribbean population. This observation demonstrates that the neonatal EFA status is not always maintained after PIH. 


\section{EFA status of women in early pregnancy and postpartum}

No information was available on the changes in plasma phospholipid levels of 22:6n-3, and the other EFA, in the (very) early stage of pregnancy and on the normalization of these levels after parturition, especially in women breast-feeding their infants. In order to obtain this information, two prospective studies were performed (Chapters 5 and 6), one in women planning to become pregnant and one in women in their last trimester of pregnancy who intended to breast-feed or to exclusively bottle-feed their infant after delivery.

The results of the first study showed that during the first 10 weeks of pregnancy the absolute $(\mathrm{mg} / \mathrm{L})$ as well as the relative amounts $(\% \mathrm{wt} / \mathrm{wt})$ of plasma phospholipid 22:6n-3 rose continuously, whereas those of 20:4n-6 and the other LCPs hardly changed (Chapter 5 ). Hence, the carly wecks after conception are characterized by a specific increase in 22:6n-3.

After parturition, the percentages of these fatty acids that increased during pregnancy (22:6n-3) declined again, whereas those of falty acids declining during pregnancy $(20: 4 n-6$, 20:5n-3 and 22:5n-3) increased in the postpartum period (Chapter 6 ). These downward and upward courses in the fatty acids levels occurred in all mothers, regardless of their choice to breastfeed or bottle-feed their infants. However, lactation appeared to have a marked effect on the normalization of the n-3 LCPs. Compared to non-lactating mothers, the proportions of 22:6n-3 in plasma and erythrocyte phospholipids of lactating mothers showed a stronger decline postpartum. Moreover, as 22:6n-3 diminished, the proportions of its direct precursors, 20:5n-3 and 22:5n-3, increased considerably. These changes in the n-3 LCPs became stronger, the longer the duration of breast-feeding. From the results of the longitudinal study by Al et al (1) it is known that the plasma phospholipid content of 20:5n3 and 22:5n-3, which remained unchanged in early pregnancy (Chapter 5), steadily decline from week 10 of pregnancy until term.

Our findings combined with those from the longitudinal study by $\mathrm{Al}$ et al (1), it can be concluded that plasma phospholipid 22:6n-3 responds rapidly to conception, pregnancy, delivery and lactation (Figure 1). The proportion of 22:6n-3 in plasma phospholipids increases continuously from prepregnancy through week 18 of pregnancy, after which a slight decline occurs. The opposite changes occurring in 22:6n-3 as compared with those in its precursors $20: 5 n-3$ and 22:5n-3 suggest that 22:6n-3 synthesis changes considerably during these events. The formation of $22: 6 \mathrm{n}-3$ from its direct precursor is a complex " $\Delta 4-$ desaturation" step, which includes the elongation of $22: 5 n-3$ followed by $\Delta 6$-desaturation of the resulting fatty acid and one cycle of peroxisomal $\beta$-oxidation $(8,9)$. Possibly, these final steps in the 22:6n-3 synthesis are stimulated during pregnancy, by an increased activity of the enzymes involved and/or a proliferation of hepatic peroxisomes, processes which no longer exists postpartum in order to enable the normalization of maternal plasma 22:6n-3 content. 
The increase in 22:6n-3 during pregnancy has been shown to be associated with an increased hepatic synthesis of specific phospholipid molecular species containing 22:6n-3 (10-13). In rats, late gestation is characterized by an increase in molecular species of plasma phosphatidylcholine (PC) containing 22:6n-3 in both plasma and liver, independent of dietary EFA intake (10). The PC species contained 16:0 at the $s n-1$ position, PC 16:0/22:6n3 species. Recently, Burdge and Postle have shown that early pregnancy in guinea-pigs is associated with a considerable increase in the amounts of PC 16:0/22:6n-3 in plasma and in liver (13). Although no molecular species were determined in our present studies, the increase in 22:6n-3 concentrations coincided with a significant increase in the concentrations of 16:0 (Chapter 5), which is compatible with an increase in 16:0/22:6n-3 PC species in early pregnancy. Such an increase in plasma PC 16:0/22:6n-3 species in human pregnancies have been demonstrated previously (12).

The above suggested modifications or pregnancy-associated adjustment of the (hepatic) metabolism of 22:6n-3 is based on biochemical observations in (early) pregnancy and lactation. Further studies should be conducted to elucidate the underlying mechanism in the changes in the LCPs during pregnancy and lactation. The role of the altered concentrations of maternal hormones following conception, during pregnancy, upon delivery and during lactation should be evaluated as well. Several of these hormones are known to affect the activity of the enzymes involved in fatty acid desaturation (14).

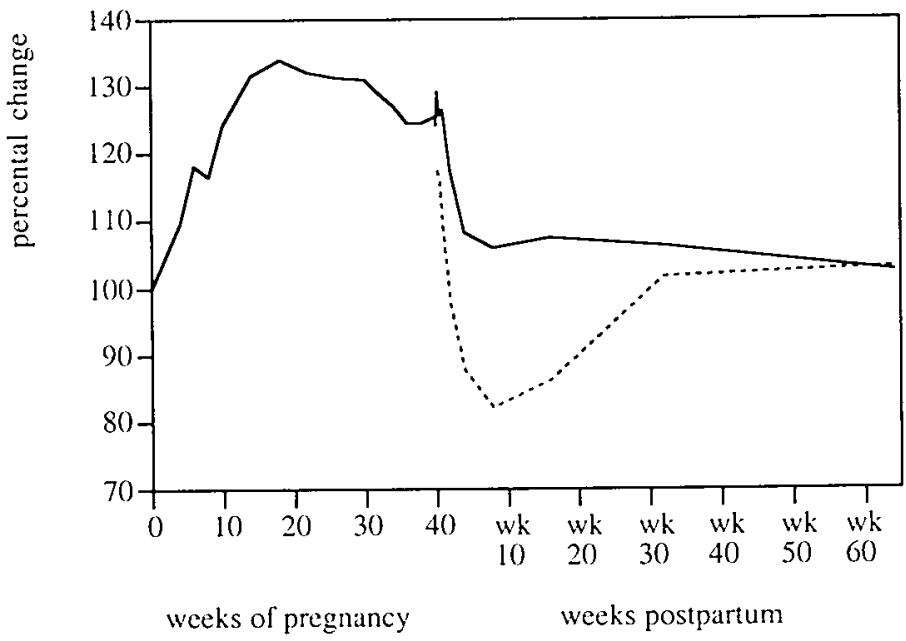

Figure 1. Pattern by which maternal plasma phospholipid 22:6n-3 seemingly changes during pregnancy and the postpartum period. Data are adapted from Chapter $5(n=24$; early pregnancy, weeks $0-10)$, reference 1 ( $n=110$ : during pregnancy, weeks $10-40)$ and Chapter $6(n=22$, non-lactating women: postpartum). The dotted line represents the pattern of the lactating group $(n=35)$. 


\section{Habitual dietary 22:6n-3 intake in pregnancy and lactation, and maternal supplementation with $22: 6 \mathrm{n}-3$}

Despite the pulative increase in the matcrnal synthesis of 22:6n-3 during pregnancy (Figure 1), most likely in an attempt to meet the enhanced 22:6n-3 requirement, the relative 22:6n-3 content of plasma phospholipids declines in the second half of pregnancy (Chapter 3 ). Lactation is also accompanied by pronounced decreases in plasma phospholipid 22:6n-3. These changes could not be explained by alterations in food consumption. This conclusion could be drawn from the studies in which the fatty acid intake was assessed, using a food frequency questionnaire (FFQ), which had previously been designed and validated to assess the fat content and the fatty acid compositions of the diet (15). Hence, the habitual intake of 22:6n-3 might not be sufficient to cope with the demand in late pregnancy and lactation. As the major concern is to cnsure 'adequate' supply of 22:6n-3 to the developing fetus/infant, increasing the dietary maternal 22:6n-3 intake should be considered. Data obtained from studies in which the 22:6n-3 status of vegetarian and diabetic pregnant women (16), women pregnant with twins or triplets (17) and pregnant multiparous women (18) also argue for an increase in matemal dietary $22: 6 n-3$ intake. The plasma/erythrocyte levels of $22: 6 n-3$ of these pregnant women were significantly lower than those measured in healthy (omnivorous) women during normal singleton pregnancies. Increasing the dietary intake might also be considered for multiparous lactating women. After an additional analysis, we observed that in the postpartum period, until week 16 , the multiparous women in the lactating group had lower plasma phospholipid 22:6n-3 lcvels compared to the primiparous mothers in the same group (Chapter 6). This difference no longer existed at week 32 postpartum, the time point at which most mothers had stopped breastfeeding.

Several siudies demonstrated that plasma and erythrocyte 22:6n-3 levels of pregnant (19-21) and lactating women (22-25) increase significantly after supplementation with 22:6n-3. Such supplementation has been shown to hardly affect the n-6 fatty acid levels of lactating mothers, but in pregnant women supplementation significantly decreased the $n-6$ fatty acid levels (19). Since n-6 LCPs, especially 20:4n-6, also play an important role in the fetal development $(26,27)$, maternal supplementation in pregnancy would require a wellbalanced combination of both n-6 and n-3 fatty acids. As described in Chapter 7 and 8 , attempts were made to find a supplement containing 22:6n-3 that would increase the 22:6n3 levels without decreasing the total levels of the n-6 LCPs in both plasma and erythrocyte phospholipids, during pregnancy. The supplemented amounts of 22:6n-3 were based on the paper by Houwelingen et al (19), in which a daily dose of $=920 \mathrm{mg} \mathrm{22:6n-3}$ as fish oil, was reported. Our supplementation study was first conducted in non-pregnant female volunteers using different supplements (differing in fatty acid mixtures and dosages; Chapter 7 ). The supplement that met the study objective, a mixture of $570 \mathrm{mg} 22: 6 \mathrm{n}-3$ and $259 \mathrm{mg} 20: 4 \mathrm{n}-6$ from single cell oil, proved to be effective in pregnant women as well, but the results achieved in this short-term pilot study need to be extended in a longer-term study. The 
effects of this supplement on the LCP levels of the newborns and on their clinical and functional outcome should be evaluated also. Further studies should not concentrate on the total $n-6$ LCPs, since this would mainly provide information on its major fraction 20:4n-6 rather than on the other individual n-6 LCP, 20:3n-6, 22:4n-6, and 22:5n-6. In addition, the levels of 20:5n-3 should also be evaluated. Both 20:3n-6 and 20:5n-3 are precursors of cicosanoids, with comparable biological activities, but opposed to those derived from 20:4n6. Since an imbalance in the ratio of the vasoconstricting thromboxane to the vasodilating prostacyclin is thought to be involved in the onset of preeclampsia (28), the changes in 20:3n-6 and 20:5n-3 should be monitored.

\section{Further research}

Combined with the data of Al et al (3), the results of the studies described in this thesis have extended the knowledge of the course of EFA following conception, during pregnancy, upon delivery and during lactation. The results of these studies also bring about many questions, which need to be elucidated

- Further studies should be performed to unravel the mechanism involved in the changes of 22:6n-3 in particular and the EFAs in general, in early pregnancy and postpartum in lactating and non-lactating women. Attention needs also to be focused on the role of the hepatic EFA synthesis in pregnancy. The latter should be studied in very-low-densitylipoproteins (VLDL), as their concentration increases considerably during pregnancy (29-31), and they transport newly synthesized lipids/fatty acids from liver to plasma (peripheral tissues). Furthermore, the possible influence of the hormonal alteration in pregnancy and lactation on the (hepatic) EFA metabolism should be evaluated as well.

Before providing guidelines on the dietary EFAs and 22:6n-3 intake during pregnancy and lactation, and the amounts required for maternal supplementation, studies should be planned to relate the wide range of maternal habitual dictary EFAs/22:6n-3 intakes with clinical and functional parameters of the mothers and their neonates/infants. The potential benefits of increasing dietary EFAs/22:6n-3 intake for the mother also need to be investigated.

\section{REFERENCES}

1. Al MD. Houwelingen ACY. Kester AD. Hasaart TH. de Jong AE, Hornstra G. Maternal essential fatty acid patterns during normal pregnancy and their relationship to the neonatal essential fatty acid status. $\mathrm{Br}$ J Nutr 1995:74:55-68.

2. Al MD, van Houwelingen AC. Hornstra G. Long-chain polyunsaturated fatty acids, pregnancy, and pregnancy outcome. Am J Clin Nutr 2000:71:S285-91. 
3. Al MDM. Essential fatly acids, pregnancy, and pregnancy outcome: relationship between mother and child. PhD Thesis. Human Biology. Malastricht: Maastricht University. 1994.

4. Al MD, Hornstra (i, van der Schouw YT. Bulstra Ramakers MT. Huisjes HJ. Biochemical EFA status of mothers and their neonates after normal pregnancy. Early Hum Dev 1990;24:239-48.

5. Crawford MA, Costeloc K. Doyle W. Leeighfield MJ. Lennon EA. Meadows N. Potential diagnostic value of the umbilical artery as a definition of neural fatty acid status of the fetus during its growth: the umbilical artery as a diagnostic tool. Biochem Soc Trans 1990:18:761-6.

6. Al MD, van Houwelingen AC, Badart Smook A. Hasaart TH. Roumen FJ. Hornstra G. The essential fatty acid status of mother and child in pregnincy-induced hypertension: a prospective longitudinal study. Am J Obstet Gynecol 1995:172:1605-14.

7. Velzing-Aarts FV, van der Klis FR. F.P. vdD. Muskiet FA. Umbilical vessels of preeclamptic women have low contents of both $n-3$ and $n-6$ long-chain polyunsaturated fatty acids. Am J clin Nutr 1999;69:293-298.

8. Voss A, Reinhart M. Sankarappa S. Sprecher H. The metabolism of 7.10.13.16.19-docosapentaenoic acid to 4.7.10,13.16.19-docosahexacnoic acid in rat liver is independent of a 4-desaturase. J Biol Chem 1991:266:19995-20000.

9. Sprecher H. Luthria DL. Mohammed BS. Baykousheva SP. Reevaluation of the pathways for the biosynthesis of polyunsaturated fatty acids. J Lipid Res 1995:36:2471-7.

10. Burdge GC. Hunt AN. Postle AD. Mechanisms of hepatic phosphatidylcholine synthesis in adult rat: effects of pregnancy. Biochem J 1994;303:941-7.

11. Burdge GC. Postle AD. Hepatic phospholipid molecular species in the guinea pig. Adaptations to pregnancy. Lipids 1994:29:259-64.

12. Postle AD. AI MD. Burdge GC. Hornstra G. The composition of individual molecular species of plasma phosphatidylcholine in human pregnancy. Early Hum Dev 1995:43:47-58.

13. Burdge GC. Postle AD. Pregnancy-associated adaptations to hepatic phosphatidylcholine biosynthesis in the guinea-pig. Comp Biochem Physiol 1998:119:265-72.

14. Bezard J. Blond JP. Bernard A. Clouet P. The metabolism and availability of essential fatty acids in animal and human tissues. Reprod Nutr Dev 1994:34:539-68.

15. Al MD. Badart Smook A. Houwelingen ACv, Hasaart TH. Hornstra G. Fat intake of women during normal pregnancy: relationship with maternal and neonatal essential fatty acid status. J Am Coll Nutr 1990:15:49-55.

16. Lakin V. Haggarty P. Abramovich DR. Ashton J. Moffat CF. McNeill G. Danielian PJ. Grubb D. Dietary intake and tissue concentration of fatty acids in omnivore. vegetarian and dabetic pregnancy. Prostagland Leuk Essent Fatty 1998:59:209-20.

17. Zeijdner EE, van Houwelingen AC. Kester AD. Hornstra G. Essential fatty acid status in plasma phospholipids of mother and neonate after multiple pregnancy. Prostaglandins Leukot Essent Fatty Acids 1997:56:395-401.

18. Al MDM. Houwelingen ACv. Hornstra G. Relation between birth order and the maternal neonatal docosahexaenoic acid status. Eur J Clin Nutr 1997:51:548-53. 
19. Houwelingen AC , Sorensen JD, Honstra G, Simonis MM. Boris J. Otsen SF. Secher NJ. Essential fatty acid status in neonates after fish-oil supplementation during late pregnancy. Br J Nutr 1995;74:723-31.

20. Connor WE. Lowensohn R. Hatcher 1 . Increased docosahexaenoic acid levels in human newborn infants by administration of sardines and fish oil during pregnancy. Lipids 1996:31 Suppl:S183-7.

21. Borod E. Atkinson R, Barclay WR. Carlson SE. Effects of third trimester consumption of eggs high in docosahexaenoic acid on docosahexalenoic acid status and pregnancy. Lipids 1999;34:S231.

22. Henderson RA. Jensen RG. I.ammi KC. Ferris AM. Dardick KR. Effect of fish oil on the fatty acid composition of human milk and maternal and infant erythrocytes. Lipids 1992:27:863-9.

23. Makrides M. Neumann MA. Gibson RA. Effect of maternal docosahexaenoic acid (DHA) supplementation on breast milk composition. Eur J Clin Nutr 1996:50:352-7.

24. Helland 113. Saarem K. Satugstad OD. Drevon CA. Fatty acid composition in maternal milk and plasma during supplementation with cod liver oil. Eur J Clin Nutr 1998;52:839-45.

25. Jensen CI. Maude M. Anderson RE. Heird WC. Effect of docosahexaenoic acid supplementation of lactating women on the fatty acid composition of breast milk lipids and maternal and infant plasma phospholipids. Am J Clin Nutr 2000:71:S292-9.

26. Koletzko B, Braun M. Arachidonic acid and early human growth: is there a relation? Ann Nutr Metab $1991: 35: 128-31$.

27. Leaf AA, Leighfield MJ. Costeloe KL. Crawford MA. Long chain polyunsaturated fatty acids and fetal growth. Farly Hum Dev 1992:30:183-91.

28. Mills JL.. DerSimonian R, Raymond E, Morrow JD, Roberts LJ, 2nd, Clemens JD. Hauth JC. Catalano P. Sibai B, Curet LB, Levine RJ. Prostacyclin and thromboxane changes predating clinical onset of preeclampsia: a multicenter prospective study. Jama 1999:282:356-62.

29. Dejager S, Turpin G. [Hyperlipidemia in pregnancy]. Presse Med 1996;25:1839-45.

30. Alvarez JJ. Montelongo A. Iglesias A. Lasuncion MA. Herrera E. Longitudinal study on lipoprotein profile, high density lipoprotein subclass, and postheparin lipases during gestation in women. J Lipid Res 1996:37:299-308.

31. Sattar N. Greer IA. L.ouden J. Lindsay G. McConnell M. Shepherd J. Packard CJ. Lipoprotein subfraction changes in normal pregnancy: threshold effect of plasma triglyceride on appearance of small, dense low density lipoprotein. J Clin Endocrinol Metab 1997;82:2483-91. 


\section{SUMMARY}

The essential fatly acids (EFAs) are indispensable for human development and health. especially the long-chain polyenes (LCPS). These LCPs have important biological functions, which are particularly attributed to their role as structural components of cell membranes. As such, these LCPs are essential for the formation of new tissues, as is the case during pregnancy and fetal development. An appropriate supply of LCPs in the prenatal as well as in the early postnatal period is of importance to ensure a normal development of cognitive and visual functions. The studies presented in this thesis were to further elucidate the availability of maternal EFAs, particularly 22:6n-3, during pregnancy and postpartum period.

The EFA status is usually studied in blood samples collected by venapuncture. However, studies in preterm infants often rely on 'diagnostic' blood samples, which can be of either venous or capillary origin, resulting in a longitudinally collected series of both venous and capillary blood samples. To obtain a reliable impression of the carly postnatal EFA status of preterm infants, the fatty acid profiles of venous and capillary plasma and erythrocyte phospholipids should be comparable. Therefore storage conditions need to be such that fatty acid profiles are unaltered. As demonstrated in Chapter 2, plasma phospholipid fatty acid profiles from venous and capillary blood remained comparable after 4 weeks of storage at $-20^{\circ} \mathrm{C}$. However, substantial losses of LCPs were observed in erythrocyte samples, particularly in those of capillary origin. In an attempt to prevent these changes, erythrocyte samples were subsequently stored at $-50^{\circ} \mathrm{C}$ and lipid extracts prepared within one week of blood collection. Nevertheless, plasma and erythrocyte samples collected longitudinally are preferably analyzed simultaneously, to keep laboratory conditions comparable. Therefore, a study was performed on the storage life of erythrocyte samples stored in presence of the antioxidants deferoxamine (desferrioxamine) and butylated hydroxytoluene (BHT) for up to one year. The results of the study Both compounds were effective in avoiding the detrimental effect of storage on the stability of erythrocyte phospholipid fatty acids.

In Dutch pregnant women a steady decline was observed in the EFA status, expressed by the EFA index $([n-3+n-6] /[n-7+n-9])$, throughout pregnancy. To investigate whether this decline is specific for the Dutch population and its dietary habits, the EFA status of healthy women from the Netherlands, Hungary, Finland, England and Ecuador during uncomplicated, singleton pregnancy was compared among the five populations (Chapter 3). The EFA statuses of the neonates were also compared. All European mothers were Caucasians, whereas the Ecuadorians were mixed Indian/Caucasian (Mestizos). The results showed considerable differences in the absolute amounts $(\mathrm{mg} / \mathrm{L})$ and the relative levels $(\%$ $w t / w t)$ of the EFAs between the five groups. However, the pattern by which the absolute as well as relative amounts of the EFA changed during pregnancy followed a comparable 
course in all countries. The EFA index declined in all groups. Therefore, the reduction in maternal EFA status during pregnancy as observed in Dutch women is a general pregnancyassociated phenomenon, largely independent of habitual diet and ethnic origin. The neonatal EFA levels reflected the differences found among the mothers, particularly for the $n-3$ LCPS. Since in a given group the lowest values observed for certain maternal EFAs were often higher than the highest values in some other group(s) throughout pregnancy, the functional implications of the pregnancy-associated reduction in the maternal EFA status for fetal and neonatal development are not obvious and need further study.

In Dutch Caucasian women with pregnancy-induced hypertension (PIH) were shown to have higher levels of LCPs than healthy pregnant women. These elevated levels of LCPs were associated with reduced levels of the 'parent' EFAs, 18:2n-6 and 18:3n-3. This observation suggested an enhanced desaturation and elongation of the latter as a possible compensatory mechanism in PIH to ensure an adequate supply of LCPs through the placenta to the letus. The occurrence of this putative mechanism under completely different nutritional and geographical conditions was studied in an Ecuadorian Mestizo population (Chapter 4). Plasma phospholipid fatty acids of primiparous Ecuadorian Mestizo women with normotensive and PIH pregnancies were assessed at delivery and compared with similar data of Dutch Caucasian women. In addition, neonatal values, determined in umbilical plasma and umbilical vessel walls, were compared. Unlike Dutch women, Ecuadorian mothers did not respond to PIH with an increased fatty acid desaturation and elongation. The most likely explanation for the difference between the Dutch and the Ecuadorian populations may be a genetically determined lower $\Delta 5$-desaturase activity in Mestizos than in Caucasians, which has been suggested previously (in Chapter 3 ). However, the EFA status of the Ecuadorian neonates born after PIH did not differ from that of the neonates born after uncomplicated pregnancies. Because their mothers did not show such an enhanced fatty acid desaturation and elongation, additional mechanisms may be active in maintaining the LCP status of neonates born after PIH in Mestizo women.

The pattern of the EFAs, including 22:6n-3, changes considerably from week 10 of pregnancy on. The course of the EFAs, particularly 22:6n-3, in women before conception and in the first 10 weeks of pregnancy was investigated and is described in Chapter 5 . The dietary EFA intake in this period was also estimated by using food frequency questionnaires (FFQ). Healthy women planning to become pregnant in the near future were recruited and blood samples collected (every month) on the first or the second day of the menstrual cycle and in case of pregnancy at weeks $4,6,8$ and 10 of gestation. No significant changes were observed in the mean estimated dietary intake of EFAs before and during pregnancy. However, the circulatory amounts of most phospholipid-associated EFAs increased considerably. For the n- 6 fatty acids the differences from prepregnancy reached statistical significance at week 10 of pregnancy only. In the n-3 series, only $22: 6 n-3$ increased significantly. This rise in the amounts 22:6n-3 was already at week 6 of pregnancy significantly different from prepregnancy and could not be explained by changes in the dietary intake. Possibly, this increase in 22:6n-3 reflects enhanced synthesis of 22:6n-3 from 
its precursor fatty acids, however, mobilization from maternal stores, reduced oxidation or both cannot be excluded.

Pregnancy is associated with increased absolute amounts of docosahexacnoic acid (22:6n-3) in plasma phospholipids. Expressed as proportion of total fatty acids, 22:6n-3 declines slightly in late pregnancy. Until now, hardly any information was available on the normalization of 22:6n-3 postpartum. Therefore, the postpartum course of the maternal 22:6n-3 (and EFAs in general) was studied in healthy lactating and non-lactating mothers (Chapter 6). The EFA intake was assessed at weeks 4 and 32 postpartum using FFQs. The fatty acids were determined in plasma and erythrocyte phospholipids from blood collected at entry and after parturition on the 2nd day, the 5th day, and at weeks 1, 2, 4, 8, 16, 32 and 64. The mean estimated daily intake of EFAs did not change significantly in either group. The total fatty acid amounts ( $\mathrm{mg} / \mathrm{L}$ ) of plasma phospholipids declined in both lactating and non-lactating women after parturition, suggesting that postpartum normalization of the quantitative fatty acid amounts is independent of the practice of breastfeeding or bottlefeeding. The individual n-3 and $n-6$ fatty acids showed comparable courses in the two groups. However, significant differences were observed between non-lactating and lactating group with respect to 22:6n-3. Plasma and erythrocyte phospholipid levels of 22:6n-3 decreased postpartum, but in the lactating women a significant further reduction was observed, which was stronger the longer the duration of lactation. This observation implies an effect of lactation on the recovery of the postpartum levels of 222:6n-3.

The results of these studies suggest that the habitual intake of $22: 6 \mathrm{n}-3$ might not be sufficient to cope with the high demand of 22:6n-3 in pregnancy. As the major concern is to ensure 'adequate' supply of 22:6n-3 to the developing fetus, it could be beneficial if mothers increase their 22:6n-3 intake during pregnancy. Since the maternal supplementation with one essential fatty acid family is known to be associated with a concomitant reduction in the levels of the other, a dose-finding study was performed to find a proper mixture of $n-6$ and $n-3$ LCPs as a possible supplement to the diet of pregnant women. The aim of this study was to find a supplement that would enhance levels of 22:6n-3 without decreasing the $n-6$ LCP levels in both plasma and erythrocytes phospholipids. This study was performed first in healthy non-pregnant women (6 groups, $n=12-15$ per group; Chapter 7 ). Over a 4 -week period the non-pregnant women received daily the following supplements: fish oil $(0.266 \mathrm{~g}$ or $0.532 \mathrm{~g} / \mathrm{d})$, single cell-derived oils containing either $22: 6 \mathrm{n}-3$ alone $(0.285 \mathrm{~g}$ or $0.570 \mathrm{~g})$ or a mixture of $22: 6 n-3$ and 20:4n-6 (0.570 g 22:6n-3 and $0.259 \mathrm{~g} 20: 4 \mathrm{n}-6)$. The control group received a placebo containing microcrystalline cellulose. The 22:6n-3 and n-6 LCP levels in plasma and erythrocytes phospholipids of the placebo group were unchanged after 4 weeks. In comparison to the control group, the plasma and erythrocyte phospholipid levels of 22:6n-3 increased significantly. In general, the n-6 LCP levels were significantly reduced, except for the group that received the mixture of $22: 6 n-3$ and 20:4n-6.

Subsequently, this EFA mixture was administered to a group of healthy pregnant women $(n=12$, gestational age $18.0 \pm 0.5$ weeks). The control group $(n=12$, gestational age $17.2 \pm$ 0.4 weeks; Chapter 8) received no supplements. Likewise, this mixture proved to be 
effective in maintaining the n-6 LCP levels and increasing the 22:6n-3 levels of both plasma and erythrocyte phospholipids in pregnant women. Whether the effect of this supplement will be maintained until term, needs to be confirmed in a long-term study. In addition, the effect of the maternal supplementation on the LCP status of the newborn should be studied as well.

In Chapter 9 the findings of the above-mentioned studies are discussed. The biochemical results indicate that mothers should increase their dietary intake of 22:6n-3 during pregnancy and lactation. However, the functional implications of this procedure for both mother and fetus/neonate should be investigated. 


\section{SAMENVATTING}

Essentiële vetzuren (essential falty acids: EFAs) zijn belangrijk voor de ontwikkeling en de gezondheid van de mens. Dit geldt met name voor de lange-keten meervoudig onverzadigde vetzuren (long-chain polyenes: LCPs). Deze LCPs vervullen verschillende biologische functies, die voornamelijk zijn gerelateerd aan hun rol als bouwstenen van het celmembraan. Hierdoor zijn ze belangrijk voor de vorming van nieuw weefsel, zoals het geval is tijdens zwangerschap en foetale ontwikkeling. Een adequate aanvoer van deze LCPs is zowel voor als na de geboorte van belang voor optimale ontwikkeling van de hersenen. De in dit proefschrift beschreven studies zijn uitgevoerd om meer inzicht te krijgen in het verloop van de EFA status van vrouwen tijdens de zwangerschap en na de bevalling.

De EFA status wordt meestal bepaald in bloedmonsters verzameld via een venapunctie. Echter, in premature zuigelingen kunnen geen experimentele bloedafnames worden verricht $\mathrm{en}$ is men voor het verkrijgen van bloedmonsters afhankelijk van diagnostische punctics. Dit houdt in dat bloedmonsters verzameld tijdens een longitudinaal onderzoek van zowel veneuze als capillaire oorsprong kunnen zijn. Deze monsters zijn echter alleen bruikbaar als de vetzuursamenstelling van veneus en capillair bloed vergelijkbaar is. Zoals beschreven in Hoofdstuk 2 zijn veneuze en capillaire plasmamonsters na een bewaartijd van 4 weken bij $-20^{\circ} \mathrm{C}$ nog steeds vergelijkbaar. Daarentegen is na 4 weken bewaren de hoeveelheid LCPs in de erytrocytenmonsters, met name in de capillaire monsters, sterk gedaald. Om deze daling te voorkomen werd besloten de lipiden binnen een week na bloedafname te extraheren en de extracten bij $-50^{\circ} \mathrm{C}$ te bewaren. Echter, monsters verzameld in een longitudinaal onderzoek worden bij voorkeur gelijktijdig geanalyseerd om alle analytische condities gelijk te houden. Daarom werd een experiment uitgevoerd naar de houdbaarheid van lipidenextracten na toevoeging van de antioxidanten deferoxamine of butyl hydroxytolueen (BHT). De vetzuursamenstelling van deze extracten werd maandelijks tot een jaar na de bloed afname bepaald. De resultaten toonden aan dat onder deze omstandigheden beide antioxidanten het verlies van LCPs tijdens bewaren kunnen voorkomen.

Het is gebleken dat de EFA status van Nederlandse vrouwen, uitgedrukt als de ratio tussen de som van alle n-3 en n-6 vetzuren en de som van alle n-7 en n-9 vetzuren, daalt tijdens de zwangerschap. Deze waarneming leidde tot de vraag of deze situatie specifiek is voor de Nederlandse vrouw en haar voedingsgewoonten. Dit werd onderzocht door de EFA status van Nederlandse vrouwen te vergelijken met die van gezonde zwangere vrouwen uit Hongarije, Finland, Engeland en Ecuador (Hoofdstuk 3). De EFA status van de pasgeborenen werd eveneens onderzocht. Alle Europese moeders behoorden tot het Caucasische ras, de Ecuadoraanse moeders waren van gemend Indiaans-Caucasische 
afkomst (Mestizo's). Tussen de diverse groepen waren zeer significante verschillen gevonden in de absolute ( $\mathrm{mg} / \mathrm{L}$ ) en relatieve (gewichts\%) hoeveelheid EFAs in moederlijke plasma. Ondanks deze verschillen, vertoonde het verloop van de vetzuren tijdens de zwangerschap hetzelfde patroon. In alle groepen trad een daling van de EFA status op De daling van de mocderlijke EFA status tijdens zwangerschap lijkt dus een algemeen verschijnsel te zijn, dat grotendeels onafhankelijk is van verschillen in voedingsgewoonten en etnische afkomst. De verschillen in vetzuurspiegels tussen de pasgeborenen reflecteerden de verschillen gevonden tussen de moeders. De neonatale EFA status blijkt dus sterk afhankelijk te zijn van de moederlijke EFA status. Functionele implicaties voor de ontwikkeling van de foetus en de pasgeborene als gevolg van de daling in de moederlijke EFA status dienen verder onderzocht te worden.

Nederlandse vrouwen met zwangerschap-geinduceerde hypertensie (pregnancy-induced hypertension: PIH) hebben hogere LCP spiegels dan gezonde zwangeren vrouwen. Deze hogere LCP spiegels gaan gepaard met lagere waarden van de precursor vetzuren 18:2n-6 en 18:3n-3, hetgeen ecn verhoogde omzetting suggereert van deze vetzuren in hun respectievelijke LCPs. Deze verhoogde LCP productic wordt wel gezien als een compensatic voor de slechtere placentadoorstroming bij PIH, zodat een adaquate aanvoer van LCPs naar de foetus toch gewaarborgd is. Het vóórkomen van dit mogelijke compensatiemechanisme onder compleet verschillende voedingsgewoonten en geografische omstandigheden werd onderzocht bij een groep Ecuadoriaanse Mestizo vrouwen (Hoofdstuk 4). Het vetzluurprofiel van plasmafosfolipiden van Ecuadoriaanse primiparae met en zonder PIH werd vergeleken met gegevens van Nederlandse vrouwen. Daarnaast werden ook de vetzuurprofielen van de pasgeborenen vergeleken. In tegenstelling tot de situatie in Nederland, werden er bij de Ecuadoriaanse vrouwen met PIH geen aanwijzingen gevonden voor een verhoogde productie van LCPs uit hun precursor vetzuren. De meest waarschijnlijke verklaring voor dit verschil tussen beide populaties is een lage activiteit van het $\Delta 5$-desaturase enzym bij de Mestizo vrouwen. Ondanks de afwezigheid van een verhoogde LCP synthese bij Ecuadoriaanse vrouwen met PIH bleck dat de EFA status van hun kinderen niet was verslechterd ten gevolge van PIH. Dit zou kunnen wijzen op een ander compensatiemechanisme bij Mestizo vrouwen met PIH

In Hoofdstuk 5 wordt een onderzoek beschreven naar het verloop van de EFA status, en met name van de 22:6n-3 status, in de eerste 10 weken van de zwangerschap. De EFAinname in deze periode werd geschat met behulp van voedselfrequentievragenlijsten (food frequency questionnaires: FFQs), die vóór de zwangerschap en gedurende de $10 \mathrm{de}$ zwangerschapsweck werden afgenomen. Bloedmonsters werden elke maand verzameld bij gezonde niet-zwangere vrouwen, op de eerste dag van de verwachte menstruatie. Als de vrouw zwanger bleek te zijn (meestal reeds tijdens week 4 van de zwangerschap) werden vervolgens bloedmonsters afgenomen op week 6,8 en week 10 van de zwangerschap. Er werden geen statistisch significante verschillen gevonden in de EFA-inname vóór en tijdens de (vroege) zwangerschap, maar voor de meeste EFAs waren de hoeveelheden in het bloed van de moeder gestegen ten gevolge van de zwangerschap. De hoeveelheid n-6 vetzuren 
was op week 10 van de zwangerschap signilicant hoger dan de hoeveelheden gemeten vóó de zwangerschap. Van de n-3 vetzuren was alleen 22:6n-3 significant toegenomen. Deze stijging was reeds significant vanaf de Ge zwangerschapsweck en kon niet worden verklaard door veranderingen in de inname van dit vetzuur. Mogelijk is deze verhoging in 22:6n-3 in de vroege zwangerschap het gevolg van een verhoogde synthese uit 18:3n-3, van mobilisatie van 22:6n-3 uit moederlijke voorraden, of van verlaagde oxidatic van dit vetzuur.

Zwangerschap is dus geassocieerd met verhoogde plasmaspiegels van 22:6n-3. Uitgedrukt als relatieve hoeveelheid (in gewichts\% van de totale hoeveclheid aan fosfolipiden gebonden vetzuren) vertoont $22: 6 \mathrm{n}-3$ echter een daling vanaf het $2 \mathrm{c}$ trimester van de zwangerschap. Tot nu toe was er geen informatie over het verloop van de 22:6n-3 concentratie na de bevalling. Daarom werd vervolgens een onderzock uitgevoerd naar het verloop van 22:6n-3 (en van EFAs in het algemeen) na de bevalling (Hoofdstuk 6). Aan dit onderzock namen zowel moeders deel die borstvoeding gaven als moeders die uitsluitend flesvoeding gaven. De EFA-inname tijdens week 4 en week 32 na de bevalling werd geschat met behulp van FFQ's. De vetzuren werden bepaald in fosfolipiden geïsoleerd uit plasma en erytrocyten afgenomen tijdens week 36 van de zwangerschap, op dag 2, dag 5 en dag 7 na de bevalling en tijdens week 2, 4, 8, 16, 32 en 64 postpartum. In beide groepen werden geen veranderingen in de EFA-inname waargenomen. Na de bevalling normaliseerde de totale hoeveelheid vetzuren $(\mathrm{mg} / \mathrm{L})$ in plasma fosfolipiden in zowel de lacterende als de niet-lacterende groep. Het verloop van de verschillende vetzuren was vergelijkbaar tussen de twee groepen. De hoeveelheid 22:6n-3 in plasma en erytrocyten fostolipiden daalde na de bevalling, maar was significant sterker en duurde bovendien langer bij de lacterende moeders dan bij de moeders die flesvoeding gaven. Deze daling in 22:6n-3 was niet gerelateerd aan de inname van dit vetzuur. De bereikte waarden in de lacterende groep significant lager dan die van niet-zwangere vrouwen. Op ca. 30 weken na de bevalling waren alle vrouwen weer terug op het nivo van niet-zwangere vrouwen.

De resultaten van deze studies wijzen er op dat tijdens de zwangerschap de habituele 22:6n-3 inname onvoldoende is om de grote behoefte aan dit vetzuur te dekken. Aangezien een adequate anvoer van 22:6n-3 naar de foetus van groot belang is, zouden moeders hun inname van 22:6n-3 wellicht moeten verhogen tijdens de zwangerschap. Echter, het supplementeren met de ene essentiële vetzurenfamilie heeft vaak een daling tot gevolg van de hoeveelheid van de andere EFA familie in plasma fosfolipiden. Daarom werd getracht een combinatiesupplement te vinden dat de 22:6n-3 status van zwangere vrouwen verbeterde, zonder dat er een significante daling optrad in hun $n-6$ LCP status, zowel in plasma als in erytrocyten fosfolipiden. Verschillende preparaten (in verschillende doses) werden eerst bij niet-zwangere vrouwen getest ( 6 groepen, $n=12-15$ per groep; Hoofdstuk $7)$. Gedurende 4 weken kregen deze vrouwen één van de volgende supplementen toegediend: visolie $(0.266 \mathrm{~g}$ of $0.532 \mathrm{~g} / \mathrm{dag})$; een 'single-cell olie' die alleen $22: 6 \mathrm{n}-3$ bevatte $(0.285 \mathrm{~g}$ of $0.570 \mathrm{~g}$ per dag) of een mengsel van single-cell oliën dat zowel $22: 6 \mathrm{n}-3$ als 20:4n-6 bevatte (0.570 g 22:6n-3 en 0.259 g 20:4n-6 per dag). De controlegroep kreeg een 
placebo tocgediend, bestaande uit microkristallijn cellulose. In deze controle groep werden geen veranderingen waargenomen in de relatieve hoeveelheden 22:6n-3 en n-6 LCP in plasma en erytrocyten fosfolipiden. In vergelijking met deze controlegroep steeg de hoeveelheid 22:6n-3 in de interventiegroepen, terwijl de hoeveclheid n-6 LCP significant daalde, behalve in de groep die het mengsel van 22:6n-3 én 20:4n-6 kreeg toegediend.

Vervolgens werd dit combinatiesupplement onderzocht bij een groep van 12 zwangere vrouwen met een gemiddelde zwangerschapsduur van $18.0 \pm 0.5$ weken (interventiegroep) Een even grote controlegroep (zwangerschapsduur $17.2 \pm 0.4$ weken) kreeg geen supplement toegediend (Hoofdstuk 8). Net als bij de niet-zwangere vrouwen verhoogde de dagelijkse dosering van $570 \mathrm{mg} 22: 6 \mathrm{n}-3$ plus $259 \mathrm{mg} \mathrm{20:4n-6}$ de $22: 6 \mathrm{n}-3$ status van de zwangere vrouwen zonder dat hun n-6 LCP status significant daalde.

In Hoofdstuk 9 tenslotte worden de bevindingen van bovengenoemde studies besproken. Deze biochemische resultaten wijzen er op dat moeders tijdens de zwangerschap en lactatie de inname van DHA wellicht zouden moeten verhogen. Naar de functionele betekenis hiervan voor zowel moeder als kind moet echter eerst nader onderzoek worden gedaan . 


\section{DANKWOORD}

Zoals door veel promovendi kenbaar is gemaakt, is het tot stand komen van een proefschrift iets dat je niet in je centje klaarspeelt. In mijn geval zijn er ook veel mensen die, direct of indirect, een "steentje dan wel rots" hebben bijgedragen en hen wil ik ook graag bedanken.

- Allereerst mijn promotor Gerard Hornstra en mijn co-promotor Rian van Houwelingen, voor de mogelijkheid die jullie mij hebben gegeven om dit "vetzuuronderzoek" uit te voeren. Bedankt voor jullie begeleiding en vertrouwen in mijn werk en kritische opmerkingen bij het corrigeren van alle stukjes die ik heb geschreven.

- De proefpersonen (te veel om allemaal op te noemen) wil ik bedanken; zonder jullie medewerking is onderzock nict mogelijk.

- Alle verloskundigen die zich hebben ingezet voor het werven van de nodige proefpersonen, in het bijzonder Annie Heuts, Cécile Smeets en Astrid Merkx.

- André de Jong en Taco van de Berg van het ABL Assen, voor de vele vetzuuranalyses.

- Arnold Kester, bedankt voor al je statistische adviezen (al was ik vaak je wijze woorden alweer bijna vergeten zodra ik de straat overstak).

- Marianne Simonis, Hasibe Aydeniz, Esther Bakker, mijn kamergenoten van "k.2330" en Anita Badart, Renate de Groot, mijn kamergenoten van "k.2326" (conform het HBverhuisbeleid). Ik wil jullie bedanken voor jullie hulp, luisterend oor en steun, de vele discussies en jullie vriendschap. Verder, alle medewerkers van de capaciteitsgroep Humane Biologic voor de gezellige werksfeer.

- Magda Antal, Auli Manninen, Keith Godfrey and Patricio López-Jaramillo, for your teamwork in conducting the international comparative study.

- I am thankful to Prof. dr. ir. P.A. van den Brandt, Prof. dr. C.E. Blanco, Prof. dr. E.R. Bocrsma, Dr. P. Sanjurjo and Prof. dr. ir. W.H.M. Saris for their time and effort in critically evaluating this thesis.

- Alle familieleden, vrienden en bekenden, en al degenen die ik wellicht ben vergeten: bedankt voor jullie steun en belangstelling in mijn werk. 



\section{CURRICULUM VITAE}

Suzic Judessa Otto werd geboren op 30 oktober 1965 te Curaçao. In 1985 behaalde zij het VWO diploma aan het Maria Immaculata Lyceum te Curaçao, waarna zij een jaar Bestuurskunde heeft gedaan aan de Universiteit van de Nederlandse Antillen. In 1986 begon zij aan de studic Gezondheidswetenschappen, met als afstudeerrichting Biologische Gezondheidkunde, aan de Universiteit Maastricht, waar ze in 1991 afstudeerde. Gedurende en na haar studie heeft zij gewerkt aan verschillende onderzocksprojecten gericht op de relatic voeding en gezondheid in het algemeen ziekenhuis St. Jan te Brugge (Laboratorium voor Klinische Scheikunde), Academisch Ziekenhuis Maastricht (afdeling Interne Geneeskunde) en de Universiteit Maastricht (capaciteitsgroep Humane Biologie). Het onderzock zoals beschreven in dit proefschrift werd uitgevoerd bij de capaciteitsgroep Humane Biologie, waar zij de laatste drie jaar van haar aanstelling Assistent in Opleiding is geweest (1997-2000). Sinds juli 2000 is zij werkzaam bij het instituut Maatschappelijke Gezondheidszorg van de Erasmus Universiteit Rotterdam. 


\section{Publications}

1. Otto SJ, Houwelingen ACv, Antal M, Manninen A, Godfrey K, Lopez-Jaramillo P, Hornstra G. Maternal and neonatal essential fatty acid status in phospholipids: an international comparative study. European Journal of Clinical Nutrition 1997;51:232-42.

2. Otto SJ, Foreman-van Drongelen MM, Houwelingen ACv, Hornstra G. Effects of storage on venous and capillary blood samples: the influence of deferoxamine and butylated hydroxytoluene on the fatty acid alterations in red blood cell phospholipids. European Journal Clinical Chemistry Clinical Biochemistry 1997;35:907-13.

3. Otto $\mathrm{S}$, Houwelingen $\mathrm{ACV}$, Lopez-Jaramillo P, Hornstra G. Effects of pregnancyinduced hypertension on the essential fatty acid statuses of Ecuadorian and Dutch women. American Journal of Obstetrics and Gynecology 1999;180:1185-1190.

4. Otto SJ, Houwelingen $\mathrm{ACV}$, Hornstra G. The effect of different supplements containing docossahexaenoic acid on plasma and erythrocyte fatty acids of healthy non-pregnant women. Nutrition Research 2000;20:917-927.

5. Otto SJ, Houwelingen ACV, Badart-Smook A, Hornstra G. Changes in maternal essential fatty acid profile during early pregnancy and its relation to diet. American Journal of Clinical Nutrition, accepted.

6. Otto SJ, Houwelingen ACv, Badart-Smook A, Hnrnstra G. Comparison of the peri- and postpartum phospholipid polyunsaturated fatty acid profiles of lactating and nonlactating women. Submitted.

7. Otto SJ, Houwelingen ACv, Hornstra G. The effect of supplementation with docosahexaenoic and arachidonic acid derived from single cell oils on plasma and erythrocyte fatty acids of pregnant women in the second trimester. Submitted.

8. Otto SJ. Docosahexaeenzuur tijdens zwangerschap en lactatie. Voeding lijkt niet aan grote DHA-behoefte te voldoen. Voeding NU, in press.

9. Rump P, Otto SJ, Hornstra G. Leptin and phospholipd-esterified docosahexaenoic acid (DHA) concentrations in plasma of women: observations during pregnancy and lactation. Submitted.

\section{Abstracts}

1. Otto SJ, Houwelingen AC van, Hornstra G. Essentiële vetzuurstatus bij moeder en kind: een internationaal vergelijkend onderzoek. Voeding 1997;58:32.

2. Otto SJ, Houwelingen AC van, Hornstra G. Search for a suitable long chain polyunsaturated fatty acids supplement for pregnant women. Prostaglandins, Leukotrienes and Essential Fatty Acids 1997; 57: 190.

3. Otto SJ, Houwelingen ACV, Badart-Smook A, Hornstra G. The postpartum docosahexaenoic acid status of lactating and non-lactating mothers. Lipids 1999;34:S227. 